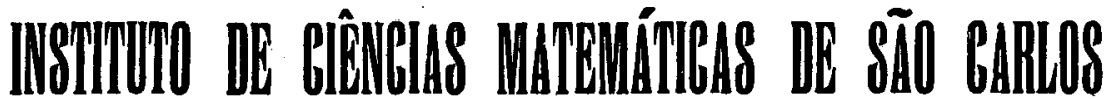

I.C.M.S.C.

SOBRE UMA ABORDAGEM OPERACIONAL PARA DESENVOLVIMENTO DE SISTEMAS DE I NFORMAÇAOO

ROSÃNGLA AP. DELLOSSO PENTEADO

\section{UNIVERSIDADE DE SÃO PAULO}

\author{
SÃO CARLOS - SAO PAULO \\ BRASIL
}


SOBRE UMA ABORDAGEM OPERACIONAL PARA DESENVOLVIMENTO DE SISTEMAS DE INFORMAÇÃO

ROSÃNGLA AP. DELLOSSO PENTEADO

Orientador:

Prof.Dr. Fernão Stella de Rodrigues Germano

Dissertação apresentada ao Instituto de Ciências Matemáticas de São Carlos, da Universidade de São Paulo, para obtenção do título de Mestre em Ciências de Computação e Estatística. 
Dedico este trabatho

A meus pais João e Noélia sempre dispostos, não medindo esforços para minha formação.

A Maria Teresa e Tia Tita pela disponibi lidade e colaboração, especialmente, durante mi nha vida estudantil.

Ao Dirceu pelo incentivo, companheirismo e pela compreensão, principalmente, durante a $\underline{e}$ laboração deste trabalho. 


\section{AGRADECIMENTOS}

A Deus pela vida e por tudo que tenho.

Ao Professor Dr. Fernão Stella de R. Germano pela orientação e disponibilidade que sempre me distinguiu, possibili tando o meu desenvolvimento cientifico.

Ao Professor Dr. Paulo Cesar Masiero pela atenção que dispensou a este trabalho para que sua conclusão fosse possível. Pela leitura dos manuscritos, pelas valiosas sugestões que o en riqueceram, pelo incentivo nos momentos de desânimo.

Aos Professores Dr. Odelar L. Linhares e Dr. Maximilian E. Hehl pelo apoio e acompanhamento de minhas atividades.

A Lucia F. Silva e Emília Nakamura que não pouparam esforços para que eu pudesse bem utilizar o centro de processamento de dados do Instituto de Pesquisas Energéticas.

A amiga Vanda Biasi que pacienciosamente leu os origi nais dando valiosas sugestões quanto à clareza de redação.

As amigas Lucia dos S. Cruz, Maria Ap. Trezza, Thelma Chiossi e Elenice Biasi pelos estudos juntos realizados proporcionando uma sólida amizade que continua, apesar das distâncias que nos separam. A lembrança desses bons momentos é a fonte para prosseguir a caminhada.

Aos alunos-amigos Marcia H. Kurike e Maurício C. Bruniera pelo trabalho de digitação e auxílio na utilização do sís tema 600 .

Aos professores e funcionärios do ICMSC pela receptividade.

As secretārias do SCE que sempre me atenderam prontamente. Em especial, a Sueli Ap. H. Ferreira pela paciência e ca pricho com que datilografou este trabalho.

A Carmen L. Pagadigorria pelo trabalho de perfuração de cartões.

As amizades que nasceram durante esta caminhada e cer tamente prosseguirão.

A CAPES e FINEP pelos auxilios concedidos. 


\title{
SOBRE UMA ABORDAGEM OPERACIONAL PARA DESENVOLVIMENTO DE SISTEMAS DE INFORMAÇÃO
}

\author{
R E S U M $O$
}

A ünica instância da abordagem operacional que jà tem disponiveis procedimentos e diretrizes bem desenvolvidos pa ra derivar as especificaçōes operacionais: Jackson System Development (JSD) è analisada nesta dissertação juntamente com Jackson Structured Programming (JSP) do qual JSD é considerado uma extensão. O levantamento bibliogräfico em que se baseou esta dissertação consta de mais de sessenta referências, que são incluídas na bibliografia. Sua análise revelou aspectos da apre sentação desses métodos que são cobertos somente com uma combinação de publicações, bem como, aspectos que não recebem a devi da cobertura em nenhuma publicação. Nesta dissertação faz-se um esforço para melhorar a cobertura desses aspectos de um modo in tegrado. Os conceitos de JSP são documentados em PSL/PSA (Problem Statement Language/Problem Statement Analyzer) e ilustrados através de problemas-exemplo implementados em COBOL. Esses problemas são variações de um problema básico a fim de evidenciar as técnicas disponiveis, em JSP, para resolvê-los. JSP é documentado usando diagramas de estrutura que são recomendados, por ele próprio, para documentar processos. A mesma diretriz é usada para documentar JSO, isto é, usam-se diagramas de estrutura para documentar cada um dos passos desse método, com os correspondentes textos estruturados que são combinados com outros recursos existentes no PSL/PSA. A implementação completa de um sistema de atendimento de pedidos, em COBOL feita num micro-computador (Sistema 600 da Prológica), juntamente com sua especificação são apresentados para ilustrar a aplicação de JSP/JSD combinados. São incluidas neste trabalho mais de mil li nhas de código, bem como, mais de cem ilustrações. 
ON AN OPERATIONAL APPROACH TO SYSTEMS DEVELOPMENT

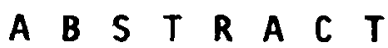

The only instance of the operational approach to have well-developed procedures and guidelines for deriving the operational specification: Jackson system Development (JSD) is analysed in this dissertation together with Jackson Structured Programming (JSP) of which JSD is considered tobe an extension. A literature survey to base the dissertation has been conducted: more then sixty references are included in the bibliography. Their analysis revealed aspects of the presentation of these methods that are covered well only in a combination of publications as well as aspects that have not received enough coverage in any publication. In this dissertation an effort is made to improve the coverage of both these aspects in an integrated way. JSP concepts are documented in PSL/PSA and illustrated through sample problems implemented in COBOL. These problems are variations of a basic problem in order to highlight the techniques available in JSP to solve them. JSP itself is documented using structure diagrams of the kind that it recomends to document processes. The same approach is used to document JSD, that is, structure diagrams are used to document each step of the method together with structure text which is combined with other facilities of PSL/PSA. The complete implementation in COBOL on a micro computer (Prologica system 600) of an order processing system, together with its specification is presented to illustrate the application of JSP/JSD combined. More than a thousand COBOL code lines are inclueded together with more than one hundred illustrations. 


\section{N D I C E}

1. INTROOUÇAO

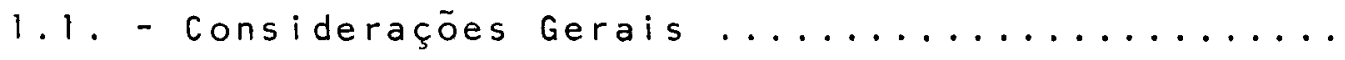

1.2. - Sobre a Abordagem Convencional para Desenvolvi mento de Sistemas ...................... 03

1.3. - Sobre a Abordagem Operacional para Desenvolvi-

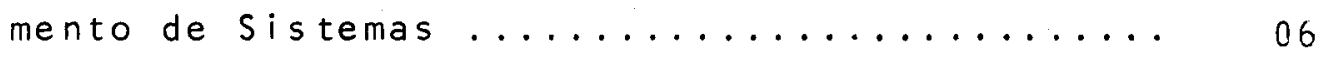

1.4. - Apresentação deste trabalho .............. 10

2. RESENHA BIBLIOGRAFICA

2.1. - Considerações Gerais ...................

2.2. - Sobre as Referências Básicas dos Métodos JSP e

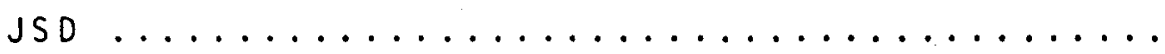

2.3. - Sobre as Repercussões dos Métodos de Jackson na Literatura Técnica Especializada ......... 18

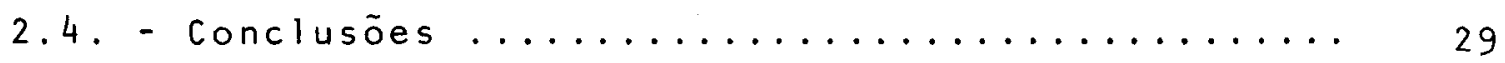

3. SOBRE O METODO JSP

3.1. - Considerações Gerais .................. 31

3.2. - Delineamento do Método ................. 36

3.3. - Passo Relativo à Especificação do programa .... 46

3.4. - Passo Relativo à Estrutura dos Dados de E/S ... 47

3.5. - Passo Relativo à Estrutura do Programa ........ 50

3.6. - Passo Relativo ao Projeto das operações ....... 60

3.7. - Passo Relativo ao Projeto da Lógica .......... 62

3.8. - Passo Relativo à Implementação do Programa .... 75

3.9. - Conclusões ........................ 81 
4.1. - Considerações Gerais ................... 83

4.2. - Delineamento do Método ................ 86

4.3. - Passo Relativo à Escolha das Entidades e Ações. 88

4.4. Passo Relativo à Estruturação Cronológica de A-

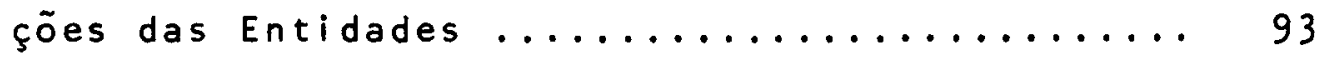

4.5. - Passo Relativo ao Modelo Inicial ............ 99

4.6. - Passo Relativo à Especificação das Funções .... 110

4.7. - Passo Relativo à Articulação Cronolögica das Funções com o Modelo ................... 123

4.8. - Conclusões ......................... 125

5. SOBRE A IMPLEMENTAÇÃO DE UM SISTEMA DE CONTROLE DE PEDIDOS USANDO JSD E JSP

5.1. - Considerações Gerais ................ 127

5.2. - Sobre a Construção do Diagrama de Implementação do sistema ............................. 129

5.3. - Sobre a Implementação dos Processos de Modela gem ................................ 133

5.4. - Sobre a Implementação dos Processos Funcionais. 149

5.5. - Sobre a Implementação do Processo de Articula -

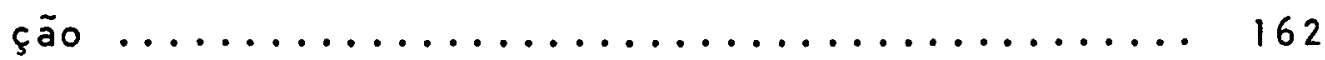

5.6. - Sobre Alguns Resultados do Processamento ...... 168

5.7 - Conclusōes ........................ 173

6. CONCLUSOES

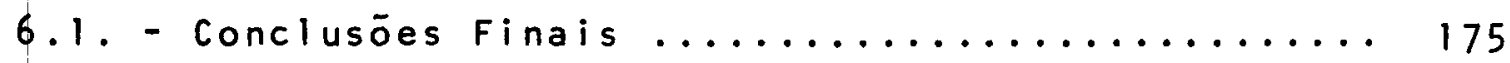

6.2. - Sugestões para Novas Pesquisas ............. 177

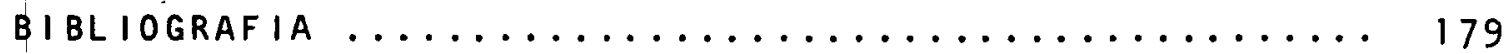

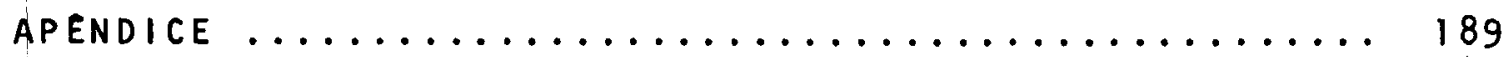




\section{NTRODUÇÃO}

1.1. - Considerações Gerais

Um dos assuntos que mais interessou a autora durante seu programa de estudos de pōs-graduação foi o abordado no capítulo 2 de [So83]. Nesse capítulo, que Shooman chama de "Program Design Tools and Techniques", é dado um arcabouço inte grado aos instrumentos e técnicas que vêm sendo objeto de atenção por parte da autora desde 1980. Dentro dessa linha, foi dedicado bastante esforço ao estudo do HIPO, [Ib74], e de sua aplicação à fase de especificação no desenvolvimento de sistemas, com base nos estudos de Gateword [Ga77]. Como fruto desse esforço, foi elaborado o trabalho [Pe82]. A esse trabalho segui ram-se outros como, por exemplo, [Pe83a] em que se procurou situar o HIPO no contexto de outros métodos de desenvolvimento de Sistemas de Informação. Como é mostrado em [Pe83d], o sistema PSL/PSA, [Te75, Te77, Te81], possui mais recursos que os outros métodos de especificação de Sistemas de Informação.

No primeiro semestre de 1983, a autora teve oportunidade de participar de um Encontro sobre Metodologias de Desen volvimento de Sistemas de Informação, no qual tambëm estiveram presentes diversos profissionais e pesquisadores de várias regiões do Brasil, tendo colaborado na apresentação do trabaliho [Ge83] e apresentado, entre outros, o trabalho [Pe83b]. Pôde, então, observar o grande interesse que todos os participantes ma nifestaram pelos trabalhos de Jackson, dos quais já conheciam [Ja75] e tinham ouvido menções a [Ja83]. Com essa motivação, de cidiu voltar as pesquisas previstas em seu programa de mestrado para o método de Jackson para Desenvolvimento de Sistemas, Jackson Systen Development, JSD, como será referenciado de ago ra em diante. 
Zave, em [Za84], refere-se ao método JSD como um dos que melhor se encaixam na abordagem operacional para desenvolvimento de Sistemas. Dai a escolha do título desta dissertação.

$\mathrm{Na}$ seção 1.2 , apresentam-se a abordagem convencional para desenvolvimento de Sistemas de Informação e alguns trabalhos do grupo de estudos ao qual a autora pertence. Na seção 1.3, apresentam-se a abordagem operacional e as diferenças exís tentes entre ela'e a convencional. Na seção 1.4, faz-se uma apresentação dos capítulo.s que compõem esta dissertação. 
1.2. - Sobre a Abordagem Convencional para Desenvolvimento de Sis temas

Zave, em [Za84], mostra, pelo esquema reproduzido a baixo, figura 1.01, como é o desenvolvimento de software através da abordagem convencional, que é baseada na decomposição "top-down" por caixas-pretas.

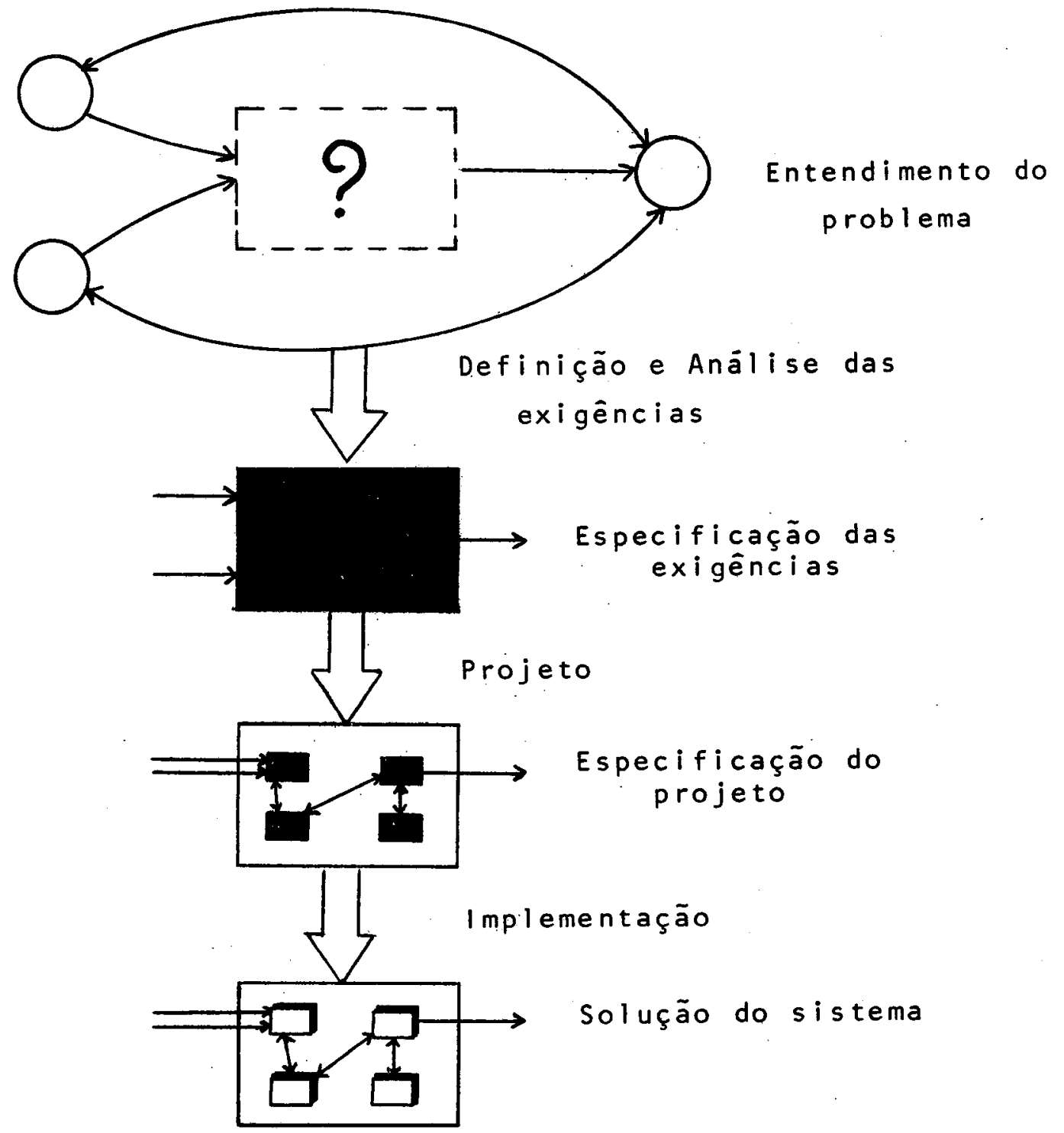

Figura 1.01 
Durante a fase de definição das exigências de um sistema de informação, os projetistas formulam um sistema para resolver o problema dado e definem esse sistema através da espé cificação dessas exigências. Essa especificação trata o sistema como uma "caixa-preta", descrevendo todas as caracteristicas externas que ele deve ter (o quê), sem descrever as características internas (como) de como irá ser gerado aquele comportamen to, As especificações são escritas em linguagem corrente, que pode ser restringida estruturalmente e completada. por figuras, tabelas, förmulas, etc..

A estrutura interna do Sistema de Informação è determinada na fase de projeto e é usualmente obtida através da decomposição em mōdulos. Essa decomposição é "top-down", hîerár quilca, de tal modo que seus módulos realizem as funções necessärias compativeis com os recursos de hardware e software onde serão executados.

Na fase de implementação, o projeto é transformado em um código executável no meio de processamento onde deverá ser executado. Esse vínculo define os mecanismos externos pelos qualis cada módulo irá satisfazer sua especificação comportamental, forma e alocação de recursos, e irá estipular os mecanismos dos módulos e as propriedades de interface dentro da lingua gem de implementação.

A abordagem convencional para desenvolvimento de Sistemas de Informação è baseada nos princípios de decomposição "top-down" por caixas-pretas e todas as suas estruturas podem ser derivadas dessa diretriz.

Muitos trabalhos foram desenvolvidos relativamente a métodos que se enquadram na abordagem convencional para o desenvolvimento de Sistemas de Informação. Em [Ge83], diversos desses métodos são comparados. Essa comparação é feita com base em outros trabalhos como [Pe82], que apresenta um sistema de Controle de Pedidos de Clientes, originalmente discutido por Grindley, [Gr75], descrito na técnica HIPO [1.b74]. Em [Pe83], es se mesmo sistema é descrito na tëcnica soP[Ib6 I, Ib63a,b,c,d]. Em [Pe82a], descreve-se em PSL/PSA [Te75,Te77] o problema-exem - 
plo apresentado por Glans, [G168], para ilustrar o método soP. Com base nesses trabalhos e em outros a eles relacionados, elaborou-se a comparação de cinco metodologias: SA/SD [Gn77], HIPO [Ib74], PSL/PSA [Te75,Te77], SOP [Ib61, Ib63a,b,c,d] e SYSTEMATICS [Gr75] . O problema-exemplo apresentado por Grindley é descrito nessas cinco metodologias, o que fornece bastante base para com pará-las. As tabelas encontradas nos trabalhos [Ci83,Pe83a,b,c, d] referem-se aos objetos que compõem cada método e às suas relações. Comparando-se essas tabelas, pode-se verificar quais os pontos fortes e as deficiências de cada um dos métodos. Todos $\underline{e}$ les são colocados do lado esquerdo de uma tabela, quando servem de base para comparação, e do lado direito, quando estão sendo comparados com os recursos disponíveis em outros métodos.

o Sistema PSL/PSA é o que possui mais recursos de documentação e é apoiado por computador. 0 trabalho [Pe83d] com para-o com os outros métodos e pode-se notar que há muitos pon tos que são abrangidos só por ele. 
1.3. - Sobre a Abordagem Operacional para Desenvolvimento de Sis temas

A figura 1.02 a seguir, reproduzida de $[2 a 84]$, mostra como é o desenvolvimento de um Sistema de Informação através da abordagem operacional.

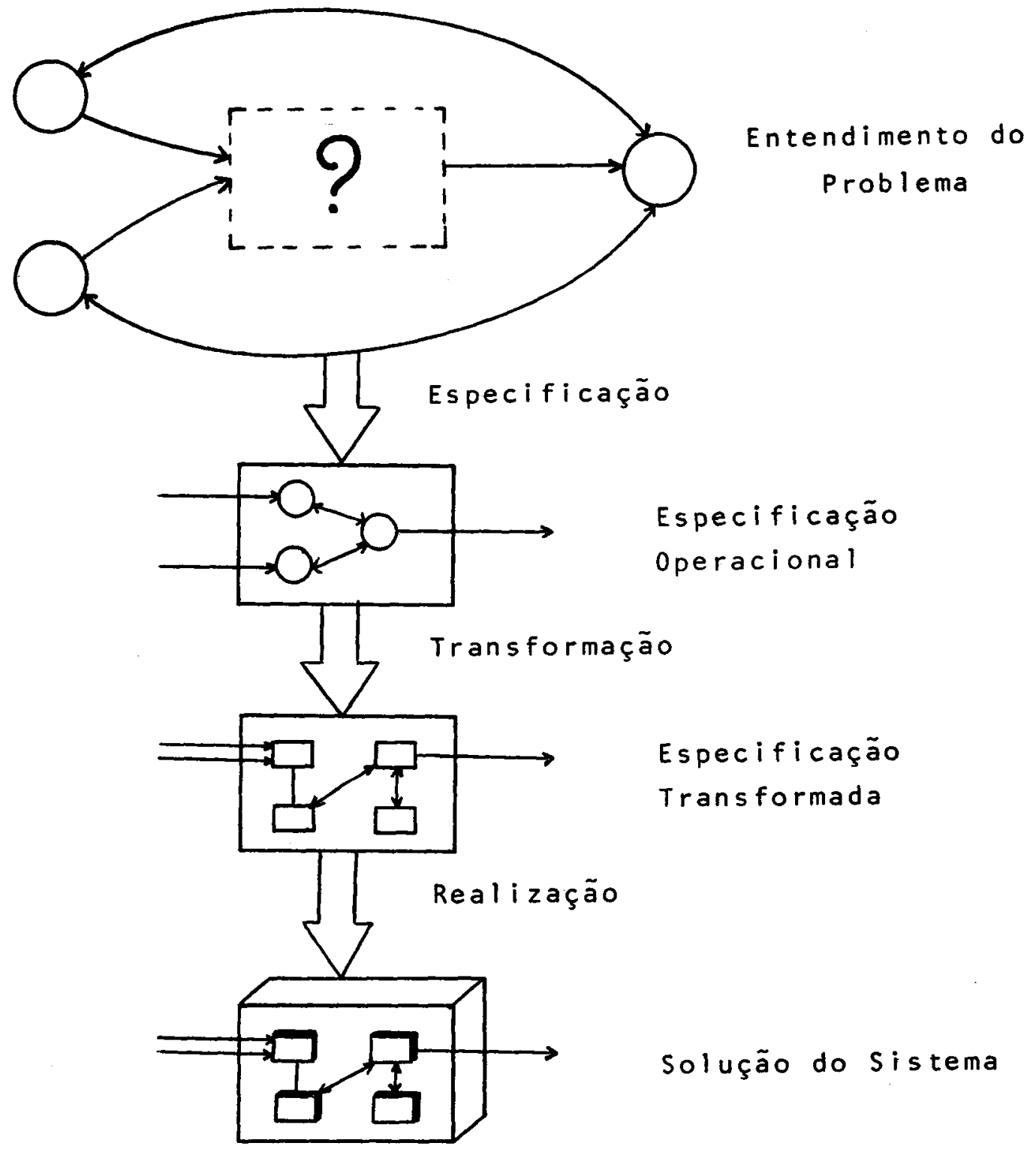

Figura 1.02 
Na fase de especificação, os projetistas formulam um sistema para resolver o problema dado e especificam esse sís tema em termos de estruturas implementadas independentemente e que vão gerar o comportamento do sistema especifico. A especifi cação operacional pode ser executável por um interpretador dedi cado. o comportamento externo está implícito na especificação, enquanto a estrutura interna está explícita.

Essa descrição pode fazer com que uma especificação operacional fique parecida com um projeto, porém não é um projeto. Em primeiro lugar, as estruturas fornecidas por uma linguagem de especificação operacional são independentes da configuração de recursos e da estratégia de alocação, enquanto que o projeto se refere ao meio especifico onde será feito o processamento.

Zave apresenta uma tabela comparativa das vantagens da abordagem convencional e da abordagem operacional, onde se pode notar que:

1) Quanto à validação, a abordagem convencional tem a vantagem das exigências do sistema serem escritas em linguagem corren te, que podem ser lidas e aprovadas diretamente pelo cliente. Por outro lado, nota-se, claramente, que as exigências informais são incompletas, inconsistentes e ambíguas. Na abordagem operacional, as especificações são formais, rigorosas, podendo ser analisadas formalmente. São processáveis por máquina, porém são de difícil entendimento pelo usuário e pessoal não-especializado. A especificação operacional pode ser usada como.um protótipo, desde que seja executável. Esse tipo de protótipo pode ser elaborado rapidamente e será produzido como uma parte integral do ciclo de desenvolvimento.

2) Quanto à verificação, a abordagem convencional utiliza-se de testes elou provas formais de correção. O teste é a técnica mais comum e pode ser usada para estabelecer consistência entre a implementação e a especificação das exigências. E um processo ärduo e nunca se pode afirmar que não restaram erros. A diretriz da implementação por transformações procura 
evitar o uso de testes e de verificações para derivar a implementação a partir da especificação. Utiliza, somente, transformações e correspondências que, comprovadamente, estão corretas por si só, ou seja, que preservam a equivalência com portamental. A compilação é um exemplo de tal transformação.

3) Quanto à automação, a abordagem convencional há muito tempo vem a ela resistindo. Isso porque as representaçóes da prēimplementação do sistema tendem a ser informais e porque cada fase inclui decisões sobre os mecanismos que geram o comportamento desejado. Na abordagem operacional, a fase de especificação è de trabalho intensivo, mas sua saída é um obje to formal. As fases de transformação e realização são altamente automatizáveis, porque todos os requisitos das exigências comportamentais são transferidos para mecanismos computacionais quando se escreve a especificação das operações.

4) Existe um conflito na estrutura de software entre eficiência e facilidade de manutenção. A abordagem convencional não faz nada para sanar esse problema, pois apoia somente a decomposi ção. A abordagem operacional cuida do conflito estrutural mais diretamente, dividindo o desenvolvimento em duas fases maiores, exatamente sobre essas linhas. A especificação operacional é otimizada para manutenção, enquanto que as transformações subdividem essa estrutura em favor de algo mais eficiente.

5) Quanto à gestão, a abordagem convencional é bem adaptada para as necessidades gerenciais e organizacionais. A especificação das exigências define uma interface entre os usuários e os projetistas; a especificação do projeto define a inter. face entre o trabalho de muitos programadores. Todas as vantagens potenciais de abordagem operacional referem-se a problemas psicológicos e técnicos.

Zave, [Za84], apresenta uma tabela onde mostra as deficiencias das duas abordagens, podendo-se notar que: a abordagem convencional força que todas as decisões comportamentais 
sejam feitas antes de qualquer decisão estrutural. Mesmo que as exigências comportamentais sejam desenvolvidas sem considerar as tendencias estruturais, haverá considerävel dificuldade em especificä-las formalmente, pois muitos formalismos são introdu zidos na estrutura interna. As exigências de "caixas-pretas"são difíceis de serem especificadas e a decomposição "top-down" tam bém è difícil e arriscada.

A abordagem operacional tem uma deficiência aparente, que é a necessidade de reduzir os comportamentos externos a mecanismos internos, antes de especificä-los. Isso sugere que as especificações operacionais sejam prematuras e excessivamente restritas. E difícil realizar as especificações com desempepenho adequado. A implementação de transformações é uma tecnolo gia nova e não desenvolvida. Zave destaca o método de Jackson para desenvolvimento de sistemas, JSD, [Ja83], como o mais evoluido e que melhor se enquadra na abordagem operacional. Diz que JSD tem procedimentos e diretrizes bem desenvolvidas para derivar a especificação operacional. Salienta que JSD não trata adequadamente todos os aspectos de desenvolvimento de sistemas, mas as técnicas de especificação de JSD são compreensíveis e são independentes da implementação. Ao comparar JSD com outras tēcnicas, Zave diz que o método favorece a manutenção e é voltạ do para obter a especificação operacional, a qual é feita em linguagem tal que as transformações podem operar a partir dela. Diz, ainda, que o método está sendo usado em problemas reais. 
1.4. - Apresentação deste Trabalho

o capítulo 2 refere-se à revisão bibliogräfica e aí são citados os textos que serviram de base para elaboração dos outros capítulos. Pesquisou-se, tambēm, publicações especializa das que tratassem do mētodo JSP e JSD. Encontra-se nesse capítu 10 a repercussão que esses trabalhos tiveram na literatura técnica especializada.

o capítulo 3 refere-se ao método JSP, apresentando os conceitos, exemplos e implementação desses exemplos relativos ao método.

0 capítulo 4 é dedicado à apresentação do método JSD. Os conceitos referentes à fase de especificação são aí encontrados. A apresentação do método é feita apoiando-se num sis tema-exemplo, extraído de [Ja83], que è o de um sistema de atendimento de pedidos.

No Apêndice são encontrados relatórios PSA, que·con tēm a descrição dos conceitos dos métodos JSP e JSD.

o capítulo 5 é dedicado à fase de implementação pelo método JSD, completando o capítulo 4. Constam desse capítulo todos os programas correspondentes à implementação do sistema-e xemplo.

o capítulo 6 contēm as conclusões sobre este trabaIho e sugestões para novas pesquisas. 


\section{RESENHA BIBLIOGRAFICA}

\section{1. - Considerações Gerais}

- livro original de Jackson sobre princípios de pro gramação data de 1975 [Ja75] e, desde então, foi publicada grande quantidade de trabalhos aplicando esse método, JSP, a exemplos práticos, discutindo aspectos não cobertos pelo livro ou, então, comparando-o a outros métodos existentes. Isso talvez se deva ao fato de tratar-se de um método com alto grau de diferencia ção dos demais existentes, principalmente quanto à sua premissa bāsica de que a estrutura interna do programa deve refletir a estrutura dos dados de entrada e saída.

Com o intuito de apoiar tambëm outras fases do desenvolvimento de Sistemas de Informação, que não apenas a de programação, Jackson criou um método para representação e projeto de Sistemas de Informação, JSD, que pode articular-se com o JSP, embora não necessariamente deva fazê-lo. JSD estende muitos dos recursos de JSP, aplicando-os à modelagem de entidades do mundo real a serem consideradas pelo sistema de Informação.

o objetivo deste capitulo é posicionar esta dissertação quanto aos dois livros principais e a uma sērie de trabaIhos relevantes, que tratam de um, de outro, ou de ambos os métodos. Isso é importante, porque permite que se mostre a relevância e a oportunidade desta dissertação, tanto no que ela pode acrescentar às lacunas não exploradas pelos autores dos vários trabalhos analisados, quanto na contribuição efetiva que pode dar aos profissionais da ärea que atualmente, usam ou pretendem usar os métodos.

Assim, na seção 2.2 , faz-se a anālise dos documen- 
tos básicos em que se apoiou esta dissertação. Na seção 2.3, ve rifica-se a repercussão obtida pelos métodos de Jackson na lite ratura técnica especializada e conclui-se o capitulo com a seção 2.4 , onde é feita uma síntese da análise realizada. 
2.2. - Sobre as Referências Básicas dos Mëtodos JSP e JSD

Em 1975, Jackson publicou seu livro, [Ja75], que trata da técncia JSP. Nesse livro estão contidos conceitos e exemplos isolados dessa técnica. A base do livro é a programa ção estruturada, utilizando-se as componentes: seqüencia, seleção e iteração. São apresentados exemplos para ilustrar cada as pecto do método, tais como: leitura avançada, retro-indiciação, choque estrutural, inversão de programas etc..

Em 1976, Jackson, em [Ja76], apresenta värias características do método JSP, resume os passos desse método em: definir as estruturas de dados a serem processadas; criar a estrutura de programa a partir das estruturas de dados; listar e alocar todas as operações executäveis etc.. Ele também salienta que as dificuldades que podem ocorrer na aplicação do método são quanto aos choques estruturais e à retro-indiciação e frisa, ainda, que o resultado obtido quando se aplica essa técnica é a simplicidade do software produzido.

Ainda em 1976, Jackson publicou [Ja76a] onde os con ceitos do método JSP são todos aplicados na solução de variantes de um mesmo problema. Com isso, a deficiência referida no primeiro parágrafo, de usar, em seu livro, exemplos isolados pa ra ilustrar os diferentes conceitos de seu método, foi resolvida. Em 1978, Jackson, em [Ja78], propõe que um sistema seja concebido como um modelo da realidade à qual pertence. e que as funções sejam sobrepostas a esse modelo. Essa forma de modelagem por uma rede de processos seqüenciais que se comunicam por fluxos de dados permite uma representação clara das modificações da atividade ao longo do tempo, e também evita a especificação em excesso da seqüenciação, pois separa as restrições de seqüenciação orientadas para o problema das orientadas para a solução. Ressalta que são necessárias transformações nas especificações, para que o modelo seja eficientemente executado num ünico processador. Apresenta diversos exemplos para ilustrar o método e diz que o objetivo desse método é separar o modelo da função e, o projeto da implementação. Nesse trabalho jã 
é apresentado o conceito de entidade quando se fala na especifí cação do sistema, bem como o conceito de transformação quando se fala em implementação. A nosso ver, esse é o trabalho de transição entre JSP e JSD.

Ainda em 1978, Bernstein, em [Bn78], relata a apli cação da técnica JSP na prática profissional. Essa técnica foi combinada com "walk-throughs" e com implementação "top-down" e recebeu o nome de Program Structure Technology, PST. Bérnstein salienta que PST não se preocupa em especificar a organização ou conteúdo dos arquivos, os formatos de entrada/saída, o projeto da base de dados, ou as exigências do processamento. PST se pre ocupa com o trabalho de projetar e implementar programas que sa tisfaçam tais especificações. Diz que os maiores benefícios des sa metodologia são a redução da complexidade dos programas; a e liminação de erros lógicos na fase de projeto ao invés de na fá se de teste ou estágios posteriores; a facilidade de manutenção dos programas; a boa documentação do programa como sub-produto do projeto etc..

Em 1979, Robinson, em [Rb 79], lembra que, muitas ve zes, o objetivo de bases de dados e sistemas de processamento da informação é modelar a realidade. Analisa, assim, os princípios que devem reger o estabelecimento de modelos e classifica os modelos em estáticos e dinâmicos. Salienta a vantagem dos mo delos dinâmicos e cita o método de Jackson como um dos pioneiros dentre os que podem conduzir a esse tipo de modelo. Apesar de referir-se a [Ja75], isto é, mais especificamente a JSP e não a [Ja78], discute conceitos que estão contidos em JSD. Fala em entidades, suas estruturas e eventos a elas relacionados. Exemplifica esses conceitos considerando um sistema de atendimen to de clientes de uma empresa atacadista, apresentando diversos diagramas de estrutura relativos a esse exemplo. Considera que sua contribuição é mostrar como o método pode ser aplicado a ca sos mais realisticos, isto é, de maior complexidade que os até então usados para ilusträ-10.

Em 1980, Menard, em [Me80], ao tratar do PST, [Bn78], diz que foi comprovado estatísticamente aumento de pro- 
dutividade e redução nos custos de manutenção de sistemas desen volvidos por esse método. A documentação, que é preparada usando PST, facilita a comunicação entre as equipes de desenvolvimento e de manutenção. O esforço de desenvolvimento de um siste ma incluindo projeto, codificação e teste, é reduzido com o uso do PST, especialmente, quando é usado PSTAIDS. Com isso, pode ser sanada a maior deficiência do método de Jackson, segundo [Bo79], que é a de ser um método manual. PSTAIDS é um instrumento de apoio por computador tanto à elaboração dos diagramas de estrutura utilizados no método de Jackson, quanto à geração de códigos correspondentes. Assim, seus usuários podem iterativamente definir os diagrams de estrutura de dados e dos programas e obter o cōdigo correspondente em uma linguagem de alto nível, tal como PL/I.

Ainda em 1980, Triance, em [Tr80], alerta que muitas estruturas existentes em JSP não podem ser implementadas em COBOL ANS, sem que se façam algumas modificações. E o caso,por exemplo, da retro-indiciação, da seleção com mais do que duas alternativas etc.. Nesse artigo, o autor mostra a codificação quivalente em COBOL ANS. Triance mostra que o pré-processador $\underline{u}$ sado pelos seguidores de JSP, chamado de lögica esquemática ou, mais comumente, de JSP-COBOL, permite utilizar "alt" no caso de seleção com mais de duas alternativas.

Em 1981, Jackson, [Ja81], no mesmo livro, [Co81], em que Chapin, [Ch81], compara o JSP com outras tëcnicas, como pode ser visto na seção 2.3 , apresenta seu método para desenvolvi mento de sistemas, JSD. Descreve os quatro princípios em que o método se baseia: 1) um método deve decompor a atividade de desenvolvimento em tarefas distintas e ordenadas, oferecendo para cada tarefa um instrumento adequado à sua execução e critérios para determinar se foi completada corretamente; 2) quem desenvolve um sistema deve começar considerando a realidade que o sistema deve modelar, ao invés da função que o sistema deve rea lizar; 3) uma realidade ativa só pode ser modelada por um modelo ativo, assim, um modelo inerte pode modelar apenas uma reali dade inerte; 4) o projeto deve preceder e não ser confundido com 
a implementação. Diz que os passos para desenvolvimento de um sistema por JSD classificam-se em três grupos: o primeiro se re fere à especificação do modelo do mundo real; o segundo, à espe cificação das funções do sistema e o terceiro, à implementação do sistema. Diz ainda que, àquela época a experiência com JSD não havia atingido um ponto em que os passos individuais já pudessem ser definidos.

$$
\text { Ainda em 1981, Cameron, em [Ca81], apresentá }
$$

os

principais pontos do método JSD e, como ele mesmo diz, omite ou tros relativos à especificação. Diz que JSD é voltado para aque les sistemas que se preocupam com objetos e entidades cujo comportamento e estado variam ao longo do tempo. Mostra que os pri meiros passos do método são voltados para a descrição formal da parte correspondente ao mundo real que interessa ao sistema. A descrição dos modelos das entidades cobre o período de tempo du rante o qual elas interessam. Os passos seguintes do método com preendem a transformação da especificação formal de um sistema executável. o último passo é a implementação que adapta os textos dos processos especificados e adiciona novos programas para articular esses processos e o acesso a seus vetores de estado. Expõe exemplos para caracterizar os pontos desse método por ele apresentado.

Em 1983, Jackson publicou o livro [Ja83], que contém todos os conceitos e passos do método JSD. Apresenta esse método em seis passos, destinando um capítulo a cada um deles. Esses conceitos são mostrados atravēs de três exemplos: um sistema para controle de träfego de elevador, um sistema de apoio à realização de concursos e um sistema de atendimento de pedidos. A medida que os conceitos e passos vão sendo apresentados, são aplicados ao exemplo que melhor pode ilusträ-los.

Ainda em 1983, em [Tr83], Triance mostra os recursos que provavelmente farão parte das prōximas versões de COB.OL ANS. Alguns desses recursos são as facilidades de programação estruturada, END-IF, o comando nulo CONTINUE, comando para sele ção com diversas alternativas, fim de loop: PERFORM com ENoPERFORM etc.. Lembra que nenhum esforço tem sido feito para sar 
tisfazer os usuários do método de Jackson, pois não hä apoio pa ra a construção "suponha", "abandone" e para inversão.

Em 1984, Jackson, em [Ja84], discute a situação dos métodos estruturados diante das linguagens de Quarta Geração e dos Geradores de Aplicação. O enfoque principal ē nos seus méto dos JSP e JSD. O método JSD não está limitado só a sistemas de informação e processamento de dados embora seja no contexto des ses sistemas que é discutido nesse artigo e esses sistemas serem o objetivo das linguagens de Quarta Geração e dos Geradores de Aplicação. Jackson conclui que a necessidade de programação tradicional explícita e do projeto de programs foi, está sendo e continuará sendo reduzida e que as linguagens de Quarta Geração e Geradores de Aplicação participarão em grande parte dessa redução. Diz ainda que, onde um método de desenvolvimento consistente, tal como JSD, for usado, uma Linguagem de Quarta Gera ção ou Gerador de Aplịcação pode fornecer implementação conveniente e barata da maior parte do sistema especificado. Ressalta que o grande sucesso que tais sistemas de software têm obtido deve-se ao modelo ser bem estabelecido e adequado, facilitan do a adição de novos programas de consulta e de produção de relatórios. Assim, espera que, cada vez mais, sistemas sejam espe cificados em JSD e implementados em Linguagens de Quarta Geração. Aborda também o papel do usuário, afirmando que a tendên cia em JSD é aumentar a responsabilidade do usuário na especifi cação dos sistemas. A descrição do mundo real, que o usuário hạ bita e do qual deseja informações, que é o passo inicial do desenvolvimento por JSD, pode ser feita pelo próprio usuärio, sen do que o projetista fica com o papel de consultor ao invés de autor. Finaliza alertando que a necessidade de um método de desenvolvimento não será reduzida apesar de que algumas tarefas, como codificação em linguagem de mãquina, não serão mais necessárias, realçando dessa maneira a necessidade de que as tarefas mais importantes de especificação sejam tratadas por um método de desenvolvimento consistente. 
2.3. - Sobre as Repercussões dos métodos de Jackson na Li teratú ra Técnica Especializada

Há vários trabalhos publicados em revistas, tutorials, proceedings etc. que mencionam os trabalhos de Jackson. JSP [Ja75] é mais citado do que JSO [Ja83], por questão cronológica. o método de Jackson, JSP, foi objeto de comparação com diversas metodologias. São apresentadas, aqui, algumas dessas comparações.

Jà em 1976, no ano seguinte que o livro [Ja75] sobre JSP foi publicado, McGowan e Kelly, em [Mc76], comparam très metodologias que consideram importantes, uma das quais é o método de Jackson. Enfatizam a importanncia do projeto no desenvolvimento de sistemas, destacando JSP como um dos métodos que melhor apoiam a documentação de projetos. Essa e outras formas de documentação de projetos são analisadas quanto à: hierarquia de programas, hierarquia de dados, interfaces, fluxo de conerole e fluxo de dados. Consideram que o método de Jackson cobre bem o primeiro, o segundo e o quarto ítens acima citados. 0 método de Jackson é descrito com bastante detalhes, cobrindo os conceitos de choque estrutural, inversão, vetor de estado, retro-indiciação etc.. os autores concluem que o método de Jackson conduz a programas simples com finalidades bem definidas. Apresentam um mesmo exemplo, que é o de análise de telegramas, que consta de [Ja75], em cada uma das metodologias. Concluem, salientando as vantagens de se usar um método de projetce entre as quais destacam a de estabelecer padrōes de comunicação para o grupo que está sempre envolvido quando se desenvolve um projeto. Em 1977, Peters, em [Pt77], compara JSP com outras metodologias de Projeto Estruturado. Enfoca JSP como sendo um processo aparentemente simples, porém alerta que essa impressão se desfaz quando da tentativa de usar essa técnica. Mostra, nes sa comparação, quais os pontos em que os seguidores de cada uma se amparam para justificā-la como a mais adequada. Um dos argumentos para o uso do JSP ē que "a identificação das estruturas de dados intrínsecas é vital e a estrutura de dados de entrada e 
saída, pode ser usada para derivar a estrutura e alguns detalhes, do programa". A comparação, propriamente dita, é feita através de dois quadros: um relativo às exigências de Análise e Especificação e outro, a atributos, grāficos especializados, de finição de procedimentos, documentos didáticos etc.. No primei ro quadro, ao se referir ao método de Jackson, ressalta que esse método oferece recursos, principalmente quanto à fase de pro jeto, não cobrindo a fase de especificação e só cobrindo parcialmente a fase de implementação. Na fase de projeto, considera que o método cobre bem o projeto de módulos, mas sua cobertú ra ao projeto de dados não oferece diretrizes substanciais. Men ciona, ainda, que a arquitetura de projeto recebe do método uma cobertura parcial. Quanto à construção do código, o mētodo fornece cobertura adequada. Ao se referir ao método de Jackson, no segundo quadro, mostra que os gräficos são diagramas de estrutu ra de dados tipo ārvore, mas que os procedimentos não são bem definidos. Relativamente aos documentos didáticos de apoio. ao mé̃odo, cita o livro de Jackson, [Ja75], dizendo que contém värios exemplos, mas salienta as dificuldades em entende--lo efeti vamente. Considera que a rastreabilidade dos requisitos é deixada a cargo do projetista e que a primeira versão do método es tá disponível desde 1972, com ênfase em aplicações comerciais. Assim, sua aplicabilidade é na área comercial e em outros siste mas com estrutura de dados bem delineadas. Ressalta que esse mé todo é compatível com outros de estruturação de dados e, quanto ao critērio de avaliação, verifica-se que o método satisfaz seus pressupostos básicos.

Otimizar o tamanho de módulos de programação relat i vamente ao custo de compilação foi o cuidado de Elshoff, em [E177]. Tal custo é função do nümero de módulos compiláveis que - programa compreende, do custo de compilação de um módulo e do nümero de vezes que cada módulo tem que ser compilado. os resul tados mostram que o cus to de compilação pode ser reduzido quando o acondicionamento de um programa é feito através de um conjunto de módulos compilàveis independentemente. 0 termo acondicionamento, "packaging", de acordo com [Yo75], refere-se ao agrupa- 
mento dos módulos que constituem um sistema em componentes que são tratadas como unidades independentes no processamento. 0 mé todo de Jackson é mencionado como uma boa técnica de desenvolvi mento de programas em que o uso de modularização é enfatizado, tanto no projeto quanto na implementação, mas em que o acondicionamento é ignorado. Assim, segundo Elshoff, o acondicionamento em grupos unitários, em que cada módulo é tratado como unida de independente de processamento, é que otimiza o custo de com pi lação.

DeWolf, [De77], apresenta a parte de projeto funcio nal de uma metodologia para especificação dos requisitos e projeto preliminar de sistemas em tempo real. o objetivo dessa metodologia é reduzir os problemas que aparecem nas fases inicialis do desenvolvimento do ciclo de vida de sistemas integrados complexos. Os processos existentes de desenvolvimento de sistemas complexos de processamento em tempo real são de alto custo, consomem tempo excessivo e apresentam dificuldades de gestão. Frequentemente levam a sistemas que não são confiàveis, não fornecem aos usuärios as respostas exigidas e são difíceis de serem analisados, mantidos ou modificados. Entre as metodolo gias disponíveis é citada, entre outras, a de Jackson. Sobre ela, DeWolf diz que, apesar de não ser voltada para tempo real, possui elementos úteis. Diz ainda que a metodologia por ele apresentada se apoia nela e nas outras, buscando sanar as deficièncias que apresentam para o desenvolvimento de sistemas de processamento em tempo real.

Krakowiak, em [Kr78], ao fazer uma sinopse do progresso obtido com referência a métodos de projeto e instrumentos desenvolvidos para aplicā-los, destaca o método de Jackson e o Sistema PSL/PSA. Expõe os conceitos do método de Jackson di zendo que a documentação de projetos é feita atravēs de gräficos, manualmente, ao passo que o sistema PSL/PSA apoia por computador a documentação de um sistema armazenando em uma base de dados todas as informações relevantes ao projeto.

Hamilton, em [Ha79], menciona que um processo de de senvolvimento de sistemas pode servir sob vários aspectos, en- 
tre os quais destaca o gerencial, de documentação, de projeto, de alocação de recursos e de verificação. Detēm-se no estudo do relacionamento entre os aspectos de projeto e verificação. Apre senta um interessante arrazoado recomendando o uso de uma metodologia nos trabalhos de desenvolvimento de sistemas. Ao discutir as propriedades desejāveis que uma metodologia deve apresen tar, cita o método de Jackson como uma das metodlogias que enfá tizam a decomposição de um sistema com base nos dados. Ressalta que, apesar de divergirem em detalhes, essas metodologias apresentam muitos aspectos positivos.

Num livro em que os rumos de pesquisa sobre tecnolo gia de software são examinados, [We 79], Boehm, [Bo79], num cap í tulo inteiramente dedicado à engenharia de software, destaca o sistema PSL/PSA, [Te75,Te77], como o pioneiro para analisar por computador as exigências de um software. Menciona a técnica de Jackson como uma das que são úteis para a fase de projeto. Apon ta que a deficiência dessa tēcnica é ser manual, o que torna di fícil o armazenamento e atualização das informações de um projé to grande.

0 mëtodo ISAC (Information Systems Work and Analysis of Changes) para o desenvolvimento de Sistemas, [Lu79, Lu81], com preende as seguintes äreas de trabalho: SI - Estudo das ativida des, S2 - Anālise das Informações, S3 - Projeto do Sistema de Dados e $\$ 4$ - Adaptação ao Equipamento. A área 53 engloba as téc nicas de D-grafos, D-estruturas, P-estruturas, listas de operações e tabelas de tarefas. As p-estruturas são usadas para descrever a estrutura dos programas e foram baseadas em JSP, conforme citado nas páginas 227 e 245 de [Lu81] e nas pāginas 103 e 104 de [LU79].

Peters, em [Pt80], faz considerações sobre a evolução na ärea de desenvolvimento de software, nos últimos dez anos. Com essa rápida evolução, diz que houve uma grande prolife ração de métodos e técnicas para ajudarem a resolver problemas de software. Assim sendo, menciona que a engenharia de software foi forçada a cuidar de meios alternativos para composição e do cumentação de projetos. Discute detalhadamente os meios desen- 
volvidos para representação de projetos e, ao abordar os métodos para composição ou criação de software, cita o método de Jackson como um dos métodos baseados na estrutura dos dados. Realça que tais métodos dão ao projetista de software diretri zes de procedimento para desenvolver um projeto em que a estrutura de dados que será processada pelo software é conhecida. Nesse caso, a estrutura refere-se às relações lögicas que existem entre elementos de dados e não ao formato físico dos dados. A premissa básica é que as estruturas dos dados e do programa devem ser compativeis.

Em setembro de 1980, o IEEE, que, em suas revistas e outras publicações especializadas, [Be81, Ba8la,Be81a,etc.], sempre tem dado cobertura aos instrumentos e métodos para análi se e projeto de Sistemas e programas, decidiu abrir espaço, na sua revista de âmbito mais geral, para esse assunto, a fim de divulgä-lo mesmo entre os não-especialistas. Dentro desse espaço, vários artigos foram publicados, entre os quais o de Lehman, [Le80], que, ao discutir estruturas de programas e elementos estruturais, nome genérico por ele utilizado para se referir a subsistemas, componentes, módulos, procedimentos, rotinas etc., refere-se ao método de Jackson como fonte de critérios para subdividir sistemas em seus elementos estruturais. Diz, ainda, que há vários cientistas preocupados com linguagens formais para expressar as especificações de um sistema de modo que a verificação de sua completeza e consistência possa ser feita por computador. Destaca, nesse caso, o Sistema PSL/PSA [Te 75, Te 77] .

A garantia da qualidade de um software foi a preocu paçăo de Goodenough, em [Go80], que discute esse problema de ma neira anăloga à que é usada para garantia da qualidade de hardware. Apresenta, para resolver esse problema, uma abordagem integrada que consiste em procurar reduzir os erros de especifi cação e projeto, procurar reduzir os erros de construção e procurar estender os princípios de testes de hardware para testar - software. Cita o método de Jackson como um dos instrumentos que permitem reduzir os erros de especificação e projeto. 
Do mesmo modo que é necessário especificar a estrutura para a construção de um edifício pelos arquitetos, na arquitetura de software também se deve especificar a estrutura pa ra a construção de um programa. Bergland, em [Be81], apresenta alguns dos conceitos, técnicas e metodologias que apoiam a execução dessa tarefa. As técnicas de engenharia de software são classificadas em três grupos: aquelas que dizem respeito princi palmente à estrutura do programa, aquelas referentes ao processo de desenvolvimento e aquelas referentes aos instrumentos que apoiam o desenvolvimento. Os conceitos de análise e projeto estruturado são classificados como os referentes, principalmente, a nivel de código, a nível de módulo e a nível de sistema. As metodologias de projeto estruturado são discutidas e comparadas. As metodologias que se baseiam na decomposição funcional são aplicadas a um exemplo específico, no projeto do fluxo de dados, no projeto da estrutura de dados e no cálculo de programação. 0 objetivo de utilizar uma metodologia de projeto estruturado- é reduzir o custo de produção e manutenção do software. Quanto à construção de fluxos de controle, o método de Jackson é citado, pois atravēs de suas trēs construçōes básicas, seqüência, seleção e iteração, pode-se obter, com clareza, um gräfico da estrú tura do programa. Alēm disso, pode-se transformar facilmente, um programa que usa essas construções gráficas em texto estrutú rado e, posteriormente, em linguagens de programação específica. Nos conceitos a nível de mödulo, o acoplamento, que é a interli gação entre os módulos, pode ser feito de modo hierárquico, na forma de estrutura de ārvore, que tem muitas vantagens para abs tração, teste e modificações posteriores. Cita o que Jackson chama de "doença de ärvores", que ataca o projetista que foge da estrutura hierärquica de ärvores. Diz que Jackson classifica a correspondência entre o mundo real e o programa de modelagem como o fator crítico na determinação do custo de um programa em seu ciclo de vida. Se essa correspondência for bem feita, muitos problemas posteriores podem ser evitados. Quanto ao nivel de sistema, o autor reproduz a opinião de Jackson com relação à otimização e acondicionamento: "é fäcil fazer um programa que 
esteja certo, rapidamente. 0 dificil é fazer um programa räpido e que esteja certo". Essa è a ültima fase de um projeto e um cuidado maior deve ser tomado, a fim de que a estrutura seja mantida.

Emerson, em [Em81], mostra técnicas e métodos para projeto de software, os quais são usualmente entendidos como re lativos ao estágio de desenvolvimento posterior à especificação das funções externas e anterior à produção de cōdigo. As aborda gens existentes para os fundamentos da engenharia de software têm falhas quanto a tratar adequadamente a diversidade das üteis teorias de projeto. Uma definição geral de projeto é usada para estabelecer uma classificação de teorias de projeto em descritivas, normativas e procedimentais. As teorias de projeto descritivas são as formadas, essencialmente, pela suposição de que o software pode e deve ser representado por uma forma parti cular de esquema. As normativas têm meios de representação como as descritivas, mas têm restrições adicionais sobre o conjunto $D(A)$ de projetos para um problema A. As teorias procedimentais possuem meios de representar soluçōes para um problema, como as teorias descritivas, e restringem os projetos expressáveis como as teorias normativas. Alèm disso, possuem um método explícito para construir o esquema de software que representa uma solução. A presença dessas componentes permite examinar a construtividade, que é o grau pelo qual esse procedimento pode ser considera do explícito e algoritmico. Se a teoria procedimental è altamen te construtiva, pode ser possivel automatizar seus procedimentos. Como exemplo desse tipo de teoria, é citado o método de Jackson que tem promovido uma teoria de projeto na qual o fluxo de controle numa parte do software é derivado das estruturas hierärquicas que definem os dados de entrada e saída dessa parte. Emerson diz que, para problemas em que os dados internos po dem ser facilmente estruturados, a construtividade dessa teoria é muito alta.

0 livro, [Co81], apresenta as bases de possível evo lução na década de 80 relativamente à anälise e projeto de sistemas. Entre outros, inclui o artigo de Chapin, [Ch81], que 
mostra uma tabela comparativa entre os recursos gräficos de diversas metodologias, para desenvolvimento de Sistemas de Informação. Essa tabela é composta de duas partes: uma que enfatiza - uso e outra que enfatiza a natureza desses instrumentos gräfi cos. Os diagramas utilizados em JSP são colocados nessa tabela, na primeira parte, podendo-se notar uma grande aproximação quan to ao objetivo, produção e uso dos diagramas de Warnier [Wa74]. São distintos dos demais por terem como objetivo a estruturação de programas. Os diagramas são produzidos para anälise e projeto das partes automatizadas do sistema e para manutenção do pro jeto. Esses diagramas são utilizados para projeto das partes au tomatizadas do sistema, para programação, projeto físico, acondicionamento do projeto, testes, avaliação do projeto e manuten ção do programa. São de fácil preparação, e de média facilidade quanto ao uso e manutenção. Na segunda parte da tabela, fica evidente a semelhança com o método de Warnier. Na vertical dos diagramas de estruturas de Jackson, pode-se ver a pertinência entre as componentes e, na horizontal, as componentes de mesmo nível. No método de Warnier, as componentes de mesmo nível são mostradas na vertical e a pertinência entre elas, na horizontal. Essa è uma das diferenças entre as técnicas. Outra diferença é que JSP Utiliza 4 simbolos e Warnier 6. Chapin também diz que, quando se lê um diagrama de Jackson, coloca-se a palavra proces so para a maioria das caixas. No capítulo 3 , desta dissertação, quando se apresenta o método JSP, as caixas contêm a palavra "PROC" com o significado de "processe". Outra observação feita por Chapin é quanto à colocação de caixas adicionais para opera ções tais como "abra", "leia", atribuição de valores iniciais às variàveis etc.

Nelson, em [Ne81], mostra que a técnica de anälise funcional de programação pode ser aplicada a qualquer programa, para evidenciar as funções que o programa efetivamente determina e os elementos estruturais envolvidos nessa determinação. Es sa técnica contribui para o entendimento do programa. Sua aplicação tem mostrado não só que as funções podem ser explicitadas, mas que o nümero de funções distintas, determinadas por um pro- 
grama especifíco, é muito menor do que geralmente se pensa. Existem muitos caminhos lógicos aparentes que não são executäveis, chamados de caminhos ficticios. Muitos programas construí dos de acordo com a teoria funcional de programação são estrutú rados, entretanto, a anālise funcional de programação tem mostrado que alguns programas estruturados têm uma estrutura lógica complicada. Programas estruturados complexos podem ser simpli ficados em programas funcionais estruturados. Cita o método de Jackson como desẹvolvido com conceitos básicos de programação funcional que, porém, não cuida dos caminhos fictícios que possam surgir.

Jones, em [Jo81], fornece uma visão geral das tëcni cas de especificação e projeto de programas. Diz que são encontradas diversas arquiteturas e linguagens na literatura sobre programas. Menciona que as arquiteturas podem ser subdivididas em dois grupos, de arquitetura de anālise de dados e de arquite tura funcional. Considera arquitetura como um modo de pensar em um problema e, então, partir para uma solução, que é a decomposição do problema em módulos elementares que sejam programáveis. A arquitetura de análise de dados é a que explora os dados que são utilizados ou transformados pelo sistema de processamento. Situa nessa arquitetura, com destaque, o método de Jackson.clas sifica as linguagens que são usadas para representar essa arqui tetura como linguagens gräficas e linguagens de cadeia de carac teres. Os diagramas de estrutura de Jackson, dentro das linguagens gräficas, são enquadrados na categoria dos gräficos deriva dos, que são baseados em conceitos de programação estruturada. Os textos estruturados correspondentes aos diagramas de estrutura, dentro da cadeia de caracteres, são enquadrados na ca tegoria das linguagens naturais que podem usar, também, símbolos matemáticos, simbolos Booleanos etc..

Basili, em [Ba8l], menciona o método de Jackson, JSP, como um dos métodos para desenvolvimento de software, cujo uso alegadamente traz benefícios em termos de produtividade. Diz, todavia, que hä falta de provas experimentais dessas alega ções, não só com relação ao método de Jackson, como em relação 
aos demais. Descreve uma experiência de desenvolvimento

software realizada com uma certa metodologia de programação estruturada, em que se usa grupo de controle trabalhando sem qual quer metodologia. Comenta os resultados do experimento, que mos tram diferença com significancia estatística entre os dois grupos e que favorecem o grupo que utilizou a metodologia.

Yamano em [Ya81] trata da tëcnica UFDT - Unified

Functional Design Technique, por ele desenvolvida, para especificar as funções de um software. Ao analisar o progresso dos ú timos anos na ārea de especificação das exigências de software, destaca, entre outros, os instrumentos automatizados fornecidos pelo projeto ISDOS [Te75,Te77] e a técnica de Jackson, baseada em diagramas que descrevem a estrutura e a função dos sistemas de software.

livari, em [1 i82], apresenta uma taxionomia para abordagens de desenvolvimento de sistemas baseada num modelo denominado Ploco. P com o sentido de pragmätico, $1 / 0$ com o sentido de entrada e saida, C com o sentido de construtivo, 0 com o sentido de operativo. Cada um desses sentidos define um modelo do sistema em desenvolvimento. O método de Jackson, JSP, é cita do na descrição do modelo construtivoloperativo. Mais especificamente, é usado para ilustrar o modelo das conexões ao ser detalhado o modelo de processamento que, por sua vez, faz parte do modelo primário de ações, que é um dos componentes do modelo construtivo/operativo.

Rosenquist, em [Ro82], ao discutir a aplicabilidade dos métodos disponiveis para projeto de Sistemas de Informação, refere-se ao método de Jackson e à contribuição de Robinson, a ele dada em [Rb 79], como um dos mais significativos métodos de modelagem existentes. Enquadra esse método no estägio que ele chama de "estägio de implementação" e o classifica como voltado para as estruturas dos programas/sistemas. Diz que a documen tação final do projeto efetivo do programa e das funções que o constituem é melhor efetuada usando-se a meta-linguagem desenvolvida por Jackson, que consiste dos diagramas de estrutura. 
Schneider, em [Sc82], cita [Ja75] entre outras meto dologias para desenvolvimento de sistemas, ao discutir critérios para a avaliação dos instrumentos e técnicas disponiveis para a especificação, realização e avaliação de Sistemas de Informação. Entre os critērios destacam-se: independēncia da estrutura do problema, independencia do tamanho do problema, completeza de conceitos, facilidade de aprendizado e ensino, e fle xibilidade nas modificações.

Shooman, num capítulo de [So83], inteiramente dedicado àstëcnicas e instrumentos para projeto de programas, lembra que um projeto pode ser entendido mais facilmente se for ex presso através de alguma técnica racional. Apresenta várias téc nicas para essa descrição e cita outras, entre as quais a de Jackson, salientando que o importante é usar algum método para exprimir o projeto, ao invés de descrevê-lo meramente em folhas datilografadas. Em outro capítulo, de [So83], dedicado às técni cas de gestão do desenvolvimento de software, destaca o sistema PSL/PSA, [Te75, Te77], como a técnica mais avançada, em termos präticos, para apoiar por computador a especificação das exigên cias do projeto. 


\section{4. - Conclusões}

A técnica JSP è aparentemente simples, porèm, como diz Peters, em [Pt77], ao se tentar usä-la na prätica, essa impressāo se desfaz. Uma das vantagens dessa técnica é a de condu zir à construção de um programa claro, baseado nos diagramas de estrutura, com as operações executáveis, e nos textos estrutura dos correspondentes, que constituem documentação complementar à listagem do programa. A crítica ao JSP surgiu por ser uma técni ca manual, como dito por Boehm, em [Bo79], porēm, com o PSTAIDS, de que trata Menard, em [Me80], esse problema parece ter sido, em parte, contornado.

0 método JSD, considerado por Jackson, em [Ja81], co mo uma extensão de JSP, cobre as fases de especificação e imple mentação de um sistema. o pröprio autor salienta, em [Ja78], que, na fase de especificação, surgem inūmeros processos tanto de modelagem como funcionais e que tentar, na fase de implementação, fazê-los compartilhar de um ünico processador não é tare fa tão simples.

No livro de JSP, os exemplos com que os conceitos são apresentados são relativos a problemas diferentes, o que torna mais difícil o seu entendimento claro. Já em [Ja76], os conceitos são aplicados a exemplos melhor integrados, mas notase a falta de, pelo menos, uma listagem de programa que melhor salientasse tais conceitos, como acontece no livro de Yourdon [Yo79].

A documentação do método JSP, em [Ja75], foi feita somente por texto, em linguagem corrente. Já Shaw, em [Sh82], melhora essa documentação atravēs de diagramas de estrutura para cada passo do método, utilizando as construções do próprio método de Jackson. Aliàs, é comum que os métodos de desenvolvimento de Sistemas de Informação preocupem-se em prescrever normas para documentar procedimentos, mas se esqueçam de aplicálas na documentação dos procedimentos que recomendam, ao conträ rio do que é feito por Lundeberg, em [Lu81], ao apresentar o mé todo ISAC. 
O mētodo JSP foi aplicado a inümeros casos präticos como, por exemplo, os citados por [Bn78] e [Me80], [Be81]. Sobre - JSD não foi encontrada referência a nenhuma aplicação prática. 0s exemplos fornecidos por Jackson, em [Ja78,Ja81 e Ja83], e por Cameron, em [Ca81], são para ilustrar tópicos do método, mas não hä, disponivel, nenhum exemplo suficientemente completo para facilitar a solução de problemas reais com seu uso. o método JSD, também, é documentado apenas em uma linguagem natural. 0 seu entendimento poderia ser facilitado se fosse melhor documen tado com o auxilio de outros recursos, por exemplo, gráficos.

Pelo levantamento bibliogräfico efetuado, pode-se concluir que os métodos de Jackson tiveram bastante repercussão na literatura técnica especializada. Em 2.3, são citadas vinte e cinco referéncias sobre trabalhos que ilustram essa repercussão. Pela variedade das fontes dessas referéncias, pode-se ter uma idéia da amplitude dessa repercussão.

Quanto aos documentos de apresentação dos métodos, parece, como se pode ver em 2.2, que Jackson usou estratégias diferentes para divulgar JSP e JSD. Em relação ao primeiro, ini cialmente, publicou um livro e depois trabalhos complementares que melhor apresentavam certos pontos já abordados nesse livro e, quanto ao segundo, publicou trabalhos preliminares em que foi apresentando o método, à medida que ia evoluindo. A seguir, publicou um livro em que todos os pontos do método foram consolidados. Os problemas mais complexos eram resolvidos através da decomposição em problemas mais simples, até que se conseguisse aplicar o método JSP. Parece ter sido dessa forma que surgiram outros trabalhos desenvolvidos por Jackson, para complementar o livro sobre o método JSP, chegando-se, assim, à elaboração de um livro sobre o método JSD. 
SOBRE O METODO JSP

3.1. - Considerações Gerais

Este capitulo tem por objetivo fornecer uma visão geral do método JSP - Jackson System Program [Ja75], para facilitar o entendimento de JSD - Jackson System Development [Ja83] onde JSP é considerado conhecido.

os conceitos aqui apresentados são os que compõem o livro de Jackson [Ja75]. Alguns conceitos são mais detalhados no Apêndice e são distinguidos pelo símbolo (\$) enquanto outros são detalhados neste capítulo. Com isso, espera-se evitar redun dância de informaçōes. Maiores detalhes dessa técnica podem ser encontrados nas outras referencias indicadas no capítulo 2 .

Primeiramente, apresenta-se um resumo do método JSP segundo as considerações feitas por Bergland em seu artigo [Be81], onde aplica o método a um problema prático.

os detalhes são mostrados utilizando-se os diagramas sugeridos por Shaw, [Sh82], que aplica as notações e as estruturas existentes no pröprio método JSP. Convēm salientar que - mesmo enfoque é dado ao método JSP tanto por Bergland como por Shaw, só que o primeiro o faz de uma forma mais resumida.

os exemplos apresentados são extraídos de [Ja76a] e a programação correspondente a cada um deles encontra-se neste capitulo. Os programas são implementados em linguagem COBOL uti lizando-se o sistema 600 da Prológica.

o método JSP, [Ja75], fornece instrumentos para a $\underline{e}$ laboração de programas estruturados que, segundo Jackson, são facilmente entendidos e modificados quando necessārio. 
Um programa é composto por estruturas hierárquicas, isto é, é subdividido em partes. Cada parte é projetada indepen dente estruturadamente.

A figura 3.01 , reproduzida de [Be81], apresenta os passos do método JSP.

Um outro modo de representar os pontos principais do método de Jackson é mostrado em [ $1 n 78]$, reproduzido aqui na figura 3.02. Essa figura é uma variante do diagrama sugerido por Bergland.

A figura 3.03 é uma reprodução dos diagramas apresentados por [Sh82] e nenhuma alteração foi feita quanto à otimização. Shaw, em [Sh82], apresenta o método JSP utilizando as no tações do prōprio método: seqüência (\$), seleção (\$) e iteração $(\$)$. Nesses diagramas è comum encontrar a sigla JDM, que significa projetar o programa segundo os passos mostrados nessa figu ra.

Para melhor ilustrar o método JSP, a seção 3.2 fornece uma idéia geral dele, de acordo com o esquema proposto por Bergland e que é o mostrado na figura 3.01 . Alguns conceitos ci tados nessa seção serāo detalhados e exemplificados nas seções 3.3 a 3.8 onde se apresentam os passos do método JSP com base nos diagramas de Shaw. 


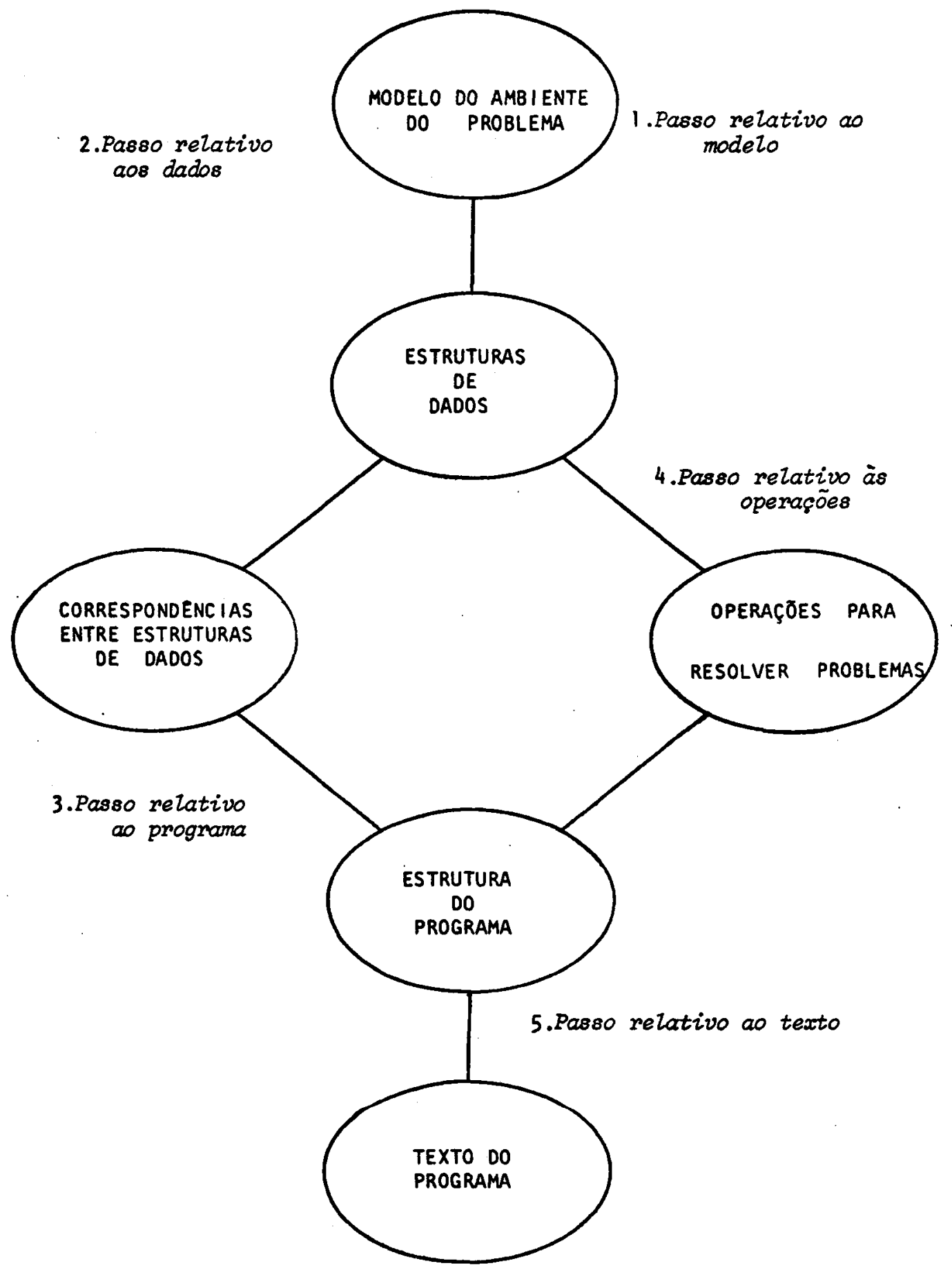

Diagrama relativo aos passos do método JSP sugeridos por Bergland [Be81]

Figura 3.01 


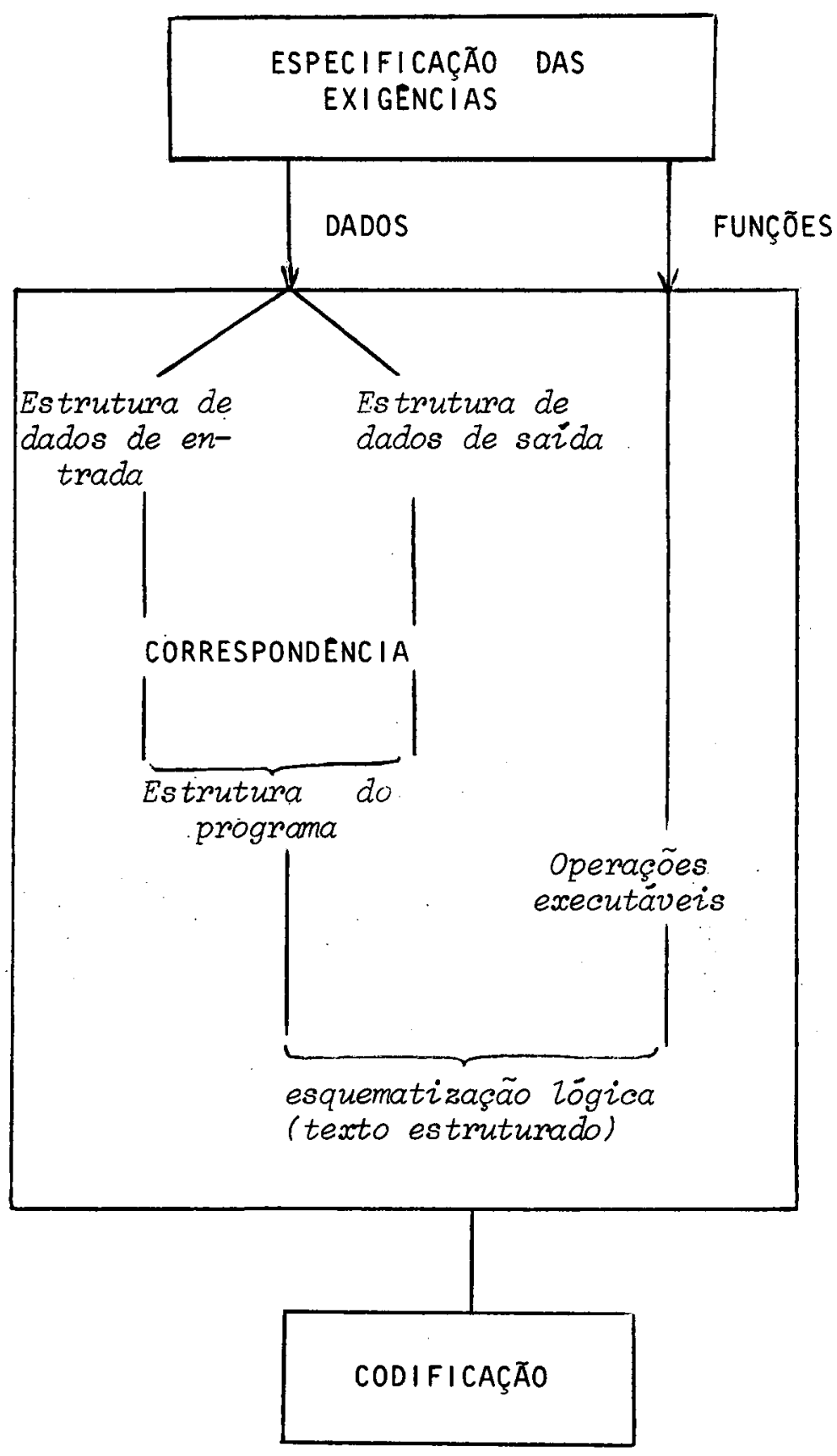

Diagrama relativo às principais características do método JSP reproduzido de [ $1 n 78]$

Figura 3.02 


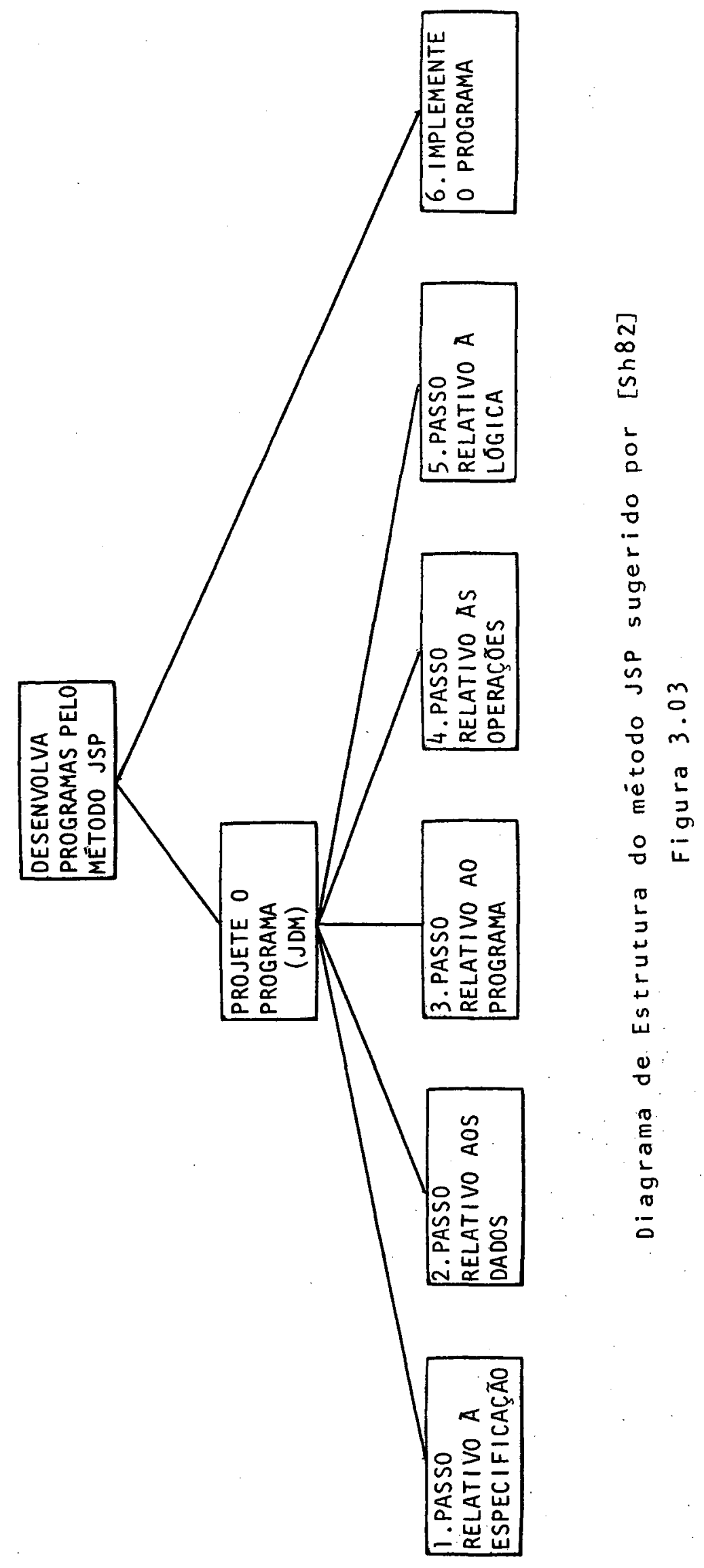


3.2. - Delineamento do método

Bergland, em [Be81], mostra de maneira resumida os passos para se desenvolver um programa simples pelo método JSP.

Todo programa complexo pode ser transformado em um ou mais programas simples, como serā visto na seção 3.7 . Bergland diz que, se os passos enumerados abaixo foram obedecidos, obtēm-se um programa bem estruturado e com facilidade para sofrer alterações. Jackson salienta a importāncia de que um pró grama complexo seja subdividido em programas menores dizendo que: "se os programas simples são difícieis de serem escritos, os programas complexos serão impossiveis".

os passos sugeridos por Bergland estão representados em forma de diagrama na figura 3.01 e são os seguintes:

1) construir um diagrama de fluxo em rede que modele o meio em que o problema existe.

2) definir e verificar os fluxos de estruturas de dados.

3) derivar e verificar as estruturas dos programas.

4) derivar e alocar as operações elementares.

5) escrever o texto estruturado e texto do programa.

Os programas simples são implementados como estrutü ras hierärquicas modulares ligadas através de uma rede de fluxo de dados. Essa rede pode estar dentro de uma hierarquia que "chama" ou "é chamada" por um procedimento de articulação, conhecido por inversão de programa, que é executado como um passo separado depois de já se ter definido a estrutura do programa. Esse tōpico é discutido na seção 3.7 .

os programas simples são representados através de diagramas de estrutura como uma rede de funções que consomem, transformam e produzem arquivos seqüenciais.

Como será visto na seção 3.5 , quando não há corres pondência entre as estruturas de dados e a estrutura do programa, ocorre um choque estrutural.

A estrutura final de um programa é formada obtendose, primeiro, as correspondēncias entre as estruturas de dados 
e, em seguida, colocando-se nela as operações executäveis, tam bēm derivadas das estruturas de dados. A documentação do modelo do processo é feita atravēs de diagramas de estrutura e a do programa, por textos estruturados.

A fim de ilustrar esses passos considere-se o exemplo a seguir, extraído de [Ja76a].

Exemplo 3.1 - Seja um arquivo de entrada composto de cartões perfurados, ordenado em ordem crescente por uma chave contida em cada cartão.

Nesse arquivo, o primeiro cartão de cada grupo, com - mesmo valor da chave, é o cartão-título e os outros são cartóes-detalhe. Deseja-se como saida um relatório que mostre os totais de uma dada informação para cada uma das chaves.

A fim de exemplificar o método JSP, considere-se que os campos do cartão-título são: tipo do cartão, sigla do departamento, número do departamento, entidade educacional e cidade. os cartōes-detalhe contêm os seguintes campos: tipo do cartão, estado civil do funcionärio, nümero do departamento ao qual o funcionärio pertence, nümero de dependentes e nome do funcionário.

Aplicando-se os passos sugeridos por Bergland ao exemplo 3.1 , tem-se:

19) Passo Relativo ao Modelo - aqui ocorre o primeiro contato com o problema e a construção de um diagrama de fluxo de re de do sistema, que representa qual o objetivo do programa, ou seja, mostra a entrada, o processamento e a saida.

No exemplo tem-se como entrada um arquivo ordenado de cartões, e deseja-se um relatório, como saída, contendo - nümero do departamento, a sigla do departamento e o total de dependentes de todos os funcionärios desse departamento. os esquemas correspondentes aos dados de entrada e o relató rio desejado podem ser vistos na figura 3.04 , e o diagrama de rede do sistema é o mostrado na figura 3.05 .

20) Passo Relativo aos Dados - è quando se constrói e se verifí ca o diagrama de estrutura $(\$)$ dos dados de entrada e de saí 


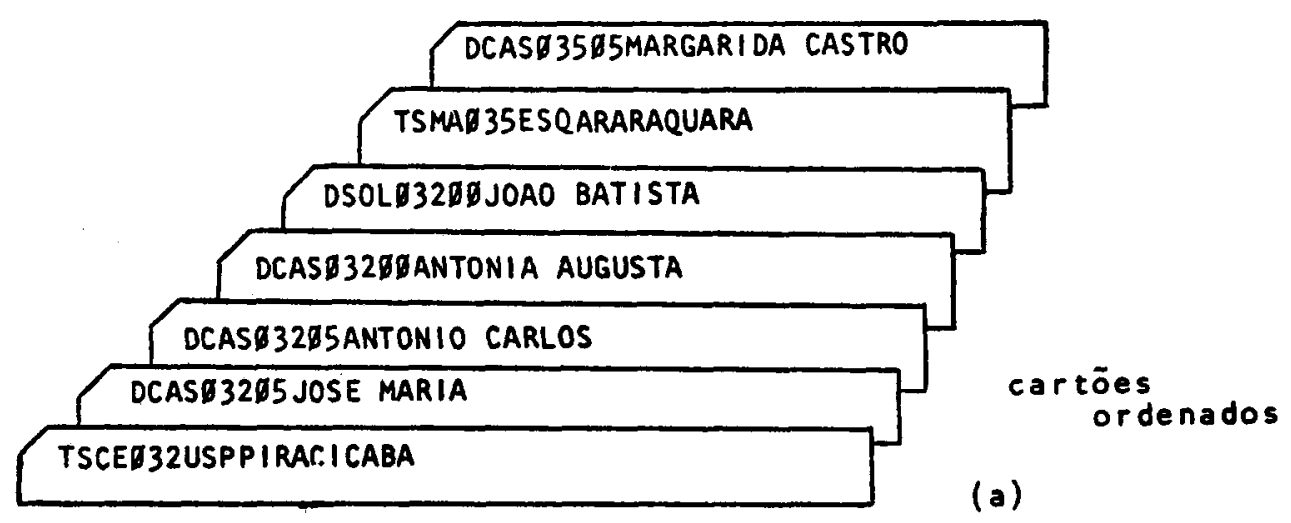

RELATŌRIO

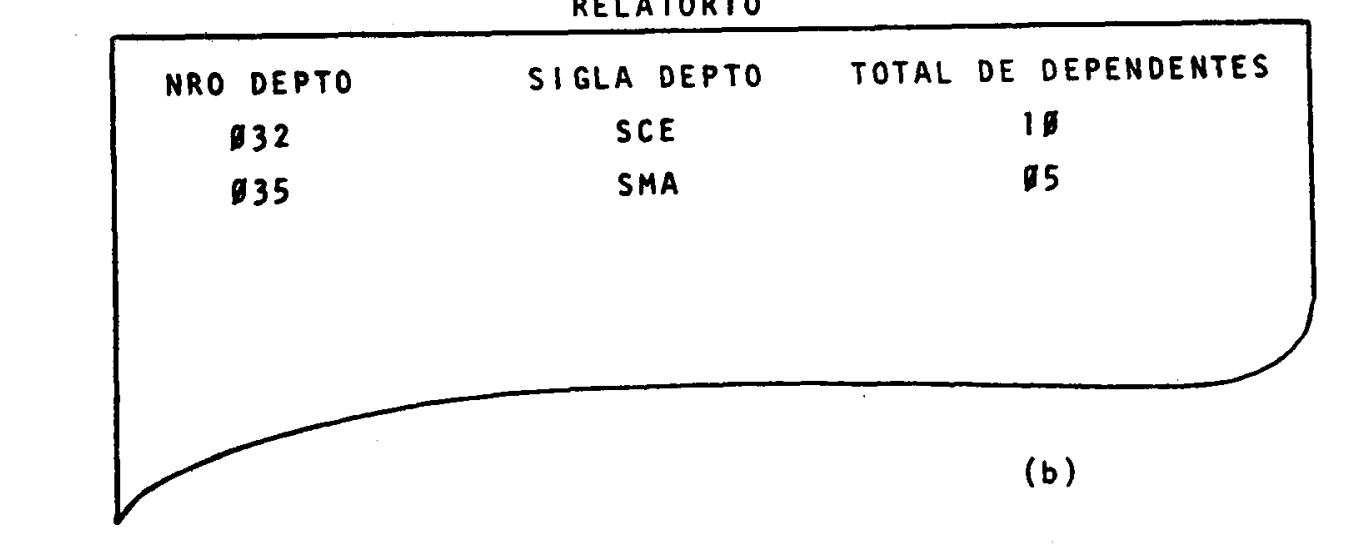

Disposição dos dados de entrada/saída do problema exemplo 3.1 Figura 3.04

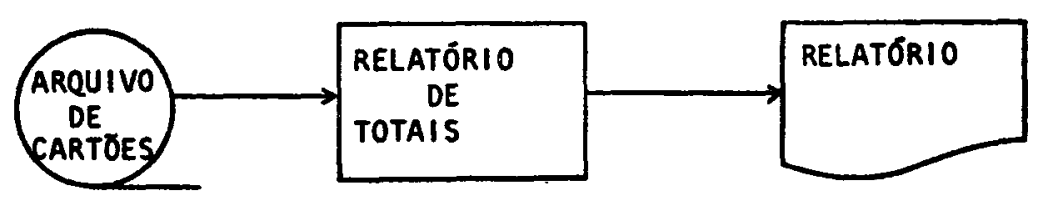

Diagrama de Fluxo em Rede do Sistema

Figura 3.05 
da para cada arquivo utilizado pelo programa. No exemplo, tem-se o ARQUIVO-DE-CARTOES que é dado de entrada e o RELATORIO que é dado de saída. Assim, os respectivos diagra mas de estrutura devem ser construidos.

O ARQUIVO-DE-CARTOES, como pode ser visto na figura $3.04(a)$, é formado por grupos de cartões onde cada grupo con tēm um primeiro cartão que é o título e um conjunto de cartões-detalhe. Nesse caso, o diagrama de estrutura de entrada é formado por ARQUIVO-DE-CARTOEES que é uma iteração de GRUPO-CART que, por sua vez, é uma seqüência formada por CARTTITULO e CORPO-GRUPO-CART. CORPO-GRUPO-CART è uma iteraçào de CART-DETALHE, que é uma seqüēncia formada por chave (nümero do departamentol e outras informações. o diagrama de estrutura correspondente é o mostrado na figura 3.06(a).

o RELATORIO, como pode ser visto na figura $3.04(b)$, é formado por um CABEÇALHO e por um conjunto de linhas que formam o relatório. Assim, o diagrama de estrutura de saída é formado por uma seqüēncia de CABEÇALHO-RELATORIO e CORPORELATORIO. CORPO-RELATORIO é uma iteração de LINHA-RELATORIO que por, sua vez, é uma seqüência de chave e total correspondente a essa chave. O diagrama de estrutura é o mostrado na figura $3.06(\mathrm{~b})$.

39) Passo relativo ao programa - constrói-se o diagrama de estrutura do programa a partir da estrutura de dados. Observando-se a figura $3.06(a)$ - 3.06 (b) nota-se que existe uma correspondēncia biunivoca entre as estruturas do ARQUIVO-DECARTOES e a do RELATORIO. Nesse caso, O ARQUIVO-DE-CARTÓES é consumido para produzir um RELATORIO. Do mesmo modo, GRUPO-CART é consumido para produzir LINHA-RELATORIO.

A figura 3.07 mostra o diagrama de estrutura do pro grama onde aparecem todas as partes de cada estrutura de da dos. Utiliza-se o nome PROC significando "processe" em vez de "consuma para produzir". Os módulos que não estão em cor respondência biunívoca são leituras, se fizerem parte da es trutura de entrada, e impressões, se fizerem parte da estru tura de saida. 

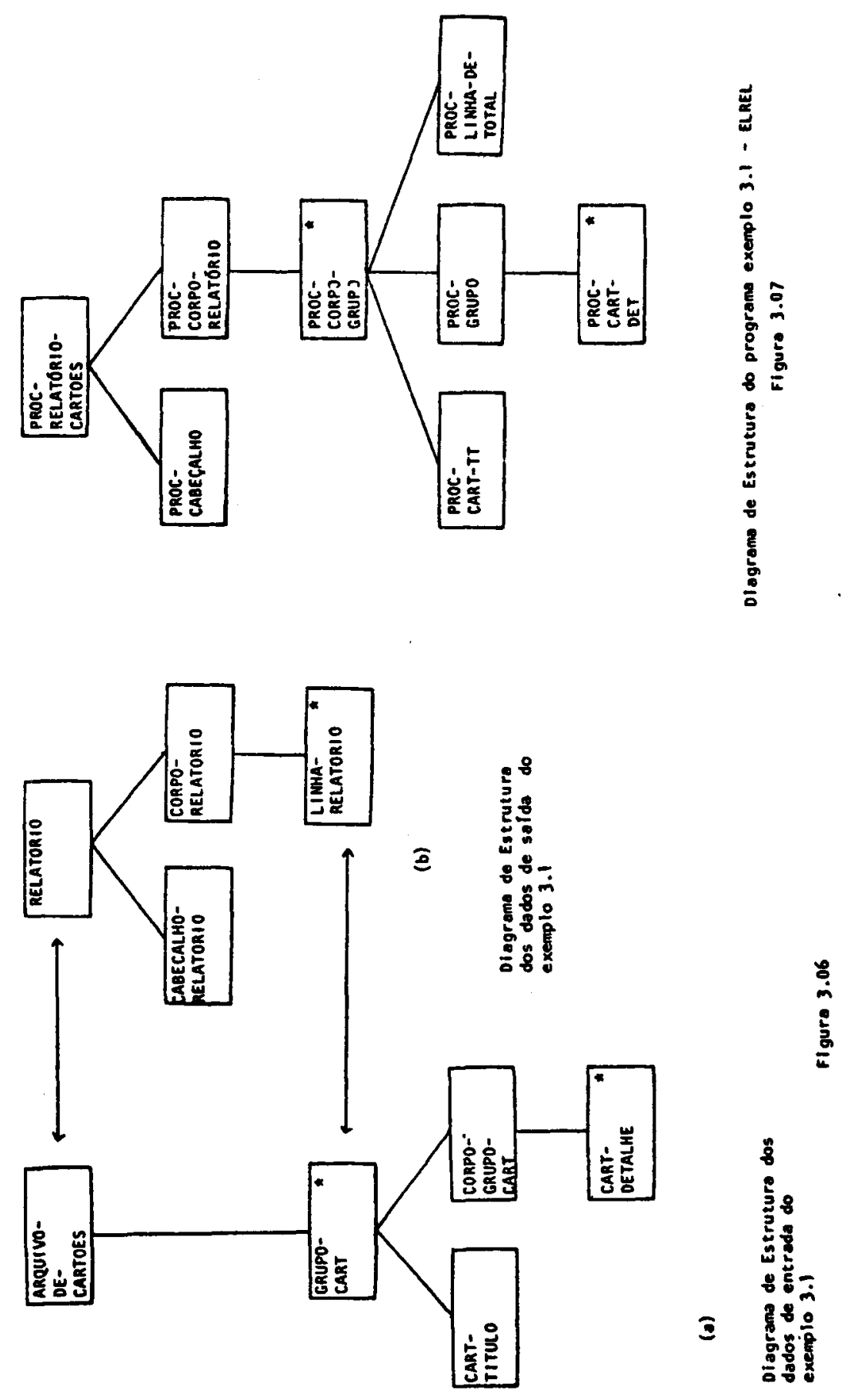
Através dessa correspondēncia, pode-se notar que as estruturas de dados são sub-ārvores da estruturas do progra ma.

4:) Passo Relativo às Operações - A identificação das operações de entrada, saída e de cálculos é feita retrosseguindo as estruturas de saída até chegar às estruturas de entrada. Sempre que houver necessidade, pode-se construir um diagrama de fluxo de dados para representar as variáveis intermediàrias.

As operações devem ser compatíveis, de modo que se possa garantir que cada saída é produzida e cada entrada é consumida.

A lista de operações relativas a esse exemplo, a partir das saídas até as entradas, è a mostrada na figura 3.08 , juntamente com o diagrama de estrutura com essas operações.

o passo relativo às operações envolve o alojaménto de todas essas operações executāveis na estrutura do progra ma. Nesse caso, cabem perguntas do tipo: "como deve ser exe cutada essa operação ?". A resposta a essas questões ocorre tendo-se em mente que um arquivo deve ser aberto antes de ser lido, e fechado antes que o processamento pare; que a a tribuição do valor inicial à uma variável ocorra antes que ela seja incrementada etc.. Como resultado final desse passo, deve-se verificar se todas as saidas e todos os resulta dos intermediārios foram produzidos e se todas as entradas foram consumidas, ou seja, se o processamento foi realizado plenamente.

50) Passo Relativo ao Texto - antes da codificação deve-se converter o diagrama de estrutura do programa para a forma de texto estruturado. E uma notação textual usada independente da linguagem de programação a ser utilizada. E também chama do de esquematização lógica. Com o texto estruturado, fica clara a lógica do programa; e os rótulos colocados no texto podem também ser colocados no programa, o que facilita o seu entendimento. 


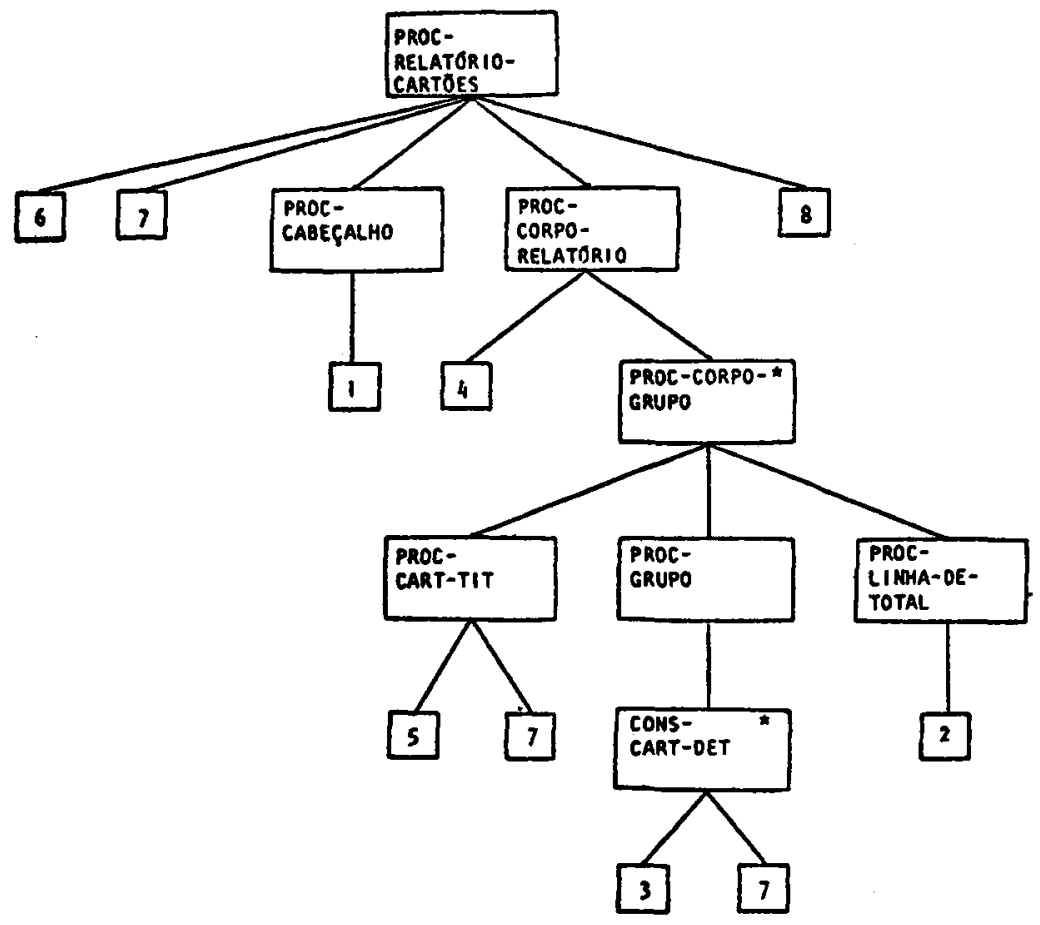

2. Imprima oabegalho

2. inprima linha di total (ohave-grupo, total)

3. total = total + quantidade - dotalhe

1. total $=\varnothing$

6. ohave-grupo = chave-tit

- abra arquivo-de-cartōes

7. Ieia arquivo-de-eartöes

- Iola arquivo-de-captöes

olegrama de Estrutura com as operaçōes execuejuels do programa exemplo 3.1 - ELREL

FIgure 3.08

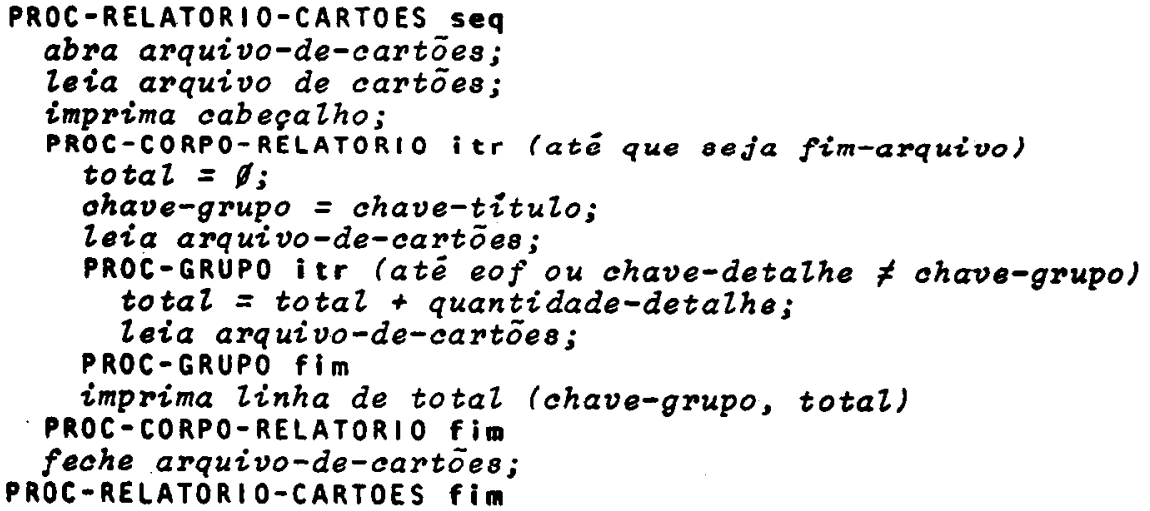

Texto Estruturado do programa exemplo 3.1 - ELREL

Figura 3.09 
o texto estruturado correspondente a esse exemplo é mostrado na figura 3.09 .

A implementação desse exemplo è o programa ELREL, figura 3.10 e pode-se notar que os nomes de parágrafos da PROCEDURE DIVISION dO COBOL são os mesmos que os rótulos que aparecem no texto estruturado. Com a elaboração do texto estrutú rado, a programação é imediata, pois a lógica é clara e as modi ficações, quando necessárias, tornam-se mais fáceis.

$\mathrm{Na}$ implementação desse exemplo utilizaram-se dados referentes a funcionários de departamentos que pertencem a entidades educacionais. A chave é o nümero do departamento e o to tal correspondente é o número total de dependentes de todos os funcionários de cada departamento.

o relatōrio de saída é constituído pelo nümero do departamento, nome da entidade educacional e total de dependentes. 
IDENTIFICATION DIVISION.

FROGRAM-ID. ELREL.

* frograma exemflo extrajdo de rjatgaj. tem for ogjettuo ilustraf

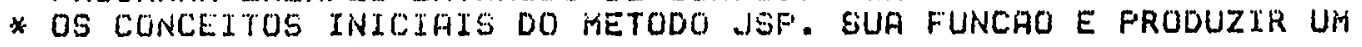

* raquivo de entradas.

AUTHOR. RUSANGELA FENTEADO.

ENUIRONMENT OIUISION.

INFUT-OUTFUT SECTION.

FILE-CONTROL.

SELECT ARQ-CARTOES ASSIGN TO DISK

ACCESS MODE IS SEQUENT IAL

ORGFNIZATION IS LINE SEQUENTIAL.

SELECT AFQ-SAIDA HSSIGN TO DISK.

DATA DIUISION.

FILE SECTIDN.

-FD ARQ-CARTTOES

LAEEL RECORDS ARE STANDARD

VALUE OF FILE-ID IS "B:CART.DAT".

DATA RECORDS ARE REG-CARTAO-TIT REG-CARTAO-DET.

Q1 REG-CARTAUUTIT.

O2 TIPO-C.ARTAO

QR SIGLA-DEFARTAMENTO

Q2. NRD-DEFRRTAMENTO

UE ENTIDADE-EDUCACIONAL

Q2 CIDADE

01 REG-CARTAO-DET.

Q2 TIFO-CARTFO

Q2 ESTADO-CIUIL

Q2 NRO-DEFARTAMENTO

DE NFO-FILHOS

G2 NOME-FUNCIONARTO

PIC $A$.

PIC $A(3)$.

FIC 999.

FIC $A(3)$.

FIC $A(10)$.

FD ARQ-SAIDA

FIC $A$.

FIC $A(3)$.

FIC 999 .

FIC 99.

PIC $A(30)$.

LAEEL RECORD IS STANDARD

VALUE OF" FILE-ID IS "E:CART . OUT"

DATA RECORD IS LINHA-IMPRESSAO.

Q1 LINHA-IMFRESSAO

WORKINO-STORAGE SECTION.

77 FIM-ARQUIVO

Q1 CAEECALHO.

Q2 FILLER

Q2 FJLLER

Q2 FILLER

Q2 FILLER

01 LINHA-DE-TOTAL.

OC FILLER

Q2 NRO-DEFARTAMENTD

g2 FILLER

GE SIGLA-DEPARTAMENTO

QZ FILLER

DE TOTAL-DE-DEPENDENTES

FIC $X(132)$.

FIC $A$.

FIC $X(20)$ VALUE SFACES.

FIC $x(11)$ VALUE "NRO DEFTO ".

PIC $x(27)$ VALUE

$"$ SIGLA DEFTD

PIC $X(26)$ VALUE

" TOTAL DE DEFENDENTES".

FIC $X(2 J)$ VALUE SFACES.

FIC 999.

FIC $X(15)$ VALUE SPACES.

FIC $A(3)$.

FIC $X(27)$ VALUE SPACES.

PIC 99.

Implementação do exemplo 3.1 - Programa ELREL

Figura 3.10 
FROCEDUKE DIVISTON.

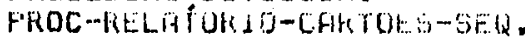

OPEN INFUT ARQ-CAKIOES

DUTPUT ARQ SATUA.

MOVE: "N" TO FIMARQTIUOO.

MOUE SFHCES TO L.. WWHA I THFESSFO.

WRI IE LINHFI-IMFRESSAI FROM CAEECALHO AF TER FDUANCING Z LINES.

READ FIRQ-CARTOES AT END MUVE "S" TO FIM-FRQUTVI.

PROC-CORFO-RELATORTO-ITH.

IF FIM-ARQUTUO = "S"

GO TO FROC-CORFO-RELATORIO-FIM.

MOUE ZEFOS TO TOTAL-OE-DEFENDENTES.

MOUE SIGLA-DEFARTAMENTO IN REG-CARTAO-TIT TO

SIGLA-DEFFRTFITLINTO IN LINHA-DE:-TOTFL.

MOVE NRO-DEPARTAMENTO IN REG-CARTAO-TIT TO

NRO-DEF'ARTAMENTO IN LINHA-DE-TOTAL.

READ ARG-CHRTOES AT END MOUE "S" TO FIM-ARQUIVO.

PROC-CIRUPO-ITR.

IF NRO-DEPARTAMENTO IN REG-CARTAO-DET NOT =

WRO-DEFARTRTENTO IN LINHA-OE-TOTAL

OR FIM-GRQUIVO $=$ "S"

GO TO FIROC-GRUPO -FIM.

ADD NRO-FILHOS TO TOTAL-DE-DEPENDENTES.

REFD ARQ-CARTOE'S AT END MOVE "G" TO FIM-ARQUIVO. GO TO PROL GRUFO-ITR.

PROC-GRUFO-FIM.

MOUE SFACES TO LINHA-IMFRESSAO.

WRITE LINHA-IMFRESSAO FEROM LINHA-DE-TOTAL AFTER

AOUFNEING 2 LINES.

GO TO FROC-CORFO-RELATORIO-ITR.

PROC-CORFO-RELATORLO-FIA.

CLUSE FRQ-CARTOES

ARQ-SATDA.

STUF RUN.

PROC-RELATORIO-CARTOES-FIM.

1: TSCEOJZUSFPIRACJCAEA

3: DCF $603 \%$ USJOSE MARIA CRUZ FEIXOTO XRUIER

3: DCASOJ_ESANTONIO CARLOS PEREJRA

4: DCASG3EUEANTONIA AUGUSTA

5: DSOLOSEQOJOAO EATISTA FERRERA

6: TSMAQBSESQHRRRAQUARA

7: DSOLEOSEGMARGGHLDA CASTRO

B: TSSFUSEREGSAO CARLOS

9. DCASESZUSMARCO FNTONIO GIEI

10: DSOLGS200JURANDIR FEIXOTO EAIXINHO

Dados de entrada do programa ELREL

$\begin{array}{ccc}\text { NRO DEFTO } & \text { SIGLA DEFTO } & \text { TOTAL DE DEFENDENTES } \\ 032 & \text { SCE } & 10 \\ 035 & \text { SMA } & 92 \\ 052 & \text { SSF } & 05\end{array}$

Dados de saída do programa ELREL

Figura 3.10 (cont.) 
3.3. - Passo Relativo à Especificação do Programa

o primeiro passo é o relativo à especificação, figu ra 3.11 . o ponto inicial, para que um programa seja desenvolvido segundo JSP, é estudá-lo. Esse estudo envolve o entendimento da especificação, ou seja, deve-se ler a especificação e resolver todas as ambigüidades que surgirem. Em seguida, define-se o fluxo de dados para então delimitar o programa. No exemplo 3.1 - resultado desse passo seria o diagrama de fluxo em rede do sistema mostrado na figura 3.03 .

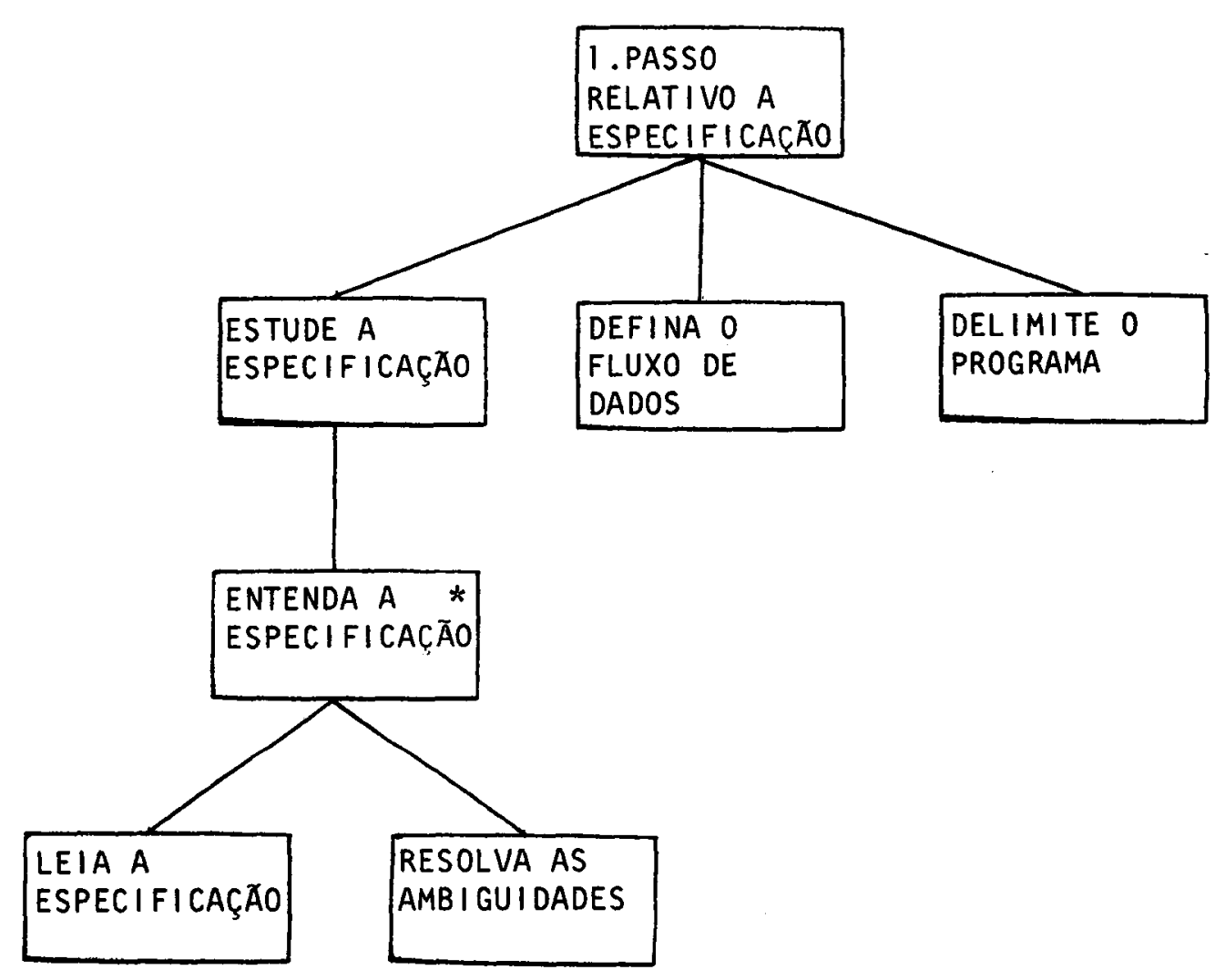

Diagrama de Estrutura do passo relativo à especificação sugerido por Shaw [Sh82]

Figura 3.11 
3.4. - Passo Relativo à Estrutura dos Dados de E/S

No segundo passo, figura 3.12 , descrevem-se os dados do problema utilizando-se as estruturas de seqüencia (\$), se leção ( $($ ) e iteração ( $($ ). Qualquer parte de uma estrutura pode incluir, novamente, combinações dessas estruturas. 0 resultado final dessa composição é um diagrama de estrutura (\$) relativo aos dados.

Após a construção de um diagrama de estrutura, deve-se revisá-lo retirando as partes não relevantes, seguindo-se as regras:

1) Substitua por nulas (-) aquelas partes que não são relevan tes na estrutura.

2) Aplique o conjunto de regras a seguir, sucessivamente, até obter uma estrutura relevante, figura 3.13 .

a) remova folha nula que é parte de uma seqüència.

b) remova folha nula de uma seleção que é parte de uma itera ção.

c) se houver uma seqüência (ou seleção) que tenha uma só par te, substitua essa seqüência (ou seleção) pela sua parte.

d) se houver uma seleção com duas partes idênticas, retire uma dessas partes.

Considere-se o exemplo 3.1 , mostrado na seção 3.2 . Nesse passo deve-se construir os diagramas de estrutura dos da dos de entrada e saída. Esses diagramas são apresentados na figura $3.06(a)$ e (b). 


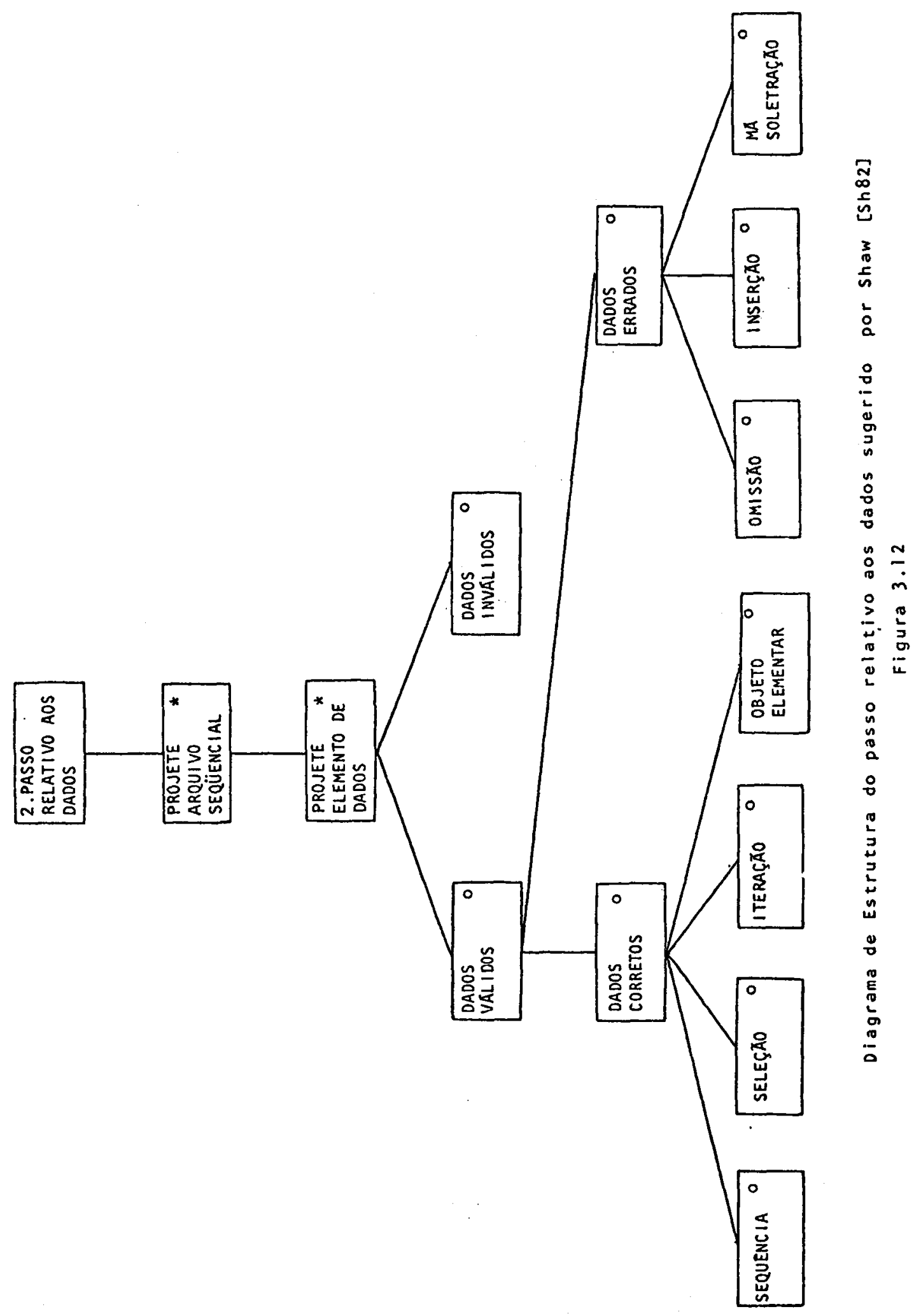




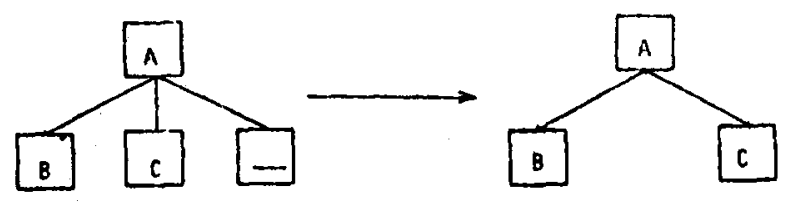

(a)

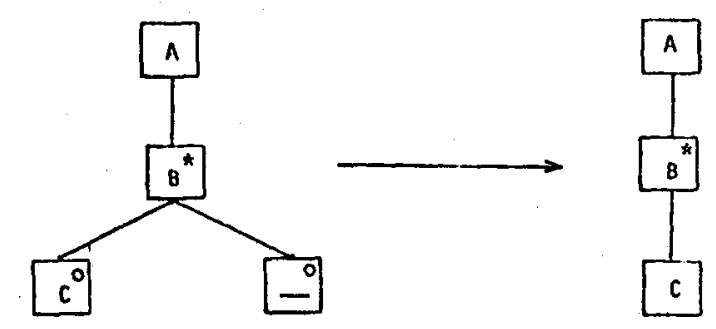

(b)
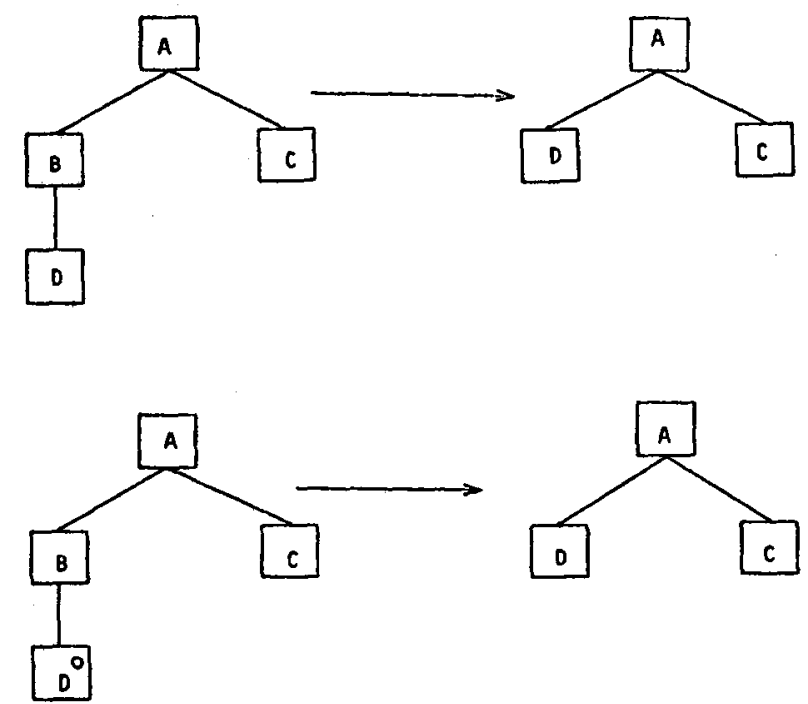

(c)

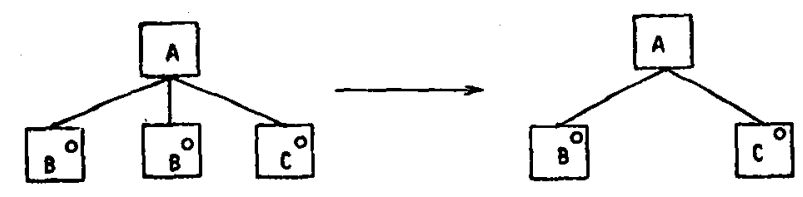

(d)

Regras de simplificapăo aplicaveis aos diagramas de estrutura Figura 3.13 
3.5. - Passo Relativo à Estrutura do Programa

A figura 3.14 mostra o que deve ser feito em relação ao programa, no terceiro passo do método JSP.

rara se construir o diagrama de estrutura do progra ma, deve-se determinar as correspondencias entre as estruturas de dados de entrada e saida. No exemplo 3.1 pode-se observar na figura 3.06 essa correspondência. Esse programa é livre de choque estrutural, é um programa simples de estado fixo e não de intercal ação.

Os programas simples são aqueles cujas entradas e saídas são arquivos seqüenciais, sem que nada deles seja necessärio em execução subseqüente e nos quais haja definição explícita da estrutura de cada arquivo de entrada e de saída. As estruturas dos dados de entrada definem o domínio do programa e a imagem è definida pelas estruturas de saída.

Após a construção do diagrama de estrutura do programa, deve-se elaborar o texto estruturado a ele correspondente.

0 diagrama de estrutura relativo ao programa, correspondente ao exemplo 3.1 dado, é o apresentado na figura 3.08 e o texto estruturado é o apresentado na figura 3.09 .

Um dos cuidados a ser tomado no terceiro passo é quanto ao choque estrutural que ocorre, quando não se consegue estabelecer uma correspondencia biunivoca entre os dados de entrada e saída de um problema. A solução nesse caso é abandonar a tentativa inicial de se construir um único programa e decompor o problema em dois ou três intermediários.

Exemplo 3.2 - Considere-se, agora, que o arquivo de entrada do exemplo 3.1 , esteja na forma de arquivo blocado. Cada bloco des se arquivo contém o tamanho do bloco e um número de registros I MAGEM-DE-CARTAOO.

A estrutura do arauivo blocado é a mostrada na figu ra 3.15 . Essa estrutura mostra um arranjo de cartoes em blocos e não em grupos, como na figura $3.06(a)$ do exemplo 3.1 . 


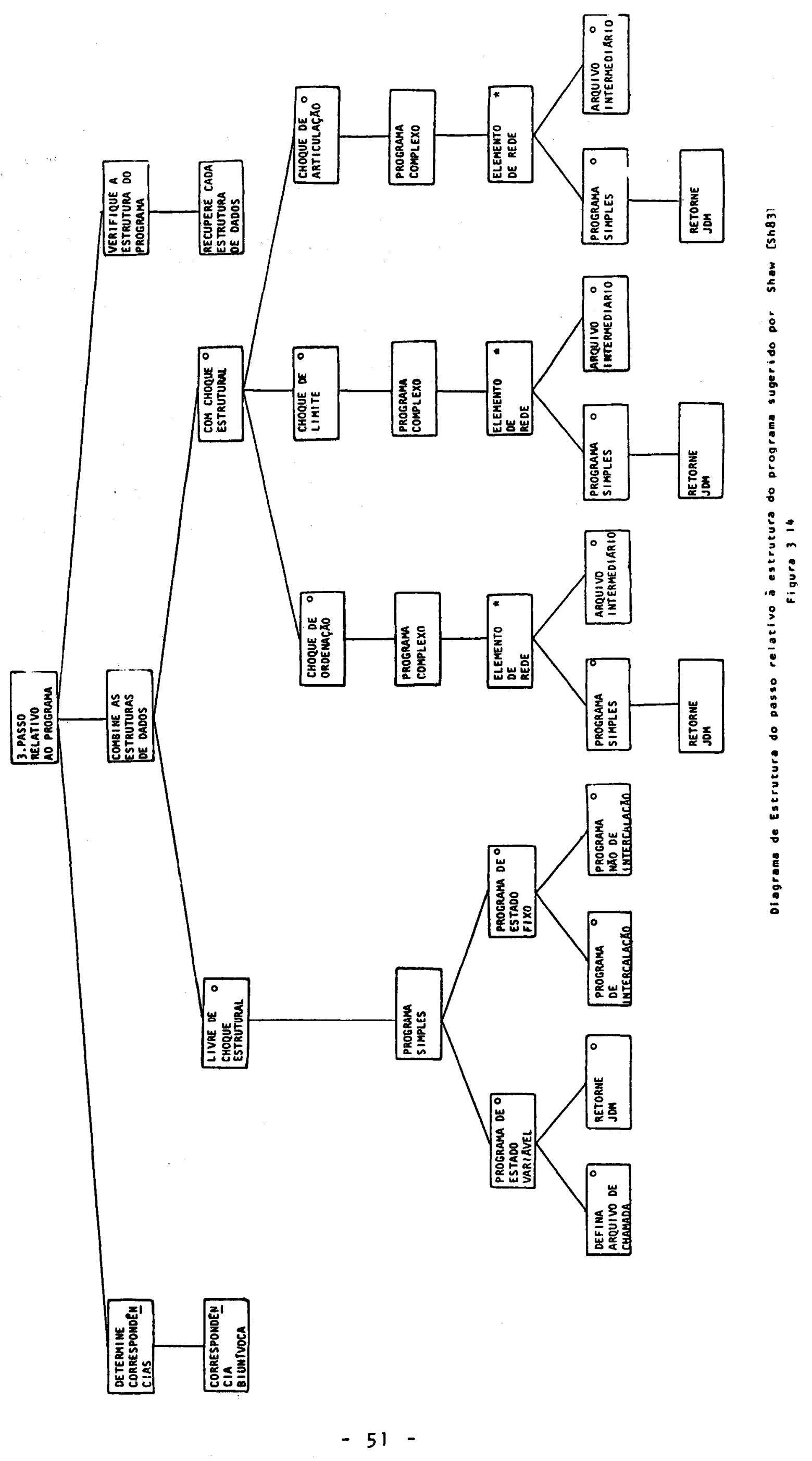




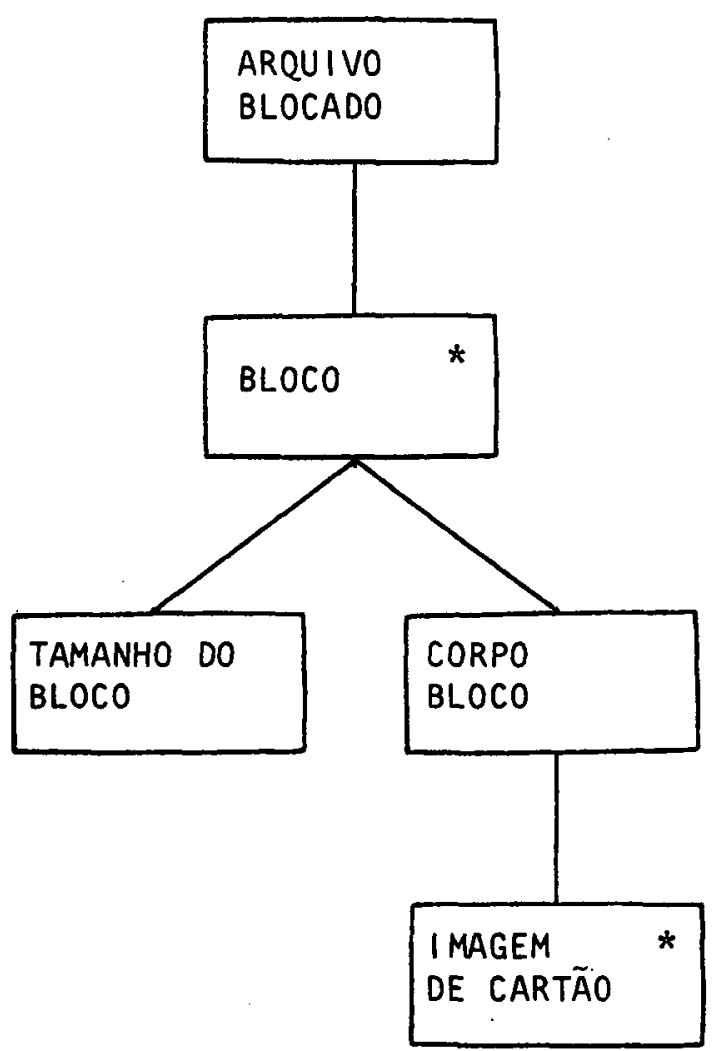

Diagrama de Estrutura dos dados de entrada do exemplo 3.2

Figura 3.15

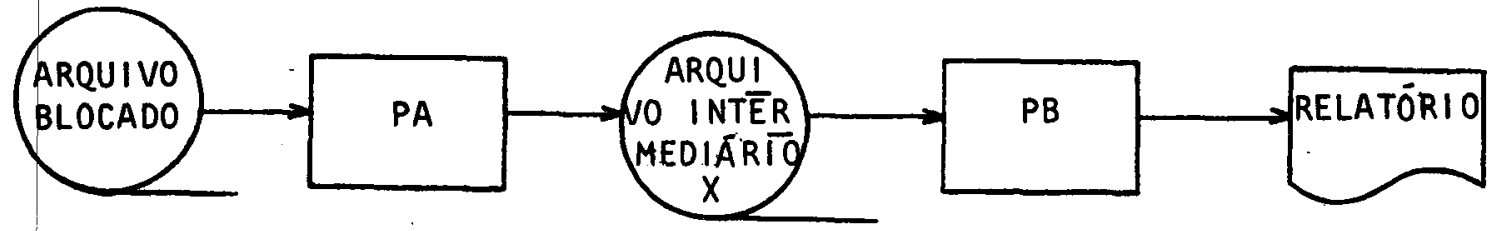

Diagrama de fluxo em rede do sistema do exemplo 3.2

Figura 3.16 
Não se consegue mostrar em uma única estrutura o ar ranjo em grupos e o arranjo em blocos. Porém, a estrutura do re latório, figura $3.06(b)$, continua como anteriormente.

- programa deveria conter operações para processar por blocos, executando uma componente "processe bloco" e também por grupos, executando uma componente "processe grupo". E impos sivel formar um único programa simples contendo as duas componentes "processe bloco" e "processe grupo".

Esse. tipo de choque estrutural é chamado de "choque de limites": os limites dos blocos não são sincronizados com os limites dos grupos. Para resolver esse caso, abandona-se a solu ção de um ünico programa complexo e decompōe-se o problema em dois ou mais programas simples. Esse tipo de choque requer decomposição, como se mostra na figura 3.16 .

o arquivo intermediário, $X$, è composto de registros, cada um dos quais è uma IMAGEM DE CARTÃo.

PA é o programa que processa as imagens de cartão em bloco.

PB è o programa que processa as imagens de cartão em grupo.

O diagrama de estrutura com as operações executáveis de PB é mostrado na figura 3.08 e de PA é mostrado na figu ra 3.17 .

0 texto estruturado correspondente a PB é o mostrado na figura 3.09 e o correspondente a PA é o mostrado na figura 3.18 .

A implementação do exemplo 3.2 é feita pelo programa DBLOC, figura 3.19, correspondente a PA e pelo programa ELREL, figura 3.10 , correspondente a PB.

Exemplo 3.3 - Considere-se, agora, o mesmo exemplo 3.1 , mas levando-se, também, em consideração que o arquivo de entrada em cartões não está com a ordenação completa. Os cartões estão par cialmente ordenados, de modo que o cartão-título de cada grupo precede todos os cartões-detalhe daquele grupo, porém nem todos os cartões-detalihe de um grupo estão colocados logo a seguir ao título desse grupo. o rélatōrio não tem cabeçalho e os totais 


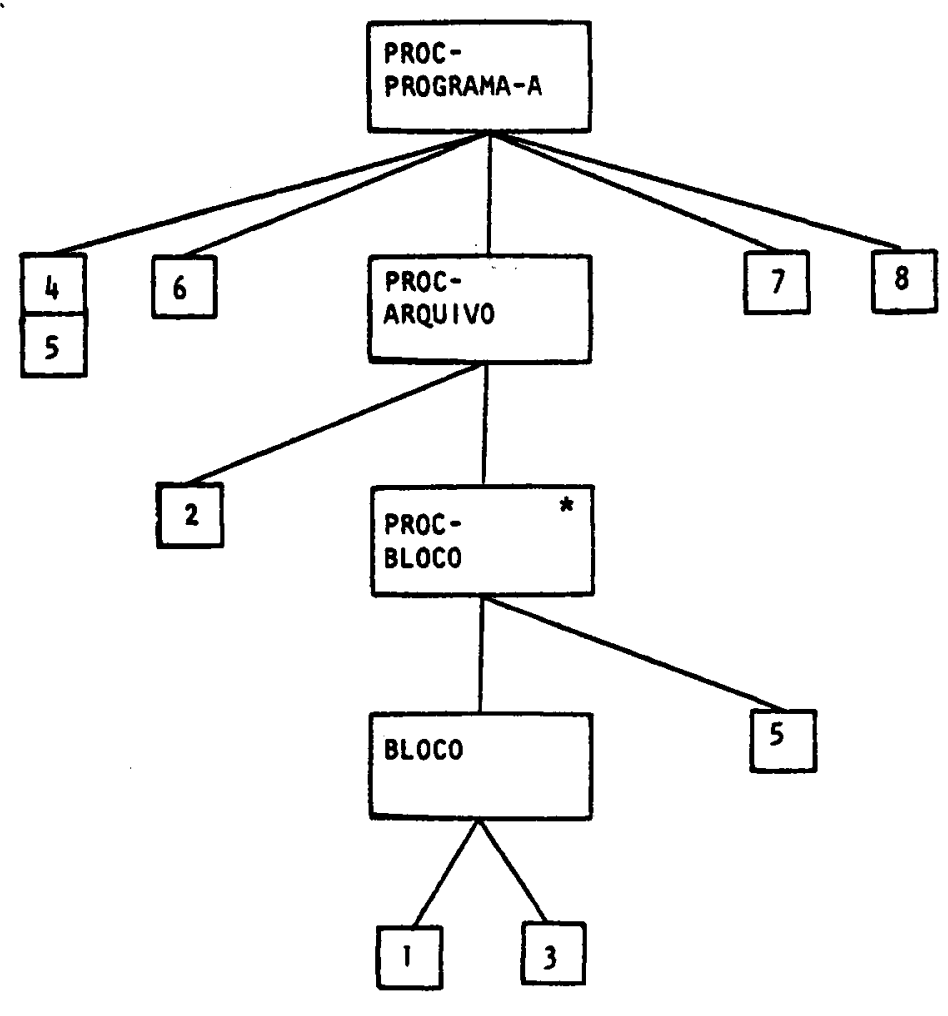

1. grave em $X$ imagem-cartão

2. contador-registro $=1$

3. contador-registro = contador-registro +1

4. abra arquivo b zocado

5. Zeia arquivo blocado

6. abra arquivo $x$

7. feche arquivo $x$

8. feche arquivo blocado

Diagrama de Estrutura com as operaçōes executäveis do programa exemplo 3.2 - DBLOC

Figura 3.17

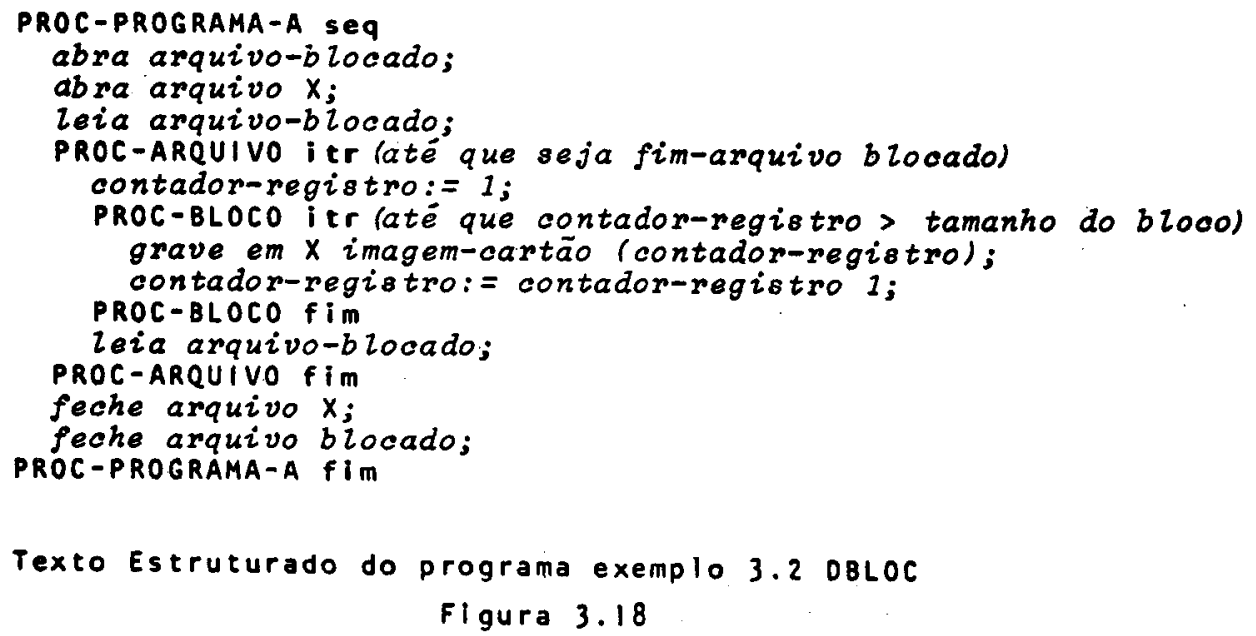

Figura 3.18 
IDENTIFICATION DIUISION.

PROGRGM-IO. DELOC.

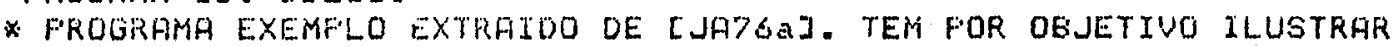

* o coive ito de choque egtrutural do metodo jsf. sua funcao e, a

* Fartir de um arquivo elocado. froduzjr lim arquivo com a mesma

* estrutura que a do arguivo de eintrada do frograma elrel.

AUTHOK. ROSANGELA PENTEADO.

ENUTRGNMENT DIUISION.

INFUT-OUTPUT SECTION.

FILE-CONTROL. .

SELECT FRQ-CARTOES-ELOCADO ASSICN TO DTSK

ACCESS MODE IS SEQUENTIAL ORGANIZATION IS LINE SEQUENTIAL.

SELECT FRQ-CARTOES-SAIDA ASSIGN TO DISK

ACCESS MOOE IS SEQUENTIAL

ORGANIZATION IS LINE SEQUENTIAL.

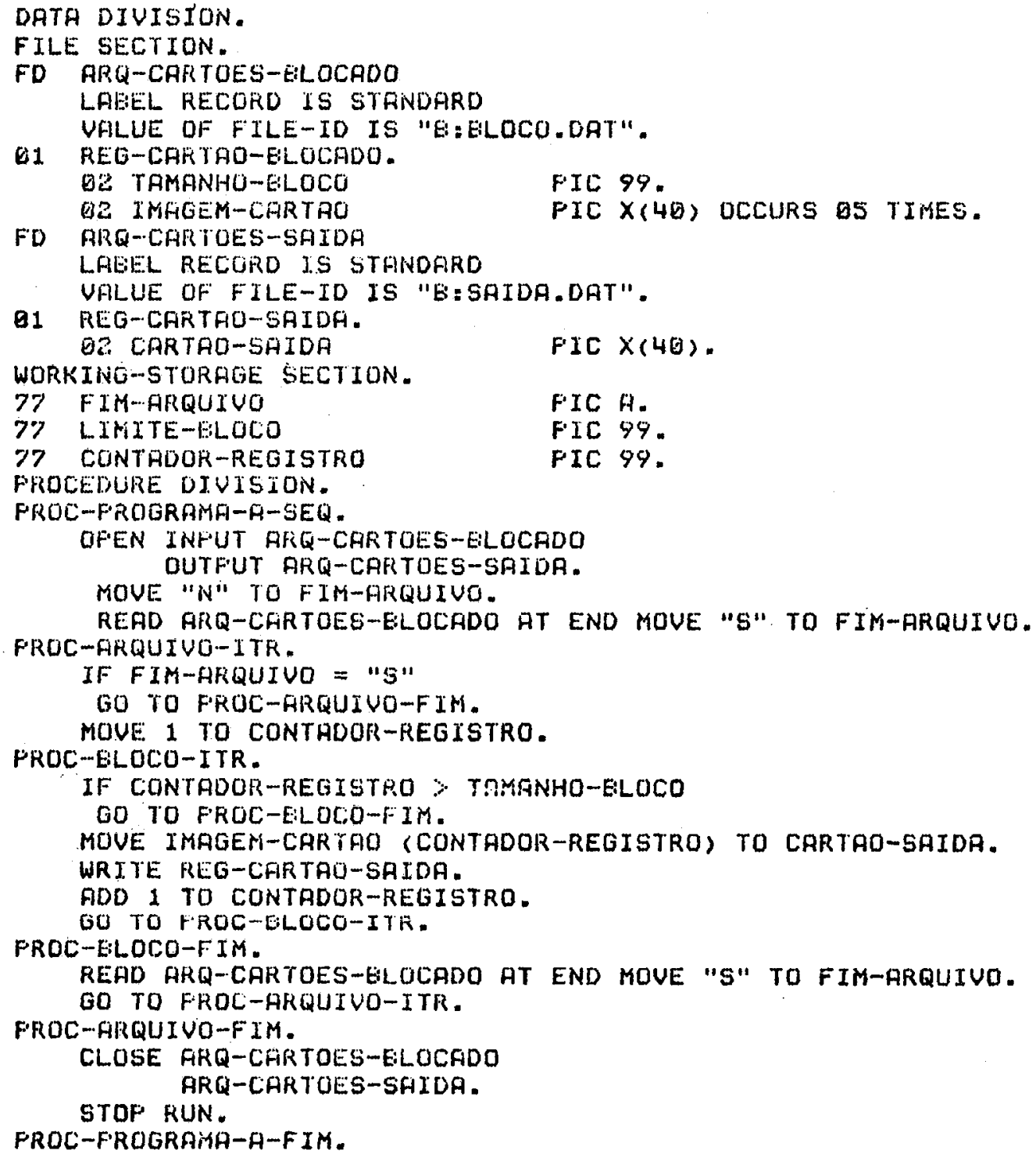



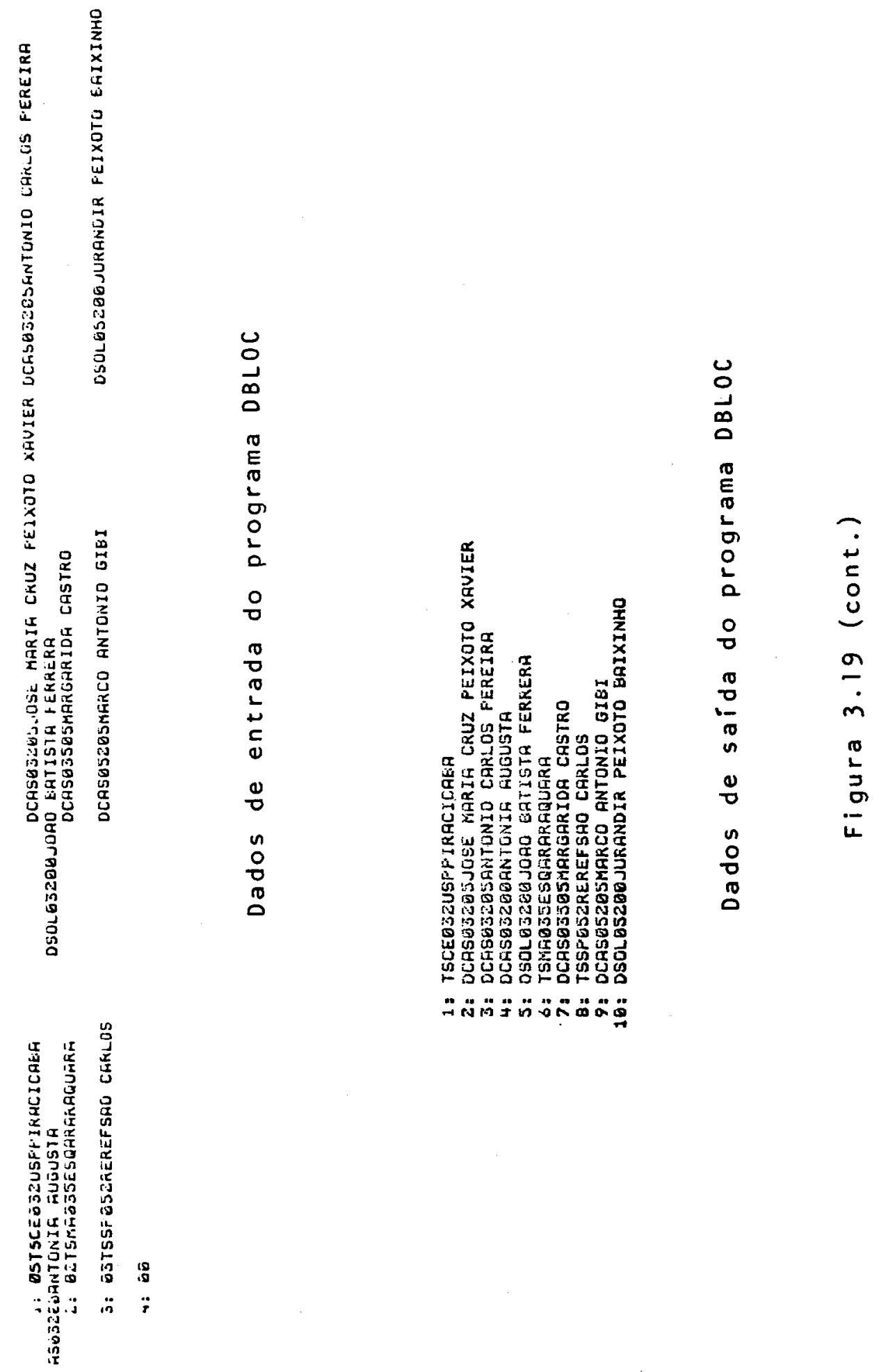
podem ser produzidos em qualquer ordem.

A estrutura do arquivo de cartões, figura 3.20 , não é compativel com a estrutura do relatörio, como se pode ver com parando as figuras 3.06 (b) e 3.20. Tem-se um choque de estrutura do tipo "choque de articulação" que é mencionado na figura 3.14. o arquivo de cartões consiste de uma certa quantidade de arquivos de grupo, cada um com a forma mostrada na figura 3.21 . o arquivo de cartóes é uma articulação arbitrária desses arquivos de grupo. Pode-se resolver esse tipo de choque estrutural, desdobrando o arquivo de cartões de acordo com os arquivos de grupo que o constituem, como mostra a figura 3.22 .

0 programa complexo pode ser decomposto em $n+1$ programas simples; desses, n são programas idênticos que processam os n grupos distintos e um é o programa que desdobra o arquivo de cartões de acordo com os arquivos de grupo que o constituem. A comunicação entre esses programas poderia ser feita através de fitas magnéticas, apesar de na prätica esse não ser o método mais usual.

Outro tipo de choque que pode ocorrer é 0 "choque de ordenação", quando as ordens dos dados das estruturas não são compatíveis. A solução, nesse caso, é proceder de modo análogo ao usado para resolver os outros tipos de choque. 


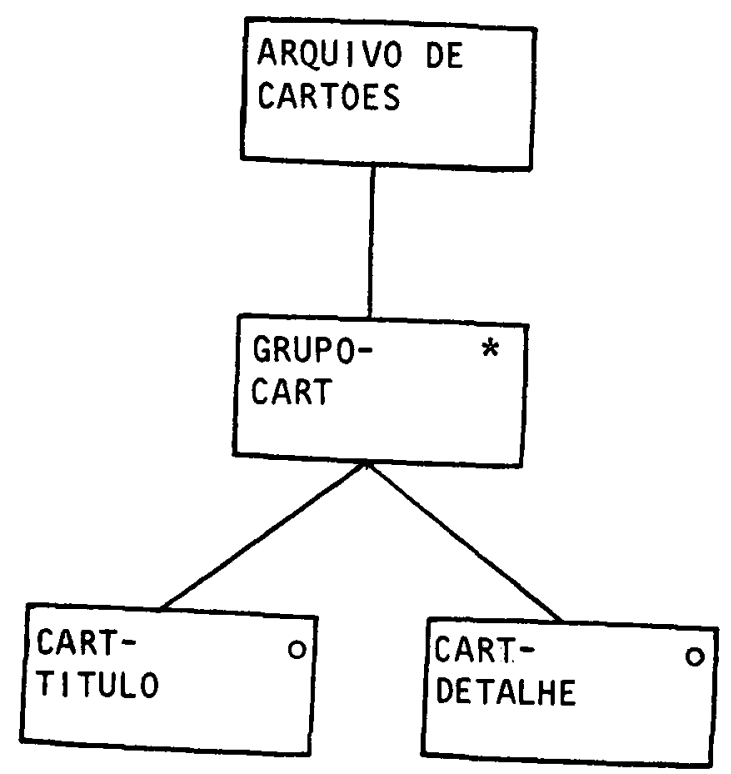

Diagrama de Estrutura dos dados de entrada do exemplo 3.3

Figura 3.20

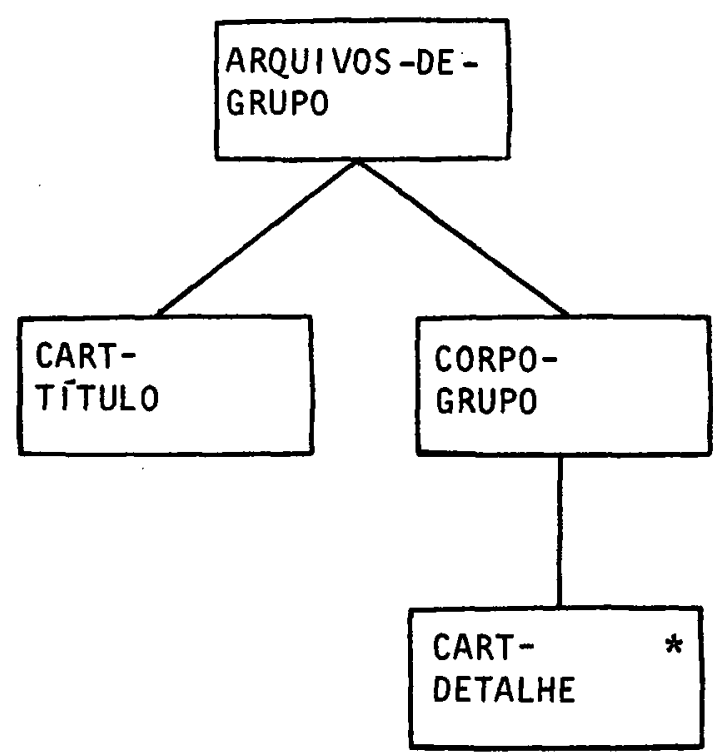

Diagrama de Estrutura dos arquivos de grupo do exemplo 3.3

Figura 3.21 


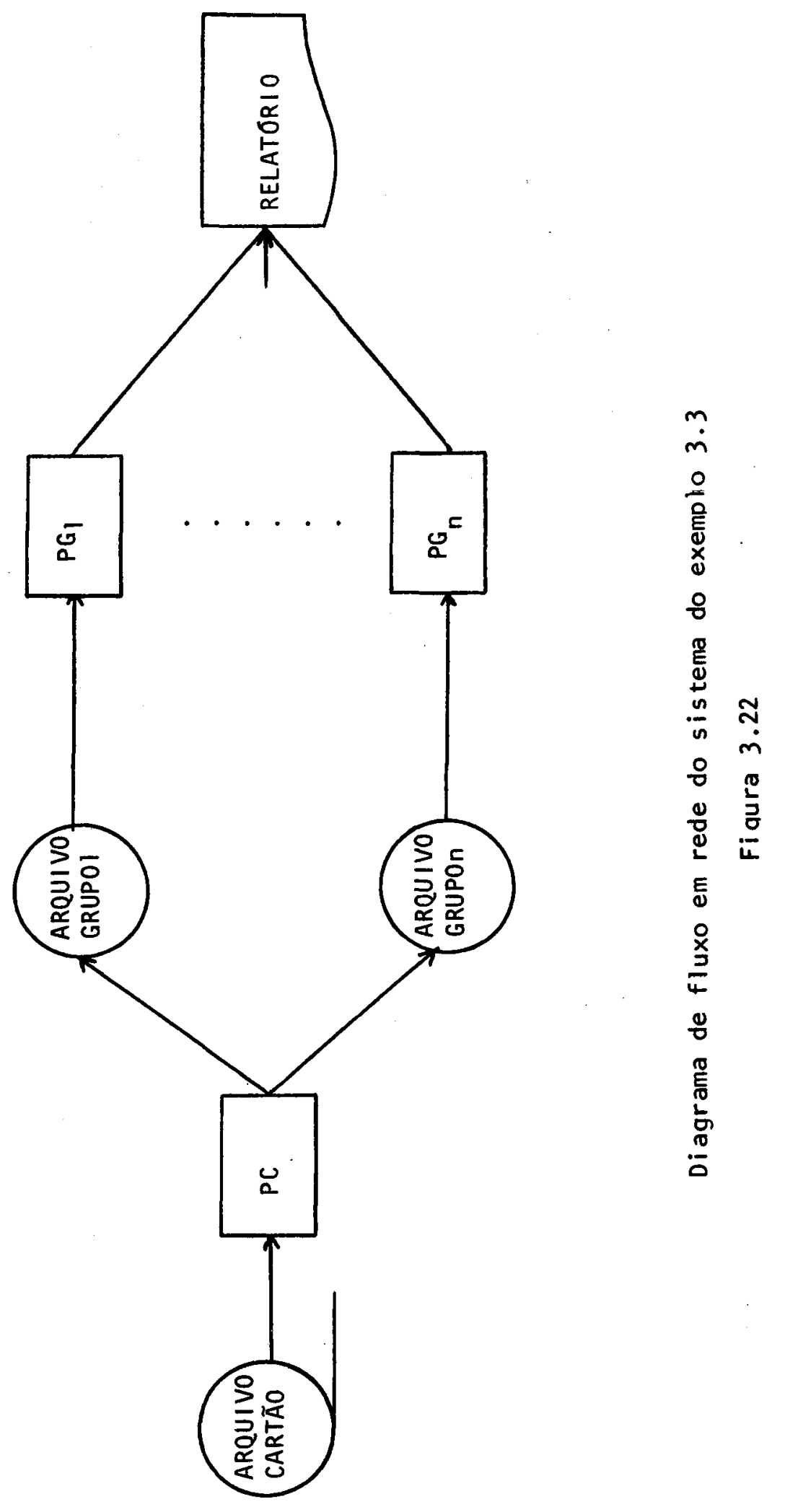


3.6. - Passo Relativo às operações

No passo relativo às operações, figura 3.23 , devese arrolar e alocar as operaçóes envolvidas no problema.

0 rol das operações correspondentes ao exemplo 3.1 é apresentado na figura 3.08 e nessa mesma figura é mostrado o alojamento dessas operações na estrutura do programa. Isso é feito para o exemplo 3.2 na figura 3.17 .

Entre as soluções para a alocação está a técnica de leitura avançada, em que cada componente do programa que proces sa um registro toma a forma: "processe esse registro e leia outro". Essa técnica foi utilizada em todos os programas-exemplo. Esse tipo de leitura ocorre lendo-se o primeiro registro logo em seguida à abertura do arquivo e realizando-se nova leitura no fim de cada componente de programa que processa um registro de entrada. 


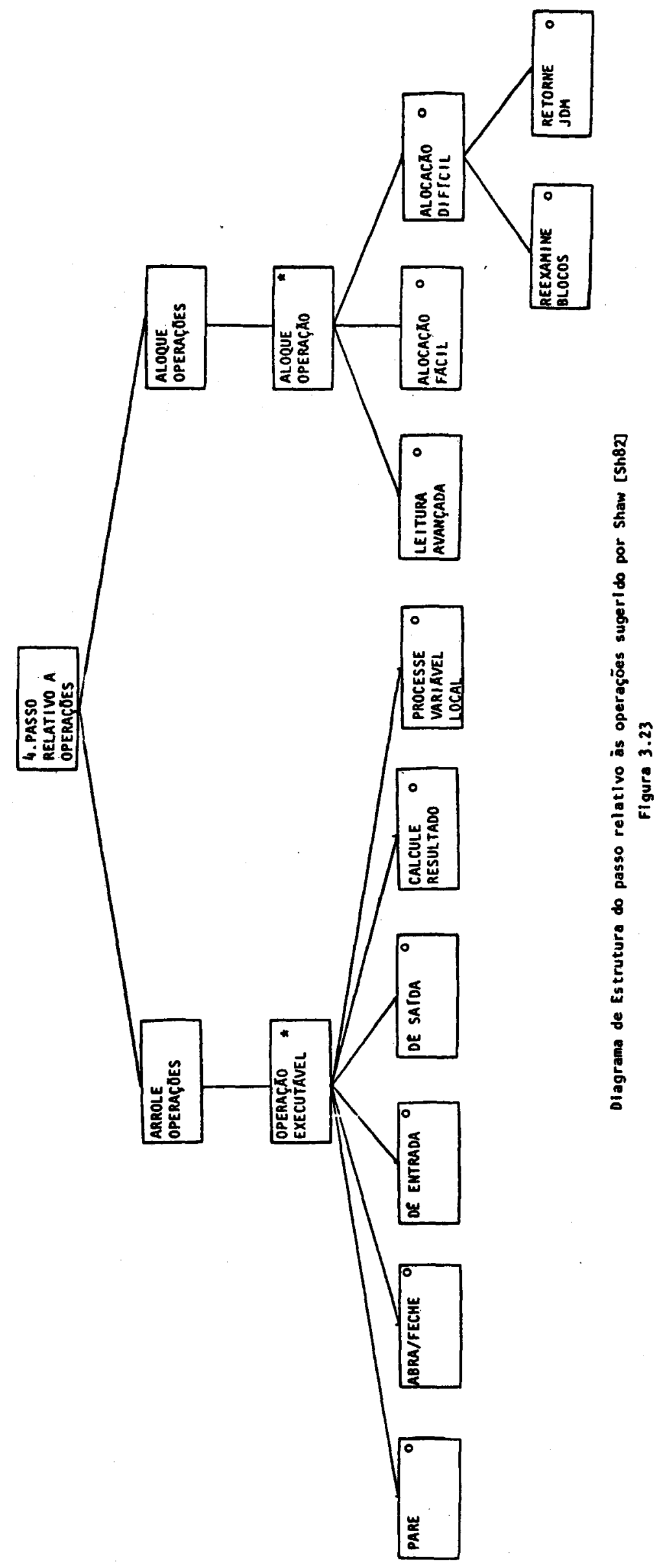


No passo relativo à lögica, figura 3.24 , deve-se fá zer um esquema da lögica do problema, verificar as condiçōes e inclui-las. Após essas fases iniciais, resolvem-se as dificuldades que ocorrem quando uma decisão deve ser tomada. Uma das tëcnicas que auxiliam nesse ponto é a da retro-indiciação indicada na figura 3.24 .

Exemplo 3.4 - Considere-se que o arquivo de cartões do exemplo 3.1 possa ter erros tais como: um grupo de cartões não ter cartão-título, ou ter outros cartões que não sejam cartões-detalhe. os grupos que contêm erros devem ser listados com a indicação a dequada quando da produção do relatörio.

A estrutura do RELATORIO permanece inalterada, como é mostrado na figura $3.06(b)$. As estruturas da LISTA-DE-ERROS e do ARQUIVO-DE-CARTOES. são mostradas na figura 3.25 .

A técnica de retro-indiciação, mencionada na fiğura 3.24 , pode ser usada nesse caso. As componentes dessa estrutura são: suposição $(\xi)$, abandono $(\$)$ e admissão (\$). Nessa técnica supōe-se, por exemplo, que um grupo é bom até que um erro seja encontrado. Nesse ponto, passa-se à fase de abandono de tal suposição e admite-se o erro, tratando-o de modo adequado.

A figura 3.26 mostra o diagrama de estrutura com as operaçōes executáveis do exemplo 3.4 e a figura 3.27 , o respectivo texto estruturado, ficando, assim, mais claros esses conceitos.

0. programa ELRELE, figura 3.28 , è a implementação desse exemplo. Como foi feito anteriormente, os parágrafos da PROCEDURE DIVISION são compatíveis com os apresentados no texto. Pode-se observar que as componentes de abandono são realizadas pelo comando IF.

Um outro ponto que é cuidado pelo passo relativo à lógica é quanto à inversão de programas. Isso é necessário quan do ocorrem choques de estrutura.

Exempzo 3.5 - Consideresse, novamente, o exemplo 3.2 do arquivo 


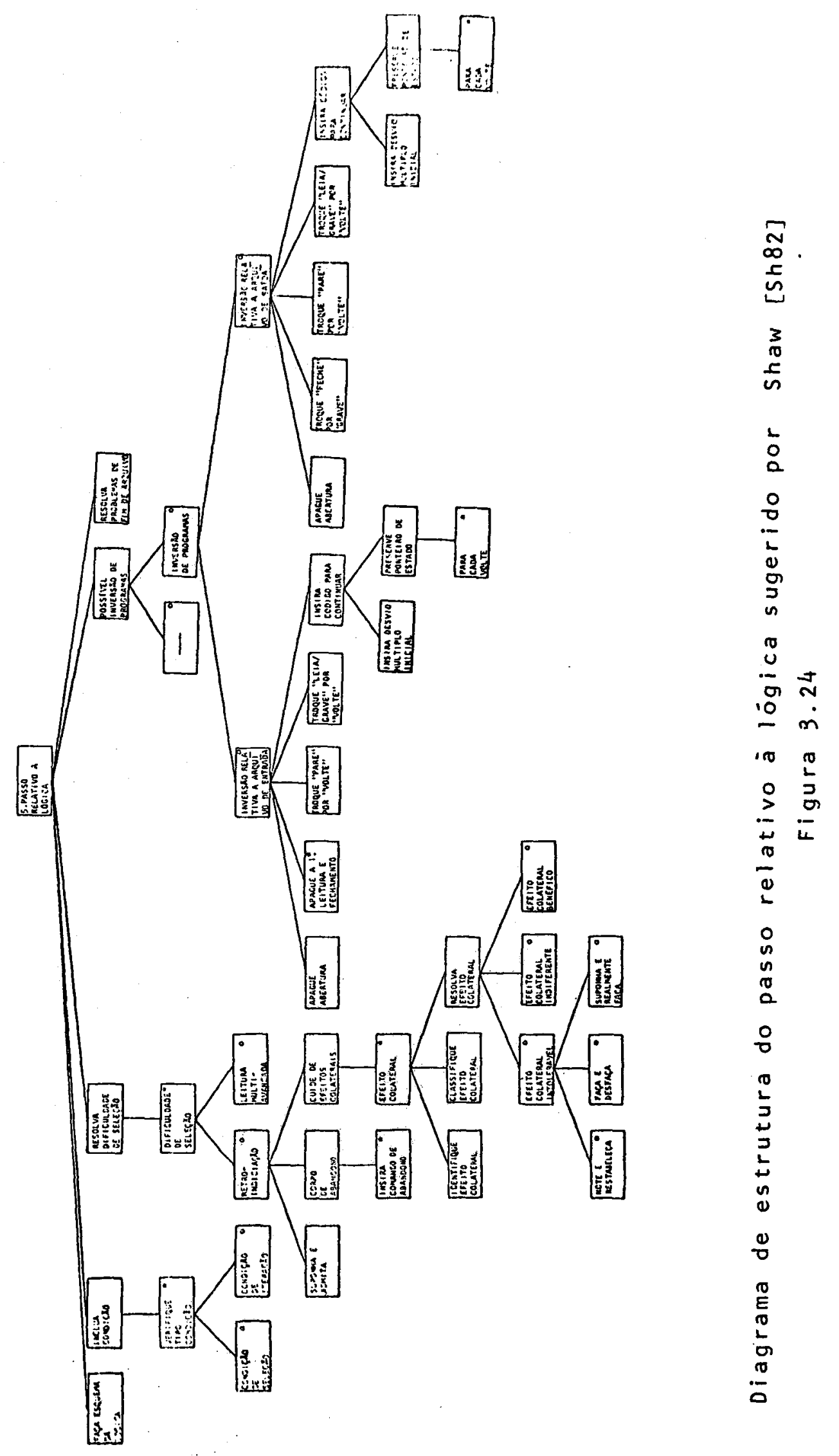


LISTA-DE-

ERROS

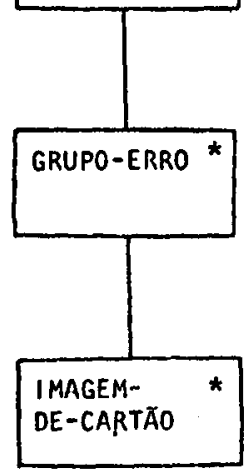

(a)

Diagrama de Estrutura da lista da erros do exemplo 3.4

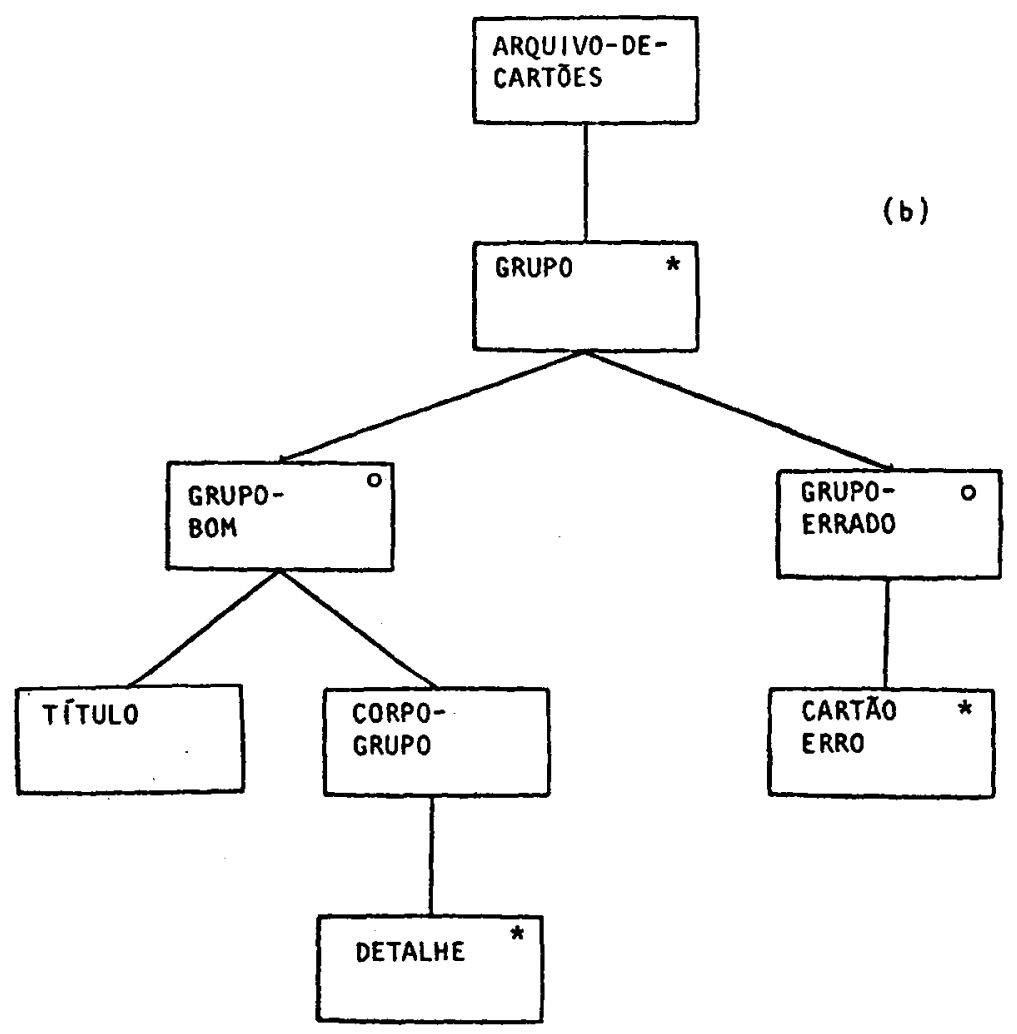

Diagrama de estrutura do arquivo de cartóes do exemplo 3.4

Figura 3.25 


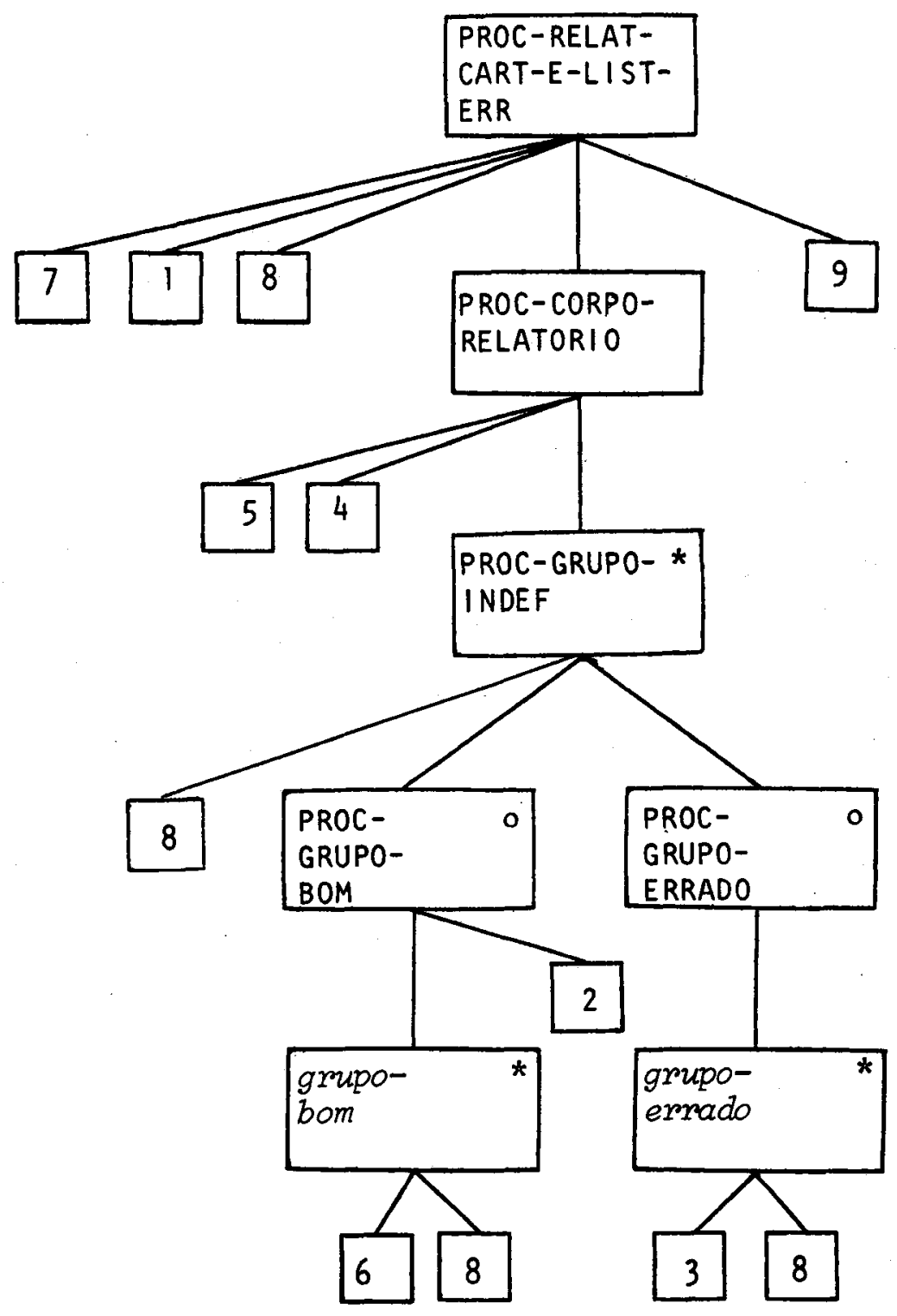

1. imprima cabegalho

2. imprima linha-de-total (chave-grupo, total)

3. imprima linha-erro (cartão)

4. total $=\varnothing$

5. chave-grupo = chave-cartão

6. total = total + quantidade-detalhe

7. abra arquivo-de-cartões

8. Leia arquivo-de-cartões

9. feche arquivo-de-cartóes

Diagrama de Estrutura com as operações executáveis do programa exemplo 3.4 - ELRELE

Figura 3.26 


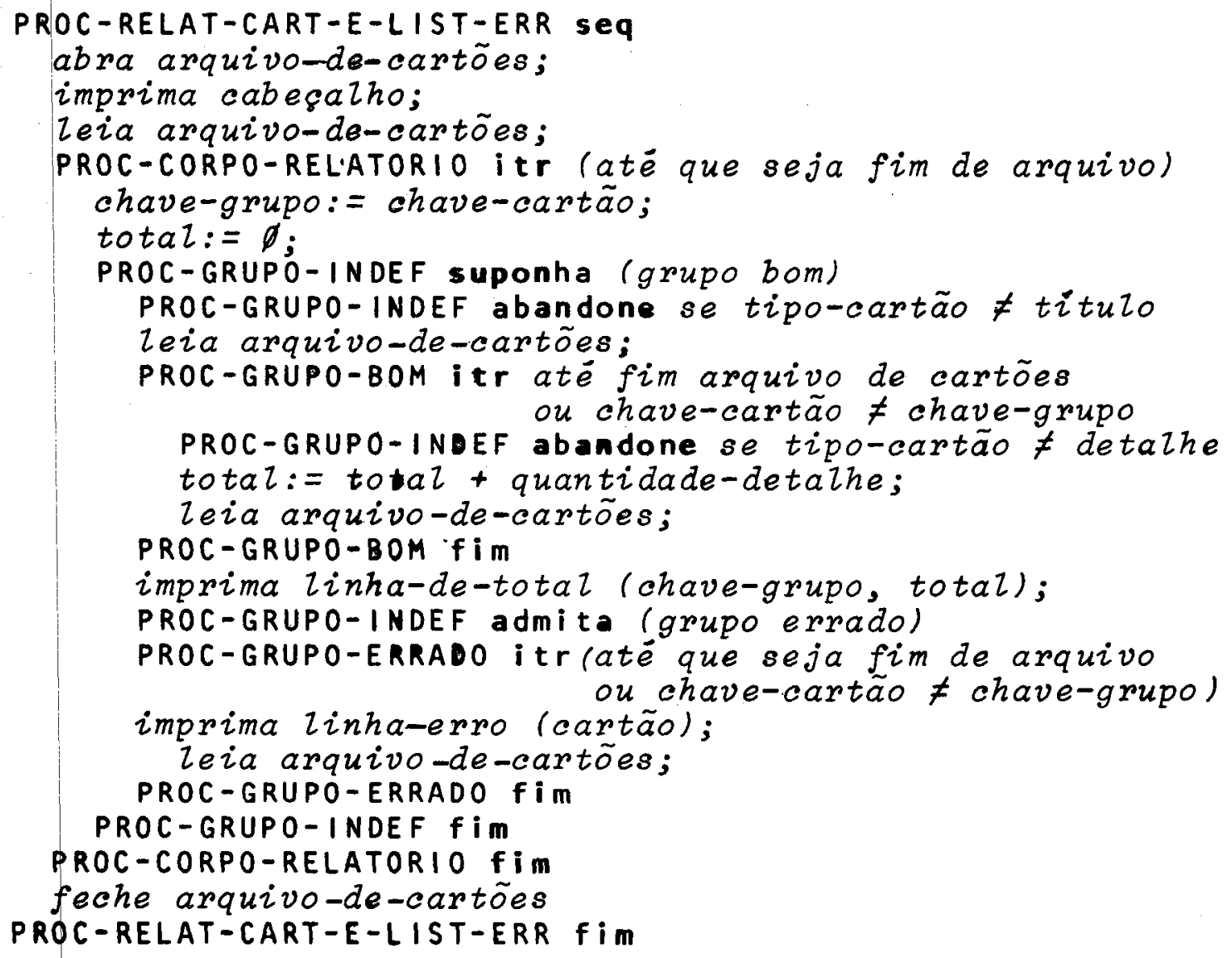

Texto Estruturado do programa exemplo 3.3 - ELRELE Figura 3.27 
IDENTIFICATION DIUISION.

FROGRAM-ID. ELLRELE.

* exemflo extraido de c jazgaj.tem for oejetivo ilustrar o con-

* ceito de retro-inolciacho do metodo JSF. tRata-se de UMa va-

* riante do frograma elrel. sua funcao e produzir lum relatorio

* de resurio e lista de ergos sofire um arquivo de entrada.

AUTHOR. ROSANGELA FENTEAOO.

ENUIRONMENT OIUISION.

INFUT-OUTFUT SECTION.

FILE-CONTROL.

SELECT ARQ-CARTOES ASSTGIY TO DISK

ACCESS MODE IS. SEQUENTIAL

DRGGINIZATION IS LINE SEQUENTIAL.

SELECT ARQ-SAIDA ASSIGN TO OISK.

DATA DIVISION.

FILE SECTJON.

FD ARQ-CARTOES

LAEEL RECGNDSS ARE STANDARO

URLUE OF FILE-ID IS "EIERRO.DAT"

DATA RECORD ARE REG-CARTAO TIT

Q1 REG-CARTAO-TIT.

REG-CHETAO-DET.

U2 TIFO-CARTHO

QZ SIGLA-DEFARTAMENTO

D2 NRD-DEFARTAMENTO

PIC A.

OZ ENTIDADE-EDUCACIONAL

02 CIUADE

GZ FILLER

01 REG-CARTAO-DET.

Q2 TIFOO-CARTAO

G2 ESTADO-CIUIL

OZ NRO-DEFARTAMENTO

O2 NRO-FILHOS

Q2 NDME-FUNCIONARIO

Q2 FILLER

PIC $A(3)$.

FIC 999.

PIC $A(3)$

PIC $A(1 \theta)$.

FIC $X(60)$.

FD ARQ-5ATDA

LAEEL RECORD IS STANDARD

UALUE OF FILE-ID IS "EIERRO.SRI"

DATA RECORD IS LINHA-IMFRESSAO.

01 LINHA-IMFRESSAD

WORKING-STURRGE SECTION.

77 FIM-ARQUIVO

01 CAEECALHO.

02. FILLER

02 FILLER

Q2 FILLER

O2 FILLER

O2 FILLER

01 LINHA-DE-TOTAL.

Q2 FILLER

O2 NRD-DEFRRTAMENTO

Q2 FILLER

OZ SIGLA-DEFARTAMENTO

O2 FILLER

Q2 TOTAL-DE-DEPENDENTES

PIC $A$.

PIC $A(3)$.

PIC 994.

FIC 99.

PIC $A(30)$.

FIC $X(51)$.

Q2 FILLER

01 LINHA-DE-ERRO.

02 FILLER

Q2 NRO-DEFARTAMENTO

Q2 FILLER

O2 SIGLA-DEFRRTAMENTO

Q2 FILLER

02 FILLER

Q2 TIPO-CARTRO-ERRO

Q2 FILLER

Q2 FILLER

FIC $X(132)$.

FIC $A$.

PIC $X(Z Q)$ UALUE SFACES.

PIC $X(11)$ VALUE "NFO DEPTO $"$

FIC $X(14)$ VALUE SFRCES.

FIC $X(27)$ VALUE

PIC $X(26)$ SIGLA

"Linha de total / mensagem".

PIC $X(23)$ VALUE SFACES.

FIC 999 .

PIC $x(17)$ VALUE SPACES.

PIC $A(3)$.

PIC $X(24)$ VALUE SPACES.

FIC 999.

PIC $X(G 2)$ VALUE SFACES.

PIC $X(23)$ VALUE SPACES.

FIC 999.

FIC $X(17)$ VALUE SPRCES.

Fic $A(3)$.

FIC $X(17)$ UALLUE SFACES.

FIC $X(21)$ VRLUE

PIC $R$.

VERIFIQUE O TIFO ".

PIC $X(11)$ VALUE " DO CARTAO"

PIC $X(33)$ VALUE SPACES.

Implementação do exemplo 3.3 - programa ELRELE

Figura 3.28 
FROCEDURE OIUISION.

FROC-RELAT-CART-E-LIST-ERR-ITR.

OFEN INFUT ARQ-CARTOES

OUTFUT ARQ-SAIDA.

MOVE "N" TO FIM-ARQUIVO.

MOUE SFACES TO LINHA-IMFRESSAO.

WRITE LINHA-IMFRESSAO FROM CAEECALHO AFTER AOUANCINB 2 LINES.

REAO ARQ-CARTOES AT END MOVE "S" TO FIM-ARQUIVO.

PROC-CORPO-RELATORIO-ITR.

IF FIM-AKQUIVO =- "S"

GO TO FROC-CORFO-RELATORID-FIM.

MOVE NRD-DEFARTAMENTO IN REG-CARTAO-TIT TO

NRO-DEPARTAMENTO IN LINHA-DE-TOTAL.

MOUE SIGLA-DEFARTAMENTO IN REG-CARTAO-TIT TO

SIGLA-DEFARTAMENTO IN LINHA-DE-TOTAL.

MQUE ZERO TO TOTAL-DE-DEFENDENTES.

FROC-GRUFO-INDEF-SUFONHA-CERTO.

IF TIFO-CARTAO IN KEG-CARTAO-TIT NOT = "T"

GO TO FROC-GRUPO-INDEF-ADMITA-ERRO.

READ ARQ-CARTOES AT END MOUE "S" TO FIM-ARQUIUD.

PROC-GRUFO-EOM-ITR .

IF NRO-DEFARTAMENTO IN REG-CARTAO-DET NOT -

NRO-DEPAR TAMENTD IN LINHA-DE-TOTAL

DR FIM-ARQUIVO = "S"

CO TO FROC-GRUFO-EOM-FIM.

IF TIFO-CARTAO IN REG-CARTAO-DET NOT $\Rightarrow " D "$

GO TO PROC-GRUFO-INDEF-ADMITA-ERRO.

ADD NRO-FILHOS. TO TOTAL-DE-DEFENDENTES.

REAO ARQ-CARTOES AT END MOUE "S" TO FIM-ARQUIVO. GO TO FROC-GRUFO-EOM-ITR.

PROC-QRUFO-EOM-FIM.

MOVE SFACES TO LINHA-IMPRESSAO.

WRITE LINHA-IMPRESSAO FROM LINHA-DE-TOTAL AFTER

ADUANCING 2 LINES.

GO TO FROC-GRUFO-INDEF-FIM.

FROC-GRUFO-INDEF-RDMITA-ERRO.

PRDC-GRUFO-ERRADO-ITR.

IF NRO-DEFARTAMENTO IN REG-CARTAO-DET NOT =

NRO-DEFARTAMENTO IN LINHA-DE-TOTAL

OR FIM-ARQUIVO = "S"

GO TO FROC-GRUFO-ERRADO-FIM.

MOVE NRO-DEFARTAMENTO IN REG-CANTAO-TIT TO

NRO-DEFARTAMENTO IN LINHR-DE-ERRO.

MOVE SIGLA-DEFARTAMENTD IN LINHA-DE-TOTAL TO

SIGLA-DEFARTAMENTO IN LINHA-DE-ERRO.

MOUE TIPO-CARTAO IN REG-CARTAO-DET TO

TIPO-CARTAO-ERRO.

WRITE LINHA-IMFRESSAO FROM LINHA-DE-ERRO

AFTER ADUANCING 2 LINES.

READ ARQ-CARTOES AT END MOVE "S" TO FIM-ARQUIVO.

GO TO FROC-GRUFO-ERRADO-ITR.

FROC-GRUFO-ERRADO-FIM.

PROC-GRUFO-INDEF-FIM.

GO TO FROC-CORFO-FELATORIO-ITR.

PROC-CORFO-RELATORIO-FIM.

CLOSE ARQ-CARTOES

ARQ-SAIDA.

STOF RUN.

FROC-RELAT-CART-E-LIST-ERR-FIM.

Figura 3.28 (cont.) 


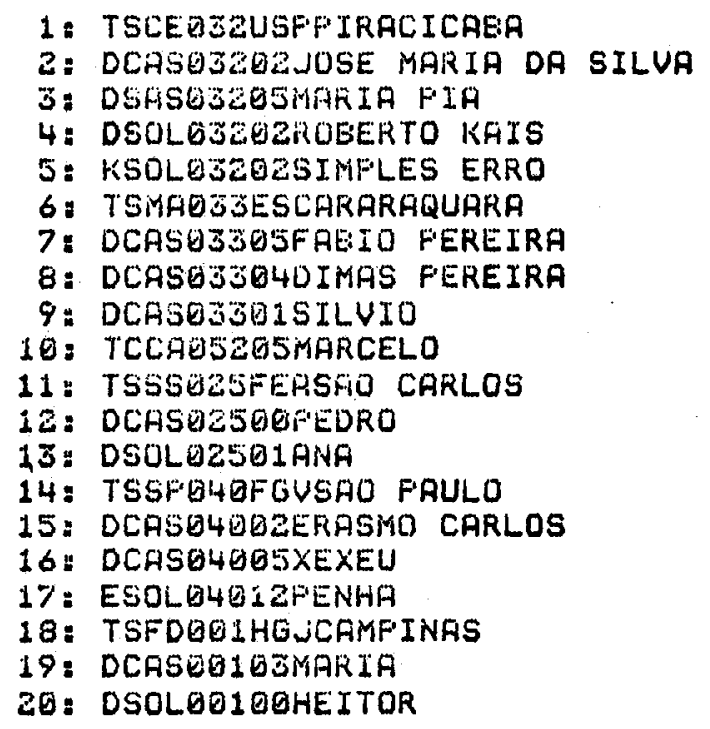

Dados de entrada do programa ELRELE

$\begin{array}{cc}\text { NRO DEFTO } & \text { SIILA DEFTO } \\ 032 & \text { SCE } \\ 033 & \text { SMA } \\ 052 & \text { CCA } \\ 025 & \text { SSS } \\ 040 & \text { SSF } \\ 001 & \text { SFD }\end{array}$

Dados de saida do programa ELRELE

$$
\text { Figura } 3.28(\text { cont.) }
$$


blocado apresentado na figura 3.15. O programa PA mostrado na figura 3.16 grava um arquivo intermediärio $X$. Pode-se transformá-10 em um procedimento PAX com as mesmas características de um procedimento de entrada para o arquivo intermediário $X$, implementa-se as operações "abra arquivo $X$, para leitura", "leia arquivo $X " e$ "feche arquivo $X$ depois da leitura" nas chamadas do procedimento PAX. Essa mudança de PA para PAX é tratada como inversão de $P A$ em relação ao arquivo $X$. 0 mecanismo de inversão não requer modificações no texto de PA, logo PA e PAX têm a mes ma estrutura de programa.

A inversão poderia ser de $P B$ com relação ao arquivo $X$, ao invés de ser de PA, obtendo-se um procedimento de saida do arquivo $X$.

PAX é um procedimento de estado variável. 0 valor de seu estado é dado pelo vetor de estado (\$) que tem como parte $o$ ponteiro de texto $(\$)$. Os valores do vetor de estado signi ficativos são aqueles associados com a parada de PA para as operações de abertura, gravação e fechamento do arquivo $X$. Em PAX a operação de gravação corresponde à transferência de IMAGEM-DE-CARTAOO para CARTÃO-SATDA.

Os parâmetros de ligação entre PB e PAX são um registro do arquivo $x$ e um registro adicional que indica se $e^{-}$ou não o fim de arquivo.

As figuras 3.29 e 3.30 , mostram os programas. PAX (DBLOCR) e PB(ELRELS) referentes a esse exemplo. Pode-se notar que os parâmetros da subrotina $D B L O C R$ são exatamente o registro (CARTAO-SATDA) e o indicador de fim de arquivo (FIM-ARQUIVO).

Como já foi dito, o programa PAX realiza as mesmas funções que PA, porém nem todos os nomes dos parägrafos da PROCEDURE DIVISION são exatamente os mesmos, pelo fato de se iniciar a execução, ora num determinado ponto (PONTO-ENTRADA-IN! CIAL) ora noutro (PONTO-ENTRADA-SUBSEQUENTE). Portanto, esses nomes de parägrafos não aparecem em $P A$.

PB tem a mesma estrutura que a mostrada na figura 3.08, contudo ao invés de fazer a leitura do arquivo de cartões, 
IDENTIFICATION DIUISION.

BROLFAM-ID. OELOCR.

* programa exemilo extraido de [ja76aj.tem for oejetivo ilustrar

* O conceito de INUERSAO dO METODO JSF. TRATA-SE DE UMA VARIARTE

* do frograma deEloc, soe a forma de subFrograma. sua fluncho e.

* a pairtir le ui arquivo ellocado, a cada chamada produzik lum re-

* gistro com a mesija estrutura que a dos regtstros do firguivo de

* entrada do frograma elrel.

AUTHOR. ROSANGELA FENTEADO.

ENUIRONMENT DIUISION.

INFUI"-OUTFUT SECTJON.

FILE-CONTROL.

SELECT ARQ-CARTOES-ELOCADO ASSIGN TO DISK

ACCESS MODE IS SEQUENTIAL

ORGANIZATION IS LINE SEQUENTIAL.

DATA DIUISION.

FILE BECTION.

FD ARQ-CARTUES-ELLCADO

LAEEL RECORD IS STANDARD

VALUE OF" FILE-IO IS "E: ELOCO.DAT".

Q1 RECI-CFRTAO-ELOCADO.

G2 TAMANHO-ELOCO

Bi2 I HAGEHI-CARTAO

PIC 99.

PIC $X(49)$. OCCURS 05 TIMES.

WORKING-STORAGE SECTION.

$7 \%$ FIM-GRQUIVO-ELC

77 LIMITE-ELOCO

77 CDHTADOR-REGISTRO

77 FONTEIRO

L. INKAGGE SECTION.

O1 FIYY-ARQUJVO

Q1 CARTAD-SAJDA.

D2 TIFO-CARTAO

PIC $A$.

PIC 99.

PIC 99

PIC 9 VAlue 1.

UZ RESTO-CARTAO

PIC $A$.

PIC $A$.

PIC $X(39)$.

PRDCEDURE DIUISION USING FIM-ARQUIVO CARTAO-SAIDA.

FROC-FROGRAMR-A-SEQ.

GO TO FONTO-ENTRADA-INICIAL

FONTO-ENTAADA-SUESEQQUENTE

PONTD-ENTRADA-INICIAL. DEFENDING ON FONTEIRO.

OFEN INPUT ARQ-CARTOES-ELOCRDO.

MOVE "N" TO FIM-ARQUIVO.

MOVE "N" TO FIM-ARQUIUO-EILC.

READ ARQ-CARTOES-ELOCADO AT END MOVE "S" TO FIM-ARQUIVO-ELC.

PROC-ARQUIUO-ITR. -

IF FIM-ARQUIVO-EILC = "S"

MOVE "S" TO FIM-ARQUIVO

GO TD FRDC-ARQUIVO-FIM.

MOVE $I$ TO CONTADOR -REGISTRO.

PONTQ-ENTRADR-SUESEQUENTE.

PROC-ELLOCO-ITR.

IF CONTADOR-REGISTRO > TAMANHO-ELOCO

GO TO FROC-ELLOCD-FIM.

MUVE IMAGEM-CARTAO (CONTADOR-REGISTRO) TO CARTAO-SAIDA.

AOD 1 TO CONTAOOR-REGISTRO.

MOVE 2 TO PONTEIRO.

EXIT PROGRAM.

PROC-ELLOCO-FIM.

READ ARQ-CARTOES-ELOCADO AT END MOUE " $S$ " TO FIM-ARQUIVO-BLC. GO TO FROC-ARQUIUO-ITR.

PROC-ARQUIUO-FIM.

CLOSE ARQ-CARTOES-ELOCRDO.

EXIT PROGRAM.

FROC-FROGRRMAT-A-FIM.

Implementação do exemplo 3.4 - DBLOC

Figura 3.29 
faz a chamada do subprograma PAX que realiza essa função.

IDENTIFICATION OIUISION.

FROGKAM-ID. ELRELS.

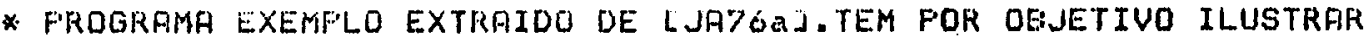

* O CONCEITO DE INUERSAO DO METODO JSF. TRATA-SE DE UMA UARIANTE

* do frograma elfrel. SUa funcho e a mesma que a daquele froggrama.

* So que. ao inves de ler os registros do arquivo de entrada cha-

* ma o suefrograma delocr fara oete-los de um arquivo eldocado.

AUTHOR. ROSANGELA FENTEADO.

ENUTRONMENT DIUISION.

INPUT-OLITFUT , SECTION.

FILE-CONTROL.

SELECT ARQ-SAIDA ASSIGN TO DISK.

DATA DIUISION.

FILE SECTION.

FD ARQ-GAIDA

LGEEL RECORD IS STAINDARD

VALUE OF FILE-ID IS "E:SAIDA.OUT"

DATA RECORD IS LINHA-IATPRESSRO.

(a) LINHA-IMFRESSAO

WOFKING-STORHGE SECTION.

$7 \%$ FIM-PRQUIVO

PIC $\times(132)$.

QI CAEECALHO.

O2 FILLER

G2 FILLER

Q2 FILLER

02 FILLER

Q1 LINHA-DE-TOTAL.

Q2 FILLER

Q2 NRO-DEFARTAMENTO

Q2 FILLER

Q2 SIGLA-DEFARTAMENTO

02 FILLER

Q2 TOTAL-DE-DEPENDENTES

01 REG-CARTAO-TIT.

D2 TIFO-CARTAO

Q2 SIGLA-DEFARTAMENTO

Q2 NRO-DEFARTAMENTO

Q2 ENTIDADE-EDUCACIONFIL

Q2 CIDRDE

D1 REG-CARTAO-DET.

Q2 TIFO-CARTAO

Q2 ESTADO-CIUTL

Q2 NRO-DEFARTAMENTO

02 NRO-FILHDS

Q2 NOME-FUNCIONARIO

01 CARTHO-SAIOA.

02 TIFO-CARTAO-SAIOA

U2 RESTO-CARTAO

FIC $A$.

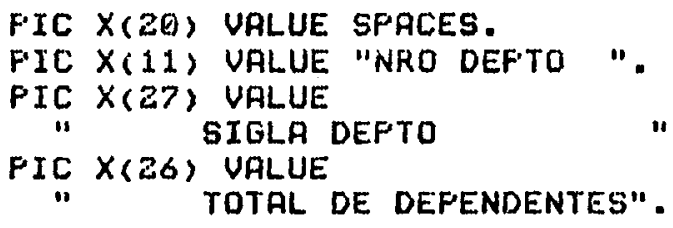

FIC $X(23)$ VALUE SFRCES.

PIC 999.

FIC $X(15)$ VRLUE SF'RCES.

FIC $A(3)$.

FIC $X(27)$ VALUE SPACES.

PIC 99.

PIC A.

PIC $A(3)$.

PIC 999 .

PIC $A(3)$.

PIC $A(10)$.

FIC 9 .

PIC $A(3)$.

FIC 999 .

FIC 99.

PIC $A(30)$.

FIC $\mathrm{R}$.

PIC $X(39)$.

Implementação do exemplo 3.5 - programa ELRELS

Figura 3.30 
PROCEDURE OIUISION.

PROC-RELATORTO-CARTOES-SEQ.

OFEN OUTFUT ARQ-SAIOA.

MOVE "N" TO FIM-ARQUIVO.

MOUE SFACES TO LINHA-IMPRESSAO.

WRITE LINHA-IMFRESSAO FROM CAEECALHO AFTER ADVANCING 2 LINES.

CALL "DELLCR" USING FIM-ARQUIVO CARTAO-SAIDR.

IF FIM-ARQUIVO $=$ " $\mathrm{S} "$

GO TO FROC-CORFO-RELATORIO-FIM.

IF TIFO-CARTAO-SAIDA $=$ "D"

MOVE CARTAO-SAIDA TO REG-CARTAO-DET

ELSE

MOVE CARTAO-SRIDA TO REG-CARTAO-TIT.

FROC-CORFO-RELATORIO-ITR.

IF FIM-ARQUTVO = "S"

GO TO FROC-CORFO-RELATORIO-FIM.

MOVE ZEFLS TO TOTAL-DE-DEPENDENTES.

MOVE SIGLA-DEFARTAMENTO IN REG-CARTAO-TIT TO

SIGLA-DEPARTAMENTO IN LINHA-DE-TOTAL.

MOUE NRO-DEFARTAMENTO IN REG-CARTAO-TIT TO

NRO-DEFARTAMENTO IN LINHA-DE-TOTAL.

CALL. "DELOCR" USING FIM-ARQUIVO CARTAO-SAIDA.

PROC-GRUPD-ITR.

IF TIPO-CARTAO-SAIDA $=" T "$

OR FIM-ARQUIVO = "S"

GO TO PROC-GRUFO-FIM.

MOVE CRRTRO-SAIDA TO REG-CARTRO-DET

IF NRO-DEF'FIRTATENTO IN REG-CARTAO-DET NOT =

NROO-DEPARTAMENTO IN LINHA-DE-TOTAL

GO TO FROC-GRUFO-FIM.

ADD NRO-FILHOS TO TOTAL-DE-DEFENDENTES.

CALL "DELOCR" USING FIM-ARQUIVO CARTAO-SAIDA.

GO TO PROC-GRUPO-ITR.

FROC-GRUPO-FIM.

MOVE CARTAO-SATDA TO REG-CARTAO-TIT.

MOVE SFACES TO LINHA-IMPRESSAO.

WRITE LINHA-IMFRESSAO FROM LINHA-OE-TOTRL RFTER

ADVANCING 2 LINES.

GO TO FROC-CORFO-RELATORIO-ITR.

PROC-CORFO-RELATORIO-FIM.

CLOSE ARQ-SAIDA.

STOF RUN.

PROC-RELGTORIO-CARTOES-FIM.

Figura 3.30 (cont.) 


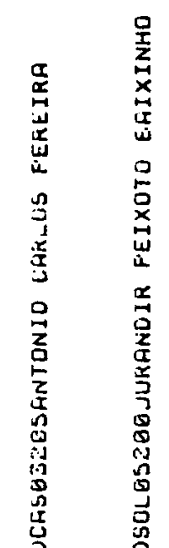

0
0
0
0
0
0
0
0
0
0
0
0
1
0
0
0
0
0
0
2
+1
0
0
0
0
0
0
0
0
0
0

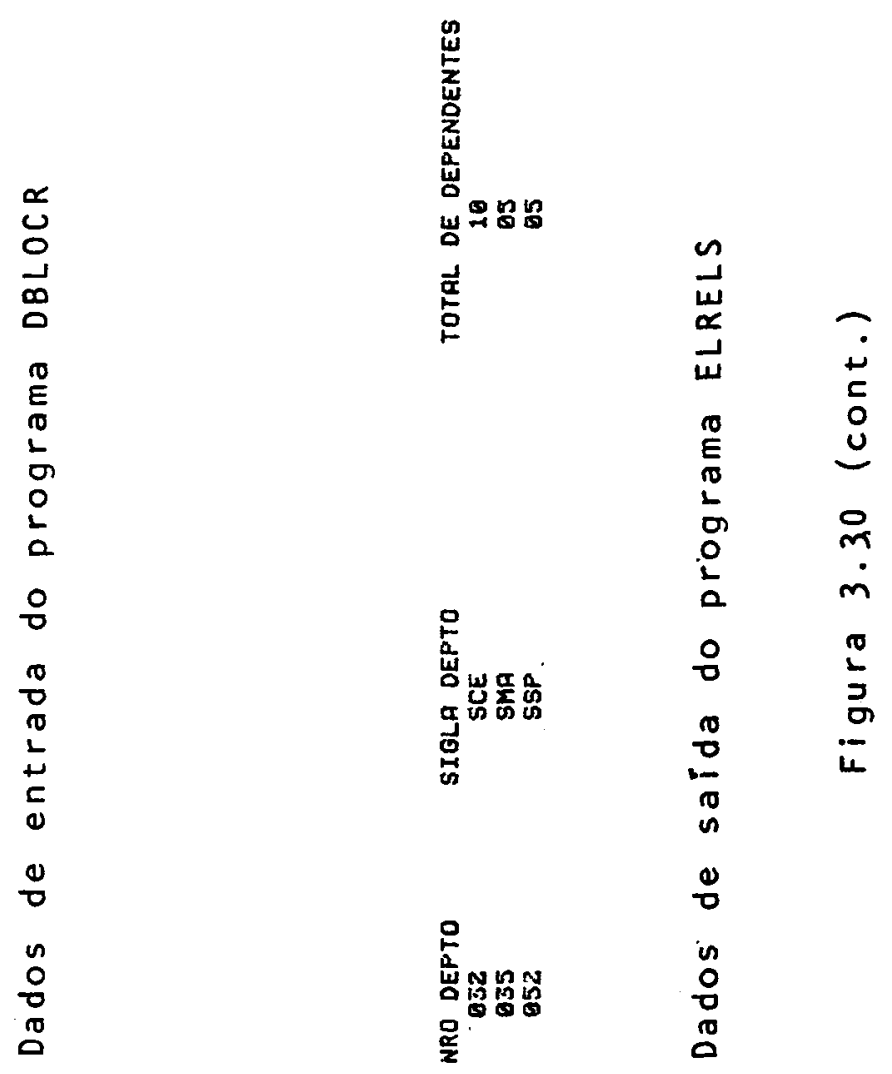

운

군

空 嵒

몸

줄 줄

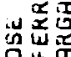

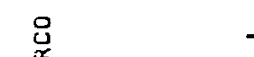

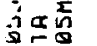

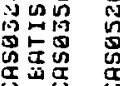

㺃密

g

。

的

㽞

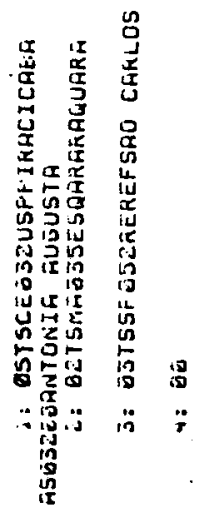


3.8. - Passo Relativo à Implementação do Programa

o sexto passo é relativo à implementação, figura 3.31, onde a codificação e os testes devem ser realizados. Esse passo é ilustrado através das figuras $3.10,3.19,3.28,3.30$, 3,29, jä mencionadas anteriormente. Em resumo, foram feitos dois programas, propriamente ditos; um que elabora o relatório de saida (ELREL) e outro, DBLOC, que transforma o arquivo bloca do em um arquivo de cartões do tipo apresentado no exemplo 3.1 . A técnica de inversão é mostrada combinando-se os programas ELRELS e DBLOCR. A técnica de retro-indicação, é mostrada através de um programa ELRELE semelhante ao ELREL, acrescentando-se a lista de erros.

Exemplo 3.6 - E possível a combinação de recursos apresentados por Jackson. A figura 3.32 e o programa ELREAB, figura 3.33 , mos tram as técnicas de inversão e retro-indiciação combinadas. Esse programa lê um arquivo blocado através da chamada da subrot i na DBLOC que desbloca o arquivo, enviando registro por registro conforme as chamadas (técnica de inversão). Esse registro contém o tipo de cartão que pode ser T, D ou "erro". Se for um car tão $T$, o cartão seguinte poderá ser um $D$ se a chave for a mesma. Se não ocorrer a mesma chave, tem-se um erro. Se o cartão não for do tipo $T$ e for o primeiro de um grupo, também ocorre erro (técnica de retro-indiciação).

Pode-se observar que esse programa ELREAB, figura 3.33, é a combinação de dois outros: ELRELE, figura 3.28 , como programa principal e DBLOCR, figura 3.29 , como subrotina. Compa rando-se o programa ELREAB, figura 3.33, com o programa ELRELE, figura 3.28 , nota-se que foi conservada a estrutura, porēm as leituras dos arquivos foram substituídas por chamadas à subrot na.

A fim de ilustrar as implementações feitas nesse ca pítulo, tem-se o esquema mostrado na figura 3.34 . 


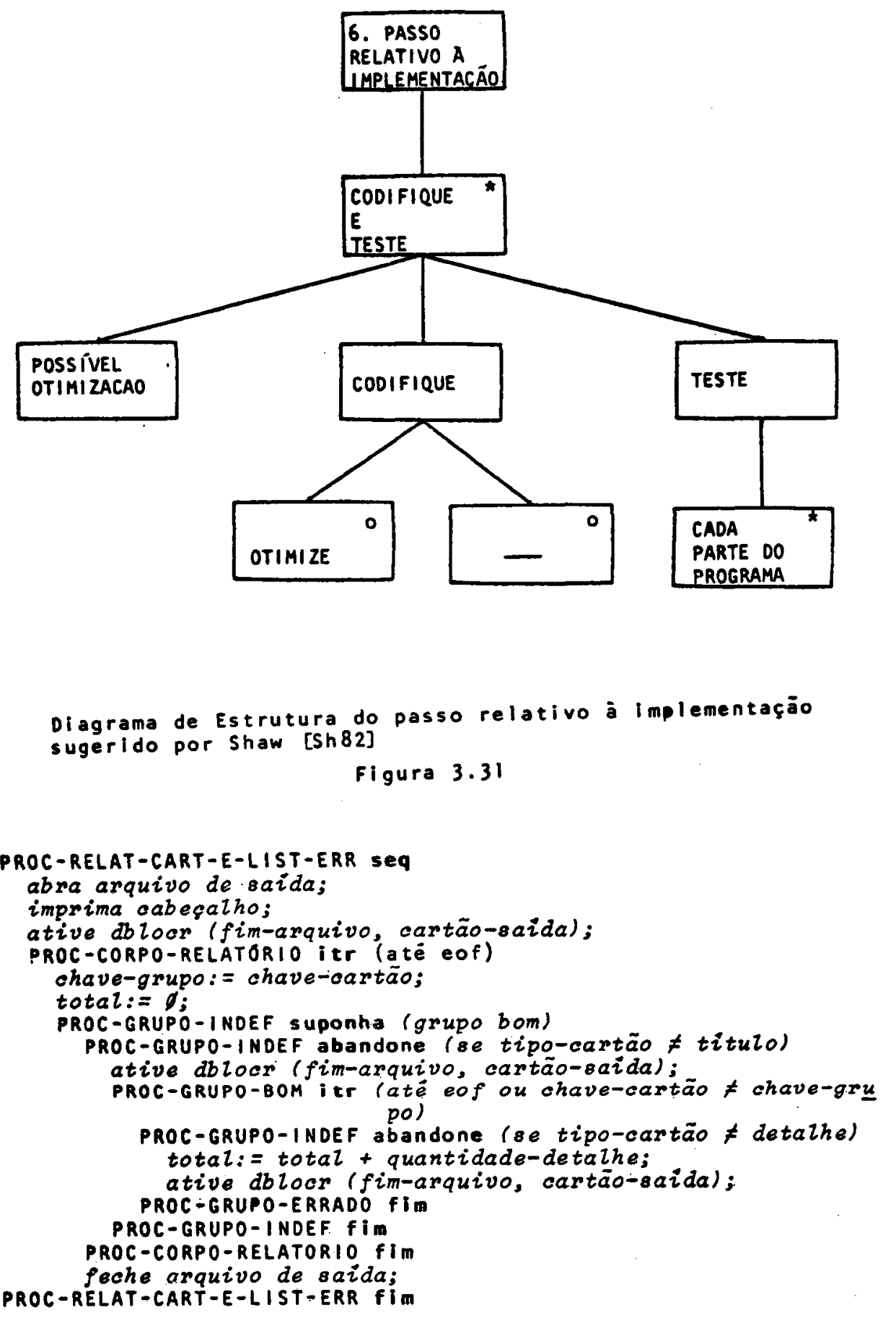

Texto Estruturado do programa exemplo 3.6-ELREAB

Figura 3.32 
IDENTIFTCATION DIUISION.

PROGRAM-ID. ELREG8.

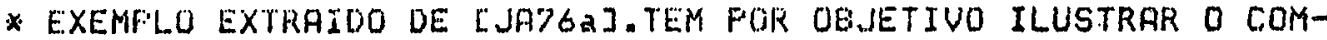

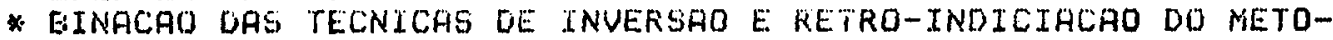

* do jsf. trata-se de utia variante do prograna elrel. sua

* funcao e produzir lum relatorio de resumo e lista de erros

* soere um arquivo elocado.

RUTHOF. ROSANGELA PEINTEAOO.

ENUIRONRENT DIUISION.

INFUT-OUTFUT SECTION.

FILE-CONTROL.

SELECT ARQ-SAIDA ASSIGN TO DISK.

DATA DIVISION.

FILE SECTIDN.

FD ARQ SAIDA

LAEELL RECORD IS STANDARD

VALUE OF FILE-ID IS "EI ERRO.SAI"

DATA RECOFD IS LINHA-IMPGESSAO.

OI LINHA-IMFRESSAO

WOFKINGMSTORAGE SECTION.

77 FIM-ARQUTVO

G1 CAEECALHO.

OZ FILLER

Q2 FILLER

G2 FILLER

Q2 FILLER

Q2 FILLER

01 LINHA-DE-TOTAL.

Q2 FILLER

Q2 NRO-DEFARTAMENTD

Q2 FILLER

Q己 SIGLA-DEFARTAMENTO

02 FILLER

QZ TUTAL-DE-DEFENDENTES

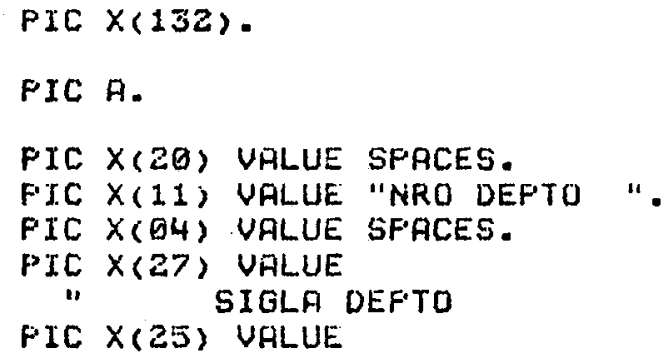

01 LINHA-DE-ERRO.

Q2 FILLER

Q2 NRO-DEFARTAMENTO

EZ FILLER

OC SIGLA-DEFARTAMENTO

Q2 FILLER

D2 FILLER

PIC $X\langle 23\rangle$ UALUE SFRCES.

FIC 999.

PIC $X(17)$ URLUE SPACES.

PIC $A(3)$.

PIC $X(24)$ URLUE SPACES.

PIC 999.

PIC $X(23)$ VALUE SPACES.

FIC 999 .

PIC $x(17)$ VAlUE SPACES.

FIC $9(3)$.

FIC $x(17)$ VALUE SPACES.

FIC $X(21)$ UALUE

"VERIFIQUE O TIPQ ".

O2 TIFO-CARTHO-ERRO

FIC $A$.

OZ FILLER

Q1 CARTAD-GAIDA.

62 TIFO-CARTAO

Q2 RESTO-CARTAO

Fic $X(11)$ VAlUE ". OO cartao".

Q1 REG-CARTAO-TIT REDEFINES CARTAO-SAIDA.

Q2 TIFO-CARTAO FIC $A$.

DI SIGLA-DEPARTAMENTO PIC $A(3)$.

Q2 NRD-DEFARTAMENTO

PIC 999.

Q2 ENTIOADE-EDUCACIONAL FIC $A(3)$.

Q2 CIDADE

Q2 FILLER

PIC $A(10)$.

PIC $X(20)$.

Q 1 REG-CARTAO-DET REDEFINES CARTAO-SAIDR.

Q2 TIFO-CARTAO PIC $A$.

QZ ESTADO-CIUIL

FIC $A(\overrightarrow{3})$.

02 NRO-DEFARTAMENTO PIC 999.

OZ NRO-FILHOS

Q2 NDME-FUNCIONARIO

Q2 FILLER

PIC 99.

FIC $A(\bar{J} \theta)$.

FIC $X$.

Implementação do exemplo 3.6 - programa ELREAB

Figura 3.33 
FAOCEDUFE UIUISIIN.

FROC-RELAT-CART-E-LIST-ERR-SEG.

OFEN OUTFUT ARG-SAIDH.

MOVE. "N" TO FIM-FRQUIVO.

MOUE SFACES TO LINHA-IMFRESSAO.

WRITE LINHA-IMFRESSAO FRUM CFEECALHO AFTER ADUANCING 2 LINES.

CALL "DELOCF" USING FIM-ARQUTVO CARTAO-SAIDA.

FROC-CORFCI-RELATORIO-ITR.

IF FIM-ARQUIUO = "S"

GO TU FROC-CORFO-RELATORTO-FIM.

MOVE ZEROS TO TOTAL-DE-DEPENOENTES.

MOUE NRO-DEFARTAMENTO IN REG-.-CARTAO-TIT TO

PRU-DEPRR TAIENTO IN LINHA-DE-TOTAL.

MOVE SIGL.A-DEFFIRTAMENTO IN REG-CARTAO-TIT TO

SIGLA-DEFAIRTAMENTO IN LINHIR-DE-TOTAL.

FROC-GRUFO-INDEF-SUFONHA-CERTO.

IF TIFO-CARTAO IN REG-CARTAO-TIT NOT = "T"

GO TO FROC-QRUFO-INDEF-ADMSTA-ERRO.

CALL "DELOCR" USINO FIM-ARQUIVO CARTRO-SAIDA.

FROC-GRUFO-EIOM-JTR.

IF NRD-DEFARTAMENTO IN REG-CARTAQ-DET NOT =

NFCO-DEFARTAMENTO IN LINHA-DE-TOTAL

OR FIM-ARQUIVO $=$ " $S "$

GO TO FROC-GRUFO-EOM-FI IA.

IF TIFO-CARTAD IN REG-CARTAO-DET NOT = "D"

GO TO FROC-GRUFO-INDEF-ADMITA-ERRO.

ADD NRO-FILHOS TO TOTAL-DE-DEFENDENTES.

CALL "DELOCR" USIIVG FIM-ARQUIVO CARTRG-SAIDA.

GO TO FROC-GRUFO-EOM-ITR.

FROC-GRUFO-EOM-FIM.

MOUE SFACES TO LINHA-TMFRESSAO.

WRITE L. INHA-JMFRESSAO FROM LINHA-DE-TOTAL AFTER

ADVANCING 2 LINES.

GO TO PROC-GRUFO-INDEF-FIM.

PROC-GRUFO-INDEF-ADMITA-ERRO.

PROC-GRUFO-ERRFDO-ITR.

IF NFO-DEFARTAMENTO IN REQ-CARTAO-DET NOT =

NRD-DEFARTAMENTO IN LINHA-DE-TOTAL

OR FIM-ARQUIVO = "S"

GO TO FROC-GRUFO-ERRADO-FIIM.

MOUE NRO-DEFARTAMENTO IN REG-CARTAO-TIT TO

NRD-DEFARTAMENTO IN LINHA-DE-ERRO.

MOVE SIGLA-DEFARTAMENTO IN LINHA-DE-TOTAL TO

SIGLA-DEFARTAMENTO IN LINHA-DE-ERRO.

MOUE TIFD-CARTAD IN REG-CARTAO-DET TO

TIFO-CARTAO-ERKO.

MOVE SFACES TO LINHA-IMPRESSAO.

WRITE LINHA-IMFKESSAO FROM LINHA-DE-ERRO

AFTER ADUANCING 2 LINES.

CALL "DELLCR" USING FIM-RRQUIVO CARTAO-SAIDA.

GO TO FROC-GRUFO-ERRADQ-ITR.

PROC-GRUFO-ERRADO-FINI.

PROC-GRUFO-INDEF-FIM.

GO TO PROC-CORFO-RELATORIO-ITR.

PROC-CORFO-RELATORIO-FIM.

CLDSE ARQ-SATDA.

STOF RUN.

FROC-RELAT-CART-E-LIST-ERR-FIM.

Figura 3.33 (cont.) 


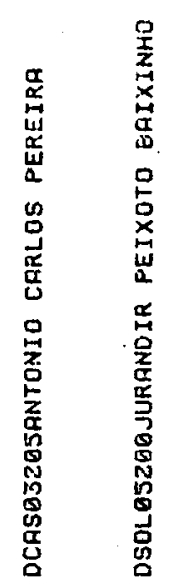

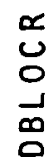

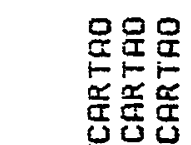

点

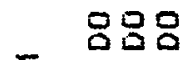

茍 $0 \times 0$

萦

5

- 900

무요

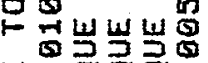

山े

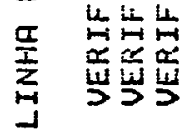

臬乐乐

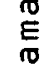

운

总 点

w

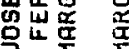

政

证

恕临

喟

뭉

音

$\stackrel{0}{0}$

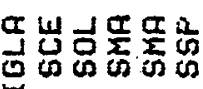

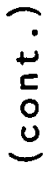

ज
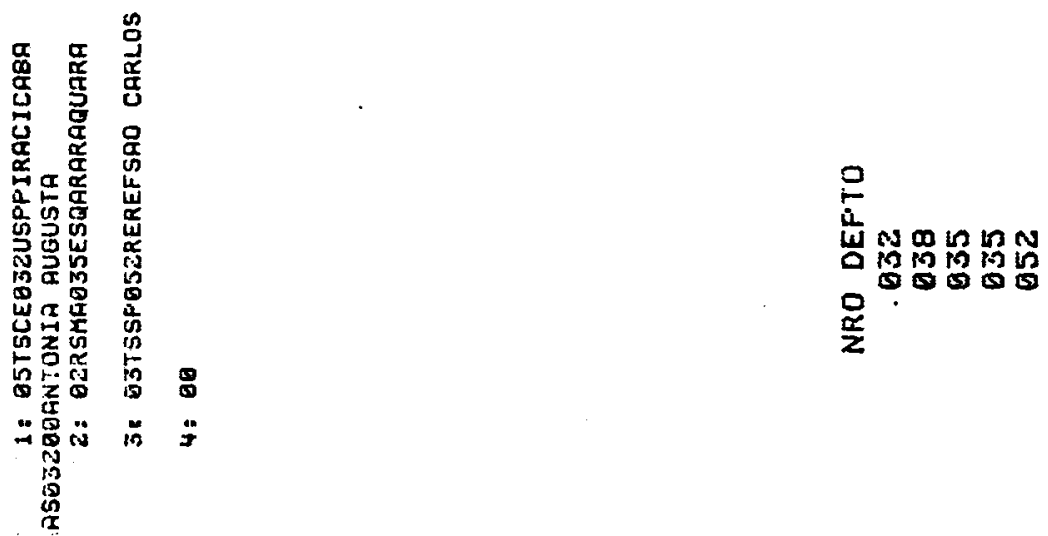

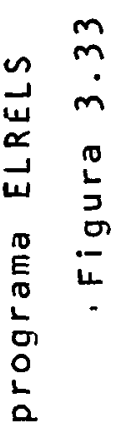

0

$\sum_{0}^{0}$

$\stackrel{0}{\circ}$

$n$
0
0
0
0 


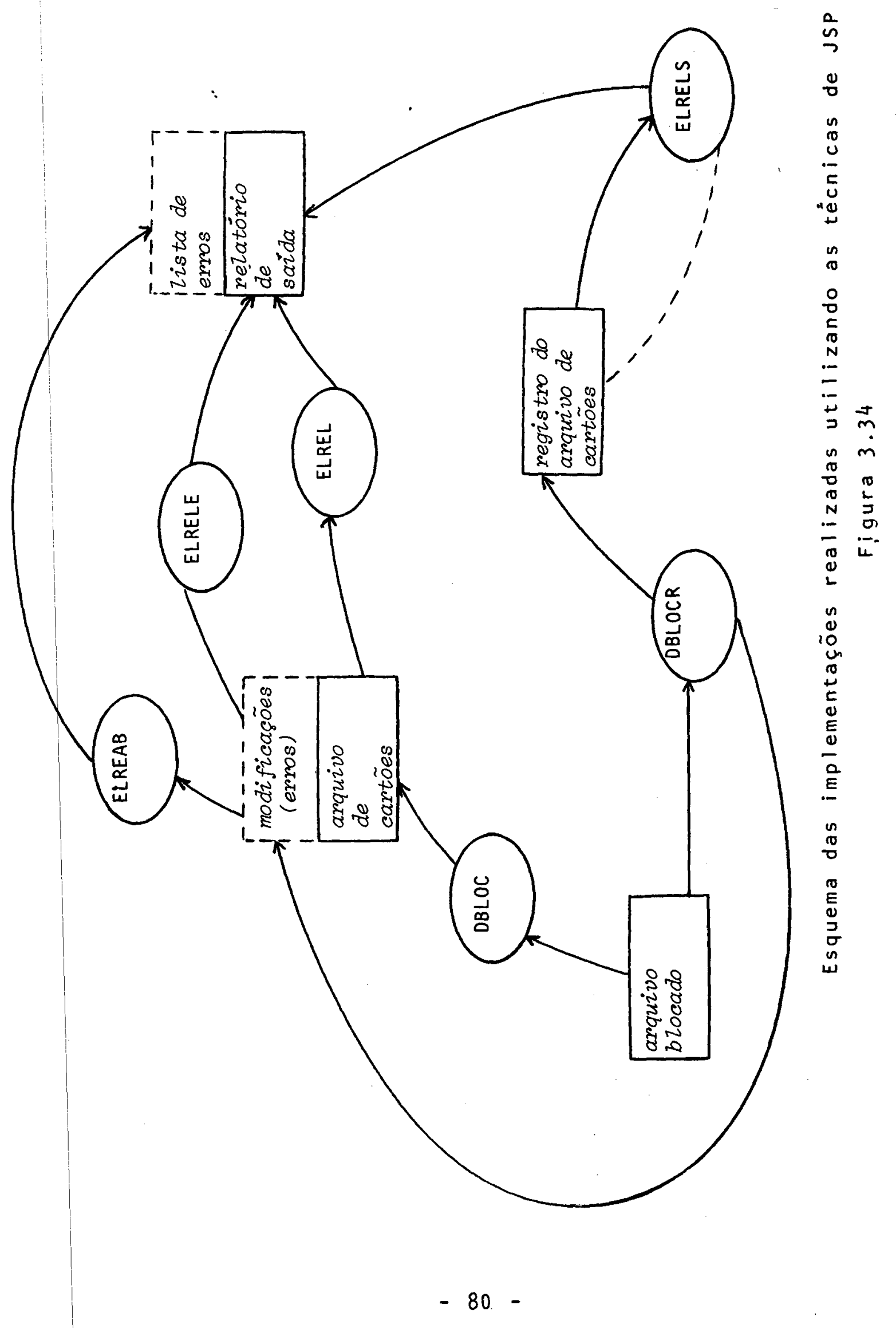




\section{9. - Conclusões}

Pode ser notado, pelos exemplos apresentados, que a implementação de programas usando-se o JSP segue fielmente o texto estruturado que, por sua vez, espelha os diagramas de estrutura dos dados de entrada e saída, e do próprio programa. Jackson diz que nos programas construidos dessa forma, as alterações podem ser feitas com um certo grau de facilidade devido á lógica do programa estar muito clara quando o texto é produzi do.

Os diagramas de estrutura de entrada e saída de dados ajudam na descrição dos mesmos e na preparação dos arquivos na DATA DIVISION.

A implementação feita em COBOL dificulta a tabulação preconizada por Jackson quando os textos estruturados são elaborados, porém a compatibilidade entre os rótulos do texto e os nomes dos parágrafos da PROCEDURE DIVISION deixa claro o-tipo da estrutura, o seu início, o seu corpo e o seu fim.

Brookes, em [Br82], ressalta que, na metodologia de Jackson, a estrutura do programa é especificada somente com base nas afirmações do problema. Esse é um aspecto que distingue as técnicas baseadas em estrutura de dados das outras. Outro ponto também elucidado por Brookes é que essa tēcnica, tanto para projeto de sistemas como para projeto de programas, obe dece a um procedimento padrão; assim, se dois analistas projeta rem a estrutura de um programa, há uma grande probabilidade de que esses projetos sejam os mesmos. Isso é muito bom para a manutenção dos programas, pois é possível fazer a manutenção deles e entendê-los sem que os tenha feito. Brookes, ainda, cita Menard como um dos adeptos desse método. O trabalho por ele relatado em [Me80] teve enfoque no capitulo 2.

Bergland em [Be81], diz que a desvantagem desse método è que envolve um nümero distinto de passos e procedimentos - que implica que, tanto os diagramas de estruturas como os tex tos estruturados, devem ser guardados como partes permanentes da documentação. Outra desvantagem citada é que, para certas 
classes de problemas, os diagramas de estrutura de dados e de estrutura de programa resultantes podem tornar-se indevidamente complicado. Brookes em [Br82], diz que críticas ao método têm surgido quando se procura aplicar essa abordagem de estrutura de dados a programas ou sistemas que não são baseados em arquivos seqüenciais e cita Peters, cujo artigo, [Pe77], foi objeto de enfoque no capítulo 2 . 
SOBRE O METODO JSD

4.1. - Considerações Gerais

Este capitulo tem por objetivo apresentar os passos do método JSD, Jackson System Development [Ja83], referentes à especificação do sistema.

A figura 4.01, reproduzida da página 39, de [Ja83], mostra como os passos do procedimento JSD podem ser considera dos sob um ponto de vista global. Foi a partir desse diagrama que surgiu a idéia de documentar o próprio método JSD, usando recursos existentes em JSP [Ja75], criando diagramas do tipo dos utilizados por Jackson para o projeto de programas. A partir de diagramas desse tipo é que os textos estruturados de pro cedimentos podem ser desenvolvidos de acordo com o método de Jackson para o Projeto de Programas, apresentado em [Ja75] e re ferido em [Ja83] como JSP, cujos recursos já foram discutidos em detalhes no capítulo 3. Assim, surgiu a idéia de combinar JSP com o sistema PSL/PSA, [Te75], para documentar o próprio mé todo JSD. A escolha do sistema PSL/PSA deveu-se ao fato de ele possuir mais recursos que outros métodos de documentação, como pode ser visto em [Pe83d]. Para o sistema PSL/PSA, cada passo do método JSD é considerado "processo", PROCESS, em cujo PROCEDURE è apresentado o texto estruturado, feito de acordo com o método JSP. Na PROCEDURE, o procedimento do passo é detaIhado. Nos diagramas de estrutura relativos aos passos do método JSD, as tarefas a serem desenvolvidas são representadas com abreviaturas a fim de satisfazer a exigência do sistema PSL/PSA de que os nomes dos objetos não podem ultrapassar 30 caracteres. No Apêndice, onde está a descrição dos conceitos e dos passos do método JSD, em PSL/PSA, tem-se além dos nomes abreviados co- 


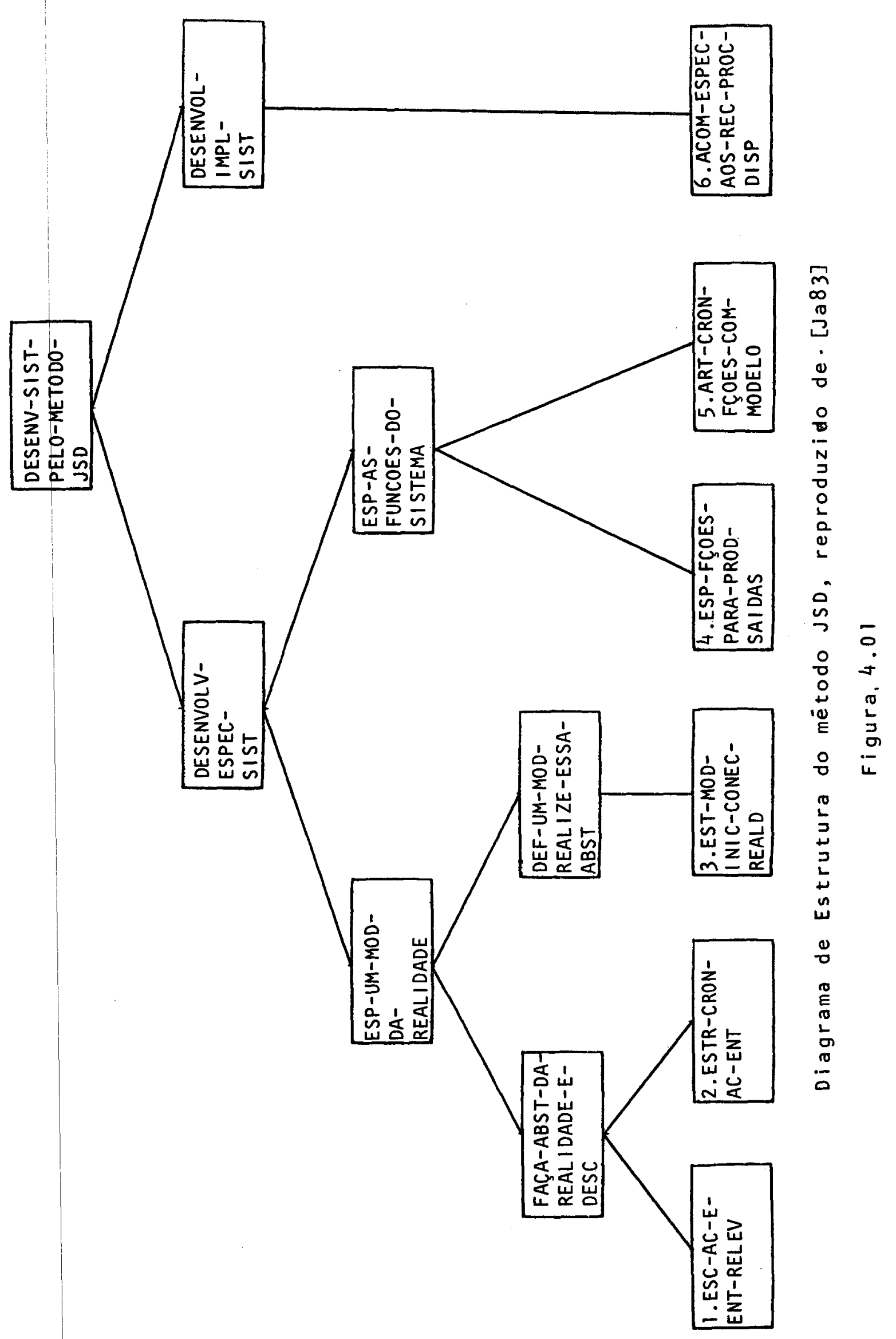


mo aparecem no diagrama de estrutura, o significado por extenso de cada abreviatura, o que pode facilitar o entendimento dos diagramas.

Quando os conceitos apresentados no Apêndice são re feridos neste capítulo, são distinguidos pelo símbolo (\$).

Maiores detalhes sobre o método JSD podem ser encontrados em [Ja81, Ja83, Ca81].

Nas seções 4.2 a 4.8 apresentam-se, respectivamente, um delineamento do método JSD, o passo relativo à escolha das entidades e ações, o passo relativo à estruturação cronológica de ações das entidades, o passo relativo ao modelo inicial, o passo relativo à especificação das funçōes, o passo relativo à articulação cronolögica das funções com o modelo e as conclusões. 
4.2. - Delineamento do método

O sistema de atendimento de pedidos (Widget Company) extraído de [Ja83] è aqui usado para ilustrar as etapas do método JSD.

Esse exemplo refere-se a uma empresa que recebe pedi dos de clientes através de carta ou telefone. os produtos podem ser olhais, flanges, acessōrios, etc, que são mantidos ém estoque num armazēm por um funcionärio. Quando há necessidade de ressuprimento de produtos, a companhia faz pedidos aos fornecedo res que a atendem. Os pedidos de clientes podem ser modificados com relação à quantidade pedida ou à data de entrega. Eventualmente, podem ser cancelados pelos clientes. Os pedidos são remetidos aos clientes quando houver estoque do produto pedido. Caso contrário, são colocados em pendência.

Não é objeto de interesse deste estudo, a parte que se refere às tarefas de ressuprimento.

Para se desenvolver um sistema pelo método JSD, de a cordo com o diagrama de estrutura mostrado na figura 4.01 , cujo texto estruturado é encontrado no Apêndice, tem-se uma seqüência $(\S)$ onde se faz: a "especificação do sistema e a implementação do sistema". O desenvolvimento da especificação do sistema é fei ta atravēs da seqüência em que se "especifica um modelo da reali dade" e se "especificam as funções do sistema".

A "abstração da realidade e sua descrição", bem como a "definição de um modelo que realize essa abstração" são partes da "especificação do modelo da realidade". o nível mais baixo desse diagrama é o relacionado aos passos do desenvolvimento pelo mé todo JSD.

A "abstração da realidade e sua descrição" é feita através dos passos 1 e 2 que são, respectivamente: a "escolhadas açōes e entidades relevantes" e a "estruturação cronológica das ações e entidades".

Quando se "estabelece o modelo incial conectado à realidade", passo 3 , define-se um modelo que realiza a "abstra ção da realidade". 
Os passos 4 e 5, "especificação das funções para produzir as saídas desejadas" e "articulação cronológica das funções com o modelo", è que fazem a especificação das funções do sistema.

A realização do desenvolvimento do sistema é feita através do passo 6 , que é a "acomodação das especificações aos recursos de processamento disponíveis".

Os diagramas de estrutura geral e dos passos do método JSD relativos à especificação são mostrados nas figuras $4.01,4.02,4.04,4.11,4.27 \mathrm{e} \mathrm{4.45.} \mathrm{No} \mathrm{Apêndice,} \mathrm{encontram-se}$ os textos estruturados correspondentes a esses diagramas de estrutura. 
4.3. - Passo Relativo à Escolha das Entidades e Ações

- primeiro passo do método JSD refere-se à escolha das entidades (\$) e ações (\$) que possam fazer parte do sistema.

A figura 4.02 mostra o diagrama de estrutura desse passo e cujo texto estruturado pode ser visto no Apêndice. Podetse notar que esse passo é realizado atravēs de uma seqüência onde se consideram todos os candidatos a entidades ( $\$$ ) é todos ns candidatos a açōes ( $($ ).

Para que um candidato seja incluído na lista das en tidades ou na lista das ações, ele deve passar por algumas verí ficações. o candidato é rejeitado se alguma exigência não for satisfeita nessas verificações.

Para um candidato entrar na lista de entidades, ele deve ser, antes de mais nada, um substantivo. Desse modo, Iendo-se a descrição do problema-exemplo e separando-se os substan tiyos que aparecem nessa descrição, consegue-se a seguinte-lís ta inicial: empresa, cliente, carta, telefone, pedido, produto, funcionārio, estoque, forncedor, armazém.

Para cada um desses candidatos deve-se verificar se:

a) 0 candidato desempenha ou sofre ações em ordem cronológica.

A empresa é inerte, logo a condição acima não se ve rifica e esse candidato é rejeitado. Pelo mesmo motivo, rejeitam-se os candidatos: carta, telefone, armazém.

o cliente desempenha a ação, por exemplo, de colocar um pedido. Não é rejeitado nessa fase.

os outros candidatos, pedido, funcionário e produto tambēm não são rejeitados pois, por exemplo, o pedido relaciona-se com cliente, ou seja, ele é colocado por um cliente. o funcionário verifica se há ou não estoque disponível de um determinado produto.

b) o candidato existe no mundo real.

o cliente está presente no mundo real e não só no sistema, como também ocorre com pedido, funcionário e produto. Logo, não são rejeitados nessa fase.

Por exemplo, a empresa existe no mundo real, porém 


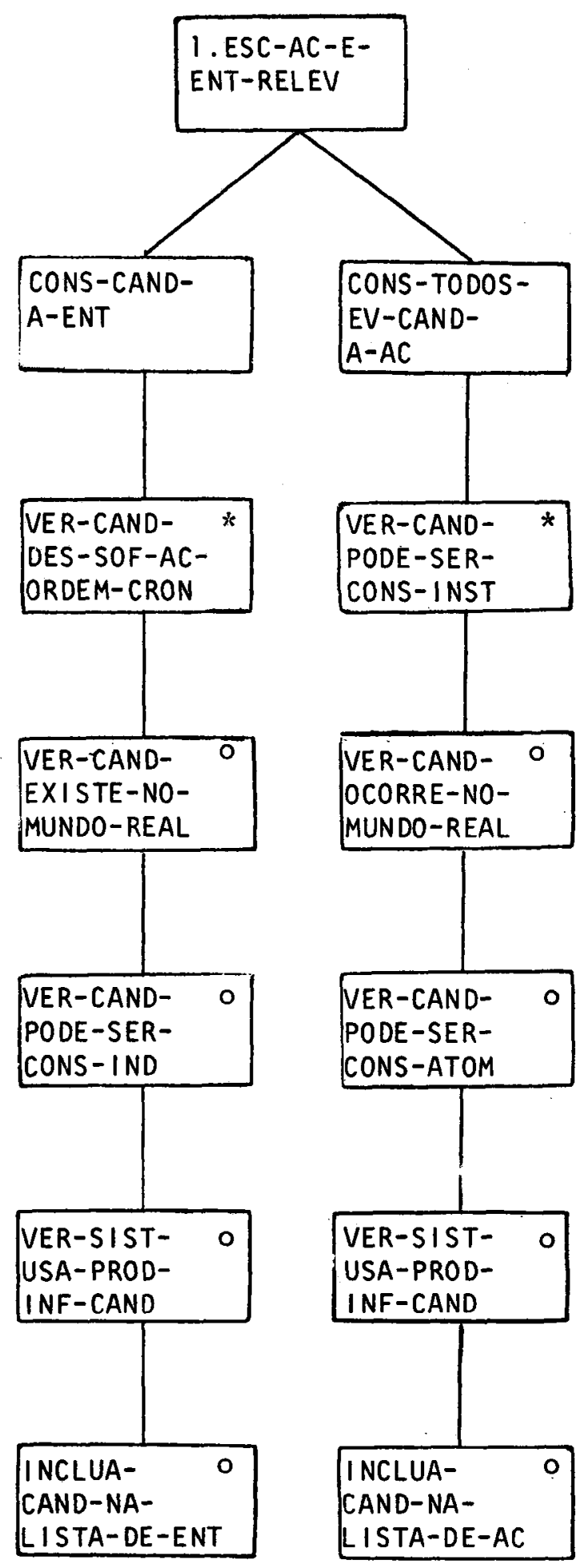

Diagrama de Estrutura do passo relativo à escolha das entidades e ações Figura 4.02 
jä foi retirada da lista de candidatos por não se enquadrar nos requistos do item a).

c) 0 candidato pode ser considerado como individual.

o cliente, por exemplo, tem um comportamento dentro do sistema através da colocação de um pedido. os outros candidatos, pedido, produto e funcionário também satisfazem essa exigência, portanto, permanecem na lista.

d) O sistema usa ou produz informações sobre o candidato.

o candidato cliente, por exemplo, envia um pedido, logo o sistema usa informações do cliente. A informação usada quanto a pedido ē, por exemplo, a modificação de um deter minado pedido feita por um cliente. O funcionário fornece a quantidade disponivel de um determinado produto, assim os quatro candidatos permanecem, tambēm, nessa fase.

Desse modo, obtém-se a lista de entidades que é for mada por:
cliente
pedido
funcionário
produto

O fornecedor não entra nessa lista por pertencer à parte do sistema referente ao ressuprimento de produtos e isso não é de interesse no caso em estudo.

Apōs a elaboração da lista de entidades, deve-se proceder à elaboração da lista de ações. Deve-se registrar todos os candidatos a ação relacionados às entidades já arroladas. Lendo-se, novamente, o problema-exemplo, deve-se se parar os verbos que estão ligados aos substantivos selecionados que agora fazem parte da lista de entidades. Procedendo-se dessa maneira, consegue-se a seguinte lista inicial: colocar pedido, modificar pedido, entregar pedido, cancelar pedido, colocar pedido em pendência, localizar produto no estoque, alocar pedido, verificar disponibilidade do produto.

Como foi feito anteriormente, as condições para que um candidato seja incluído na lista de ações devem ser verifica 
das. Esse candidato será rejeitado se alguma condição não for satisfeita. Para cada um desses candidatos deve-se verificar se:

a) o candidato pode ser considerado instantâneo.

Por exemplo, colocar um pedido ocorre num certo mo mento, logo não é rejeitado nessa fase. 0 mesmo ocorre com os demais candidatos.

b) 0 candidato ocorre no mundo real.

Todos os candidatos ocorrem no mundo real, portanto nenhum deles è rejeitado.

c) O candidato pode ser considerado atómico.

o candidato não pode ser subdividido em outras subações. Isso não ocorre com nenhum dos candidatos em questão. Assim, todos passam essa etapa.

d) o sistema usa ou produz informações sobre o candidato.

As informações utilizadas são, por exemplo, sobre o candidato colocar um pedido. Logo, esse candidato não è rejeitado nessa fase.

- candidato Zocalizar produto no estoque, por outro lado, não usa nem produz informações sobre o sistema. E, então, rejeitado.

os outros candidatos, a exemplo da colocąão de um pedido, não são rejeitados e obtém-se a seguinte lista de açöes :

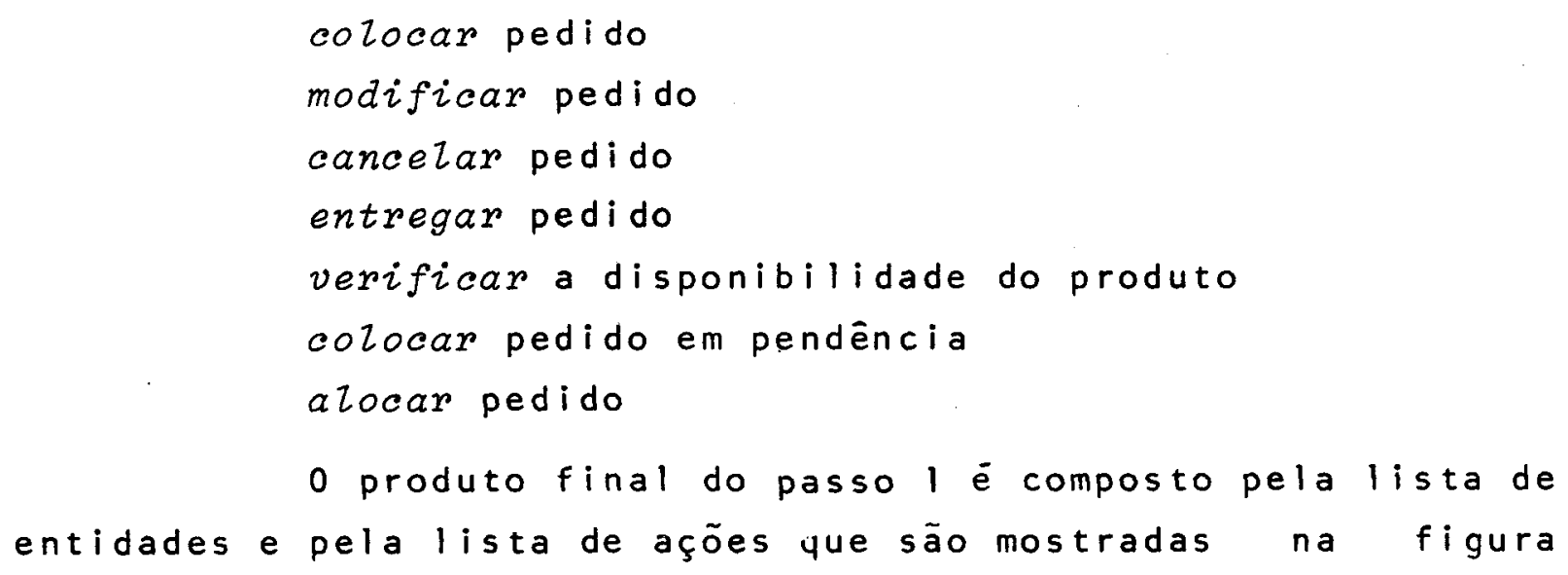
4.03: 
Cliente

Ccoloca pedido modifica pedido

Produto $\{$ estâ ou não disponivel

Pedido

cancela pedido recebe pedido $\left\{\begin{array}{l}\text { colocado } \\ \text { modificado }\end{array}\right.$

S cancelado

entregue

arocado solocado em pendência

Funcionärio $\left\{\begin{array}{l}\text { coloca pedido em pendência } \\ \text { aloca pedido }\end{array}\right.$ Lista das entidades e ações

Figura 4.03

Durante o desenvolvimento do sistema pode ocorrer que uma certa entidade seja retirada da lista inicial por parecer irrelevante e, em outro momento, tornar-se necessária. Nesse caso, a entidade é incluida na lista com suas respectivas ações. Por outro lado, pode ocorrer, tambēm, a retirada de uma entidade e suas açōes quando se nota que elas não são necessárias para o desenvolvimento do sistema. Assim, tanto a lista de entidades como a lista de ações podem ser mudadas, se necessário, durante a realização dos outros passos do método. 
4.4. - Passo Relativo à Estruturação Cronológica de Ações das Entidades

No segundo passo, ao qual a figura 4.04 se refere, e cujo texto estruturado encontra-se no Apêndice, elaboram-se os diagramas de estrutura correspondente a cada entidade selecionada. A construção dos diagramas de estrutura, para cada entidade, depende das seguintes verificações:

1. a) Verifique se ocorre paralelismo de ações, isto é, se existem ações que podem ser realizadas simultaneamente.

No caso da entidade cliente, por exemplo, isso ocor re, pois um pedido pode ser colocado enquanto um outro é cancelado, modificado ou entregue. Logo, cliente não pode ser expresso em um ünico diagrama. Existe uma entidade cliente-pedido que emerge dessa.

b) Verificando-se a situação (a), essa entidade deve ser ex pressa como entidade marsupial (\$) e deve ser feita a composição da sua estrutura com a da entidade cliente da qual ela emergiu. Cliente tem, assim, as ações de colocar, receber, modificar ou cancelar pedido. Essas ações podem ser realizadas diversas vezes, portanto, serão representadas através de iteração ( $($ ). Como sö uma dessas ações ocorre, em dado momento, usa-se a seleção (\$) para representá-las. O diagrama de estrutura para cliente é o mostrado na figura 4.05 .

A entidade marsupial cliente-pedido é expressa como mostra a figura 4.06 .

No exemplo, a existência de cliente-pedido è demarcada atravēs de uma seqüência de ações. o cliente coloca deter minado pedido, em seguida pode modifică-lo algumas vezes (itera ção) e, finalmente, pode cancelar ou receber esse pedido (seleção).

Com a entidade funcionário ocorre o mesmo que com pedido. A entidade marsupial funcionário-pedido é criada. os diagramas de estrutura são, respectivamente, mostrados nas figu ras 4.07 e 4.08 . 


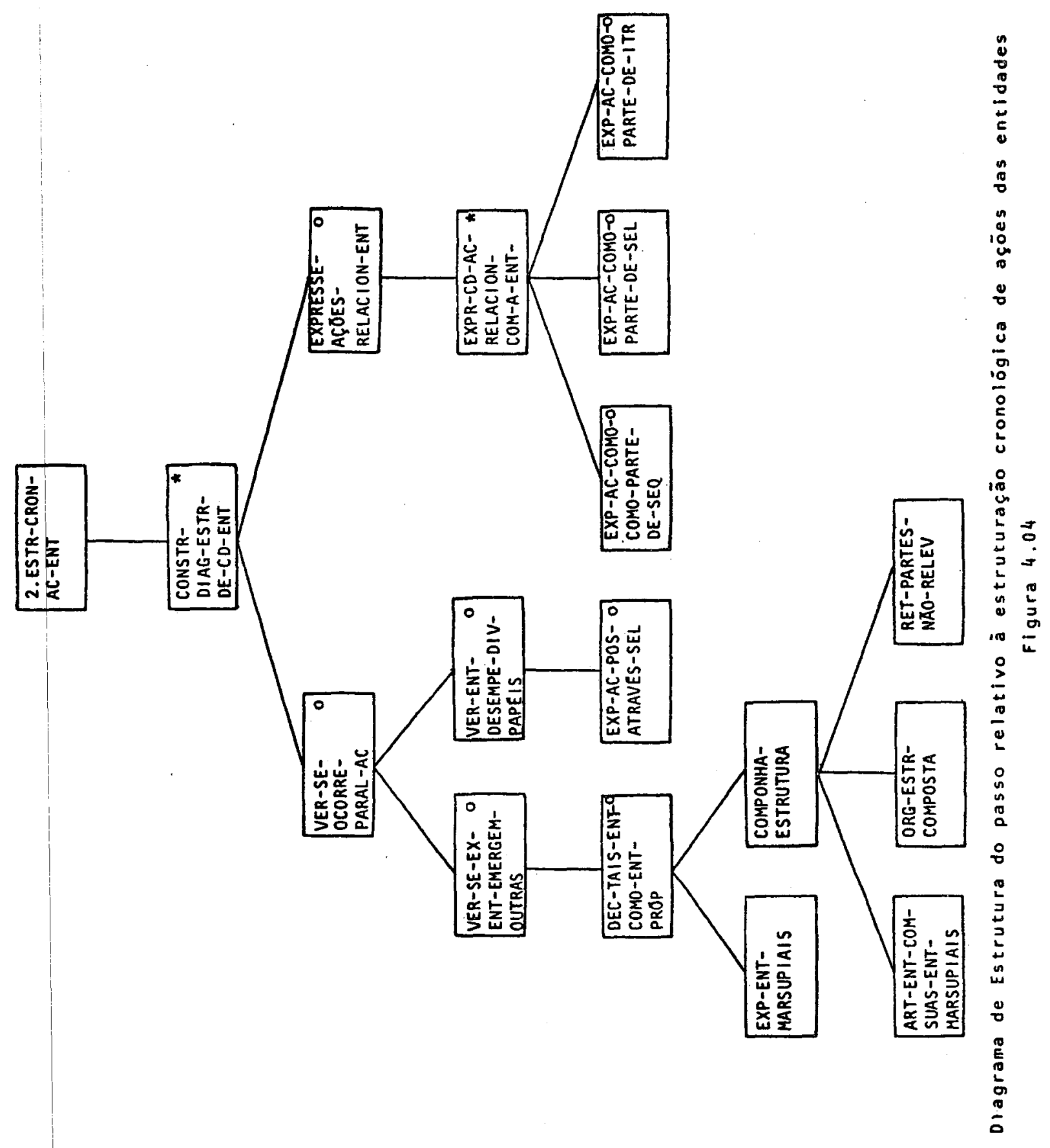




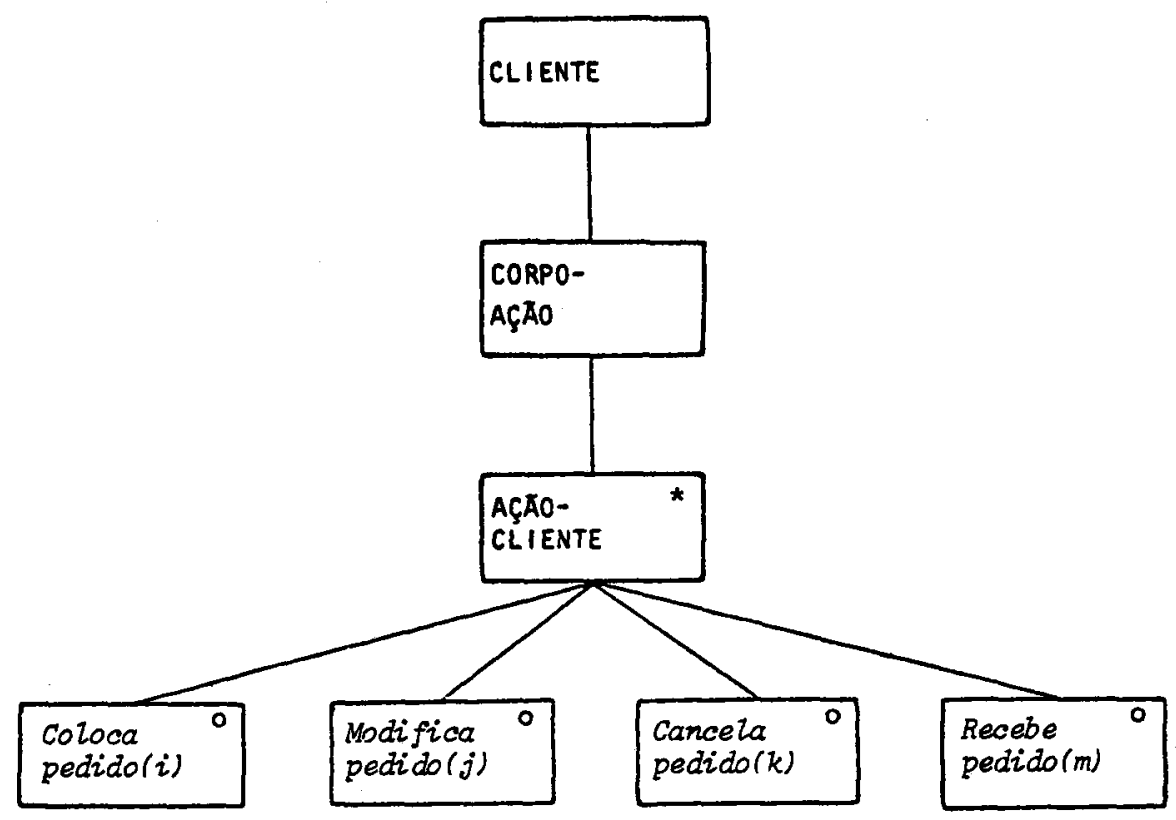

Diagrama de Estrutura da entidade CLIENTE

Figura $4: 05$

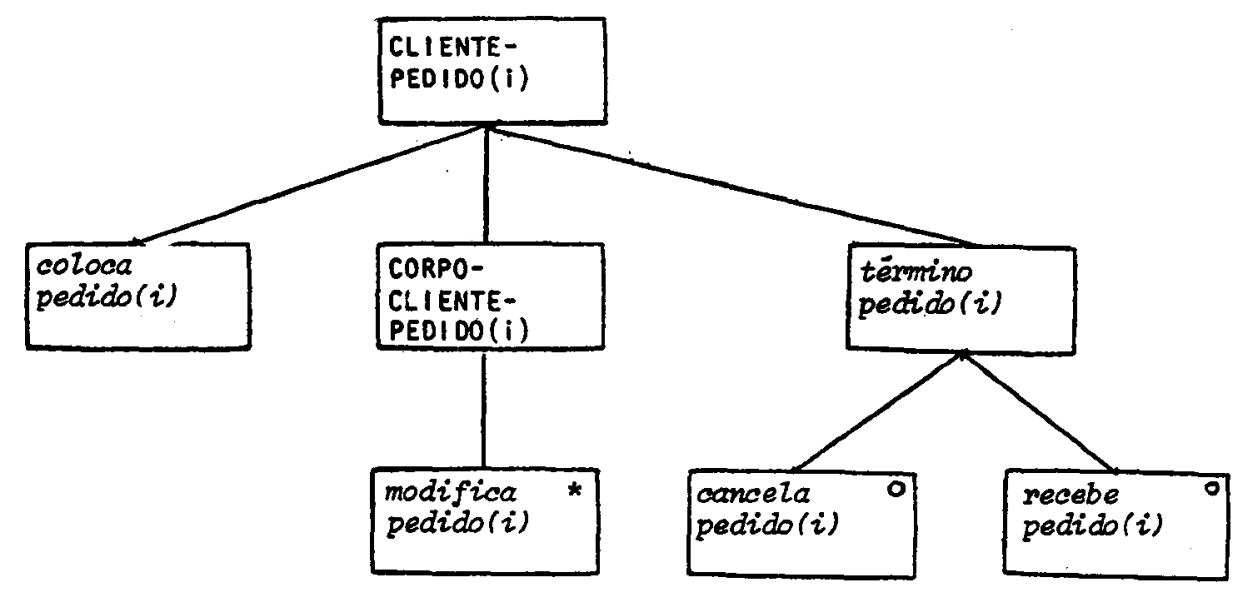

Diagrama de Estrutura da entidade marsupial CLIENTE-PEDIDO

Figura 4.06 


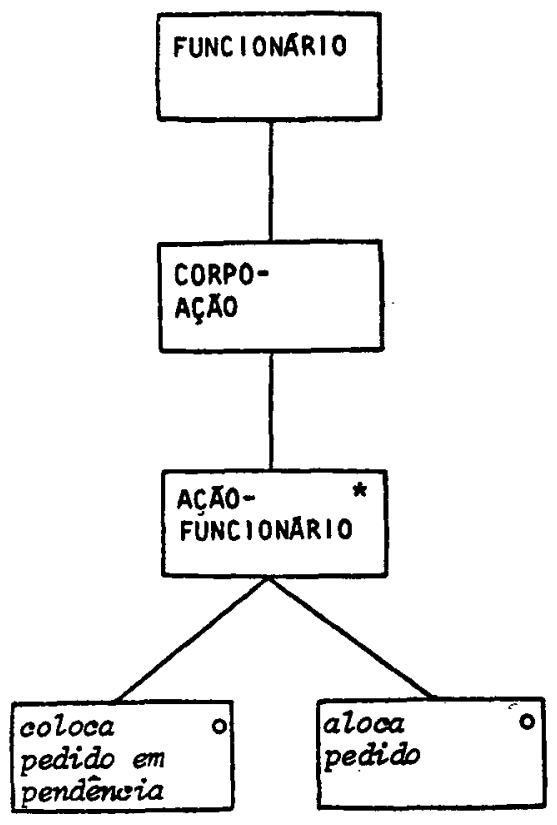

Diagrama de Estrutura da entidade FUNCIONARIO

Figura 4.07

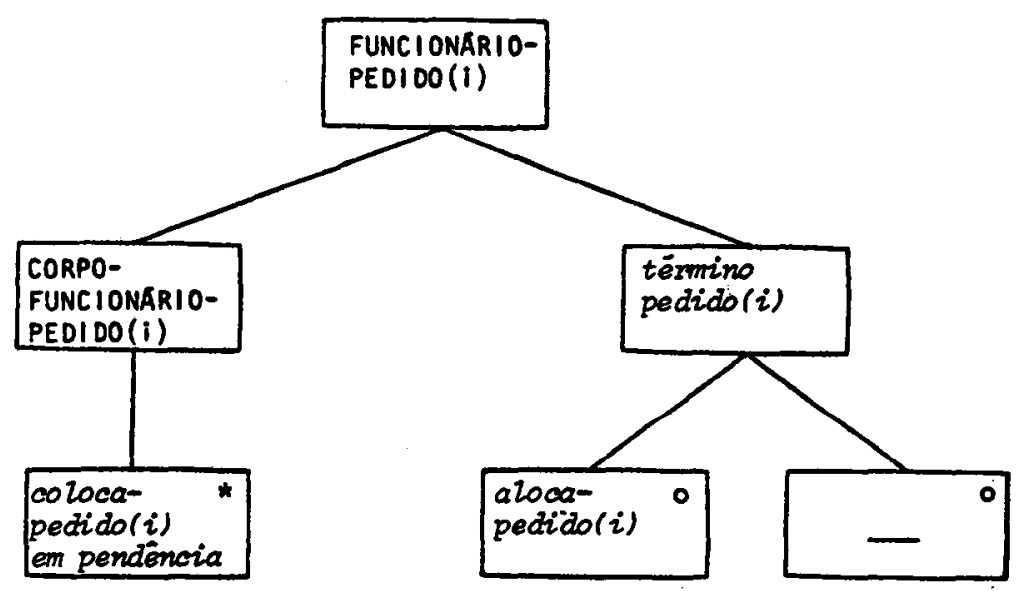

Diagrama de Estrutura da entidade marsupial FUNCIONARIO-PEDIDO

Figura 4.08 
A caixa nula é retirada dessa estrutura seguindo-se a regra "retire as partes não relevantes" que é uma das etapas dentro da atividade "componha estrutura" como pode ser vista na figura 4.04 .

Com as entidades pedido e produto não ocorre para lelismo de ações, verificando-se, então, a outra alternativa que compõe a seleção "construa diagrama de estrutura de cada en tidade".

2. a) Expresse cada ação relacionada com a entidade.

$a_{1}$ ) Expresse a ação como parte de seqüência:

No caso de pedido, por exemplo, ele será primeiramen te colocado, a seguir sofrerā alguma ação e, posteriormente, serä finalizado.

$a_{2}$ ) Expresse a ação como parte de seleção.

Depois de colocado, o pedido pode ser modificado ou colocado em pendência, essas ações são representadas através de seleção.

$a_{3}$ ) Expresse a ação como parte de iteração.

o pedido, por exemplo, pode ser modificado ou coloca cado em pendência por diversas vezes, sendo essa repetição representada atravēs de iteração.

o diagrama de estrutura para pedido è mostrado na

figura 4.09 .

o diagrama de estrutura para produto é mostrado na figura 4.10, construído de modo anàlogo.

Com a construção desses diagramas completa-se a eta pa "faça uma abstração da realidade e descreva-a". 

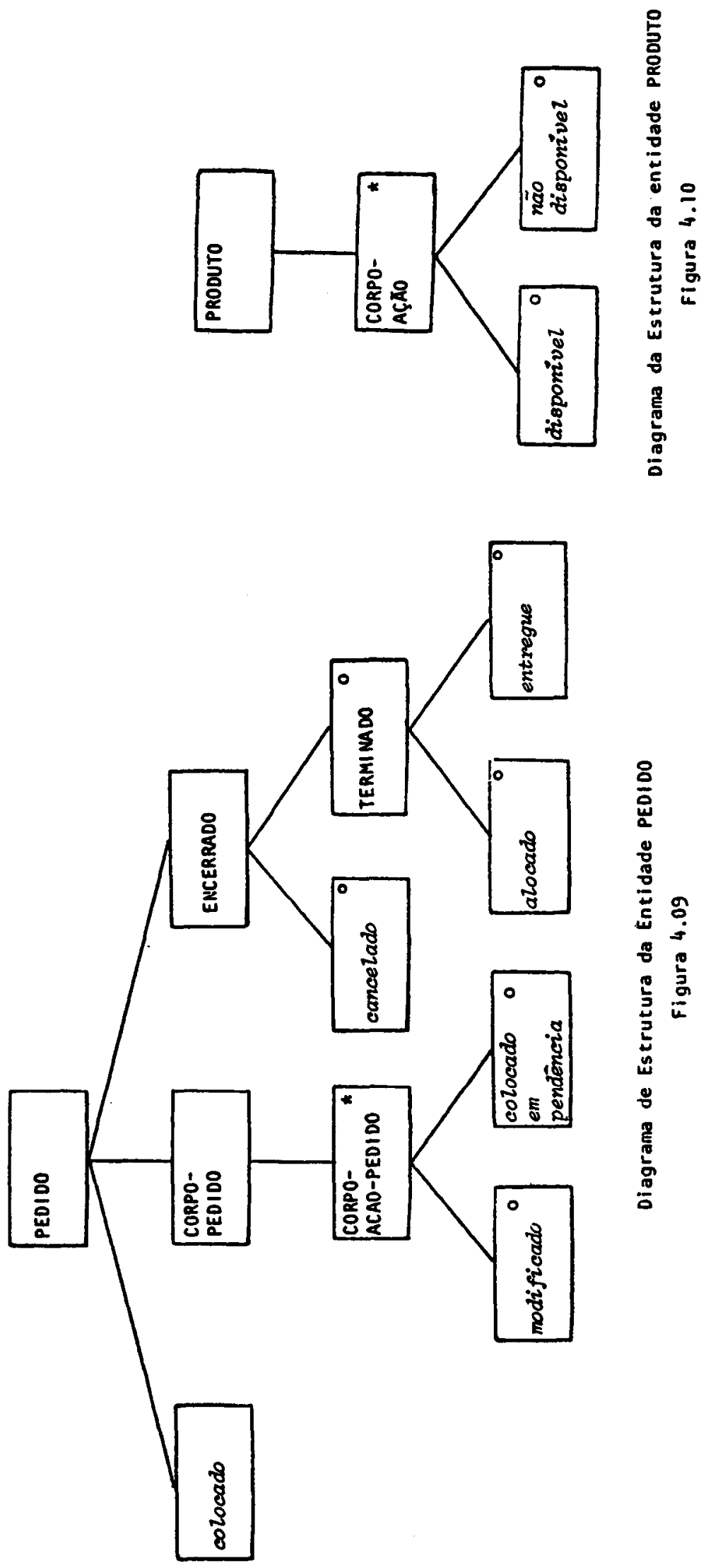
4.5. - Passo Relativo ao Modelo Inicial

No terceiro passo, cujo diagrama de estrutura é mos trado na figura 4.11 , e cujo texto estruturado encontra-se no $\underline{A}$ pêndice, é estabelecido o "modelo inicial conectado à realidade" que faz parte da definição de um "modelo que realize a abstração efetuada".

Nesse passo, inicia-se a construção do Diagrama de Especificaçāo do, Sistema, DES (\$), onde os processos de modelagem e suas conexões com os processos do mundo real são estabele cidas. Os textos estruturados correspondentes às entidades do mundo real, cujos diagramas de estrutura estão nas figuras 4.05, $4.09,4.10$ e 4.07 , são os mostrados nas figuras $4.12,4.13,4.14$ e 4.15 .

A construção do DES para os processos do mundo real é feita do seguinte modo:

1. a) Conecte cada processo do mundo real com o processo dé mo delagem correspondente.

b) Verifique se é conexão por fluxo de dados (\$).

No caso de cliente, essa é a conexão a ser utilizada. Interessa que as informações, nesse caso, sejam registradas de acordo com a sua chegada ao sistema.

A conexão de um processo do mundo real, nível zero $(\$)$, com o processo de modelagem, nivel um (\$), por fluxo de dados (§) é representada como mostra a figura 4.16. A figura 4.17 refere-se a conexão do mesmo tipo no caso de funcionário.

c) Verifique se existem entradas mültiplas.

No caso de cliente e funcionário, por exemplo, isso não acontece. Já em pedido isso ocorre, pois um pedido necessita da entrada de cliente, que o coloca, e de funcionário, que verifica o estoque do produto a que o pedi do se refere.

d) Determine a seqüência que devem ser tratadas. 


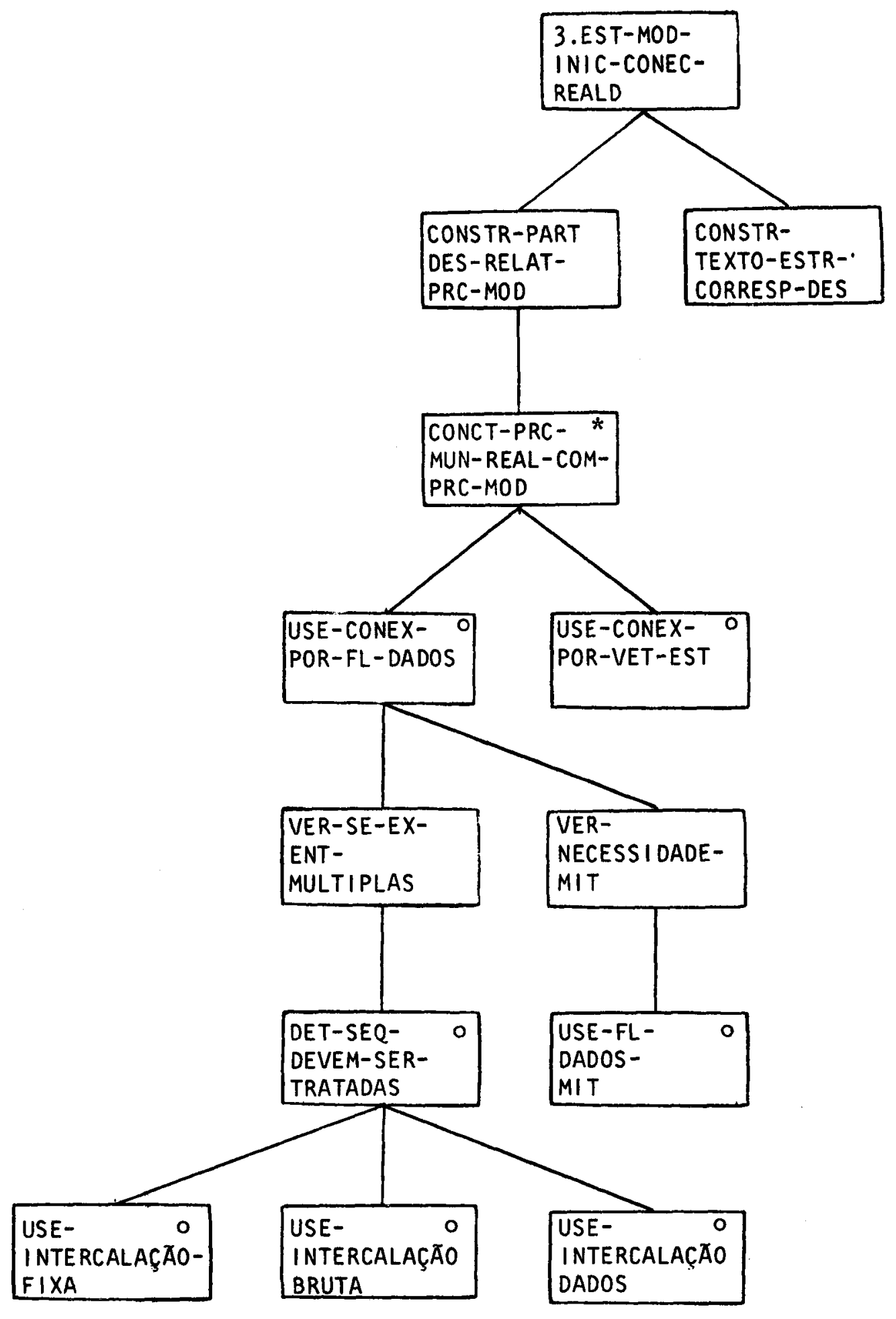

Diagrama de Estrutura do passo relativo ao modelo inicial Figura 4.11 


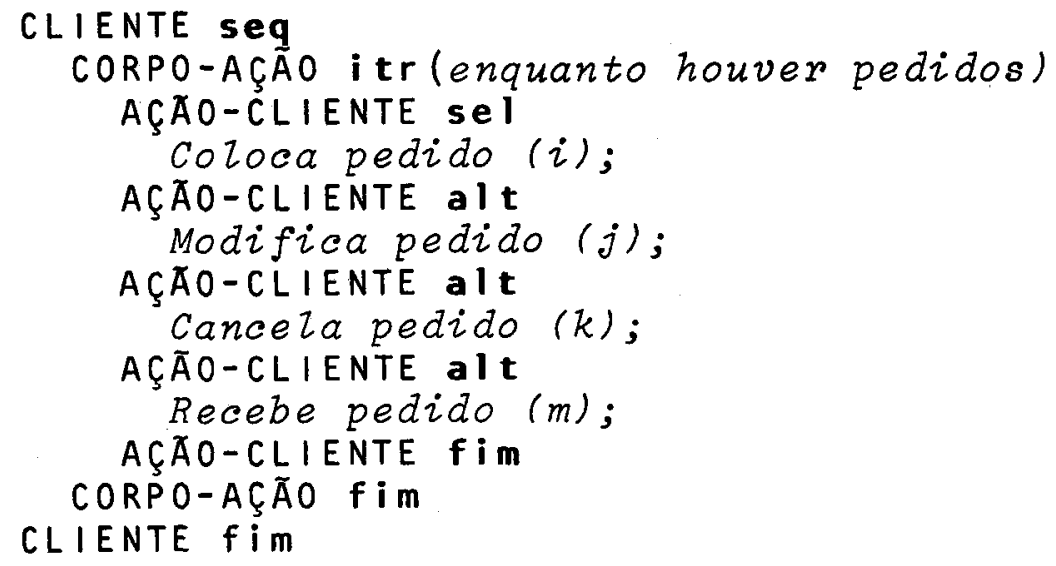

Texto Estruturado da entidade CLIENTE

Figura 4.12

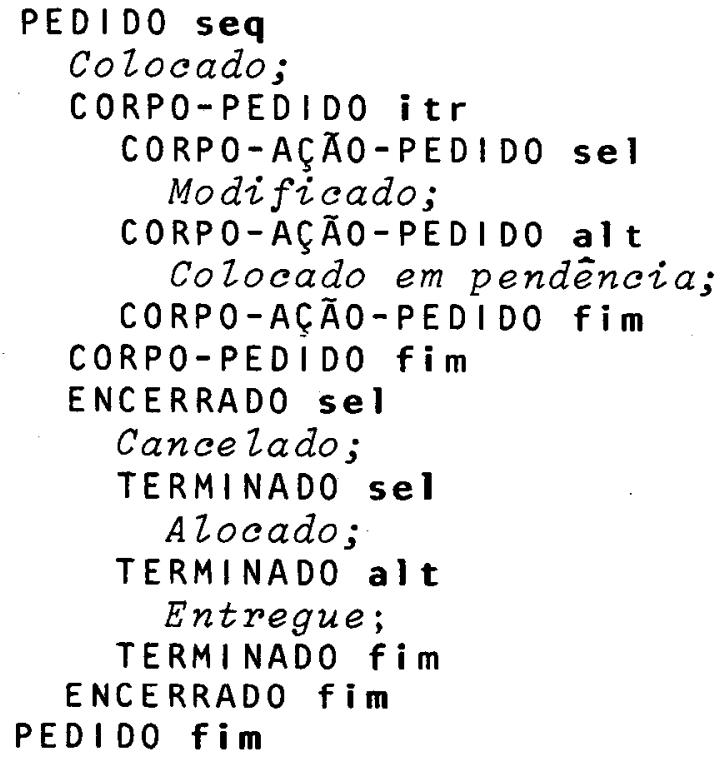




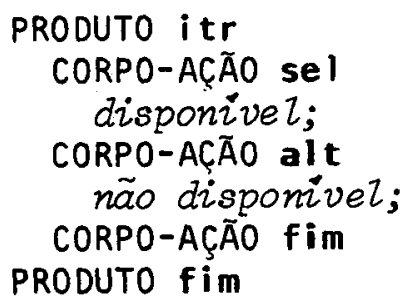

Texto Estruturado da entidade PRODUTO

Figura 4.14

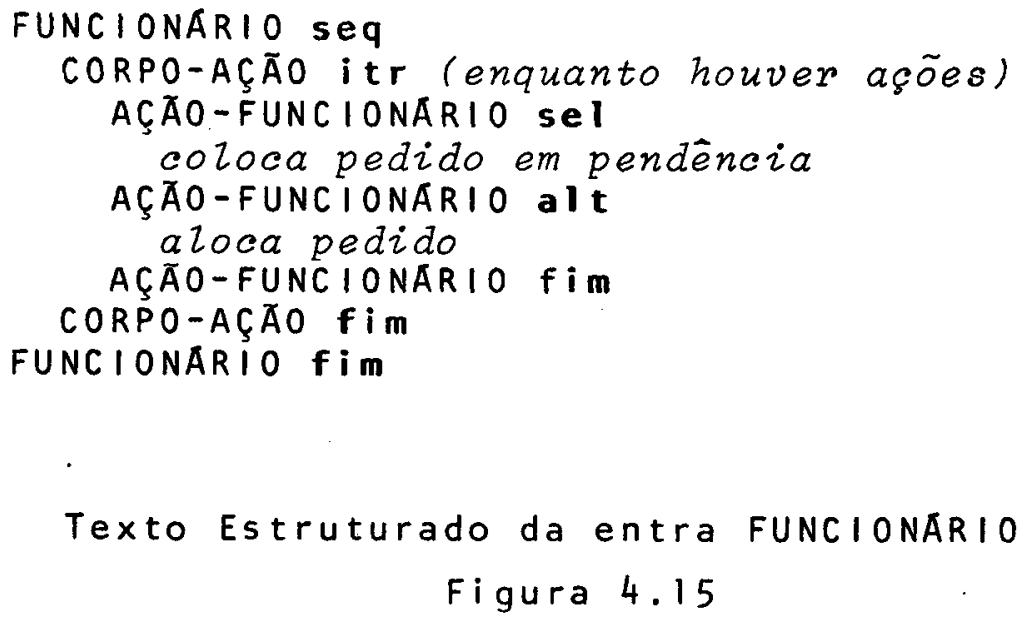



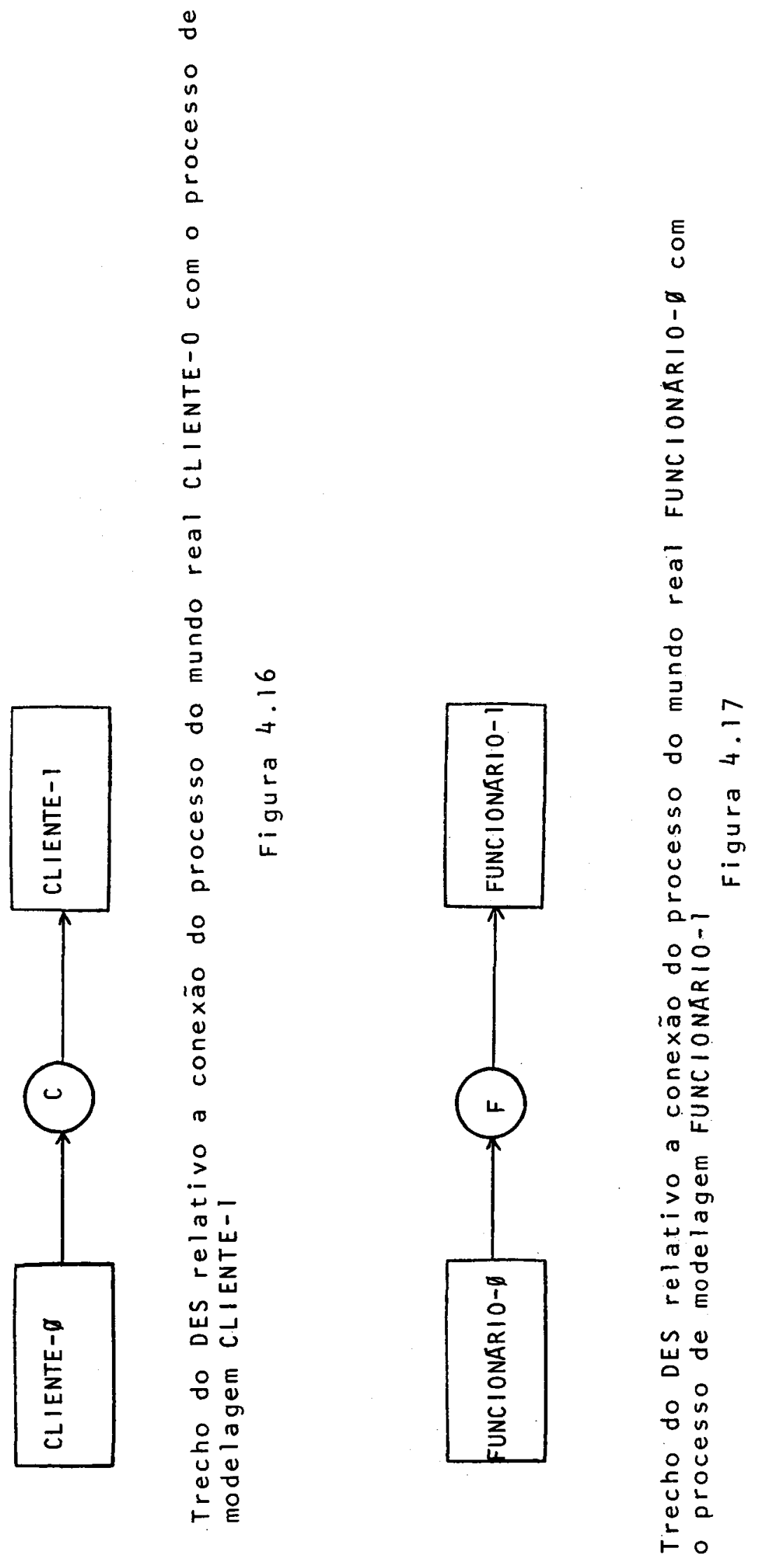
$d_{1}$ ) Use intercalação fixa (\$).

Esse tipo de seqüência não se aplica nesse caso por não haver regras fixas para intercalação dos fluxos que contém informações de cliente, IPC, e do fluxo que contēm informações de funcionārio, IPF, figura 4.18 .

$d_{2}$ ) Use intercalação bruta ( $\$$ ).

E o que se aplica nesse caso, pois os fluxos são in tercalados de acordo com a ordem pela qual os registros se tornam disponiveis. Existem diversos pedidos que o funcionário pesquisa quanto ao estoque, por í so as barras duplas nos fluxos de IPC e IPF na figura 4.18. No Apêndice são detalhados os tipos de cone xão que existem entre os processos.

Com a entidade produto deve-se usar conexão por vetor de estado $(\$)$, pois é necessário fazer uma consulta direta no registro de produto para saber o seu estoque disponível. Isso é feito com a operação getsv (\$): tome vetor de estado, e é representado no DES como o mostrado na figura 4.19.

e) Verifique se é necessário usar marcadores de intervalo de tempo $(\$)$ : MIT.

Não há necessidade no caso em estudo. Os marcadores de intervalo de tempo são usados para disparar o iní cio de alguma atividade.

Para que esse passo 3 seja completado, deve-se cons truir o texto estruturado $(\$)$ correspodente ao DES.

Esse texto é produzido com base no diagrama de estrutura e no diagrama de especificação do sistema. o diagrama de estrutura do processo de modelagem apoia-se no diagrama de estrutura do processo do mundo real. Para cliente, figura 4.16 e figura 4.05 correspondentes ao DES e ao diagrama de estrutura, respectivamente, nota-se que o processo de modelagem (\$) cliente-1 é alimentado por cliente-0, logo ocorre uma leitura (\$) do fluxo de dados C. Com base nas figuras 4.05 e 4.16 , têm-se as a 


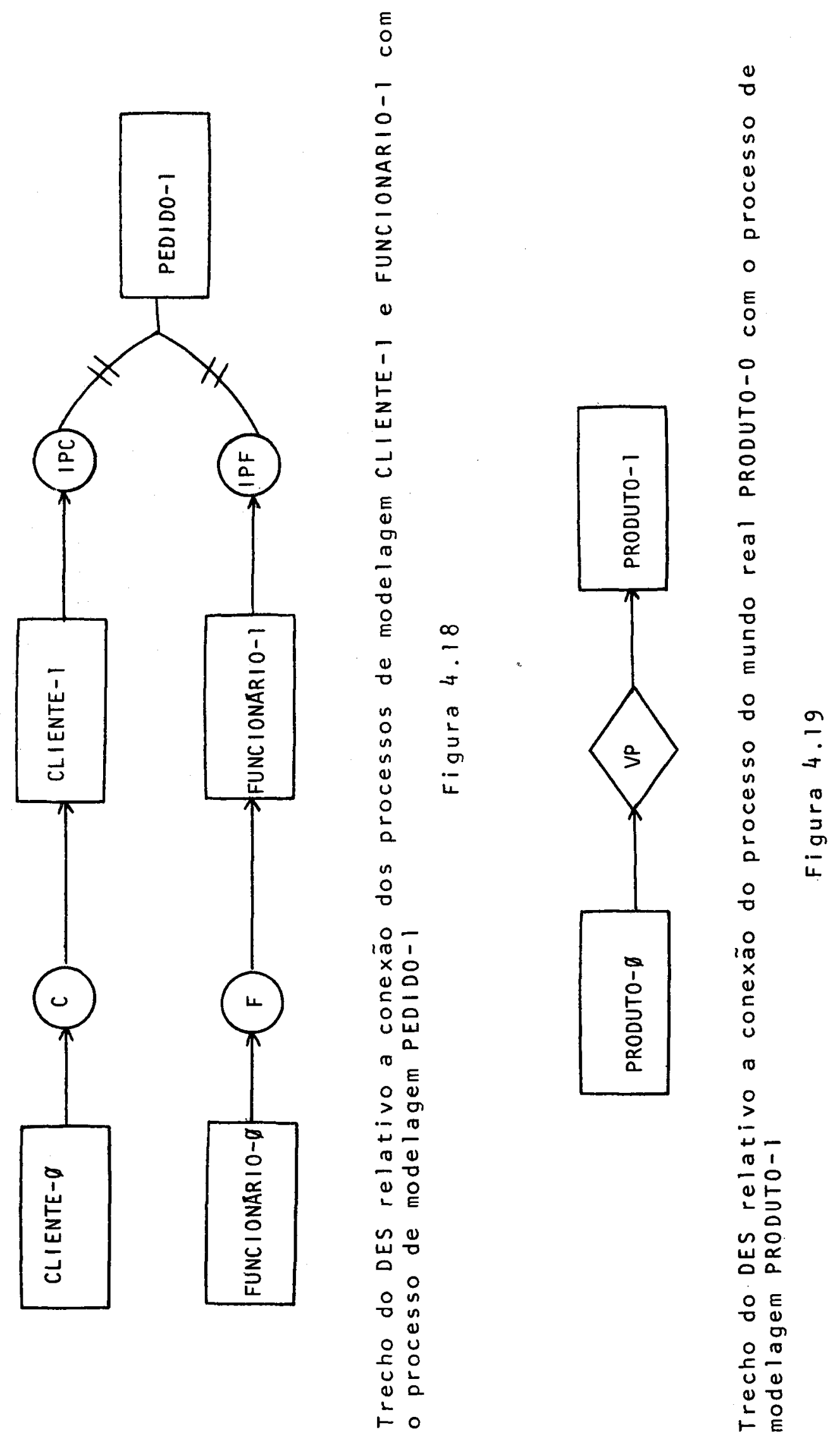




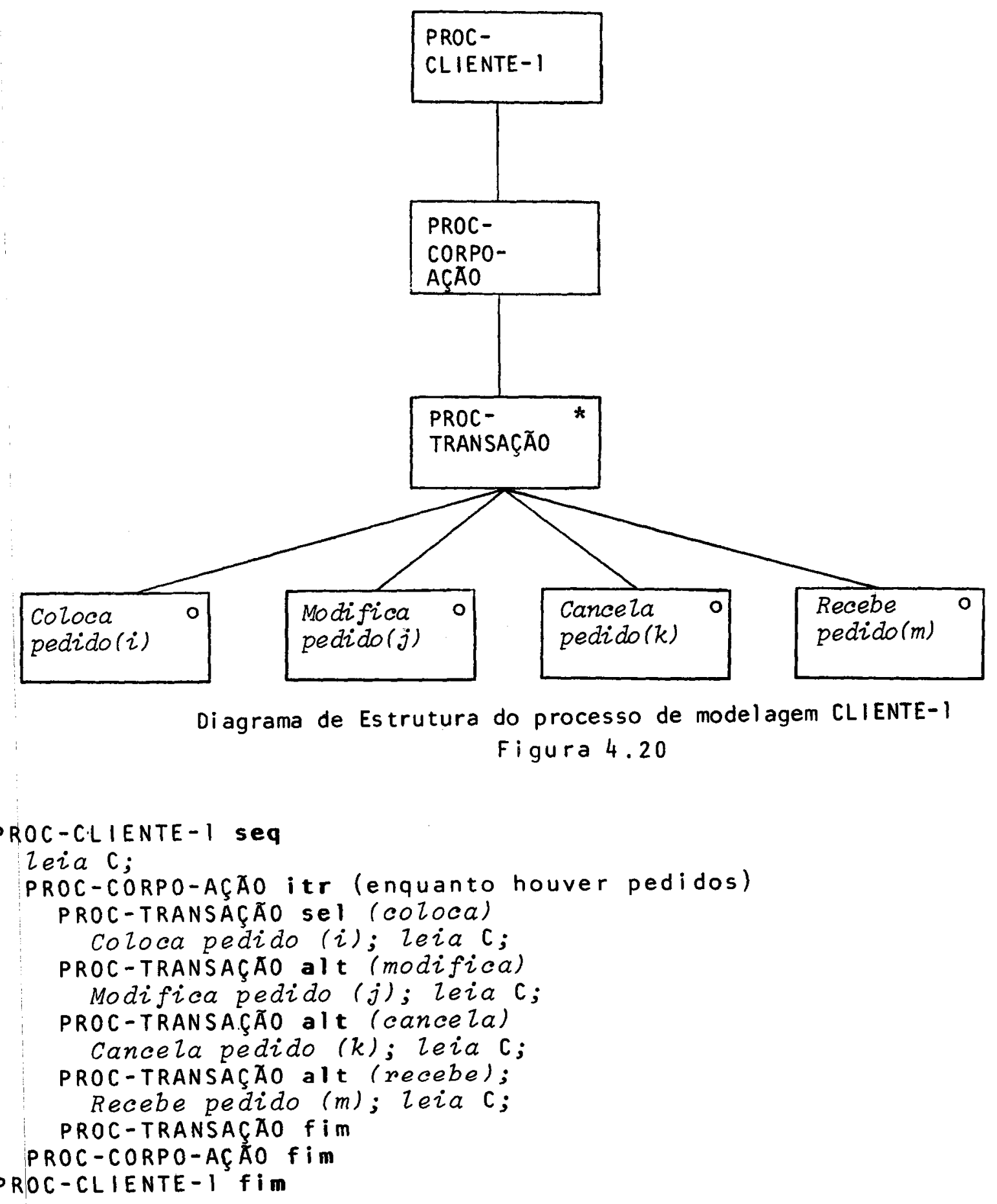

Texto Estruturado do processo de modelagem CLIENTE-1

Figura 4.21 
ções que serão realizadas pelo cliente. Após cada ação, realiza-se uma nova leitura do fluxo de dados $C$ para saber qual a ação a ser tomada.

0 diagrama de estrutura e o texto estruturado de cliente-1 são mostrados nas figuras 4.20 e 4.21 , respectivamente.

Supondo que o sistema seja automatizado, as funções do funcionário serão realizadas pelo pröprio sistema e os processos de modelagem conectados ao mundo real ficam como se mostra na figura 4.22 .

0 diagrama de estrutura, figura 4.23, é elaborado a poiando-se na figura 4.06. 0 texto estruturado, figura 4.24 , é elaborado com base nas figuras 4.13 e 4.22 .

Para produto, com base na figura 4.10 tem-se o diagrama de estrutura, figura 4.25. 0 texto estruturado, figura 4.26, é elaborado com base nas figuras 4.14 e 4.19 . 


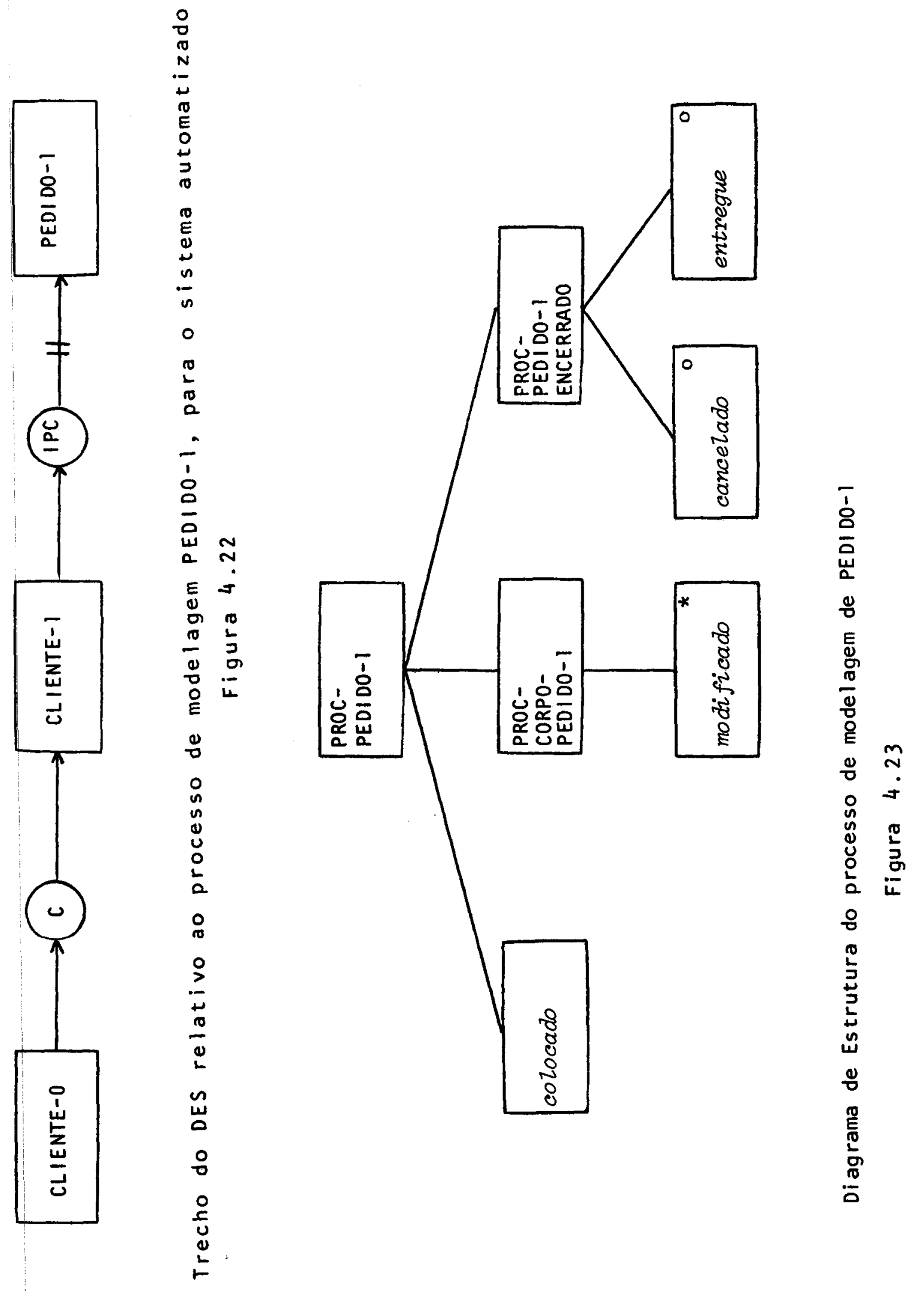



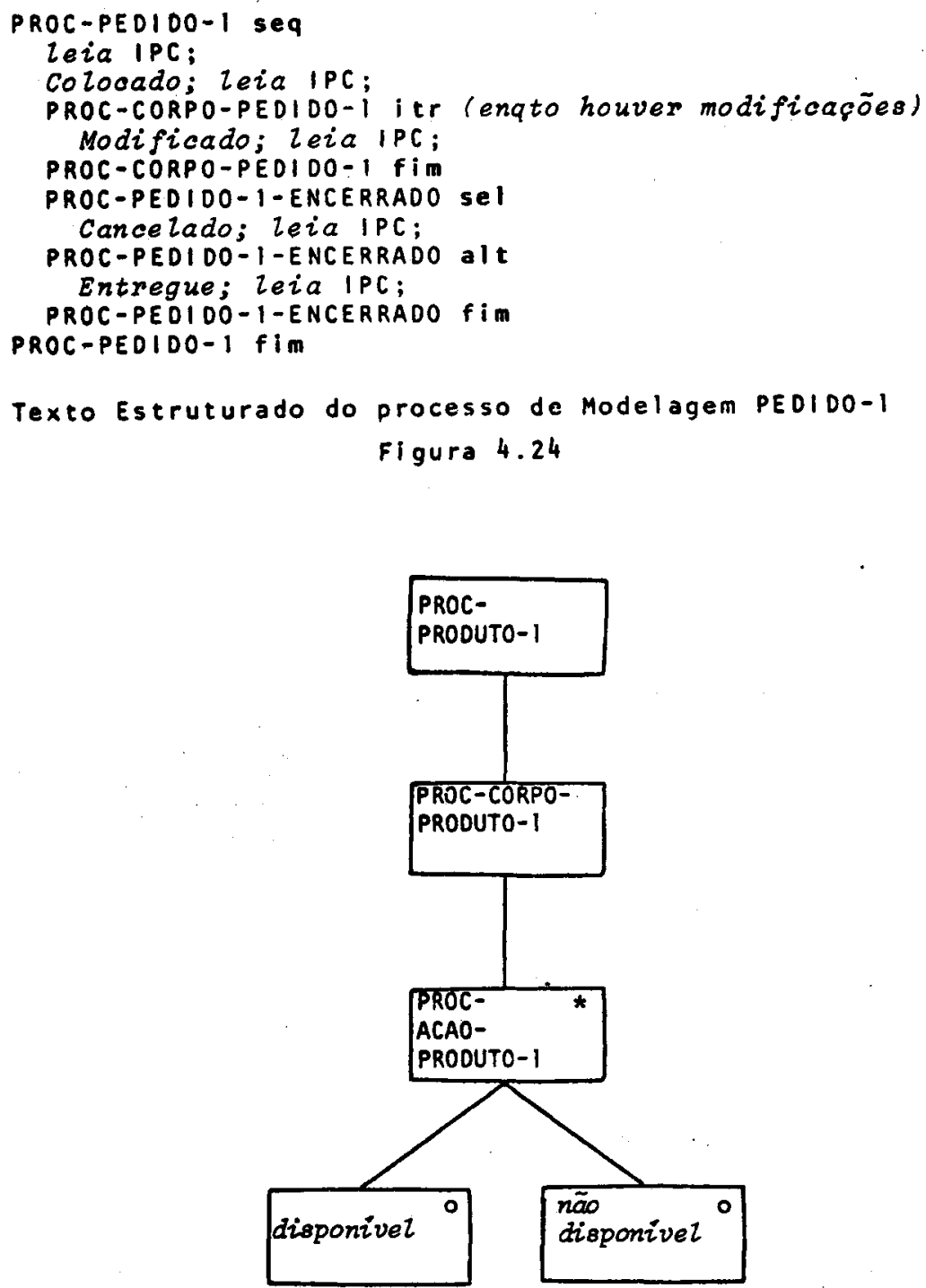

Diagrama de Estrutura do processo de modelagem PROOUTO-1

Figura 4.25

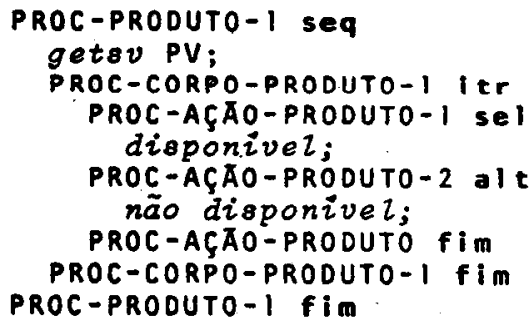

Texto Estruturado do processo de modelagem PRODUTO-I

Fi gura 4.26 
4.6. - Passo Relativo à Especificação das Funções

Nesse passo faz-se a especificação das funções para se obter as saidas desejadas. O diagrama de estrutura correspon dente a ele é mostrado na figura 4.27 e o texto estruturado no Apiêndice.

Aqui é completado o DES, adicionando-se os processos funcionais correspondentes às funções especificadas. Depois do DES estar completo, constrói-se o texto estruturado correspondente.

No exemplo em questão, deve ser especificada uma função para automatizar a alocação de estoque para os pedidos, que era antes realizada pelo funcionário.

Esse processo funcional recebe o nome de ALOCA e a gumas questões surgem quanto a suas reais funções, como por exemplo:

- quantos processos ALOCA são necessārios?

- como ALOCA é conectado com os processos PEDIDO, PRODUTO e CLIENTE ?

- o que faz, exatamente, ALOCA?

- quando ALOCA deve ser usado?

Respondidas essas indagações atravēs de contato com o usuário, conclui-se que:

a) Sob o ponto de vista da alocação não há troca de produtos, ou seja, um pedido de flanges só será atendido com flanges e nunca com olhais, por exemplo.

b) Se um pedido está pendente, ele deve ter prioridade na pröxi ma alocação, a fim de reduzir a probabilidade de ele continuar pendente.

c) A prioridade de um pedido não é afetada pelo que acontece com outros pedidos colocados pelo mesmo cliente.

d) A alocação é executada diariamente, depois de ter sido completada a atualização do arquivo de estoque pelo sistema que controla a compra e o recebimento de mercadorias para estoca gem. 


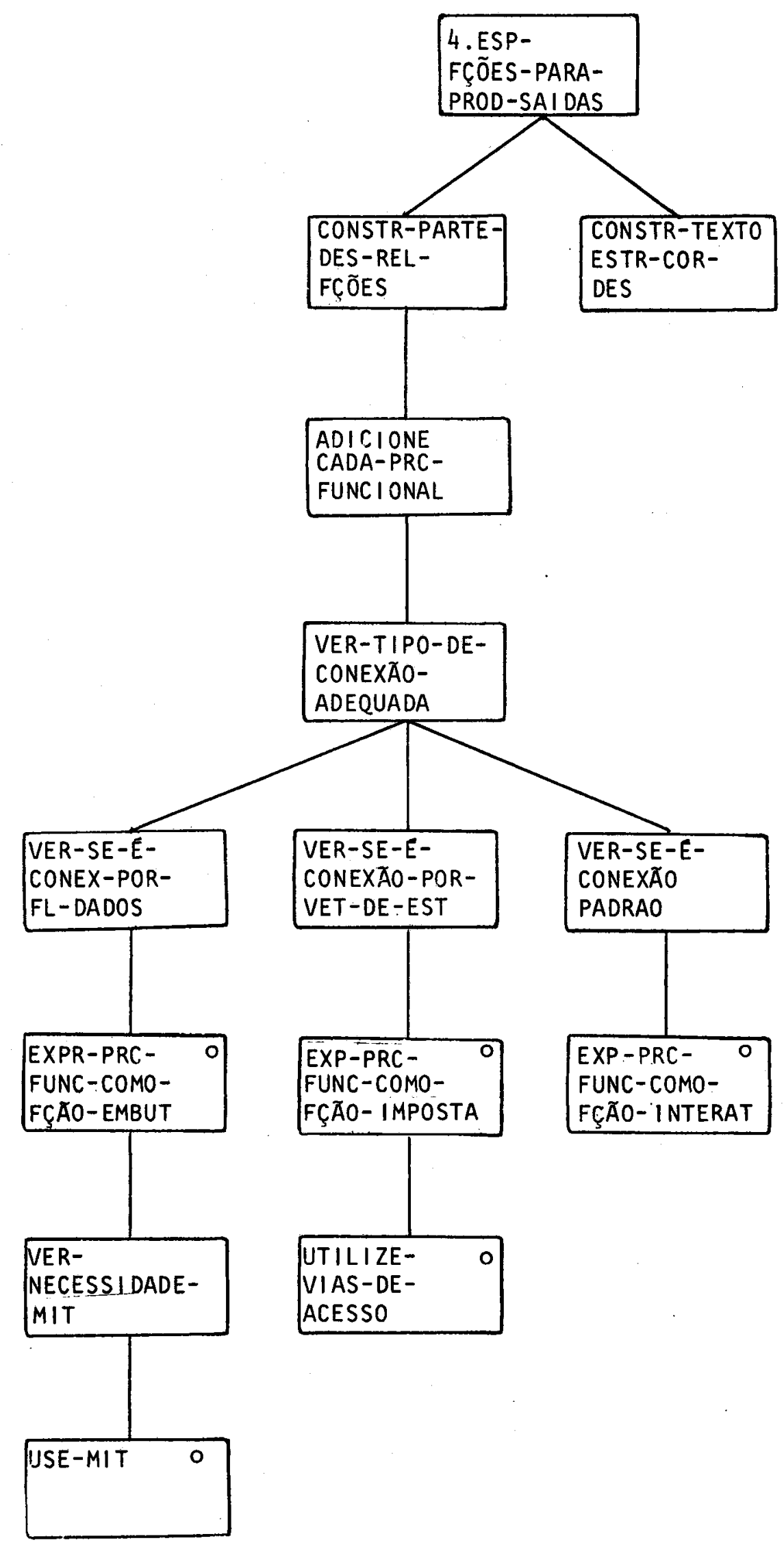

Diagrama de Estrutura do passo relativo a especificação das funções Figura 4.27 
Necessita-se de um processo ALOCA para cada produto de acordo com a figura 4.27 deve-se verificar:

1. a) o tipo de conexão adequado.

$\left.a_{1}\right)$ Verifique se é conexão por fluxo de dados. A conexão de ALOCA com PRODUTO-l não è por fluxo de dados, pois deseja-se a quantidade disponivel do pro duto num determinado instante.

$a_{2}$ ) Verifique se é conexão por vetor de estado.

Esse é o tipo que se aplica para a conexão de ALOCA com PRODUTO-1, como foi dito em a,. Essa conexäo é mostrada na figura 4.28 .

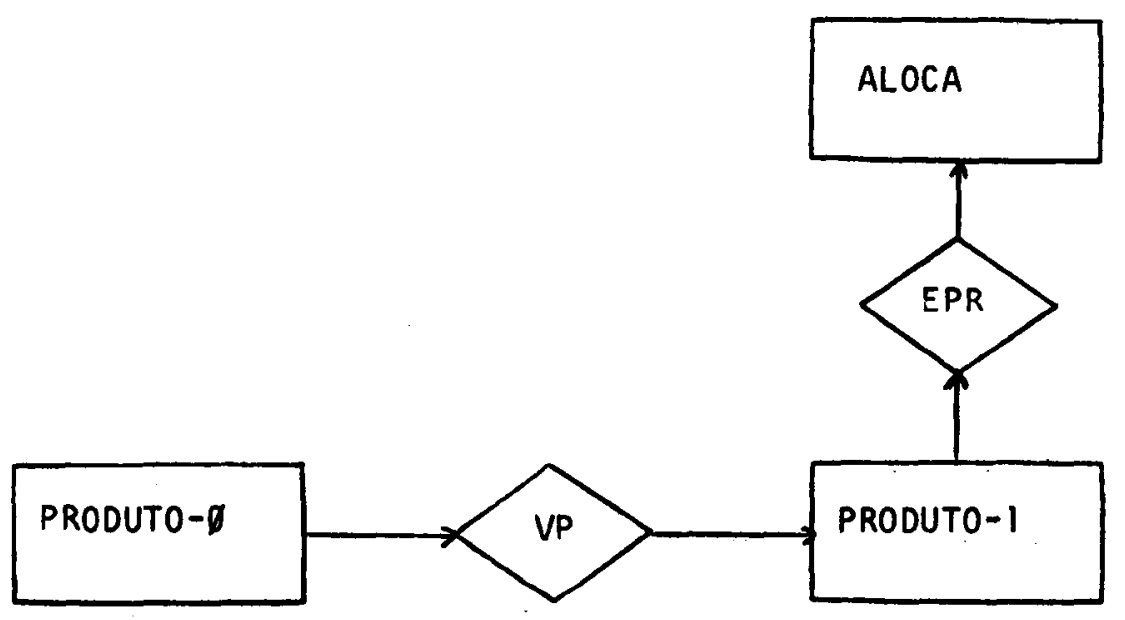

Trecho do DES relativo à conexão do processo funcional ALOCA com o processo de modelagam PRODUTO-1.

Figura 4.28 


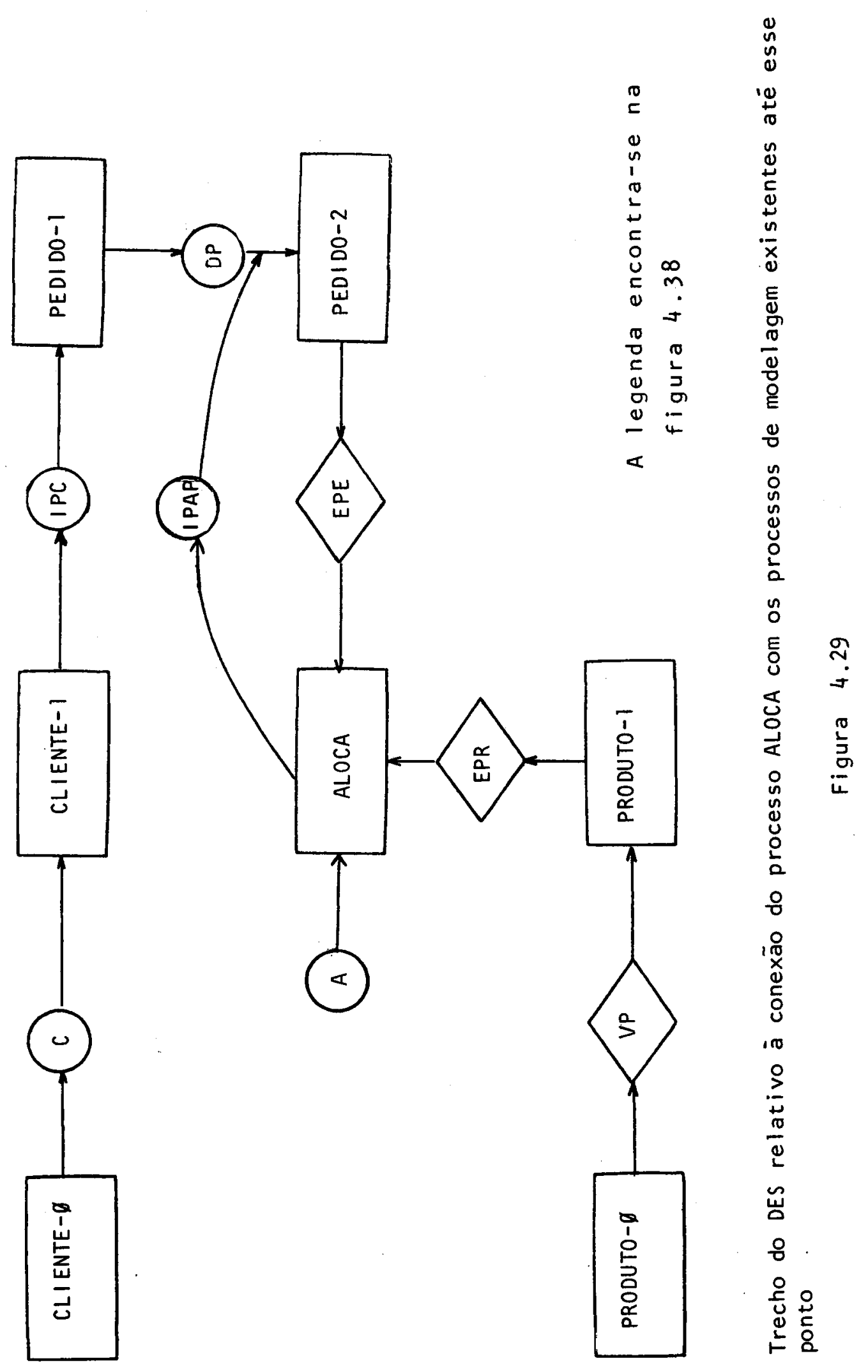


b) Expresse o processo funcional como função imposta $(\S)$.

o processo funcional ALOCA capta os dados do modelo pela inspeção direta dos vetores de estado do processo de modelagem PRODUTO-1, razão porque constitui uma função imposta.

c) Utilize vias de acesso.

Para que os pedidos pendentes e alocados sejam obtidos há necessidade da conexão de ALOCA com PEDIPO-2.

A figura 4.29 mostra a parte do DES relativa a cone xão de ALOCA com os processos jä definidos até esse ponto. 0 fluxo A assinala um pedido de alocação para um produto que é ma nipulado por ALOCA. O fluxo IPAP contém os registros dos pedi dos pendentes e alocados e é intercalado, por intercalação bruta, com DP.

o DES dessa parte é mostrado na figura 4.29.

Quando $A$ é lido, ALOCA obtēm o vetor de estado de PRODUTO-1, EPR, para saber qual o estoque disponível desse produto para alocação. Ele obtém depois, pela operação getsv, o ve tor de estado de cada PEDIDO-2, figuras 4.30 e 4.31 , relativo ao produto que está pronto para alocação: primeiro, o vetor de estado dos pedidos pendentes e depois, dos outros pedidos. Defi ne-se vias de acesso para PEDIDO-2, a fim de determinar a ordem de acesso ao vetor de estado. O diagrama de estrutura correspon dente ao processo ALOCA é mostrado na figura 4.32 e o texto estruturado correspondente é mostrado na figura 4.33 .

E necessārio adicionar o processo de modelagem PRO DUTO-2, figuras 4.34 e 4.35 e conectälo com o processo funcional ALOCA, ao invés de deixä-lo conectado a PRODUTO-l para saber a quantidade de estoque disponível para alocação. Isso porque PRODUTO-l fornece o estoque inicial disponível e poderia ocorrer o atendimento de um pedido, sem que realmente existisse estoque suficiente, pois outras alocações poderiam ter sido fei tas anteriormente sem que o estoque inicial fosse atualizado nesse intervalo de tempo. Assim, o fluxo de dados QPE sofre intercalação bruta com QA, figura 4.38 , que indica para PRODUTO-2 qual a quantidade já alocada desse produto; enquanto que o flu- 


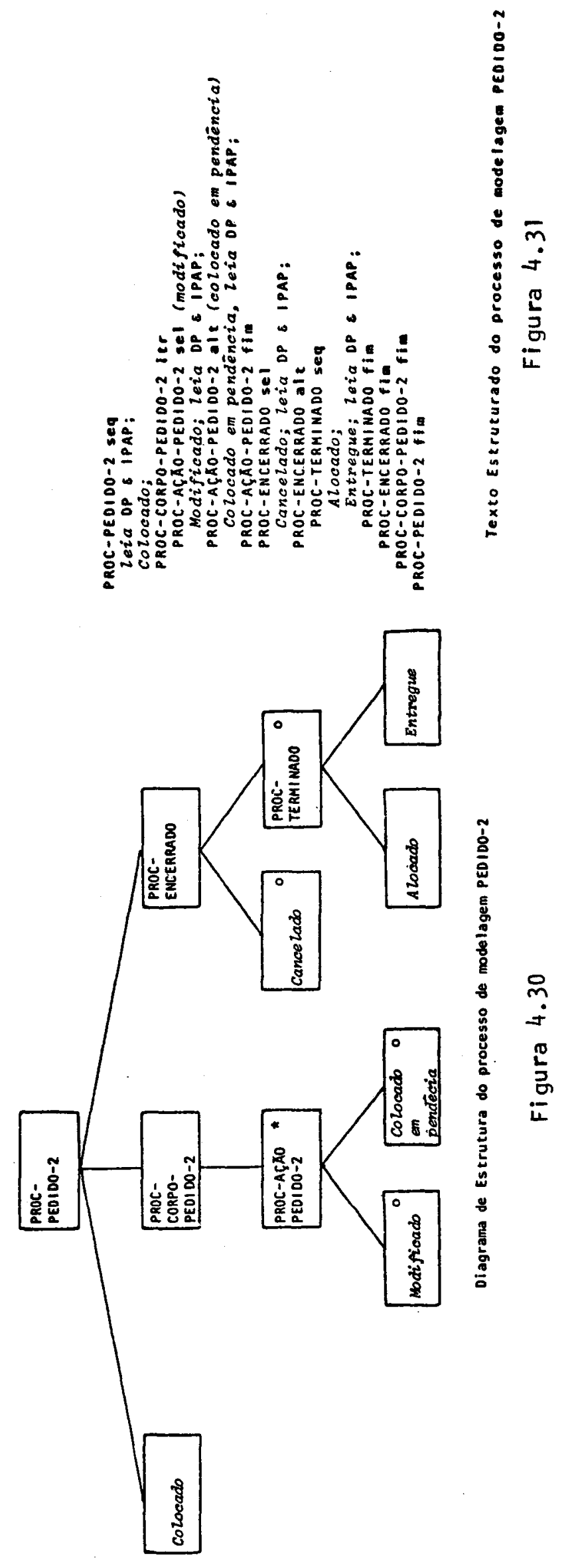




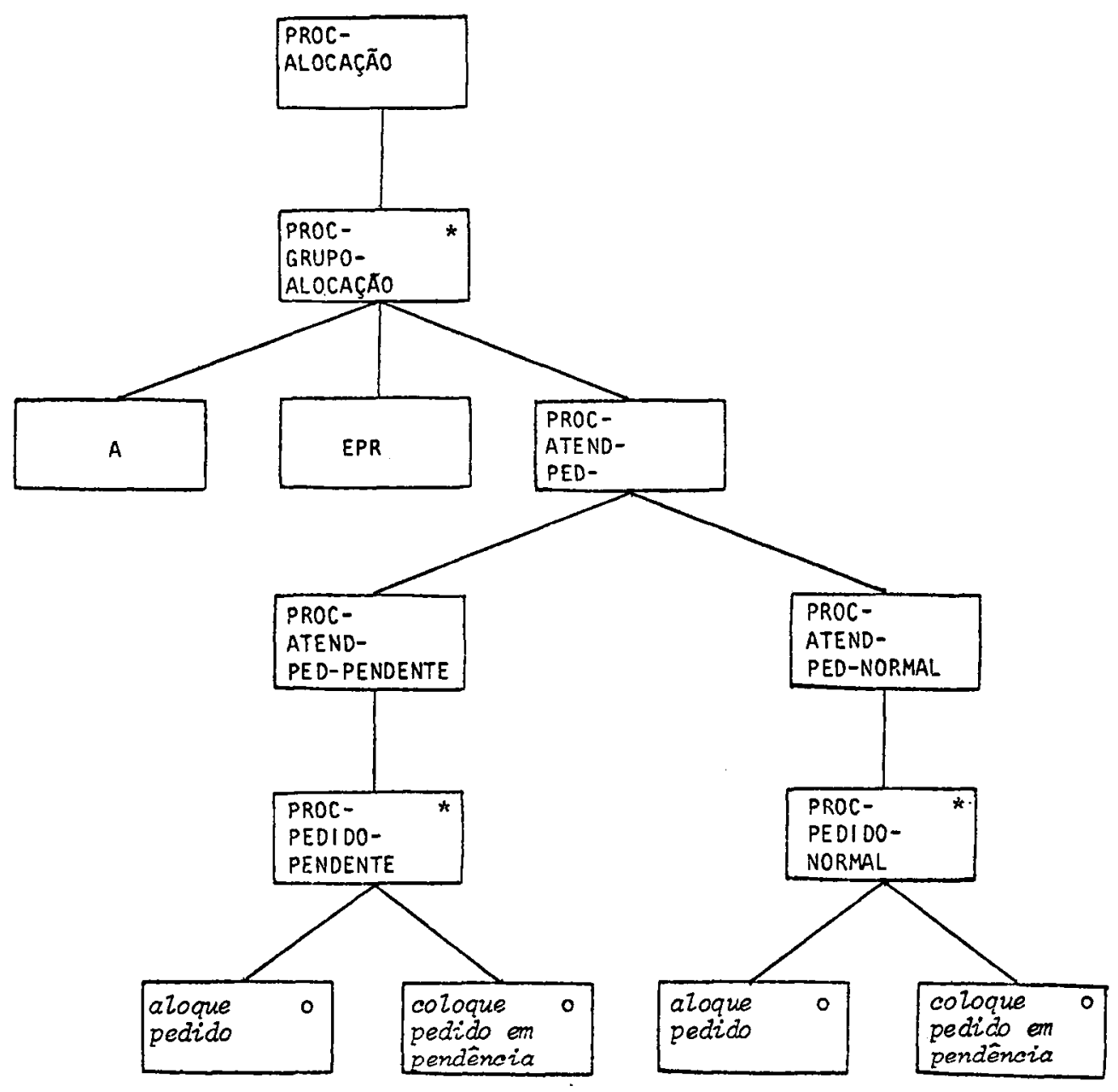

Diagrama de Estrutura do processo funcional ALOCA

Figura 4.32 


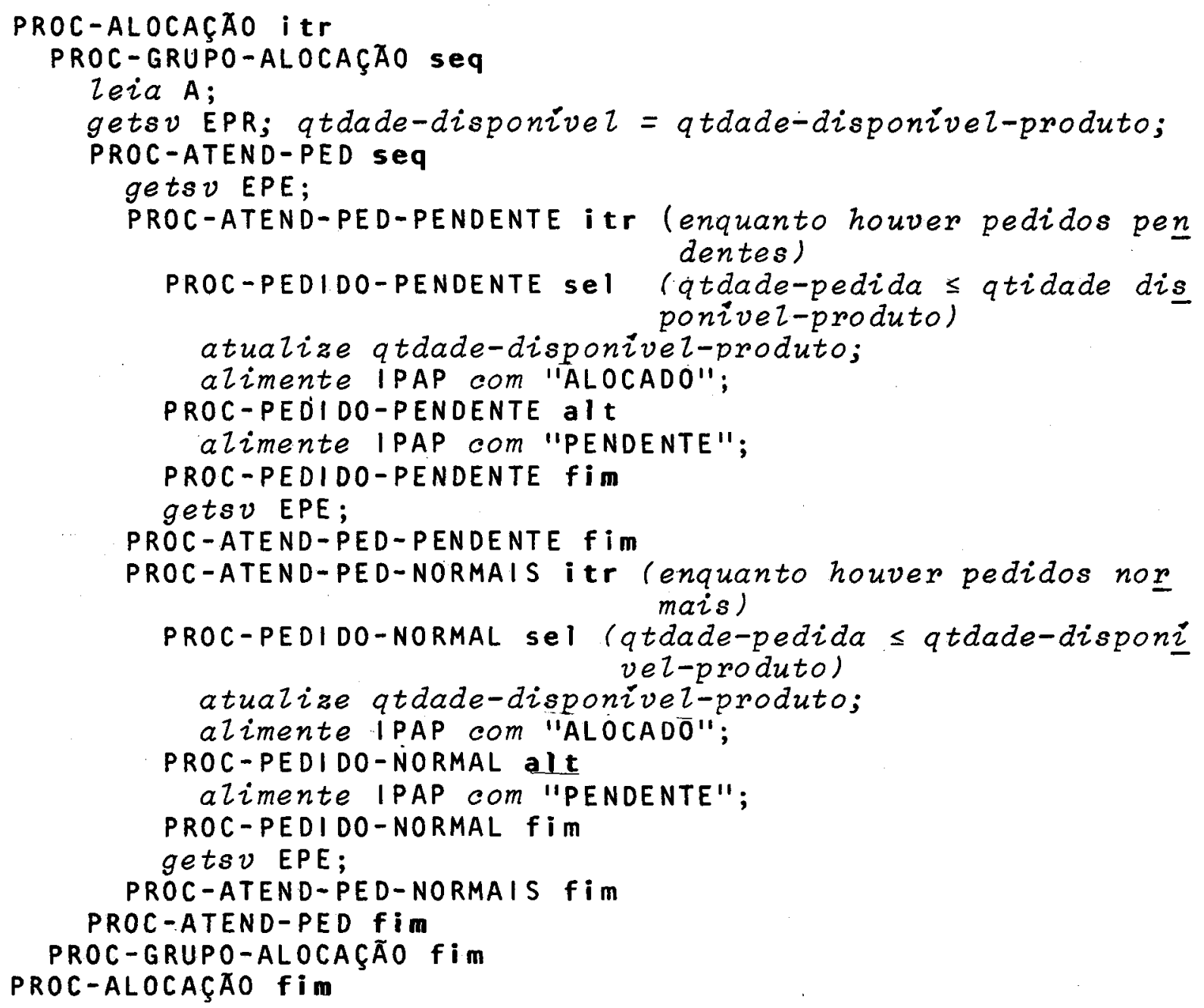

Texto Estruturado do processo funcional ALOCA

Figura 4.33 


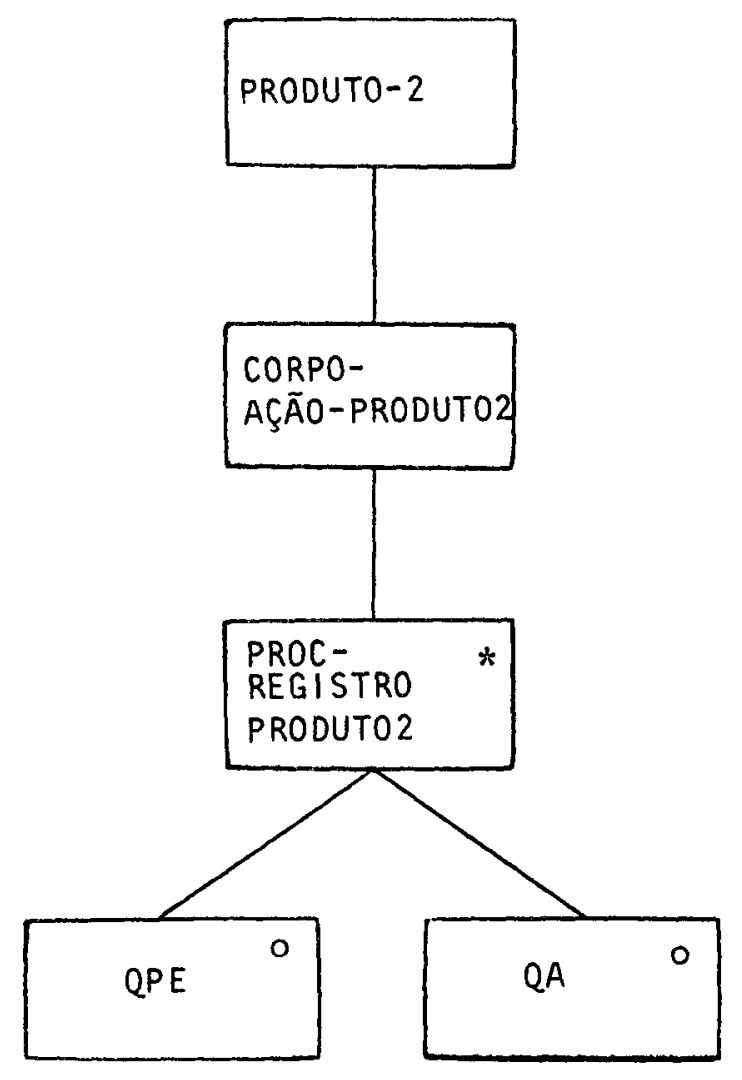

Diagrama de Estrutura do processo de modelagem PRODUTO-2 para atender às necessidade funcionais

Figura 4.34

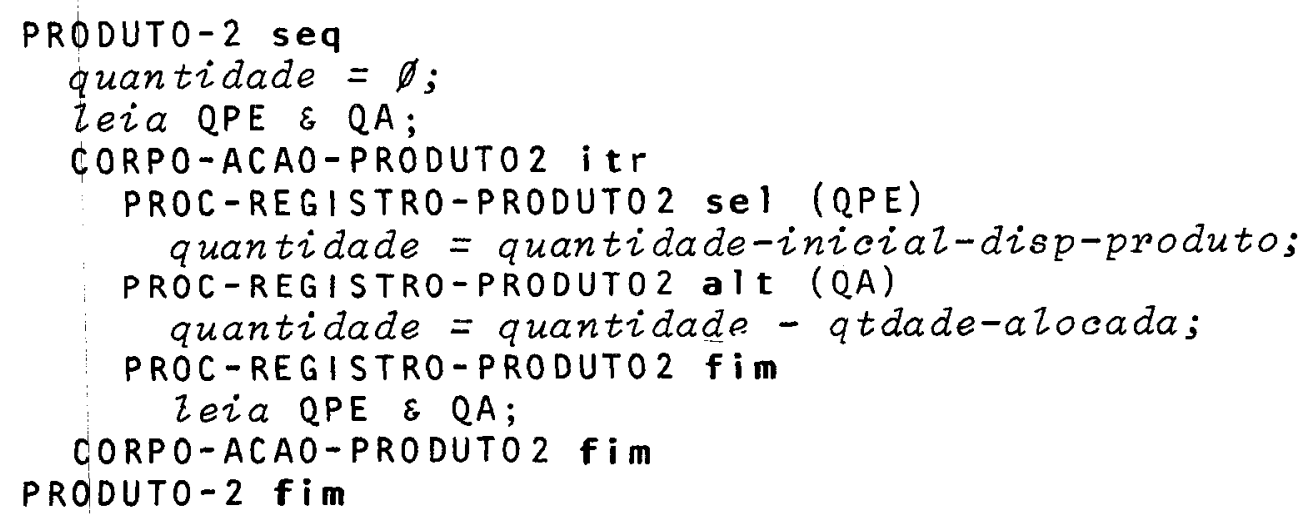

Texto Estruturado do processo de modelagem PRODUTO-2

Figura 4.35 
xo QPE indica a quantidade disponivel em estoque do produto. Atravēs da inspeção que ALOCA faz no vetor de estado, EPR, de PRODUTO-2, é possível obter a quantidade disponivel para alocação desse produto.

Outra saída desejada, no exemplo em estudo, é resposta a consultas sobre pedidos. Assim, hä necessidade de um processo funcional CONSULTA. Esse processo inspeciona o vetor de estado de PEDIDO-2 para saber qual o estado de um determinado pedido. O diagrama de estrutura relativo ao processo funcional CONSULTA é mostrado na figura 4.36 e o texto estruturado na figura 4.37 .

Um relatörio com os pedidos pendentes e alocados tambēm se faz necessärio, criando-se assim o processo funcional LISTA. Esse processo necessita de um marcador de intervalo de tempo, que sofre intercalação bruta com IRL, como pode ser visto na figura 4.38. o diagrama de estrutura do processo funcional LISTA é mostrado na figura 4.39 e o texto estruturado na fi gura 4.40 .

O DES completo, com os processos funcionais e os processos de modelagem, a ser utilizado no passo de implementação é o mostrado na figura 4.38 . 


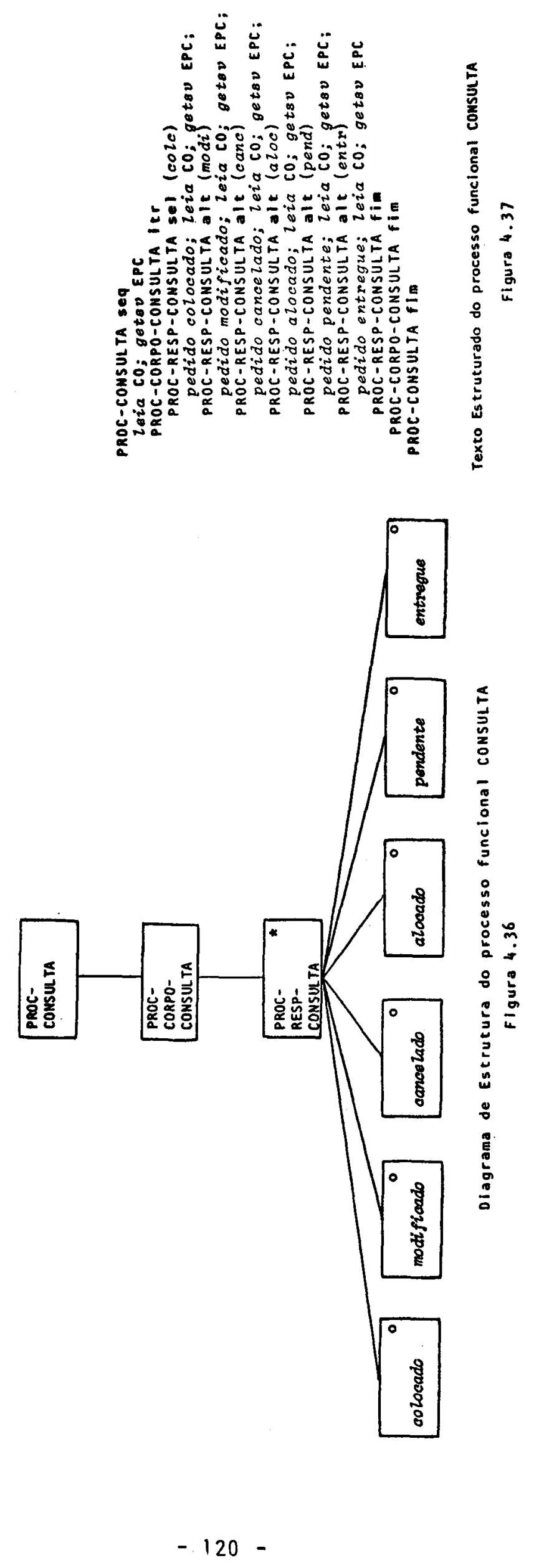



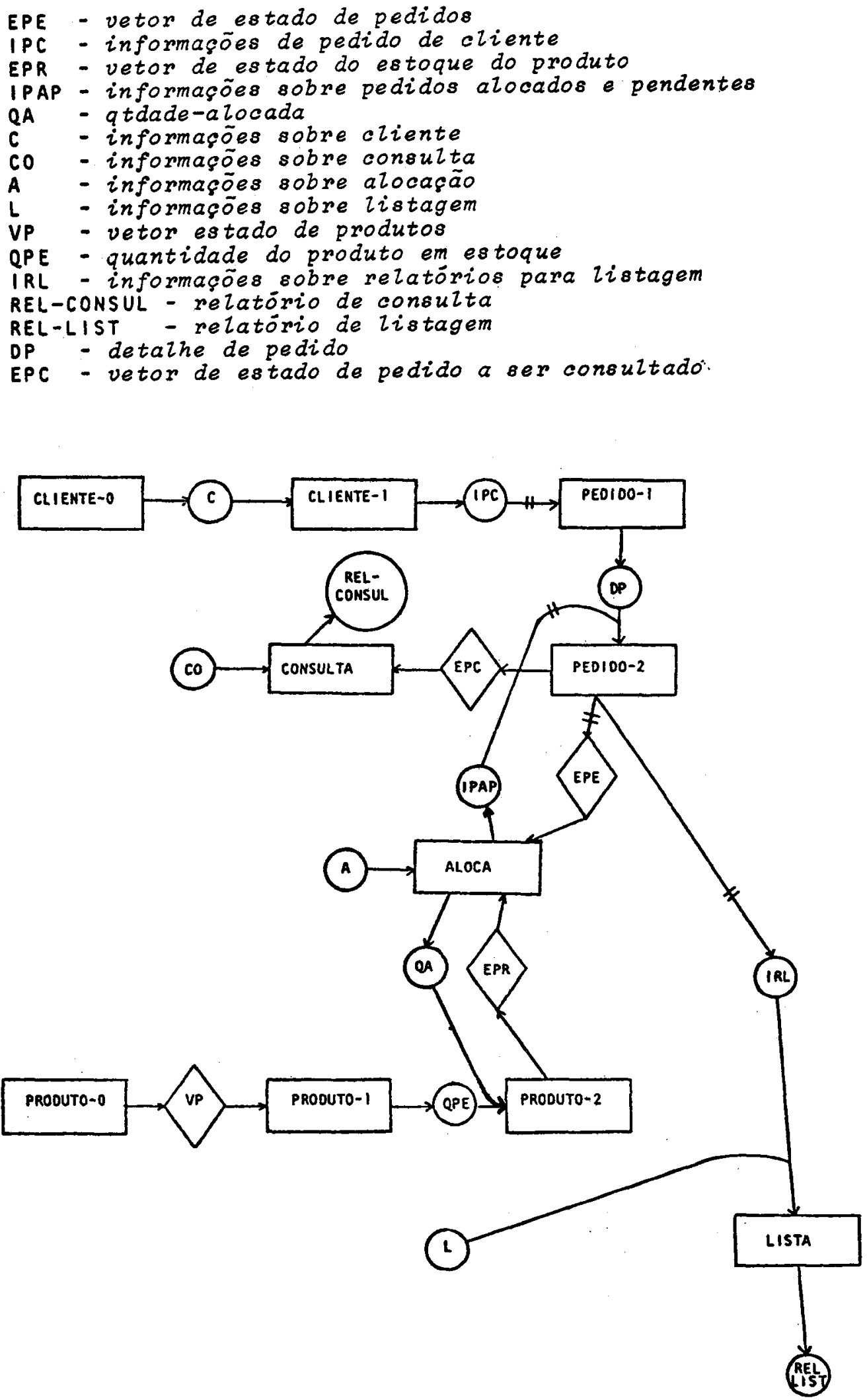

DES relativo ao sistema de atendimento de pedidos

Figura 4.38 


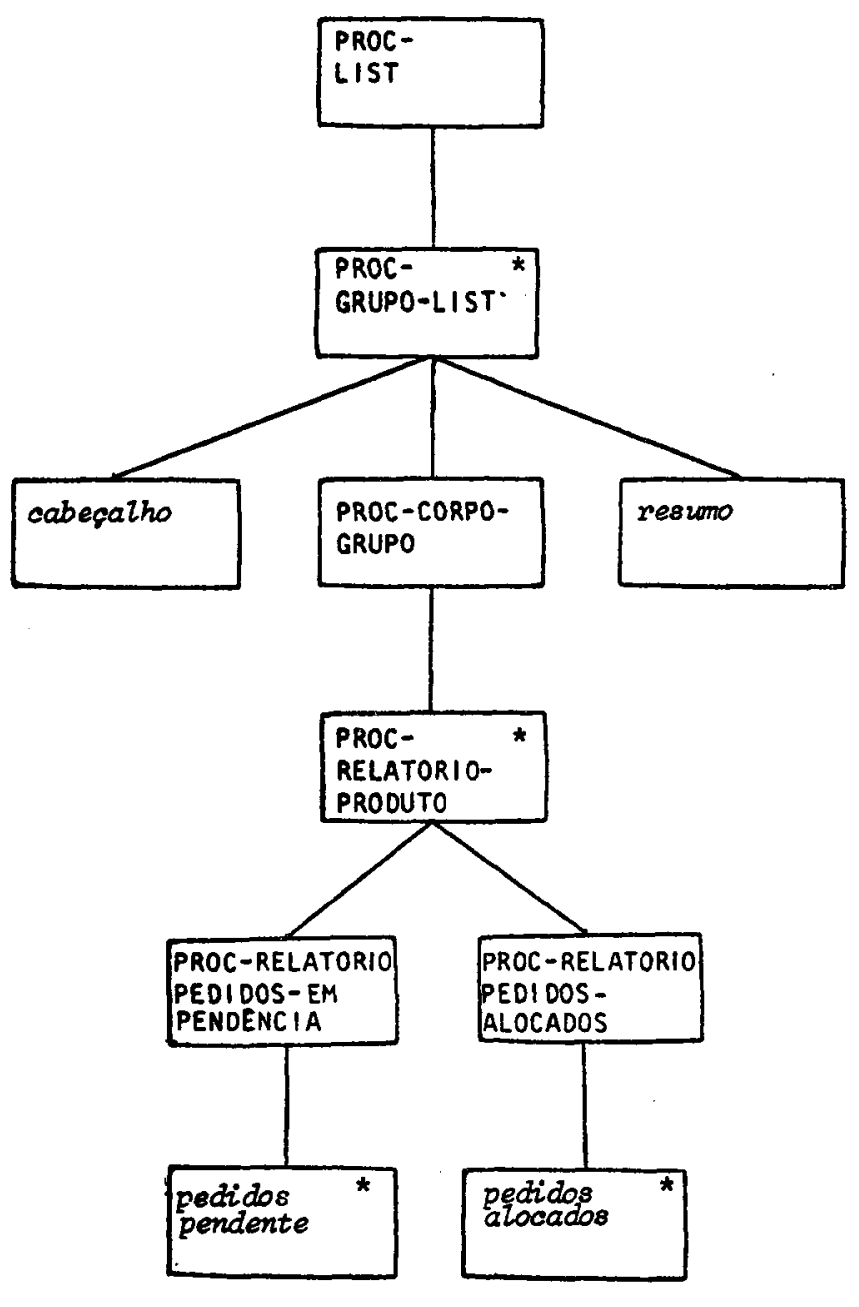

Diagrama de Estrutura do processo funcional LISTA

Figura 4.39

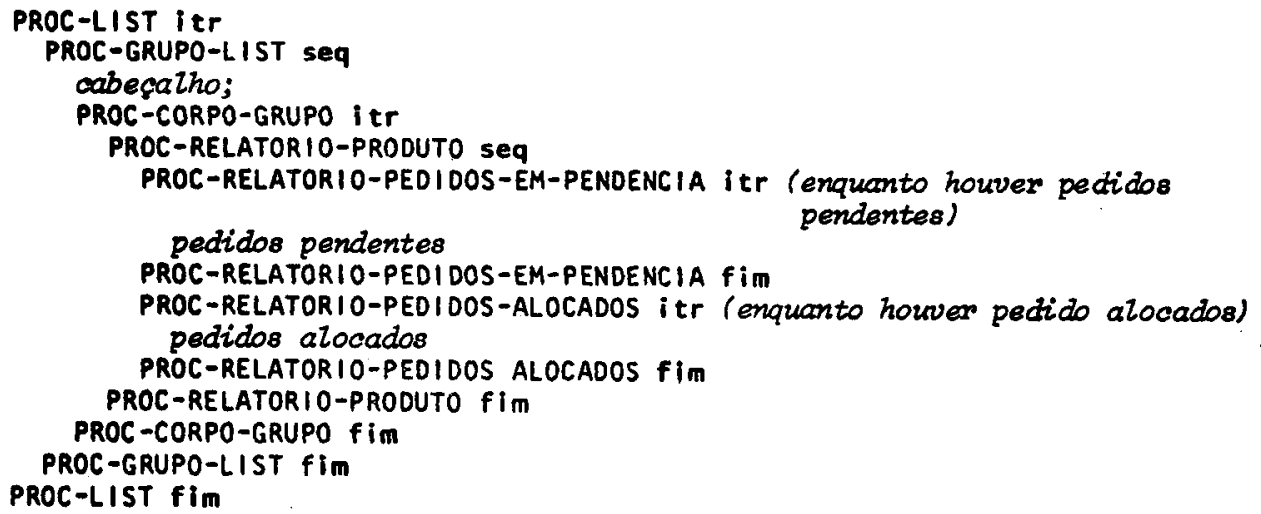

Texto Estruturado do processo funcional LISTA

Fiqura 4.40 
4.7. - Passo Relativo à Articulação Cronológica das Funções com - Modelo

Nesse passo, deve-se verificar as restrições que ocorrem quanto à cronogramação para cada função, como mostra o diagrama de estrutura da figura 4.41 e o texto estruturado que è encontrado no Apêndice.

a) Toda vez que a saída de um processo sofrer intercalação bruta com o fluxo de dados de entrada de outro processo, devese cuidar da sincronização dos processos. Esse caso ocorre com o processo LISTA. Ele recebe como entrada o fluxo L e so fre intercalação bruta com o fluxo IRL, que é saída do processo PEDIDO-2. Como pode ser visto na figura 4.42, é necessärio que o processo PEDIDO-2 tenha sido completado quando ocorre essa intercalação.

b) Outro ponto a ser cuidado é a atualização dos processos de modelagem, quando seus vetores de estado são obtidos. No caso do problema-exemplo, o processo funcional CONSULTA inspeciona o vetor de estado EPE, de PEDIDO-2, para saber qual o estado de um determinado pedido. E necessário que esse vetor esteja sempre atualizado.

c) 0 processo PRODUTO- $\emptyset$ é conectado com o processo PRODUTO-I por vetor de estado, como pode ser visto na figura 4.38. Deve-se tomar cuidado para que a operação de consulta ao vetor de es tado seja realizada com uma frequência mínima, para que PRoDUT0-1 obtenha sempre a quantidade disponivel em estoque.

Ao terminar esse passo, completa-se a fase de especificação do sistema. Essa parte é utilizada para a subseqüente, que é referente à implementação, e será descrita no capitulo 5 . 


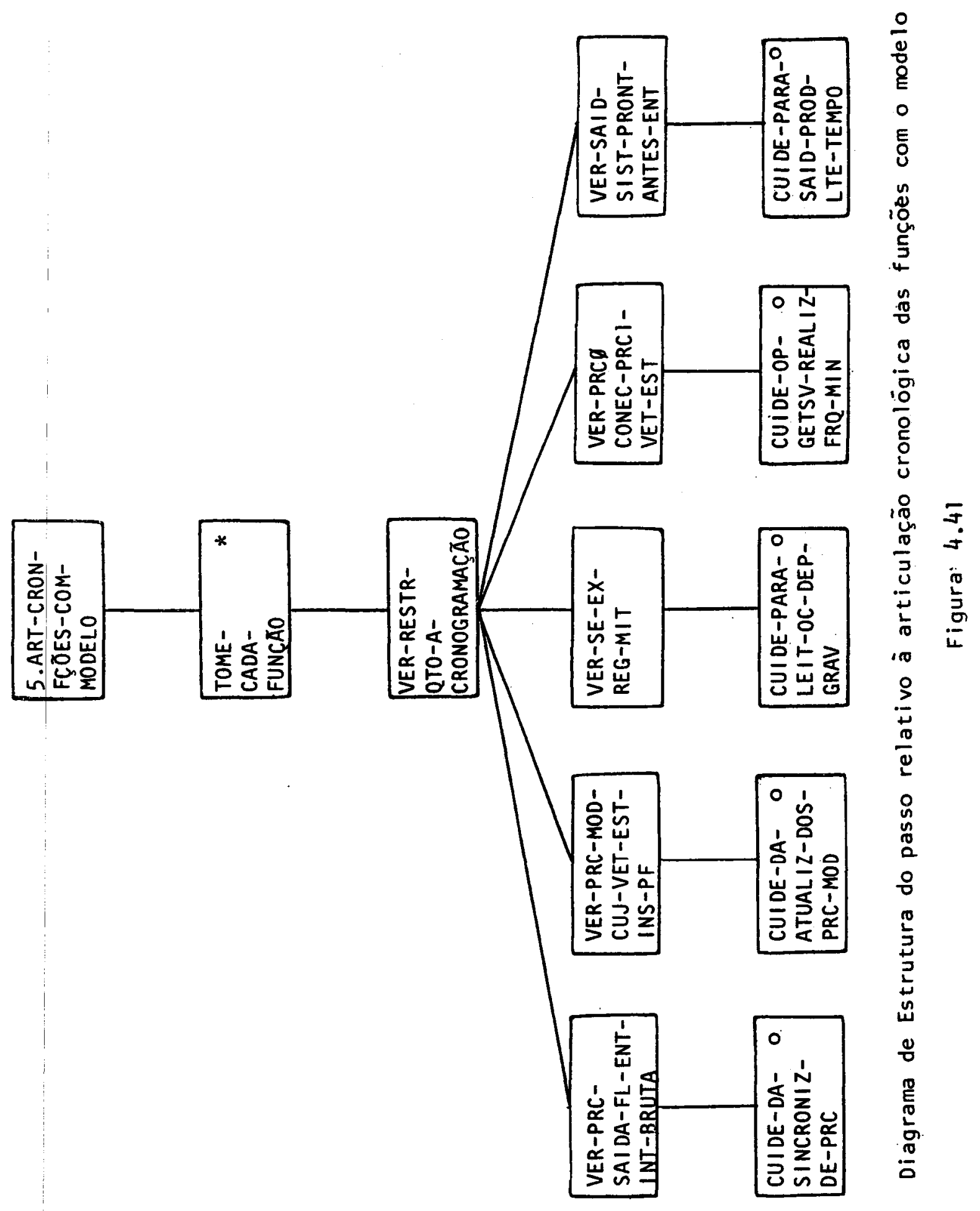


4.8. - Conclusões

0 método JSD, como diz o pröprio Jackson em [Ja81a], pode ser considerado uma extensão do método JSP, que foi objeto do capitulo 3 , dentro das àreas de anälise de sistemas, especificação, projeto e implementação, pois ele incorpora o conceito central de JSP da comunicação de processos seqüenciais, que ali mentam e são alimentados por fluxos de dados sequenciais. As e $\underline{s}$ truturas dos proçessos são determinadas pelas estruturas dos fluxos de dados. Cameron, em [Ca81], diz que o JSD não deve ser considerado só como uma extensão para suprir as fases de anälise e projeto de sistemas de informação, pelo fato do JSP estar voltado para a programação. Ele é formado por seis passos distintos, sendo que os cinco primeiros referem-se à especificação do sistema, como foi visto neste capítulo, e o sexto passo refe re-se à implementação do sistema, como pode ser visto no capítú 105 .

o primeiro passo, que é referente à elaboração da lista de entidades e respectivas ações, não é tão simples como aparece nas ilustrações feitas por Jackson, em [Ja83]. A aplica ção do método em um problema prático apresenta algumas dificuldades. Jackson salienta, em [Ja83], que o maior perigo no passo 1 è chegar a conclusões sem um estudo adequado. Recomenda que a lista inicial seja extensa, podendo, entretanto, a lista resultante ser pequena e simples.

Não hã preocupação, nesse método, com os aspectos tradicionais de Análise de Sistemas, por exemplo, ele não especifica qual o melhor meio para obter as informações do usuário. A comunicação com o usuário, utilizando os recursos que o método oferece, não é fácill. o usuärio precisa ter conhecimento do método para que possa fornecer subsídios, a fim de que o sistema seja desenvolvido a contento. 0 usuärio sem conhecimento algum do método poderá até entender as partes do sistema já proje tadas, porém, é difícil que ele consiga dar informações para continuidade do projeto. Já o programador encontrará facilidade para a programação, utilizando-se dos textos estruturados 
que o analista lhe fornecer. Assim, os programas não devem omitir nenhum ponto vital ao sistema. Eventuais omissões podem ser detectadas observando-se o diagrama de estrutura e texto estruturado.

Alguns pontos desse método não foram citados por năo se aplicarem ao exemplo em estudo. Jackson, em [Ja83], apré senta três exemplos, cobrindo assim mais aspectos do método. Por outro lado, conseguiu-se melhor entendimento do mëtodo ào fazer - estudo a fundo desse exemplo específico e ao implementä-lo, co mo se pode ver no capítulo 5. Todos os aspectos seriam cobertos aqui, se fosse feito o mesmo para os outros exemplos, como Jackson fez.

outro fator relevante para o entendimento do método foi a construção dos diagramas de estrutura de cada passo e sua descrição em PSL/PSA, como pode ser visto no Apêndice. Os detalhes intrínsecos de cada um dos passos puderam ser melhor per cebidos após essa tarefa. 
SOBRE A IMPLEMENTAÇÃO DE UM SISTEMA DE CONTROLE DE PEDIDOS USAN DO JSD E JSP

5.1. - Considerações Gerais

Este capitulo tem por objetivo mostrar a fase de im plementação que segue a fase de especificação para desenvolvimento de sistemas pelo mëtodo JSD.

A fim de que o problema-exemplo, apresentado no capítulo 4, ficasse completo, foi feita uma implementação, a primeira, que Jackson usa como exemplo em [Ja83]. Essa implementação baseia-se nos conceitos do método JSD, de que trata o capítulo 4, sendo que os recursos de JSP, apresentados no capitulo 3, foram, também, utilizados. Triance, em [Tr80], mostra como im plementar os recursos de JSP em linguagem COBOL ANS. As formas de implementar as estruturas bāsicas, inversão e retro-indiciação, por ele apresentadas, foram utilizadas com poucas altera ções. Triance salienta que muitas das técnicas de JSP, tais como, retro-indiciação, seleção com mais de duas alternativas, etc. são implementadas com adaptações, pois o processador COBOL ANS não tem uma forma específica para tais casos e mostra como são implementadas essas estruturas. A retro-indiciação é implementa da com as componentes "suponha", "admita" e "abandone" colocadas sob a forma de comentários. A inversão é implementada em forma de subrotina, por ter algumas vantagens sobre o comando PERFORM que são: todas as variáveis são locais, a comúnicação de dados é por parâmetros, cada mödulo é um programa separado e - controle é transferido para outro módulo pelo comando CALL ou pelo comando EXIT PROGRAM, que retorna o controle para o progra ma que o chamou. 
Triance diz, como mencionado no capitulo 2, que - pré-processador JSP-COBOL tem meios para representar as estrú turas básicas de programação estruturada.

os programas referentes a essa implementação foram executados no Sistema 600 da Prolögica, sendo necessárias algumas adaptações conforme será mencionado no decorrer deste capítulo.

Nas seções 5.2 a 5.7 apresentam-se, respectivamente, a construção do Diagrama de Implementação do Sistema (DIS), a implementação dos processos de modelagem, a implementação dos processos funcionais, a implementação do articulador, alguns re sultados do processamento e as conclusões.

Os conceitos JSD, apresentados no Apêndice, são dís tinguidos pelo simbolo $\$$. 
5.2. - Sobre a Construção do Diagrama de Implementação do Siste ma

Apōs a fase de especificação do sistema obtēm-se o Diagrama de Especificação do Sistema, DES, figura 4.38 , e a partir dele constrōi-se o Diagrama de Implementação do Sistema (\$), DIS, figura 5.01 .

0 DES, que é entrada para o passo de implementação, mostra os processos seqüenciais, como eles são conectados uns aos outros, as entradas e as saídas do sistema. A especificação JSD envolve muitos processos: um para cada cliente, um para cada pedido, um para cada produto.

Considere-se que o sistema-exemplo, seja implementa do sobre um ünico processador, assumindo-se que o processador se ja dedicado e esteja constantemente disponivel.

os fluxos de entrada para esse sistema-exemplo, como pode ser visto através da figura 4.38 , são os fluxos de cliente $(C)$, de pedido de consulta ( $C 0)$, de pedido de alocação (A) e de pedido de listagem (L). o processo de articulação (\$) rece be esses fluxos e deve ativar os respectivos processos para exe cutar suas tarefas.

o articulador, ARTIC, ao ser alimentado por um fluxo de dados C, deve ativar o processo CLIENTE. Esse processo é invertido e torna-se subrotina do articulador, ARTIC, passando a ser chamado de CLI1. O processo CLIENTE-1 recebe informações sobre as ações do cliente em relação a um pedido e deve, então, alimentar o processo PEDIDO-1, como se pode ver na figura 4.38, com o fluxo IPC. Logo, esse processo é invertido e tornase subrotina de CLII, passando a ser chamado de PEDID.l. Retor nando ao DES, figura 4.38 , observa-se que PEDIDO-1 alimenta PEDI DO-2 com o fluxo DP, assim sendo, PEDIDI ativa PEDID2, como é agora chamado, tornando-se por inversão uma subrotina de PEDIDI. Quando o articulador é alimentado por um fluxo co, é necessārio que o processo funcional CONSUL, que é implementação de CONSULTA, seja ativado. Ele é, então, invertido e tornase subrotina de ARTIC. 0 arquivo ARQ-VET-EST-PEDIDO-1-2 é consultado para informar sobre o estado de um determinado pedido. 


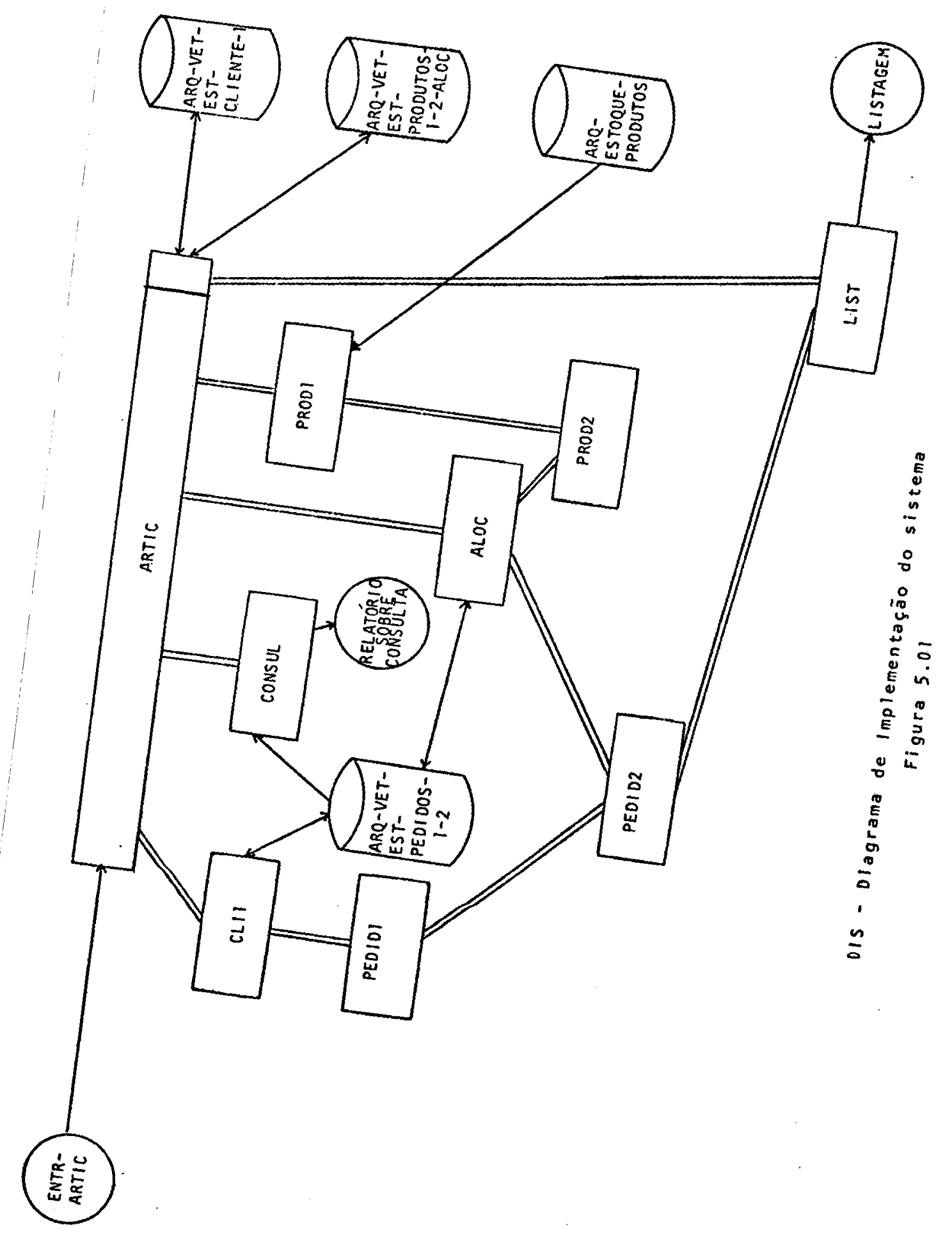


Ao ser alimentado por um fluxo A, ARTIC deve ativar PRODl, que é a implementação de PRODUTO-l. PRODl pesquisa o ar quivo de estoque de produtos, ARQ-ESTOQUE-PRODUTOS, para saber qual a quantidade inicial em estoque de um determinado produto. PROD1 ativa PROD2, que é a implementação de PRODUTO-2, informan do-lhe qual a quantidade inicial em estoque do produto. PROD2 é invertido e torna-se subrotina de PRODI. O processo de articula ção, ARTIC, recebe de PRODl a quantidade inicial em estóque de um determinado produto, consulta o arquivo de produtos já aloca dos, ARQ-VET-PRODUTOS-1-2-ALOC, para saber qual a quantidade já alocada do produto e, a partir daí, ativa o processo ALOC, que é implementação de ALOCA. O arquivo ARQ-VET-EST-PEDIDO-1-2 é consultado por ALOC, para saber quais os pedidos que deve alocar. Esse processo é invertido e torna-se subrotina de ARTIC, a tiva PROD2 enviando-l he a quantidade alocada do produto e ativa PEDID2 enviando-lhe informação sobre o pedido: se ele foi aloca do ou colocado em pendência. Logo, PROD2, que já é invertido e é subrotina de PRODI, e PEDID2, que já é invertido e é subrotina de PEDIDI, são, tambēm, invertidos e tornam-se subrotinas de $A L O C$.

Ao ser alimentado por um fluxo L, ARTIC deve ativar - processo LIST, que é a implementação de LISTA. LIST, por inversão, torna-se subrotina de ARTIC e, também por inversão, tor na-se subrotina de PEDID2, que o alimenta com as informações so bre os pedidos pendentes e os pedidos alocados.

o arquivo ARQ-VET-EST-CLIENTE-1 armazena informações relativas ao cliente e é mantido por um subsistema encarregado do cadastramento de clientes.

0 arquivo ARQ-VET-EST-PEDIDO-1-2 armazena tanto flu xos de dados como vetores de estado como, por exemplo, IPC, DP, IPAP, EPC, etc.. 0 arquivo ARQ-VET-EST-PRODUTOS-I-2-ALOC armazena a quantidade jä alocada de cada produto, o arquivo ARQESTOQUE-PRODUTOS armazena a quantidade inicial disponível de es toque de produtos e é atualizado pelo subsistema responsável pe lo ressuprimento.

observando-se as figuras 4.38 e 5.01 , pode-se notar 
que os processos CLIENTE-O e PRODUTO-0 que estão no DES não apa recem no DIS, pelo fato de eles serem processos do mundo real. Assim, constrói-se o DIS como pode ser visto na figura 5.01. No Apêndice encontram-se maiores detalhes sobre as componentes utilizadas nesse diagrama. 
5.3. - Sobre a Implementação dos Processos de Modelagem

Como póde ser visto na figura 4.38, os processos de modelagem correspondem às entidades: CLIENTE, PEDIDO e PRODUTO. o diagrama de estrutura e o texto estruturado correspondentes a cada um deles são os mostrados nas figuras $4.05,4.09,4.10$, $4.12,4.13$ e 4.14 , respectivamente.

Para que esses processos pudessem ser implementados, algumas modificações tornaram-se necessärias, como se máa ilustra do a seguir.

\section{3 .1 - Processo CLII}

Comparando-se os diagramas de estrutura, figuras 4.20 e 5.02 , e os respectivos textos estruturados, ilustrados nas figuras 4.21 e 5.03 , pode-se observar que: não existe a ite ração PROC-CORPO-AÇÃO, na figura 5.02, pois essa iteração é-rea lizada pelo articulador ARTIC. Essa iteração ocorre com a leitú ra de värios fluxos C.

o programa correspondente à implementação desse pro cesso é mostrado na figura 5.04. A operação carregue vetor de estado (\$), "loadsv", que consta da figura 5.03, é realizada através de uma leitura do arquivo que armazena os vetores de estado de pedidos, ARQ-VET-EST-PEDID0-1-2. A operação armazene ve tor de estado $(\$)$, "storesv", que consta da mesma figura, é rea lizada atravēs de uma gravação no arquivo acima mencionado.

Devido à restrição de memōria no equipamento utilizado na implementação, criou-se o arquivo ARQ-NRO-CLIENTE, que não se encontra no DIS, figura 5.01, e contém o nümero do clien te. Outro arquivo que também não consta do DIS é o ARQ-CRIA-NROPEDIDO, cuja função é, como o prōprio nome diz, criar o número do pedido quando esse é colocado.

\subsection{2. - Processo PEDIDI}

Como pode ser visto no DIS, figura 5.01 , esse pro- 


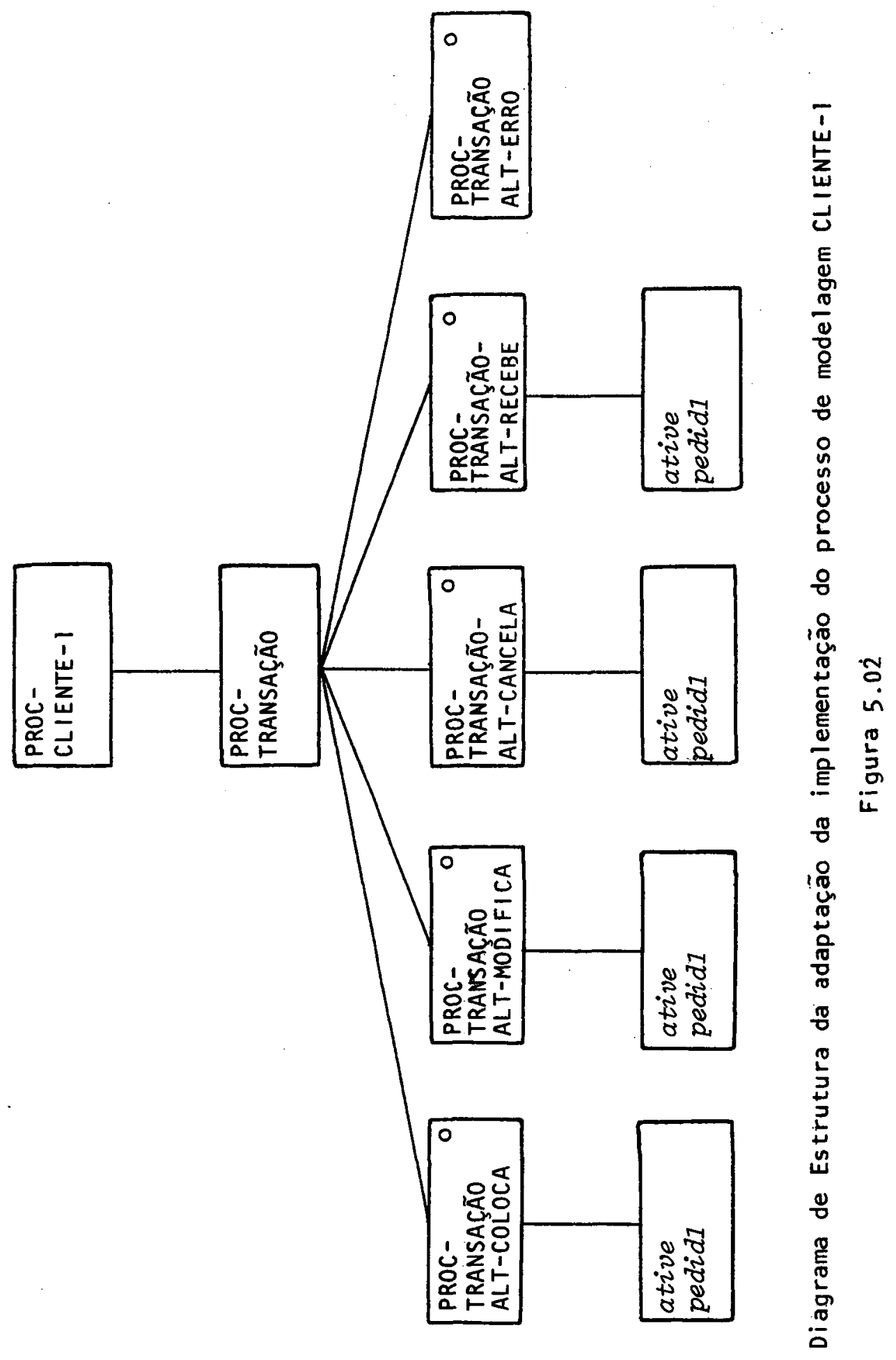




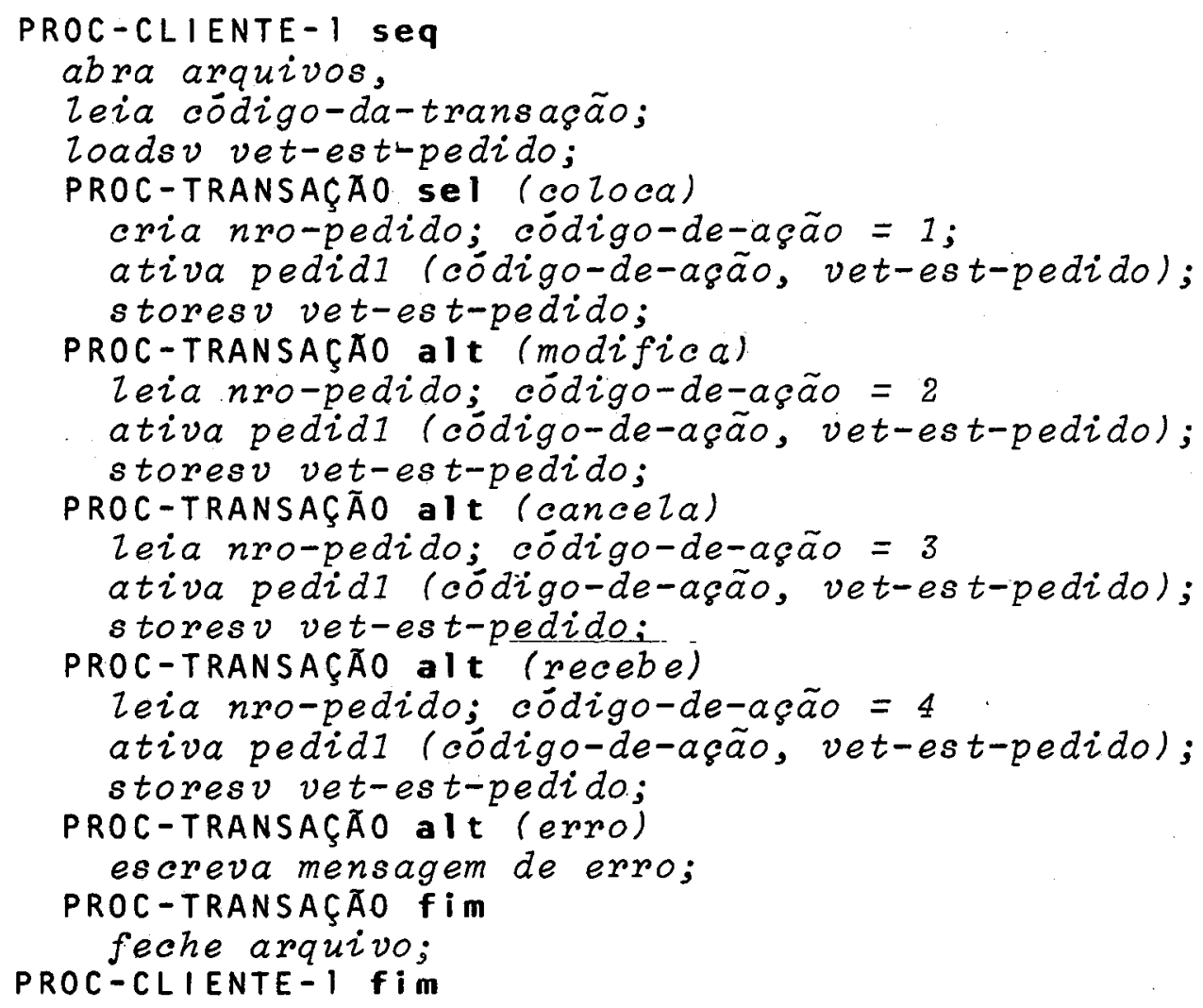

Texto Estruturado da adaptação da implementação do processo de modelagem CLIENTE-I

Figura 5.03 


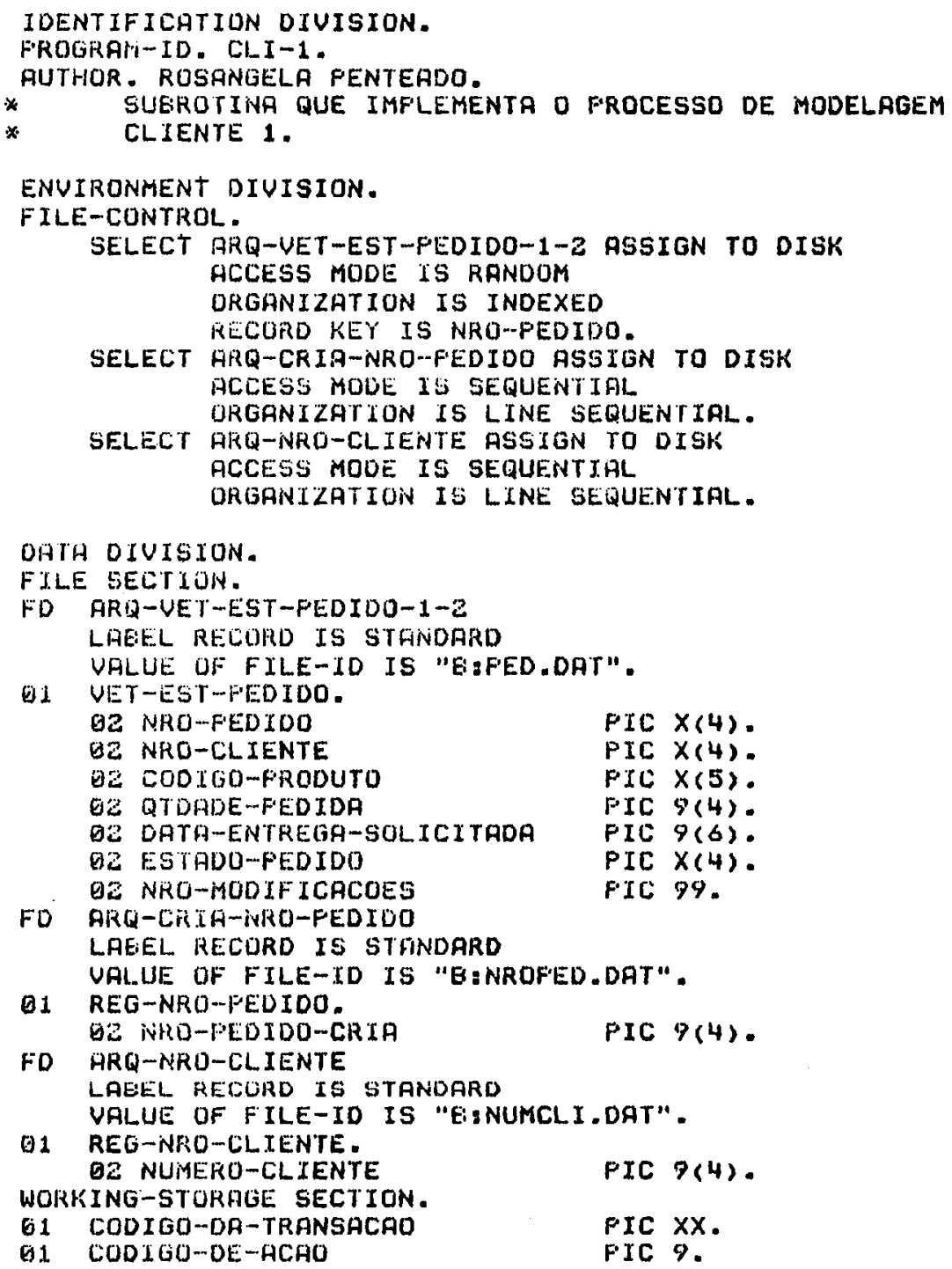

Implementação do processo de modelagem CLIENTE-I

Figura 5.04 
FROCEOURE OIVISION.

FHOC-CLIENIL-1-\$SKQ

OFEN I -O ARQ-UET - EST -FEUIDO-1-2

ARG-CKIA-NRO-FEDIDO

INFUT' ARQ-NRO-LLLIENIE.

KE.GD ARQ-HRO-CLIENTE AT ENO

DO TO PROC-CLIENTE-1-FIM.

DISPLFY (7, 1) "CODIGU DA TRANSACGO - FEDIDO DE CLIENTE".

ACCEFT (\%, 45) CODIGU-DA-TRANSACAO.

MUVE 'S TO CODIGO-DE-FCAO.

IF COUIGO-OA-TRANSACAO $=$ "CU"

MOVE 1 TO CODISTO-DE-ACAO.

IF CODIGO-OA-TRANSACAO $=$ "MO"

MUVE \& TO CODIGO-DE-HCAO.

IF COOIGO-DA-TRANSACRO = "CA"

MOVE 3 TO COOLGO-DE-ACAO.

IF CODIGO-DA-TRFNSACHO "RE"

MOUE 4 TO CODIOO-DE-AICAO.

FROC-TRANSACAO-SEL.

GO 70 PROC-TRANSACAO-IBLT-COL ICA

PROC-TKANSACAO-FL T-MOOO IF ICA

PROC-TRANSACAO-HLT-CANCEI.A

PKOC-TRANSACAO-ALT-RECEBE

PROC-TRANSACAO-RLT-ERRO

DEFENDING ON CODIOO-DE-ACAO.

PROC-TRAISSAERO-ALT - COLOCA

MUVE OS TO NRO-MODIFICACOES.

MOVE NUMERO-CLIENTE TO NRO-CLIENTE.

READ HRQ-ERLA-NRO-FEDIDO.

GDD I TO NRO-FEDIDD-CRIA.

REWRITE REG-NRO-FEDIDO.

MUVE. NRO-FEOIUO-CRIA TO INRO-FEDIOD.

CALL "PEOTDI" USING CODIGO-DE-ACAD

VET-EST-FEDIDO

WRITE VET-EST-PEDIDO.

TO TO FHOC-TRANSACAO-FIM.

FROC-TRENSACAO-ALT-MODTFICA.

DISFLAY $(9,1)$ "NUMERO DO PEOIDO A SER MODIFICADO". ACCEPT (9, 36) NRO-FEDICO.

READ ARQ-VET-EST-PEDIDO-1-2 INUALID KEY

DISPLAY $(11,1)$ "NUMERO DE PEDIDO NAO LOCALIZADO"

STOF " "

GO TO PROC-TRANSACFO-FIM.

MOVE NUMERO-CLIENTE TO NRO-CLIENTE.

CALL "FEDIDL" USING CODIGO-DE-ACAO

VET-EST -FEDIDD.

REWRITE VET-EST-PEDIOO.

GO TO FROC-TRANSACAO-FIM.

FROC-TRHINSACAO-ALLT-CANCELA.

OISPLFY $(9,1)$ "NUMEKí DO PEDIDO A SER CANCELADO". ACCEPT (9, 36) NRO-FEOTOO.

REFD ARLY-VET-EST-PEDIDO-1-2 INUHLTD KEY

DISPLAY (11, 1) "NUMERO DE FEDIDO NAO LOCALIZADO" STOP " "

GO TO FROC-TRANSACAO-FIM.

MOVE NUIYERIJ-CLIENTE 10 NRD-CLIENTE.

CALL "FEDIDI" USING COUTGO-DE-ACAO

VET TEST-FEDIOO.

REWRITE VET-EST-PEDIDO.

GO TO FROC-TRANSACAO-FIM.

FROC-TRANSACAO-ALT-RECEEE.

DISFLAT ( 9,1 ) "NUMERO DO FEOTDO RECEESDQ".

ACCEFT (9, 36) NRO-FEOIDO.

READ AR(G-VET-EST-FEDIDO-1-¿̈ INUALID KEY

DIGFLAY (11, 1) "NUMERO DE FEOIDO NAO LOCALIZADO"

STOF " "

GO TO FROC-TRANSACRO-FIM.

HOVE NUMERO-CLIENTE TO NRO-CLIENTE.

CALL "FEDIDL" USING CODILO-DE:-ACAO

VE. $r-E S T \sim P E D I D O$

REWRITE VET-EST-PEDIDO.

GO TO FROC-TRANSACAO-FIM.

FROC-TRANSACAO-ALT-ERKO.

DISFLAY $(\%, 10$ ) "TRANSACHO ERKADA - VERIFIQUE"

STOF:" ".

FHOC-TRANSFCAO-FIM.

LI.OSE BASQ-VE:T-E.ST-FEOTDOO-1-2

HISE-CRIA-NAU-FEOTDO

HHQD-NRO-CLIENTE.

CHAIN "EIAH IIC.COM".

FROL,-CLIENTE-1-FLM.

Figura 5.04 (cont.) 
cesso é subrotina de CLII.

Comparando-se os diagramas de estrutura, figuras

4.23 e 5.05 , e os respectivos textos estruturados, figura 4.24 e 5.06, nota-se que: as ações do pedido são representadas por seleção, ao invēs de por seqüência. Isso ocorre porque exís te um processo de modelagem para cada pedido, na fase de especi ficação; já na fase de implementação, como existe um ünico processador, um ünico processo è compartilhado por todos os pedi doss. Assim, as possíveis ações que a entidade PEDIDo pode reali zar são lidas em CLIl e passadas como parâmetro para PEDIDI. A itieração que aparece na figura 4.23 é realizada atravēs de diversos fluxos $C$ que alimentam o processo ARTIC. A leitura do fluxo IPC, informaçóes-de-pedido-de-cliente ocorre no processo CLII e essa informação é passada para PEDIDI, através do parâme tro código-de-acão, de acordo com os valores recebidos por CLII, (5.3.1.). Com esse cödigo-de-ação, o processo PEDID2 é ativado e realiza uma das açöes referentes ao pedido. o parâmetro vetest-pedido retorna a CLII, para que esse o grave no arquivo $A R Q$-VET-EST-PEDIDO-1-2.

A figura 5.07 mostra o programa correspondente à implementação de PEDIDI.

\subsection{3. - Processo PEDID2}

Comparando-se os diagramas de estrutura, figuras 4.30 e 5.08 , e os respectivos textos estruturados, figuras 4.31 e 5.09, nota-se que: a iteração PROC-CORPO-PEDIDO-2, figura 4.30, passa a não existir na figura 5.08, sendo realizada pelo cliente na sua interação com a empresa. A seqüência PROC-PEDIDO2, figura 4.30, é realizada só pela seqüêncla de PROC-AÇÃo-PED2, figura 5.08, pois como jä foi dito na seção 5.3 .2 ., essas ações säp recebidas por CLII. A leitura do fluxo DP $\varepsilon$ IPAP, que consta da figura 5.09, ē realizada através do parâmetro código-de-a ६ãá. Os valores de 1 a 4, para código-de-ação, são recebidos do processo PEDIDI e os valores 5 e 6 são recebidos do processo funcional ALOCA. PEDID2, após receber esse valor, grava em está 


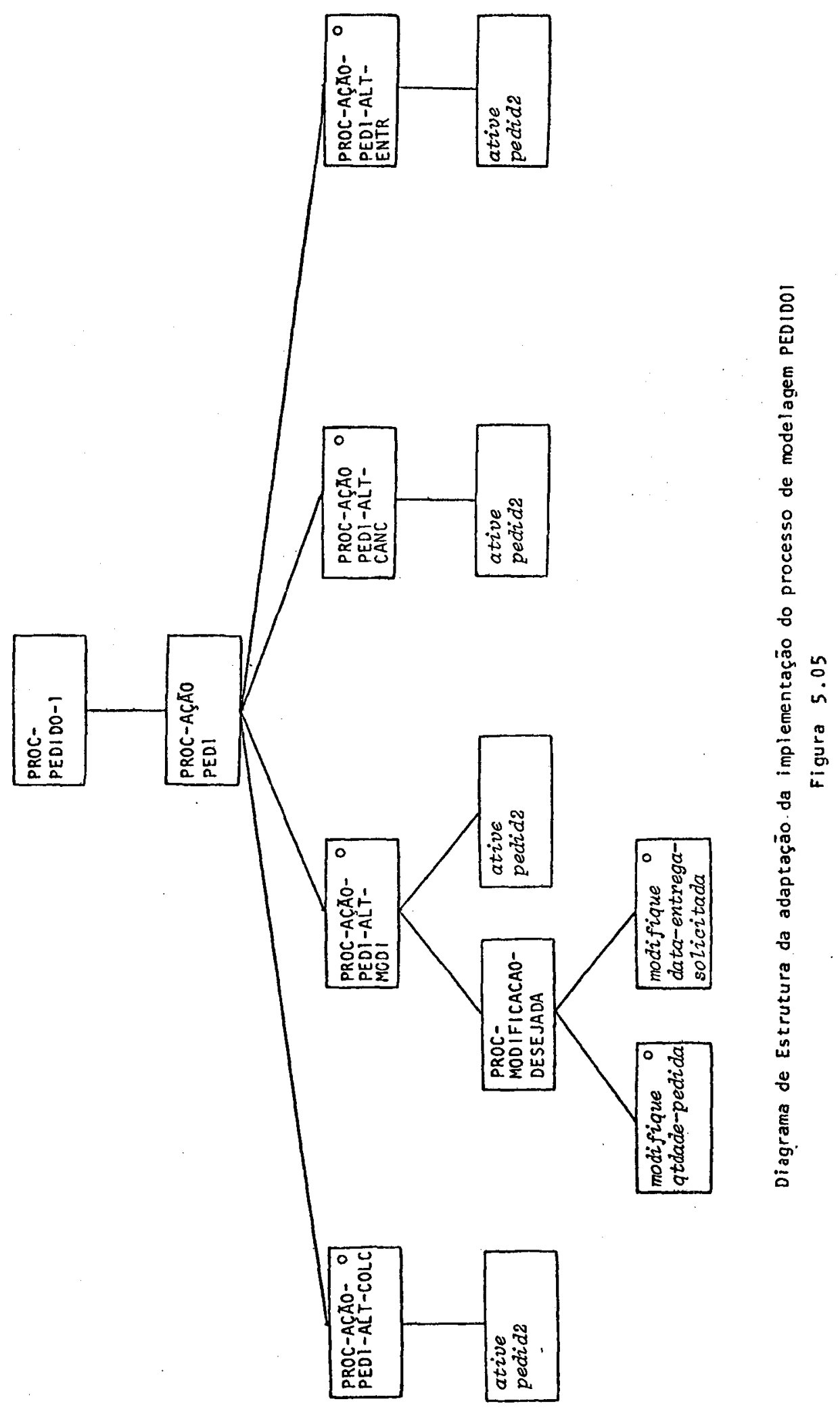




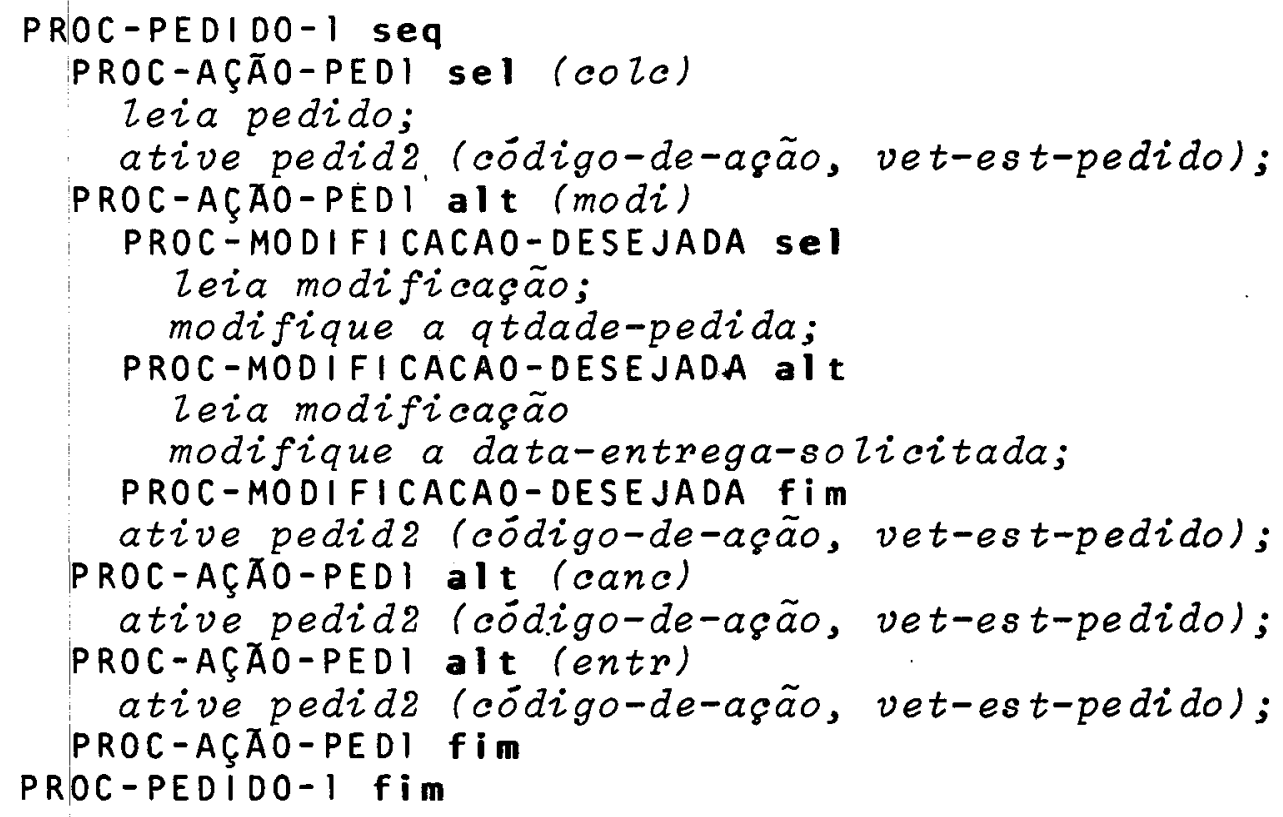

Texto Estruturado da adaptação da implementação do processo de modelagem PEDIDO-1

Figura 5.06 


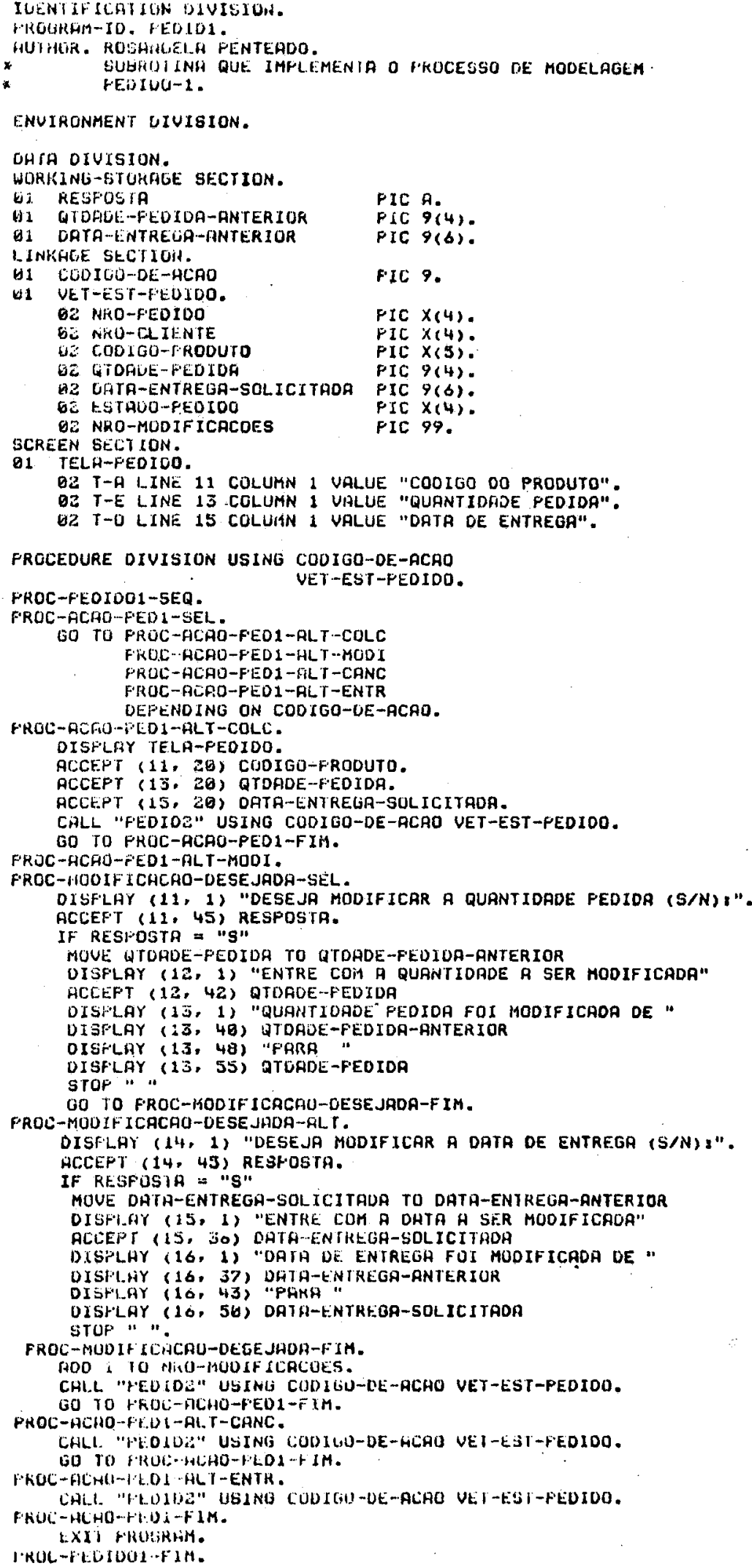

Implementação do processo de modelagem PEDIDO-1

Figura 5.07 

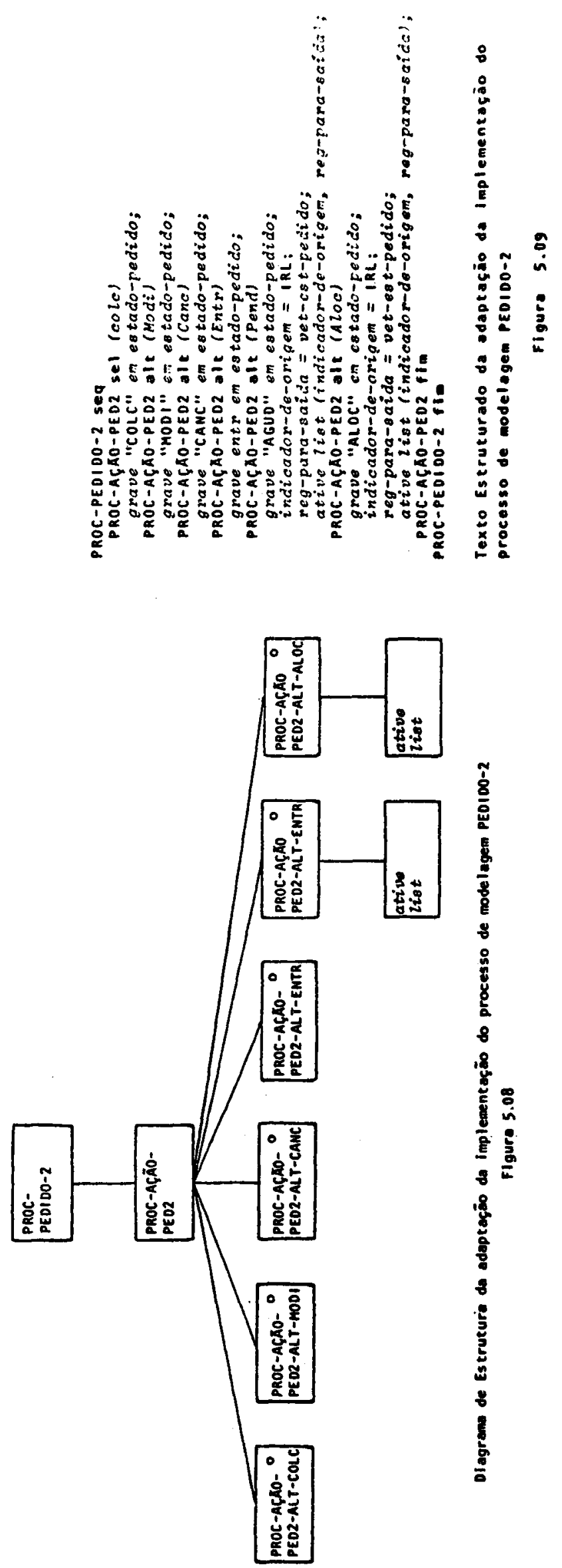
IDENTIFICATION DIUISION.

FROGRAM-ID. FEDIDZ.

* Suefrograma que tmflementa o frocesso de modelagem FEDIDO-2.

RUTHUR. ROSANGELA PENTEADO.

ENUIRONMENT DIUISION.

DATA DIUTSION.

WORKIIGG STOREGE SECTION.

Q1 INOICADOR DE-ORIGEM

Q1 REG-FARA-SAIDA.

G2 NRO FEOCOO

QC NRO-CLIENTE

Q2 CODIGO-FRODUTO

Q2 QTDFOE-FEOIDA

E2 DATA-ENTREGA-SOLICITADA

QL ESTADO-FEDIDO

QO NROA-MODIFICACOES

LINKAGE SECTION.

OI COUTGO-DE-FCAO

01 VET-EST-FEDTDO.

QC NRO-FEDIDO

62 NRO-CLIENTE

Q2 CODIGD-FRODUTO

Q2 QTDADE-PEDTDA

Q2 DRTA-ENTREGA-SOLICITADA

Si ESTADO-FEOIDO

Q2 NRO-NOO IF I CACOES

PIC XXX VALUE "IRL".

PIC $X(4)$.

Fic $X(4)$.

Fic $x(5)$.

FIC $\theta(4)$.

FIC $9(6)$.

PIC $X(4)$.

FIC 99.

FIC 9.

FIC $X(4)$.

PIC $X(4)$.

FIC $X(5)$.

FIC $9(4)$.

FIC $9(6)$.

FIC $x(4)$.

FIC 99.

PROCEDURE DIUISTON USING COOIGO-DE-ACAO

UET-EST-PEDIDO.

FROC-FEDIOO-2-SEQ.

iO TO FROC-GCAO-FEDZ-ALT-COLC

FROC-F+CAO-FEDZ-ALT-MOOI

FROC-NCAO-FEDZ-ALT-CANC

FROC-ACAO-FEDZ-ALT-ENTR

PROC-FCAO-FEDE-ALT-FEND

FROC-ACAO-FEDZ-ALT-ALOC

DEFENUTNG ON COOTGO-DE-ACAO.

PROC-ACAO-PEOZ-ALT-COLC.

MOUE "COLC" TO ESTADO-FEDIDO IN UET-EST-FEDIDO.

GO TO FROC-ACAO-FEDE-FIM.

FROC - ACAO-FED2 -.ALT - MODI.

MOVE "MOOI" TO ESTADO-FEDIDO IN VET-EST-FEDIOD.

GO TO FROC-ACAO-FEDE-FIM.

FROC-ACAO-FEDZ-AL.Y-CANC.

MOVE "CANC" TO IESTADO-FEOIDO IN VET-EST-FEDIDO.

OO TO FROC-ACAO-FEDE-FIM.

PROC-ACAO-FEDS-ALTT-ENTR.

MOUE: "ENTK" TO EGTADO-FEDIDO IN VET-EST-PEDIDO.

QO TO FROC -ACFO FEDE-FIM.

PROC-AICAO-FEDO-ALT TEEND.

MOVE: "AGUD" TO ESTADO-PEDIDO IN VET-EST-FEDTDO.

HOUE VET-EST-FEDIOO TO REG-FARA-SAIOA.

CHLL "LIST" USING INOICADOF-DE-ORIGEM

REG-PARA-SATDA.

SO TO FROC-ACAO-PEDE-FIM.

PROC $\rightarrow A C A D-F E D Z \cdots A I-T-A L D C$.

MOVE "ALOE" TO ESTADO-FEDLDO IN VET-EST-PEDIDO.

YOUE UET-EST-FEDIDO TO REG-FARA-SATDA.

CFILL "LIST" USING INDJCADOR-DE-ORIGEM

FROC-FCAO-FEOZ-FIM

REG-PARA-SAIDA.

EXIT FROQRAM.

FROC-FEDTDO-Z-FTM.

Implementação do processo de modelagem PEOIDO-2

Figura 5.10 
do pedido o correspondente estado do pedido. 0 parâmetro vetest-pedido retorna ao processo PEDIDI com a alteração e, como foi visto em 5.3.2., esse processo retorna a CLIl o registro vet-est-pedido atualizado, para que seja feita a gravação no ar quivo correspondente. PEDID2 ativa o processo funcional LISTA, no caso dos valores 5 e 6 , pelo fato de se desejar um relatörio com pedidos pendentes e pedidos alocados.

A figura 5.10 mostra o programa correspondente à implementação de PEDID2.

\subsection{4. - Processo PRODI}

Comparando-se os diagramas de estrutura, figuras 4.25 e 5.11 , e os respectivos textos estruturados, figuras 4.26 e 5.12 , pode-se notar que: a iteração PROC-CORPO-PRODUTO-1, figura 4.25, não consta do diagrama da figura 5.11 , pois essa ite ração é realizada pelo articulador, ARTIC. Se a implementação fo\$se feita para cada produto, essa iteração seria realizada pe lo usuário, que emitiria a informação sobre qual produto deveria ser realizada a alocação.

A operação "getsv", que consta das figuras 4.26 e 5.12, é realizada para obter o estoque disponivel de um produto. Essa operação estä implementada como uma leitura do arquivo ARQ-ESTOQUE-PRODUTOS, obtendo qtdade-disponivel-est. 0 processo PROD2 é ativado, com indicador-de-origem igual a "QPE", e salva a quantidade disponível inicial do produto que foi obtida quando ARQ-ESTOQUE-PRODUTOS foi consultado.

A figura 5.13 mostra o programa correspondente à implementação de PRODl.

\subsection{5. - Processo PROD2}

Comparando-se os diagramas de estrutura, figuras 4.34 e 5,14 , e os respectivos textos estruturados, figuras 4.35 e 5.15, nota-se que: a i teração CORPO-AÇAOO-PRODUTO2, figura 4.34 , não consta da figura 5.14, por ser realizada pelos proces 


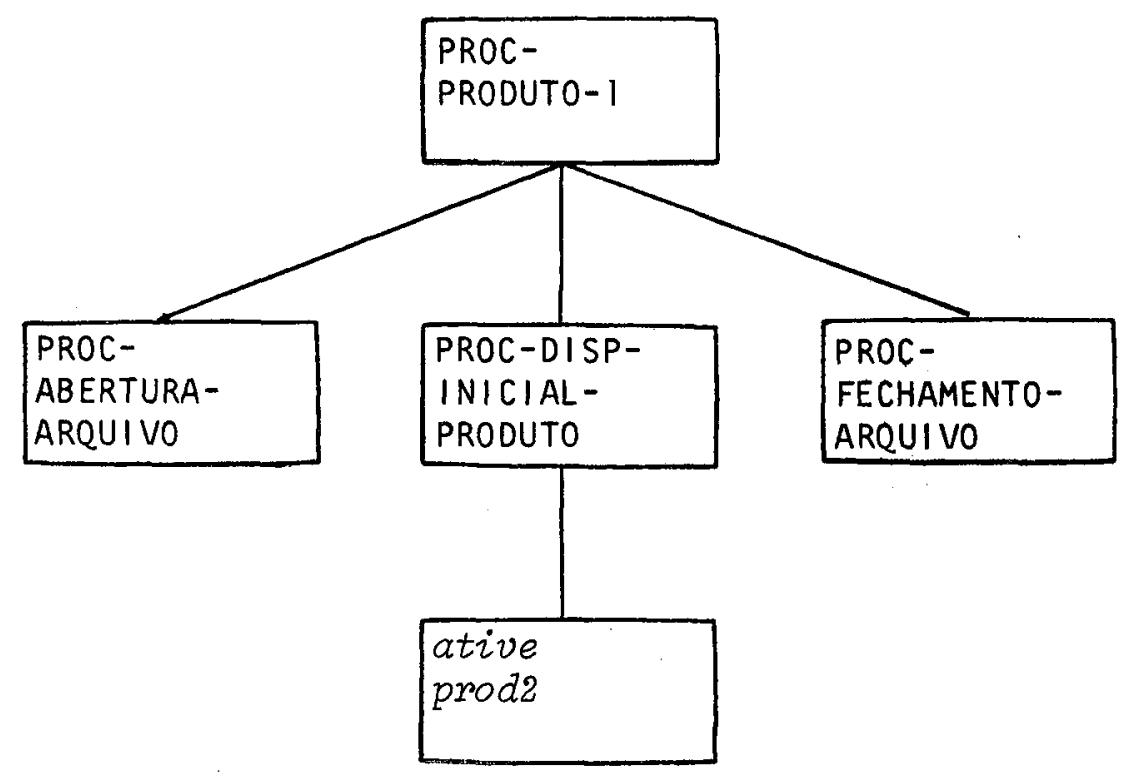

Diagrama de Estrutura da adaptação da implementação do processo de modelagem PRODUTO- 1

Figura 5.11

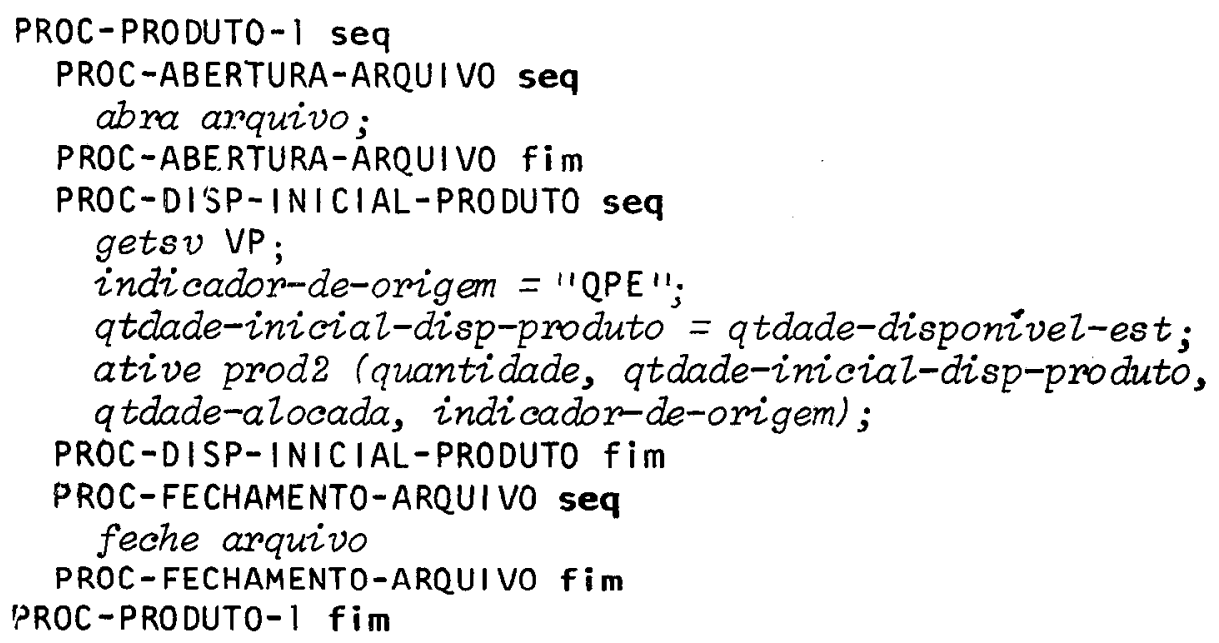

Texto Estruturado da adaptação da implementação do processo de modelagem PRODUTO- 1

Figura 5.12 


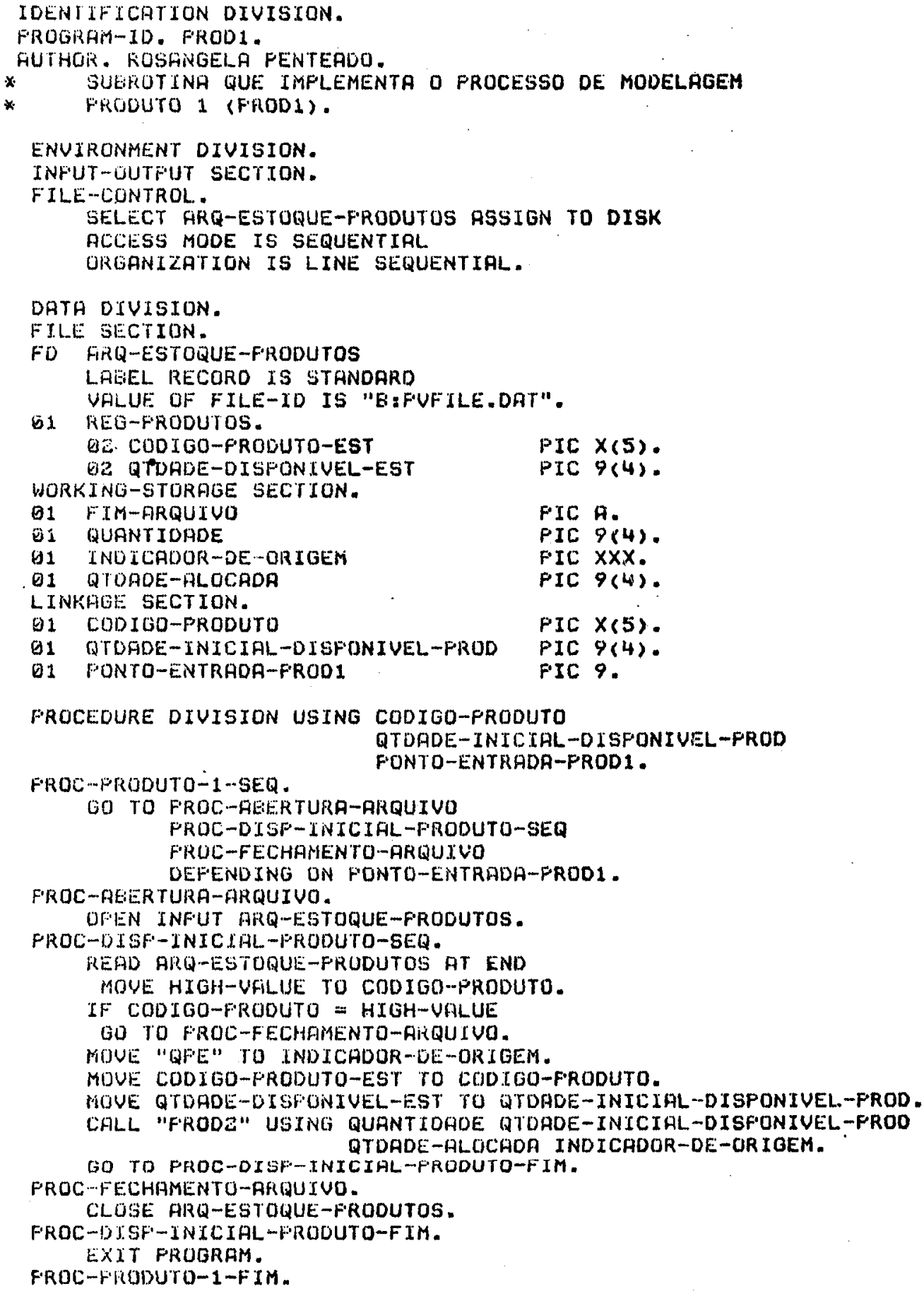

FROCEDURE DIUISION USING CODIGO-PRODUTO QTOADE-INICIAL-DISFONIVEL-FROD FONTD-ENTRADA-FROD1.

FROC -PROOUTO-1 -SEQ.

DO TO FROC-AEERTURA-ARQUTVO PROC-DISF-INTCIAL-PRODUTO-SEQ FROC-FECHAMENTO-ARQUIVO DEFENDING ON FONTO-ENTRADA-FRODL.

F'ROC-FEERTURA-ARGUIVO.

OFIEN INFUT ARQ-ESTOQUE-FRODUTOS.

PROC-DISF-INICIAL-FRODUTO-SEQ. READ ARQ-ESTOQUE-FRUDUTOS AT END MOVE HIGH-UFILIJE TO CODIGO-PRDDUTO. IF CODIGO-FRODUTO = HIGH-UALUE GO TO FROC-FECHAMENTO-AIYQUIVO. MOUE "QFE" TO INDICADOR-UE-ORIGEM. MOVE CODIGO-PRODUTO-EST TO CODLGO-FRODUTO. MOUE GTDADE-DISFONIUEL-FST TO ETDADE-INICIAL-DISPONIVEL-FROD. CALL "FRODZ" USING QUANTIDADE GTOADE-INTCIAL-DISFONIVEL-FROD QTDADE-ALCCADA INDICADOR-DE-ORIGEM. GO TO PROC-DISF-TNICIAL-FRODUTO-FIM.

PROC -FECHAMENTO-AFIQUSUO. CLOEE ARQ-ESTOQUE-FRODUTOS.

FROC-DISF-INICIAL-FRODUTO-FIM. EXIT PROGRAM.

FROC-FRODUTO-1-FIM.

Implementação do processo de modelagem PRODUTO-I

Figura 5.13 
sos que ativam PROD2, ou seja, PROD1, via ARTIC, e ALOC. Tem-se, figura 5.14, somente a seleção que indica qual dos dois processos, PRODI ou ALOC, ativou PROD2. A leitura do fluxo QPE $\&$ QA, figura 4.35, é realizada atravès de parâmetro indicador-de-origem. Se indicador-de-origem for igual a 1 , quantidade recebe qtdade-inicial-disponivel-prod; se for igual a 2 , quantidade re cebe quantidade - qtdade-alocada.

A figura 5.16 mostra o programa correspondente à implementação de PROD2.

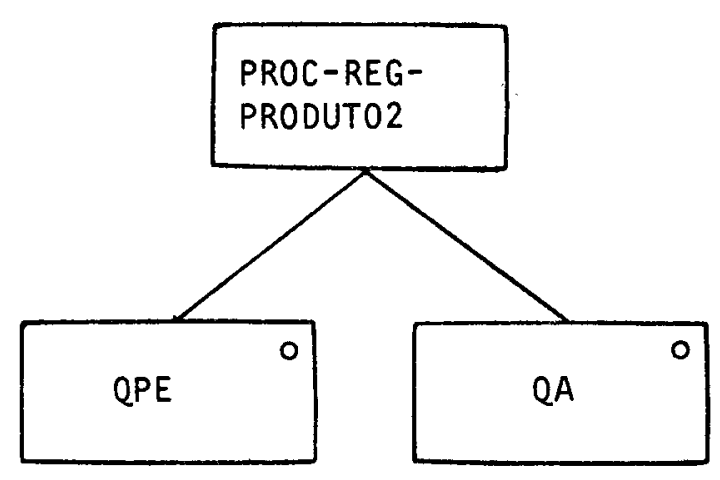

Diagrama de estrutura da adaptação da implementação do processo de modelagem PRODUTO2

Figura 5.14 


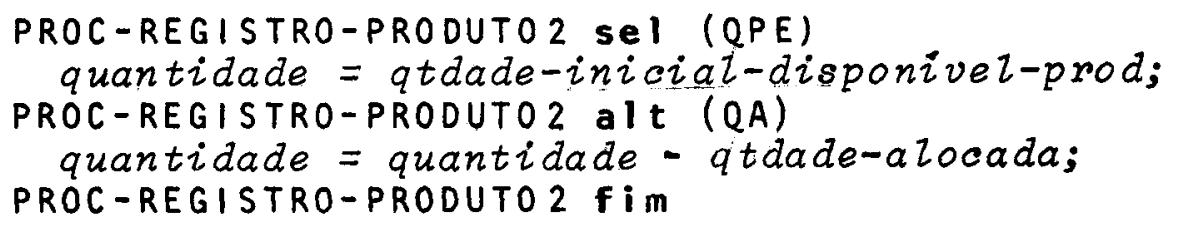

Texto Estruturado da adaptação da Implementação do processo de modelagem PRODUTO-2

$$
\text { Figura } 5.15
$$

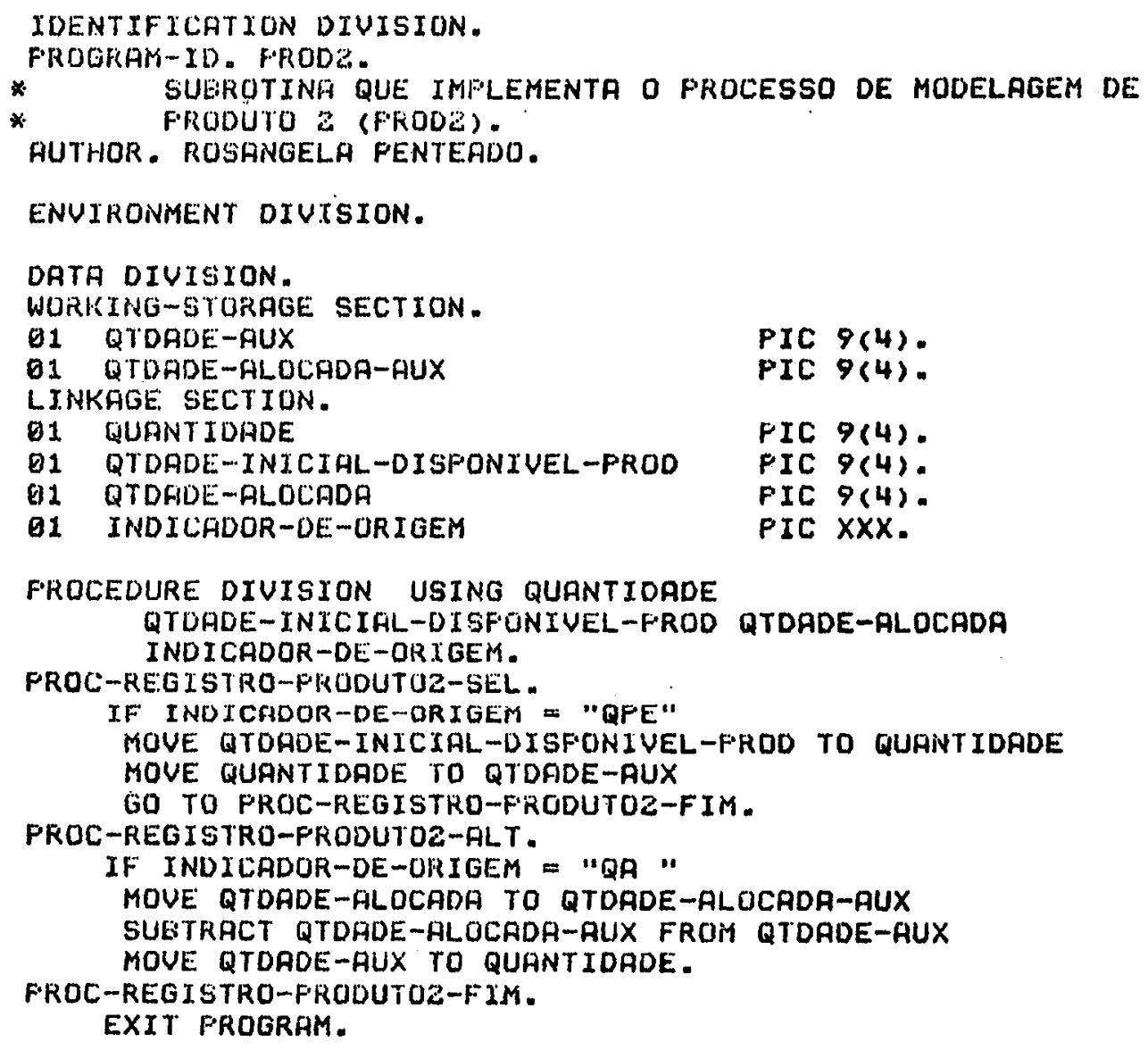

Implementação do processo de modelagem PROOUTO-2

Figura 5.16 
5.4. - Sobre a Implementação dos Processos Funcionais

Retomando, a figura 4.38 , pode-se observar que os processos funcionais são: CONSULTA, ALOCA e LISTA, jä discutidos no capitulo 4 .

\section{4 .1 . Processo CONSUL}

Comparando-se os diagramas de estrutura, figuras 4.36 e 5.17, e os correspondentes textos estruturados, figuras 4.37 e 5.18, nota-se que: a iteração PROC-CORPO-CONSULTA, figura 4.36, não consta da figura 5.17 , por ela ser realizada pelo usuário que interage com a empresa. A seleção aparece nas duas figuras, pois é relativa a um dos possíveis estados em que se encontra um determinado pedido.

Devido às restriçōes de memöria do equipamento uti lizado na implementação, tornou-se necessārio o arquivo ARQNRO-PEDIDO, que contém o nümero do pedido a ser consultado. A operação "getsv" EPC é realizada atravës de leitura do arquivo que contém todos os pedidos, ARQ-VET-EST-PEDIDO-1-2. A mensagem correspondente ao estado do pedido é escrita no vídeo. A ocorrência de um outro fluxo co é provocada pelo articulador em fun ção da demanda por consulta.

A figura 5.19 mostra o programa correspondente à implementação de CONSUL.

\subsubsection{Processo ALOC}

Comparando-se os diagramas de estrutura, figuras 4.32 e 5.20 , os respectivos textos estruturados, figuras 4.33 e 5.21, nota-se que: a iteração PROC-ALOCAÇÃ, figura 4.32 e a leitura do fluxo A näo ocorrem na flgura 5.20 por serem real I zadas pelo articulador. As i terações PROC-ATEND-PED-PENDENTE e PROC-ATEND-PED-NORMAL, flgura 4,32 , são reallzadas através de seleção, pois esse processo recebe um pedido e verifica se é ou não relativo ao produto em questão. Se for o mesmo código de 


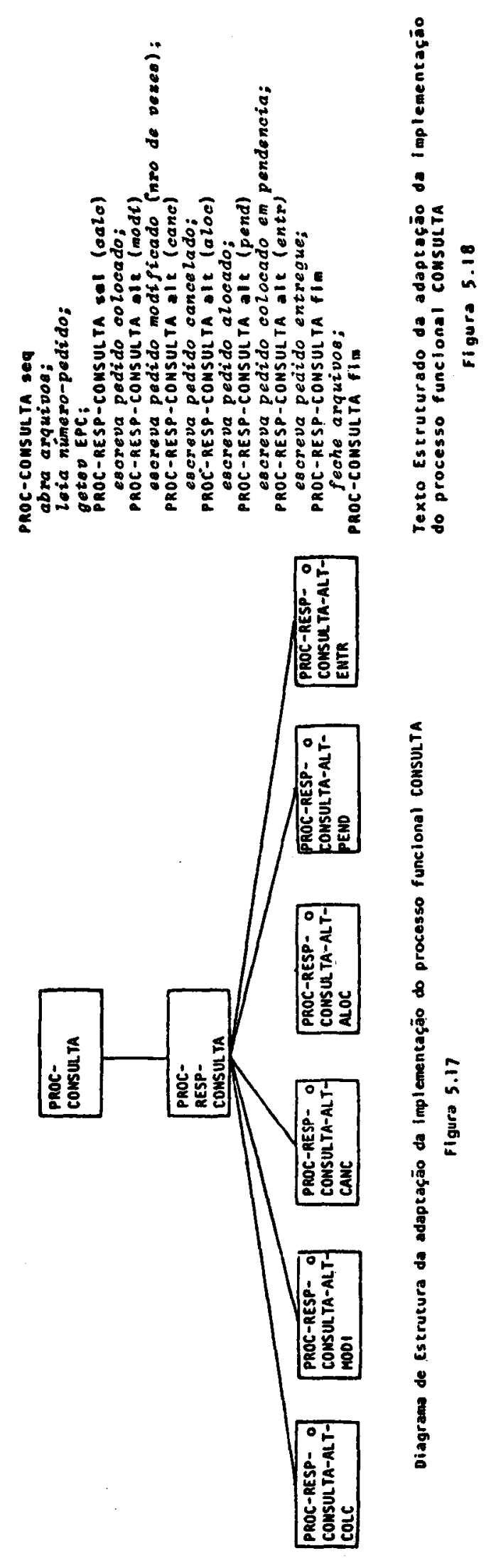


JWLNIIF ICALIUN DIVIBLON.

PHULRAM-ID. LINSLL.

HUIROR. RUSHNLELAR PENILADO.

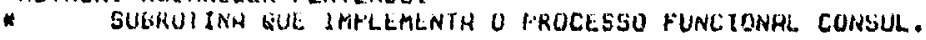

E.NUIRUNAENT DIVISION.

INFUI-UUTHUT SAETIDIR.

FILE-CON I HUL.

SELECI PIHG -VCT-EST-FCDIDU-1-2 ASSJGN TO DISh

SCEESS MUDE IS RHNOOH

ORGNIZZAIION 15 INDEXEO

HECUKD KEY IS NRU-TEDIDO.

SELECT ARL-NRUMFEDIDO HSIILN TO OISK

RCCESS MODE IS SEQUENTIAL

OREANIZRTION IS LINE SEQUENTIAL.

ORTA DIVISION.

FILE SECTION

FD ARQ-VET-EST-PEDIDO-1-2

LAELL RECONO IS STANUARO

VRLUE: OF FILE-ID IS "BaFEO.DAT" .

Q1 VET-EST-FEDIDÖ.

B2 NRO-CLIENTE-FED

O2 COOIGO-PROUUTO

Q2 QTUADE-FEDIDA

Q2 DATA-ENTREOA-SOLICITAOA

Q2 ESTADO-FEDIOO

O2 NRO-MODIF ICACOES

PIC $x(4)$.

PIC $9(4)$.

PIC $x(5)$.

PIC $9(4)$.

FIC $9(6)$.

FIC $X(4)$.

FD ARQ-NRO-FED 100

PIC 99.

LAEEL RECJRD IS STANDARD

VALUE OF FILE-ID IS "E: ANUMPED. DAT".

01 REG-NRO-FEOLDO.

TI NUMERQ-PEOIDO

WORKING-STORAOE SECTION.

GI CODIGO-DE-LONSULTA

PIC $x(4)$.

PROCEDURE DIUISION

PROC-CONSULTF-SEQ.

OFEN I -O ARQ-VET-EST-FEDIDO-1-2

INPUT FRQ-NRO-FEDIDO.

READ ARQ-NRO-FEDIDO AT END

GO TO FROC-RESP-CONSULTH-FIM.

MOVE NUMERD-FEDIDO TO NRO-FEDIOO.

KEAD GRQ-UET-EST-FEDIDO-1-2 INUALID KEY

DISPLAY (9, 16) "PEDIDO NAO ENCONTFADO"

STUP" "

GO TO FROC-RESP-CONSULTA-FIM.

DISPLAY (9, 10) "PEDIDD".

DISFLAY $(9,18)$ NKO-PEDIDO.

IF ESTADC-FEDIOO = "COLC"

MOVE 1 TO CODIGO DE-CONSULTA.

IF ESTADO-FEDIDO = "MDLI"

MOVE 2 TO CODTGO-DE-CONSULTA.

IF ESTADOAEDIDO = "CANC"

MOUE 3 :O CODIOD-DE-CONSULTA.

IF ESTADU-PEDIDO = "ALOC"

HOVE 4 IO CODIGO-OE-CONSULTA.

IF ESTADO-PEOIDO = "RGUD"

MOVE 5 TO COOIGO-DE-CONSULTA.

IF ESTADO-FEDIDO \# "ENTR"

MOVE 6 TO CODIGO-DE-CONSULTA.

PROC-RESP-CONSULTA-SEL.

GO TO PRGC-RESF-CDNSULTA-ALT-COLC

PROC-RESF-CONSLLTA-ALT-MODI

PRAC-RESF-CONSUL TA-ALT-CANC

PROC-KESF-COKBLLTA-RLTT-RLOC.

PROC-RESP-CONSUITA-ALT-PENO

PRCC-RESP-CONSULTA-ALT-ENTR
DEFENGING ON CODIGO-DE-CONSULTA.

PROL-RESP-COKEUL TA-ALT T-CULC.

OIEFLAY $(9,24)$ "ESTA COLOCADO".

PROC-AESP-COHSUL TA-ALT-MODI

DISPLAY $(9,24)$ "ESTA MOLIFICADO"

OIEFLAY 19,41$)$ NKO-MODIFICACUES.

DISFLAY $(9,45)$ "VEZ (ES)".

GO TO PKUE-RESF-CONSULTH-FIH.

PROC-RESF-COI.SULTA-HLT-LANC.

DSSFLAY (9, 24) "ESTA CANCELADO".

GO TO FKSL-RESF-CUNSULIF--F IM.

PROC-RESF-COHSUL, TA-HLT-ALUC.

DISPlar $1 \%, 24$, "ESTA ALOCADO".

GO TU FRUL - HESF-CONSUL TH-FIM.

PROC-RLL.GP-CLISLOTH-RL T FFENIS.

DISPLAY $(4,24)$ "E97A COLOCADO EN PENDENCIA". GO TO PREC:-RESSR-CUREULLTH-FIM.

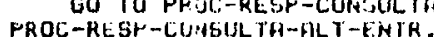

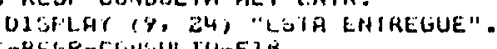

PHOC-REGF-CUISUL TH-FIR̈.

CLOUE HKG-VE I-LST - BEUIUO-1-a

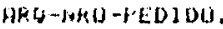

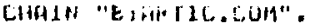

PROL-CUNBUL IA-t It4.

Implementação do processo funcional consulta

Figura 5.19 


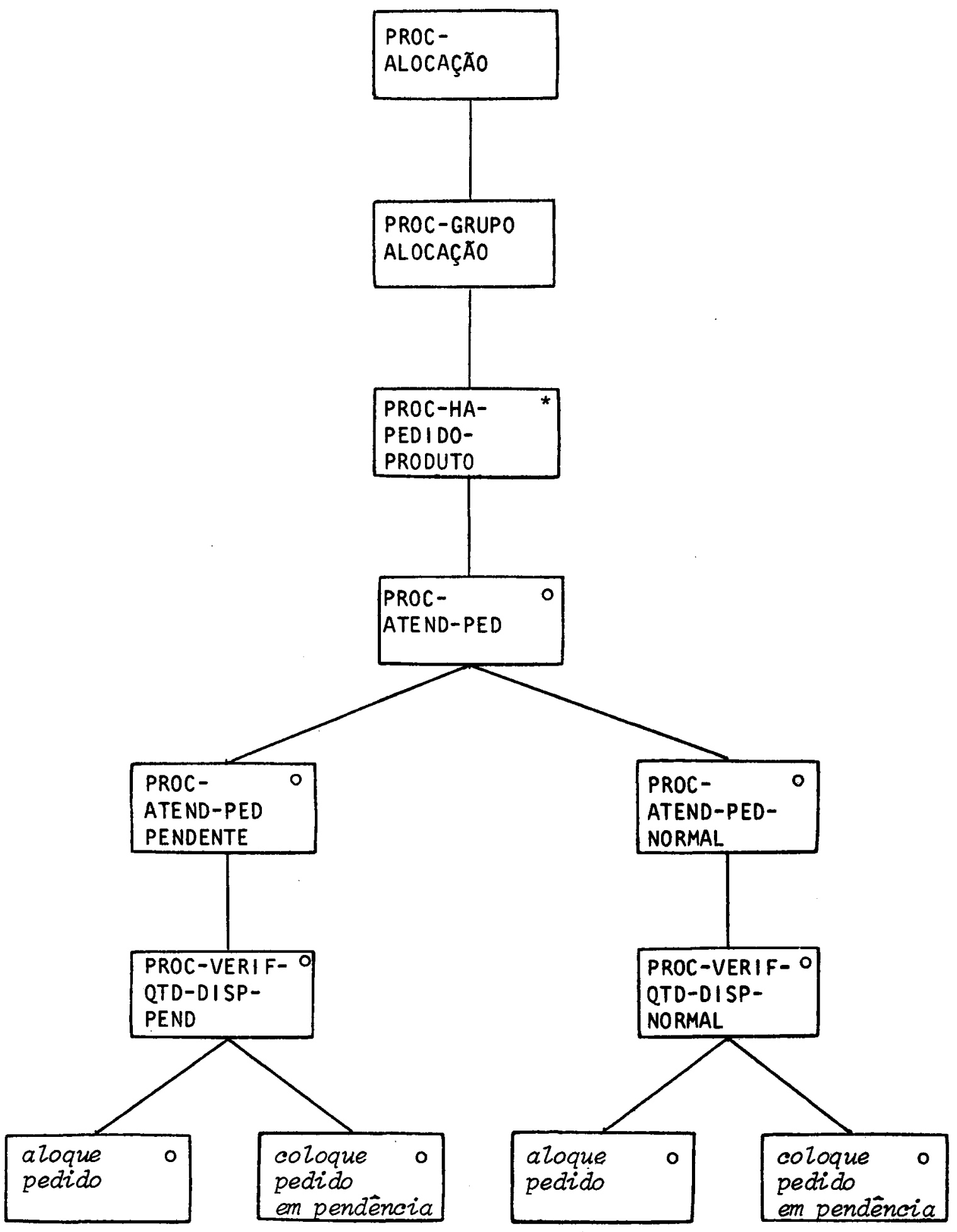

Diagrama de Estrutura da adaptação da implementação do processo funcional ALOCA

Figura 5.20 


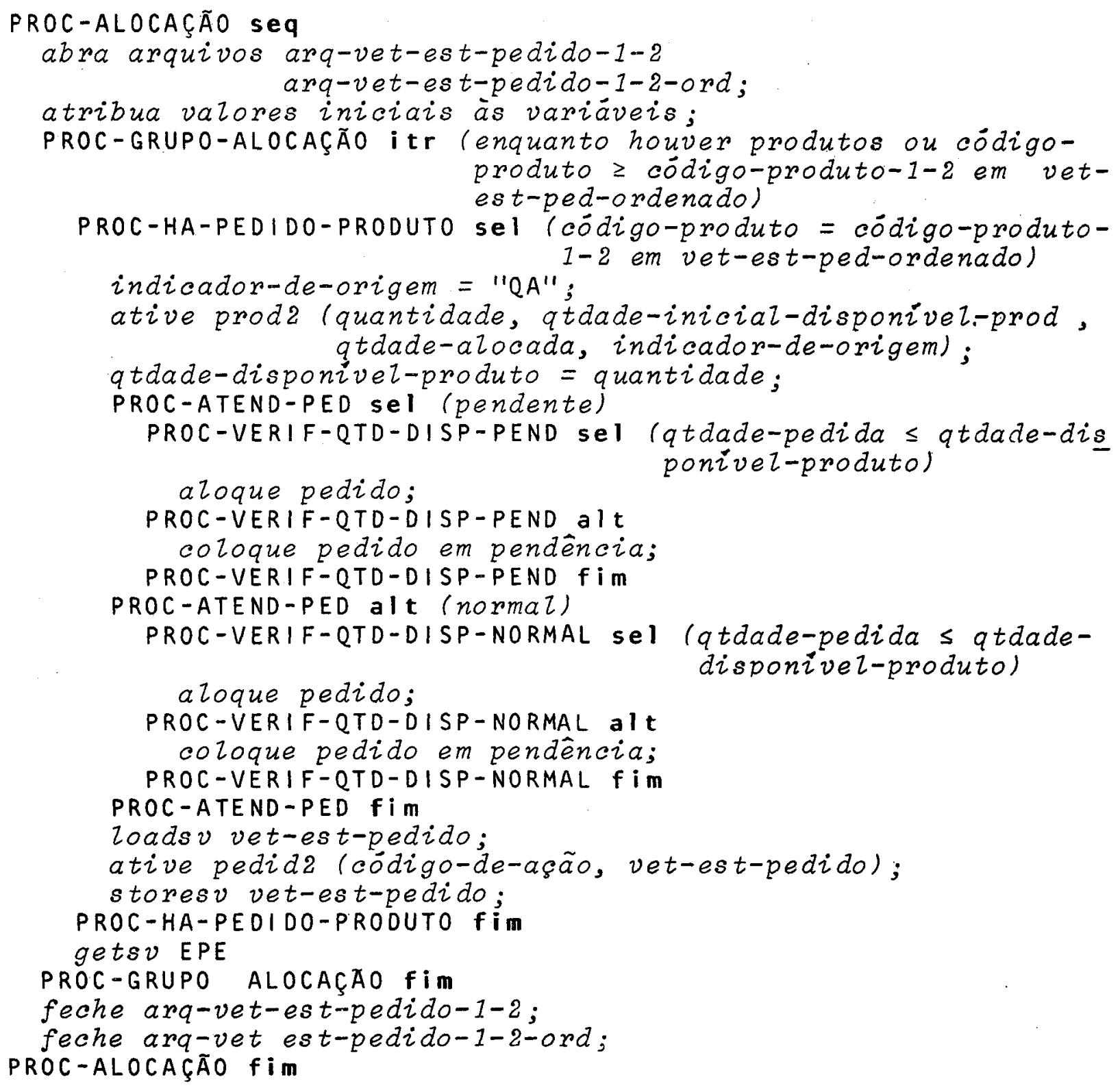

Texto Estruturado da adaptação da implementação do processo funcional ALOCA Figura 5.21 
produto, deve-se verificar se a quantidade em estoque è suficiente para alocá-lo ou se será colocado em pendência. PEDID2 é ativado para atualizar estado-pedido. 0 parágrafo PROC-HA-PEDIDO-PRODUTO foi criado devido à necessidade de balanceamento. Es sal necessidade surgiu devido ao fato de que a implementação é feita para o atendimento de pedidos de todos os produtos, quan do um fluxo a alimenta o articulador, e não para o atendimento de um produto específico fornecido pelo usuärio. Esse tipo de implementação foi utilizado para que ficasse condizente ao que ocorre na prática.

o arquivo ordenado VET-EST-PED-1-2-ORD é o resulta do da resolução de um choque estrutural de ordenação. Esse choque ocorre porque o arquivo que contém os pedidos, ARQ-VET-ESTPEDIDO-1-2, está ordenado por código de produto. Há necessidade de que o arquivo seja ordenado também por estado do pedido, a fim de que, para um determinado produto, primeiro sejam atendidos os pedidos pendentes e depois os outros.

PROD-2 è ativado por ALOCA, com indicador-de-orí gem igual a "QA", informando a quantidade já alocada do produto. PROD-2 subtrai essa quantidade da quantidade que foi salva quan do ativado por PRODI, enviando a $A L O C$ a quantidade realmente disponivel. A quantidade alocada do produto é enviada ao ARTIC para que ele atualize o arquivo ARQ-VET-EST-PRODUTOS-1-2-ALOC. Isso é necessário, pois da forma como foi implementado, pode-se ter mais do que uma alocação por periodo.

As operações "getsv" EPR e "getsv" EPE são realiza das, respectivamente, através da passagem do parāmetro qtdadeinicial-disponivel-prod e pela leitura do arquivo ARQ-VET-ESTPED-1-2-ORD. Tendo-se um código-produto, deve-se obter todos os pedidos, pendentes e normais, desse produto. Enquanto o códigoproduto for igual ao do pedido, deve-se ler somente o arquivo de pedidos, ARQ-VET-EST-PED-1-2-ORD. Quando ocorrer uma mudança de código-produto nesse arquivo, deve-se obter a quantidade dis ponivel de um novo produto.

A figura 5.22 mostra o programa correspondente à implementação de ALOC. 
IDENTIFICATION DIUISION.

FROORAM-ID. FLOC.

RUTHOR. ROSANGELA FENTEADO.

* SUEROTINa que IMFlementa o. Frocesso funcional

* aloc.

ENUTRONMENT DIUISTON.

INFUT-OUTPUT SECTION.

FILE-.CONTROL.

SELECT ARQ-UET-EST-FEDIDD-1-2 ASSIGN TO DISK

ACCESS FODE IS RANDOM

ORGANIZATION IS INDEXED

AECORD KEY IS NRD-FEDIDO.

SELECT ARQ-VET-EST-FEDIDO-1-Z-ORD ASSIGN TO DISK

ACCESS MODE IS SEQUENTIAL

ORQANIZATION IS LINE SEQUENTIAL.

DATA DIUISION.

FILE SECTION.

FD $A R Q-V E T-E S T-F E D I D D-1-2$

LAEEL RECORD IS STANDARD

VALUE OF FILE-ID IS "E:FED.DAT".

01 VET-EST-FEDIDO

$G 2$ NRO-FEDIDO

OC NRO-CLIENTE-FEDIDO

FIC $x(4)$.

QC COOIGOAROOUTO12

(2) QTDADE-FEDIDA

DC DATA-SOLICITADA

G2 ESTADO - FEDIDO

GZ NRO-MODIFICACOES

FD ARQ-VET-EST-FEDIOD-1-2-ORD

PIC $x(4)$.

PIC $x(5)$.

FIC $9(4)$.

FIC $9(6)$.

FIC $X(4)$.

LABEL RECORD IS STANDARD

VALUE OF FILE-ID IS "E S SAIDA. SOR"

Q1 VET-EST-FED-1-2-ORDENADO

WORKING-GTORAGE SECTION.

Q1 VET-EST-PED-OROENADO.

Q2 NRO-FEOIDO-1-2

O2 NRO-CLIENTE

G2 CODTOO-FRODUTO-1-2

Q己 QTDADE FEDIDA

Q2 DATA-SOLICITADA

0. ESTADO-FEDIDO

Q2 NIROMODIFICACOES

a1. CODTGO-OE-ACAO

01 TNDTCADOR-DE-DRIGEM

Q1 PEOIDOS-ATENDIDOS

D) QTD-ALOC-PROD

(1) QTDRDE-DISFONIVEL-FRODUTO

Q1 QTOADE-ALOCADA-AUX

Q1 QUANTIDADE

O1 QTDADE-INICIAL-DISFONIVEL-FROD

F.IC 99.

LINKAGE SECTION.

Q1 COOIGO-FRODUTO

D1 QTDFDE-ALOCADA

FIC $\times(29)$.

PIC $x(4)$.

FIC $X(4)$.

PIC $x(5)$ VALUE LOW-VALUE.

FIC $9(4)$.

FIC $9(6)$.

FIC $x(4)$.

F.IC 99.

PIC 9.

PIC $X X X$.

PIC 99.

PIC $9(4)$.

PIC $9(4)$.

FIC $9(4)$.

Fic $9\langle 4\rangle$.

FIC $9(4)$.

PIC $x(5)$.

PIC $9(4)$.

Implementação do processo funcional ALOCA

Figura 5.22 
PROCEDURE DIUISION USINI CODIOU -FRODUTO WTOADE-ALOCADA.

PROC-

OFEN I-G AHQ-VET-EST-FEDTOU-1-2.

IF CODIGU-F'RDDUTO-1-2 IN VET-EST-PED-ORLENHDO

* LOW-UAL.UE

OFEN INPUT HRQ-VET-EST-F'EDIDO-1-2-ORD.

MOVE ZEROS TO QTUADE-ALOCAUA-AUX.

MOVE ZEROS TO FEOIOOS-ATENOLOOS.

MOUE ZEROS 10 QTD-ALOC-FROD

PROC-GRUPO-ALOCACALITITR

IF CODTGO-FRODUTO $\mathrm{HIGH-VALUE} \mathrm{OR}$

CODIGOAFOUUTO $<$ CODIGO FROOUTO-I-2 IN

VET-EST-F'ED-ORDENGOO

GO TO FROC-GRUF-OD-ALOCACAO-FIM.

FROC-HA-FEDIDO-FRODUTD-5EL.

IF COOIGU-FRODUTO NOT $=$ COUIGO-FRODUTO-1-2 IN

VET -EST-FED-ORDENADO

BO TO FROC-HA-I'EDIDO-PRODUTD-FIIA.

MDVE "DA "TO INDICADOR -DE-ORZIGEM.

CALL "PRODE" USING QUANTIDADE QTDADE-TNICIAL-DISPONIVEL-FROD

QTDHDE-ALOCADA INDICADOR-DE-ORIGEM.

MOVE QUANTIDADE TO QTLADE-DISPONIVEL-PRODUTO.

PIROC-ATENO-FED-SEL-FENDENTE

IF ESTADO-FEDIDO IN VET-EST-FED-ORDENGDO NOT = "AOUD"

BO TO PRDC-ATEND-FED-ALT-NORMAL.

FROC-VERIF-QTD-UISF-FEND-SEL.

IF QTDROE-FEDIDA IN VET-EST-PED-ORDENADO >

QTOADE-DJSF DNIVEL-FRODUTO

GO TO PROC-VERIF-QTD-DISP-FEND-ALT.

ADO QTOADE-FEDIDA IN VET-EST-FED-ORDENADO

TO QTDADE-ALDCFOA-AUX

ADD QTDADE-FEDIOA IN UET-EST-PED-ORDENAUD

TO QTD ALOC-FROD

SUETRACT QTUADE-FEDIDA IN VET-EST-FED-ORDENADO

FROM QTDAOL-OISPONIVEL-PRODUTO

MOVE 6 TO CODIGOMDE-ACAO

OO TO PROC-UERIF-QTD-OISF-FEND-FIM.

PROC-VERIF-QTD-OISF-PEND-ALT.

MOUE 5 TO CODIGO-DE $A$ TCAO.

PROC-UERIF-QTO-DISF-FEND-FIM.

GD TO PROC-ATEND-FED-FIM.

FROC-ATEND-FEL-ALT-NORMAL.

PROC-VERIF-QTD-OISP-NORMAL-SEL.

IF QTDADE-PEDIDA IN UET-EST-PED-ORDENADO ?

QTDADE-DISFONIVEL -FRODUTO

GO TO FROC-UER IF-QTD-DISF-NORMAL-FLT.

ADD QTDRDE-FEDIDA IN VET-EST-PED-ORDENADO

TO QTDRDE-ALOCADA-AUX

ADD QTOGDE-FEDIDA IN VET-EST-FED-ORDENADO

TO GTD-ALOC-FROD

SUETRACT QTDADE-FEDIDA IN VET-EST-FED-ORDENADO

FROM QTOADE-DISFONIVEL-FROOUTO

MOUE $\&$ TO COOIGO-DE-ACAO

GO TO PROC-VERIF-QTD-DISF-NORMAL-FIM.

FROC-VER IF-QTO-DISF-NORMAL-ALT .

MUVE 5 TO COOIGO-DE-ACAO.

FROC-VERIF-QTD-DISF-NORMAL-FIM.

PROC-ATEND-FED-FIM.

MOVE VET-EST-FED-1-2:-ORDENADO TO VET-EST-FEDIDO.

CALL "FEDIDE" USING CUDIGO-DE-ACRO VET-EST-FEDIDO.

REWRITE VET-EST-PEDIDO.

PROC-HA-PEDIOO-FRODUTO-FIM.

READ ARQ-VET-EST-FEDIDD-1-2-DRD INTO VET-EST-PED-ORDENADO

RT END MOVE HIGH-UALUE TO CODIGO-FRDOUTO.

MOUE QTD-OLLC-PRDD TO QTOAUE-ALOCRDA.

MOVE ZEROS TO QTD-ALOC-YKOD.

OO TO FROC-GRUFO-ALOCACAO-ITR.

PROC-GRLF'O-ALULHLAU FI IM.

MOUE QTDAUE-FLUCADA-AUX TO QTDADE-ALOCADA.

IF CODIGO FROOUTO $=$ HIGH-VHLUE

CLOSE AKU-VET-EST-FED IDO-1-2-OKO.

CLOSE ARQ-VET-EST-FEDLDO-1-2

EXIT PRCOOKRM.

FROC-GLOCACAO-F IM.

Figura 5.22 (cont.) 
5.4.3. - Processo LIST

Comparando-se os diagramas de estrutura, figuras 4.39 e 5.23 , e os respectivos textos estruturados, figuras 4.40 e 5.24, nota-se que: O PROC-LIST, figura 5.23, é uma seleção por receber informaçōes de PEDID2 e também por ser ativado pelo fluxo de marcador de intervalo de tempo $L$, que è lido pelo ARTIC. Assim, a seqüència PROC-AÇÃO-LIST-IRL, figura 5.23 , é executada quando ocorre a gravação de um pedido, alocado ou pendente, que vai compor o relatório. Quando for ativado pelo ARTIC, a seqüência PROC-AÇAO-LIST-L, figura 5.23, é executada. Essa parte, com alterações, é a que a figura 4.39 se refere. A iteração PROC-LIST, aí contida, è realizada pelo articulador, quando alimentado por um fluxo $L$.

o arquivo ARQ-DE-LISTAGEM contém todas as informações enviadas por PEDID2, ou seja, armazena os registros corres pondentes aos pedidos pendentes e aos pedidos alocados. Quando - fluxo L é lido pelo ARTIC, e PROC-AÇÃO-LIST-L é executado, o arquivo ARQ-LISTAGEM é fechado. Esse arquivo contém uma chave que é formada por código-produto, estado-pedido e nro-pedido, assim, resolve-se o problema de choque estrutural de ordenação que ocorre com as informações provenientes de PEDID2. Essas informações podem gerar registros IRL's com as condições alternadas sobre o pedido, ou seja, pedidos pendentes e alocados, para um mesmo produto. A confecção do relatório é elaborada da seguinte forma: todos os pedidos pendentes e, depois, todos os pe didos alocados de um determinado produto. Esse choque estrutural foi resolvido através da chave mencionada.

A figura 5.25 mostra o programa correspondente à implementação de LIST. 


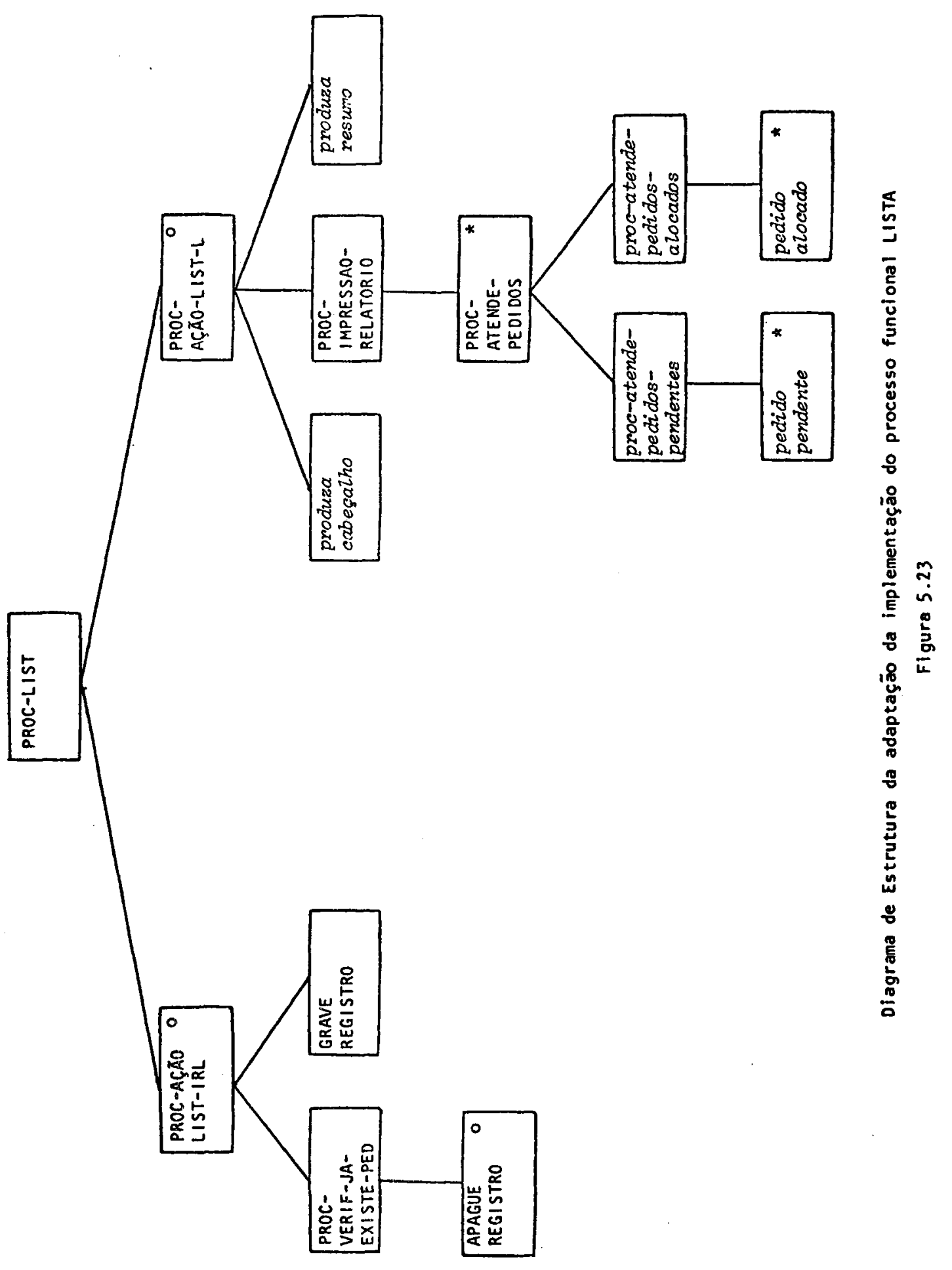




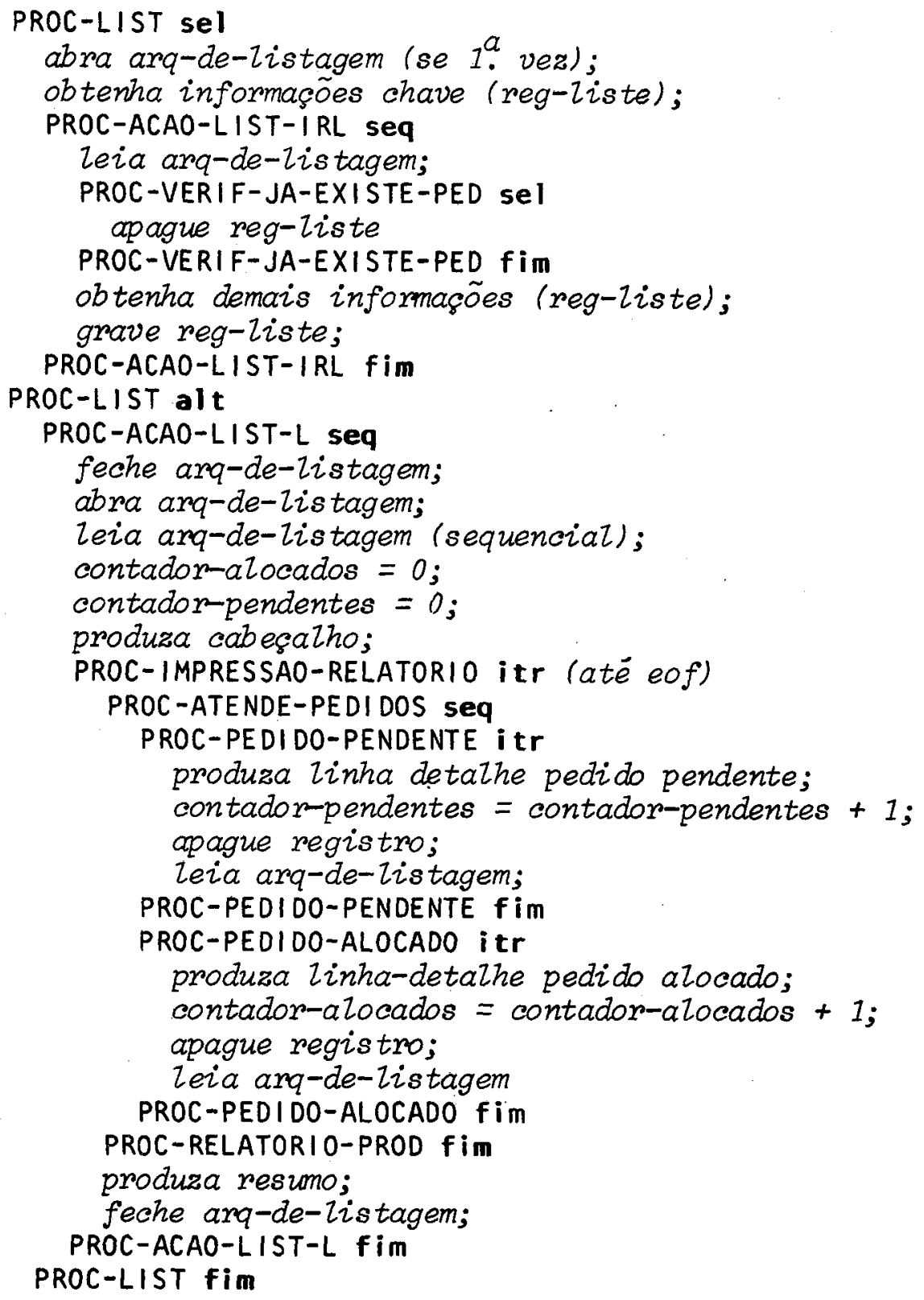

Texto Estruturado da adaptação da implementação do processo funcional LISTA Figura 5.24 


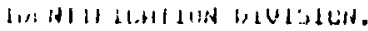

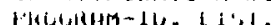

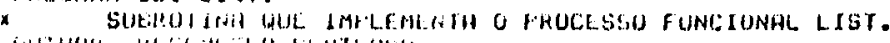

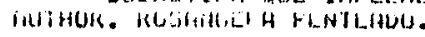

EIUIRONALNI DIVISIONO

INHUT-UUTFUI \&E

FILE-COHTRUL.

SELECT PAG-DE-LISTAGEM ASTISA TO DISK

HGCESS MUOE IS OYNIMMLO

LKISIIILZHILUN IS IHILXEU

RiLOHL KEY IS RHAUE.

SELECT HRIT-DL-IMFHESSFO ASSISN TO DISK

ACCESS MODE IS ST.MUENTIAL

OHGANILATION IS LINE GLQQULNTIAL.

OPTA UIVISIOH.

FILE SECIIUN.

FD ARG-DE-L.ISTROEM

LAGEL KECOKD IS STANOARD

VALUE OF FILE-IO IS "BILISTE.SAI".

OI RED-LISTE.

QZ CHAVE.

US COUIGO-FRODUTO
O3 ESTADO-FEDIDO

03 NRO-PEDIDO

02 NHO-CLIENTE

Q2 GTLADE-FEOTDA

Q2 OATA-ENTREGA-SOLICITHOA.

03 DIA

QS MÉS

QS ANO

03 MEES
OJ ANO
PIC 99.

D ARG-DE-IIARRESSAO

LAEEL KECORD IS STANDRRD

VALUE DF FILE-ID IS "BIIMFR OUT"

Q1 LINHA-IMFREGSAO PIC $x(132)$.

WURKING-SIORAGE SECTION.

D1 FRIMEIRA-VEZ

81 CONTADOR-FENOENTES

O1 CON RAUOR-ALUCADOS

Q1 COOIGQ-PROUUTO-AUX

61 COOIGO-FRODUTO-SALUA

CAEECALHO.

g2 FILLER

G2 FILLER

02 FILLER

O1 LINHA-DETALHE-CABECALHO.

O2 FILLER

OC FILLER

Q2 FILLER

02 FILLER

02 FILLEA

Q2 FILLER

22 FILLER

O2 FILLER

02 FILLER

92 FILLER

פ2 FILLER

O2 FILLER

D1 LINHA-DETALHE.

O2 FILLER

OC CUUIGO-PRUDUTO-SAI

02 FILLER

OC NRO-CLIENTE-SAI

Q2 F ILLER
OZ NRO-FEDIDO-SAI

BZ FILLER

G2 OTOADE-FEDIOA-SAI

OZ FILLER

O2 ESTADO-FEOIOO-SAI

D2 FILLEF

Q2 DIA-SAI

42 FILLER

U2 FILLER

Q2 KES-SA

G2 FILLER

a) LINHA-DE-TUIAL-PEND.

DE: FILLER

FIC $x(5)$.

PIC $x(4)$

FIC $x(4)$.

FIC $9(4)$.

PIC 99.

PIC 99.

Q2 FILLER

Fic 9 value 0.

PIC 999.

PIC 999.

PIC $x(5)$

FIC $X(45)$ UALUE SPACE

FIC $x(28)$ VALUE

"** RELATORIO OE PRODUTOS".

PIC $x(05)$ VALUE " ***".

FIC $X(16)$ UALUE SFACES.

PIC $X(11)$ UALUE "COD PRDDUTO".

FIC $X(B))$ VALUE SPACES.

PIC $x(11)$ VALUE "NRO CLIENTE".

PIC $x$ (08) UALUE SFACES.

$F I C X(18)$ UALUE "NRO PEOIDO".

FIC $x(0 B)$ VALUE GFACES.

PIC $x(13)$ VHLUE "QTDADE FEDIOA".

FIC $x(\theta 8)$ VALUE SF'ACES.

PIC $X(13)$ VALUE "ESTADO PEDIDO".

$P I C X(G B)$ URLUE SPACES.

PIC $x(14)$ VALUE "DATA P/ENTREGA".

FIC $X(14)$ UALUE SPACES.

PIC $X(05)$.

PIC $x(14)$ VALUE SPACES.

FIC $9(4)$.

FIC $x(15)$ VALUE BPACES.

FIC $X(4)$.

PIC $X(15)$ URLUE SPACES.

FIC $9(4)$.

PIC $x(18)$ VRLLE SPACES.

PIC $x(4)$.

PIC $X(13)$ Value sFaces.

PIC 99.

pic $X$ value " $/$ ".

PIC 99.

FIC $X$ Ualue "/".

FIC 99 .

PIC $x(40)$ VALLE SPPAES.

PIC $X(29)$ VALUE

"TOTAL DE PEUIdOS PENDENTES - "

GE CUNTHDUR-PEO-PENULNTES PIC $999^{\circ}$

Q1) L. INHA-DE-IUTRL-ALUC.

BD FII.LEN

PIC $X(40)$ VALUE SFALES.

Gid FILLi:K

O2 CUNTALUR-FED-AL.CCROUS

PIC $X(20)$ VIALUE

"TOTAL de FEDIOOS Rlocados " "

LXNKAOE SECTION.

B) INUICHUUR-DL-DIRIGEM

di) Rt:(I-P Hilis-jHIDH.

G. NRIU-F, D D OU

DE NIUU CLIENIR-YEOLOO

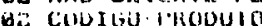

Ha: RIDHUT - COIDA

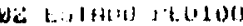

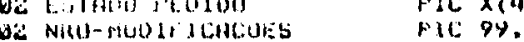
PIC 999 .

FIC $X \times X$

PlC $x(4)$.

F!C $P(11)$.

Fic is (4).

$F(c) P(1)$
lit. $P(0)$

Implementação do processo funcional LIST

Figura 5.25

- 160 - 


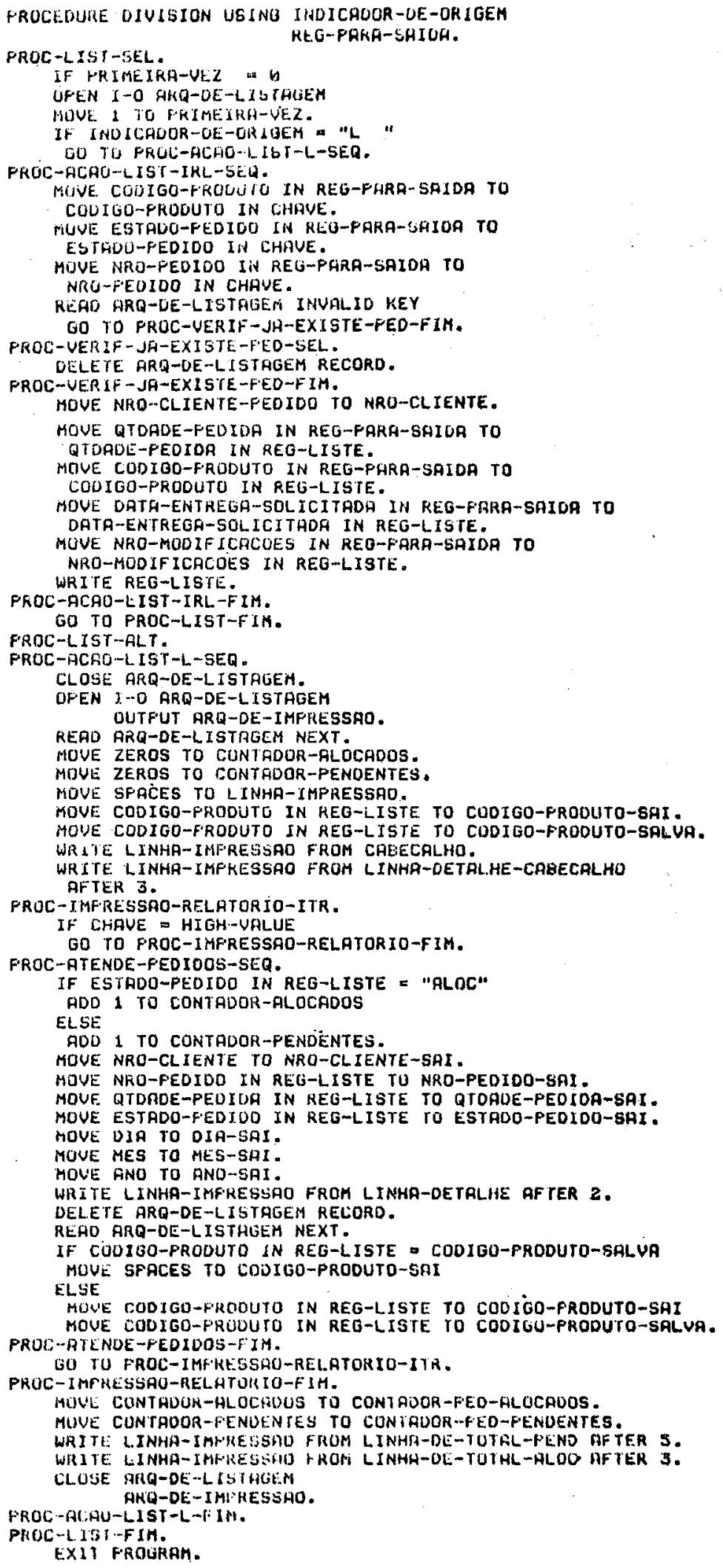

Figura 5.25 (cont.) 
5.5. - Sobre a Implementação do Processo de Articulação

A finalidade desse processo, como seu pröprio nome diz, ë ligar os demais processos. Quando for "alimentado" pelos fluxos de dados $A$ e L, a chamada das subrotinas ALOC e LIST Ocorre através do comando CALL e dos parāmetros já mencionados Ao ser "alimentado" com fluxos C e CO, os processos CLII e CONSUL, respectivamente, são ativados pelo comando CHAIN, devido às restriçōes de memöria existentes no equipamento utilizado. Comparando-se os diagramas de estrutura, figuras 5.26 e 5.28, e os respectivos textos estruturados, figuras 5.27 e 5.29, nota-se que: a seqüência PROC-ENTR-ARTIC-ALT-ALOCA, fí gura 5.28, é formada por "ative ordem", "ative prodl" e a itera ção PROC-ENQTO-HOUVER-PRODUTO, enquanto que na figura 5.26 , é realizada só por "ative prodl". Isso ocorre porque a alocação é feita para todos os produtos e não só para um determinado produto.

Da forma como foi implementado esse sistema, não correm verificaçōes, como por exemplo, um pedido pode ser modificado, mesmo que ele já tenha sido cancelado.

o processo ALOC, quando ativado, consome um certo tempo sem que outras operações possam ser realizadas, ou seja, - ARTIC fica bloqueado. Esse caso pode ser solucionado utilizan do-se reservatórios, "buffers", como Jackson mostra na segunda implementação desse problema-exemplo, em [ Ja83].

o processamento é encerrado quando o articulador é "alimentado" com o fluxo NO.

A figura 5.30 mostra o programa correspondente a essa implementação. 

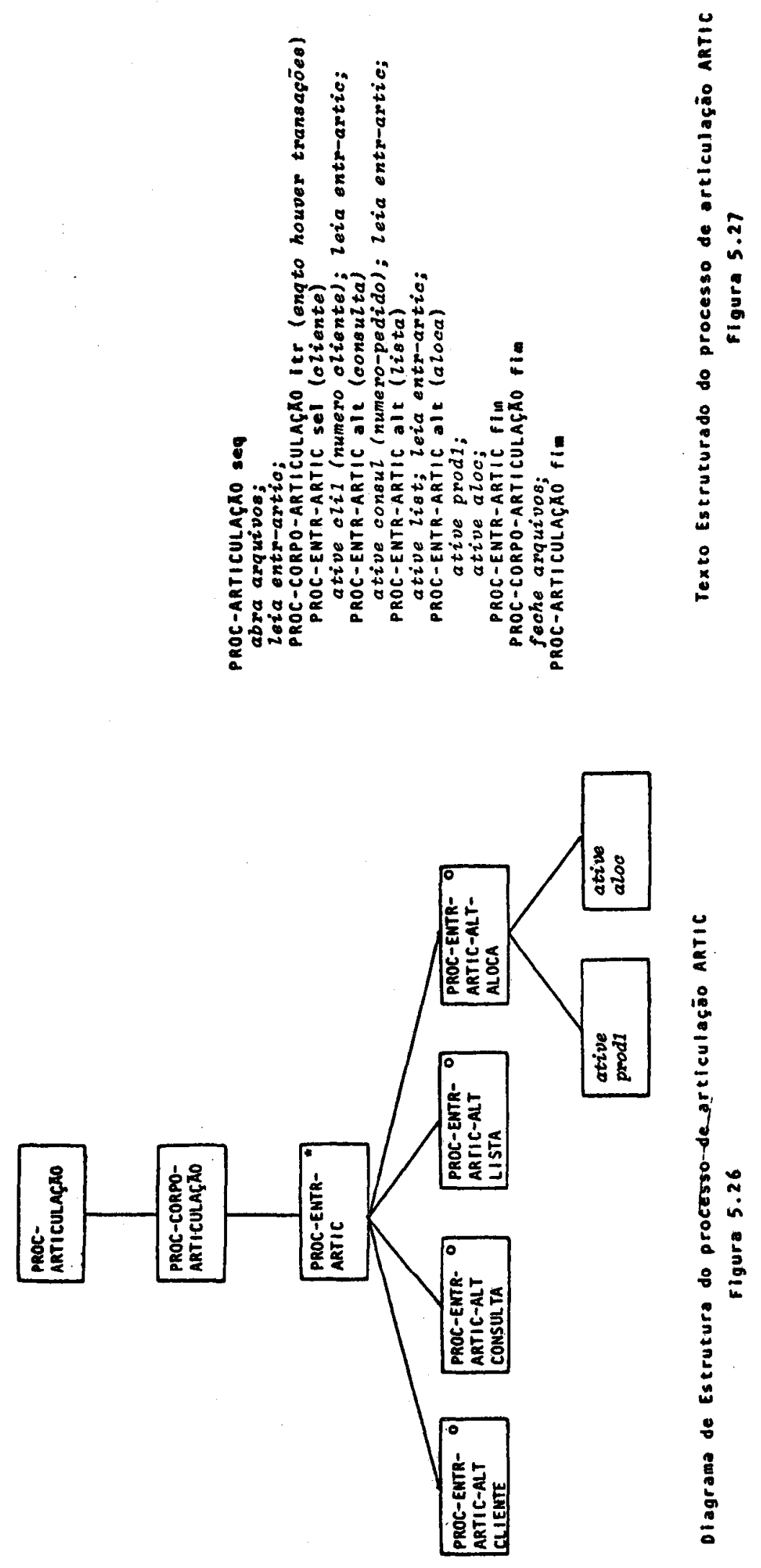


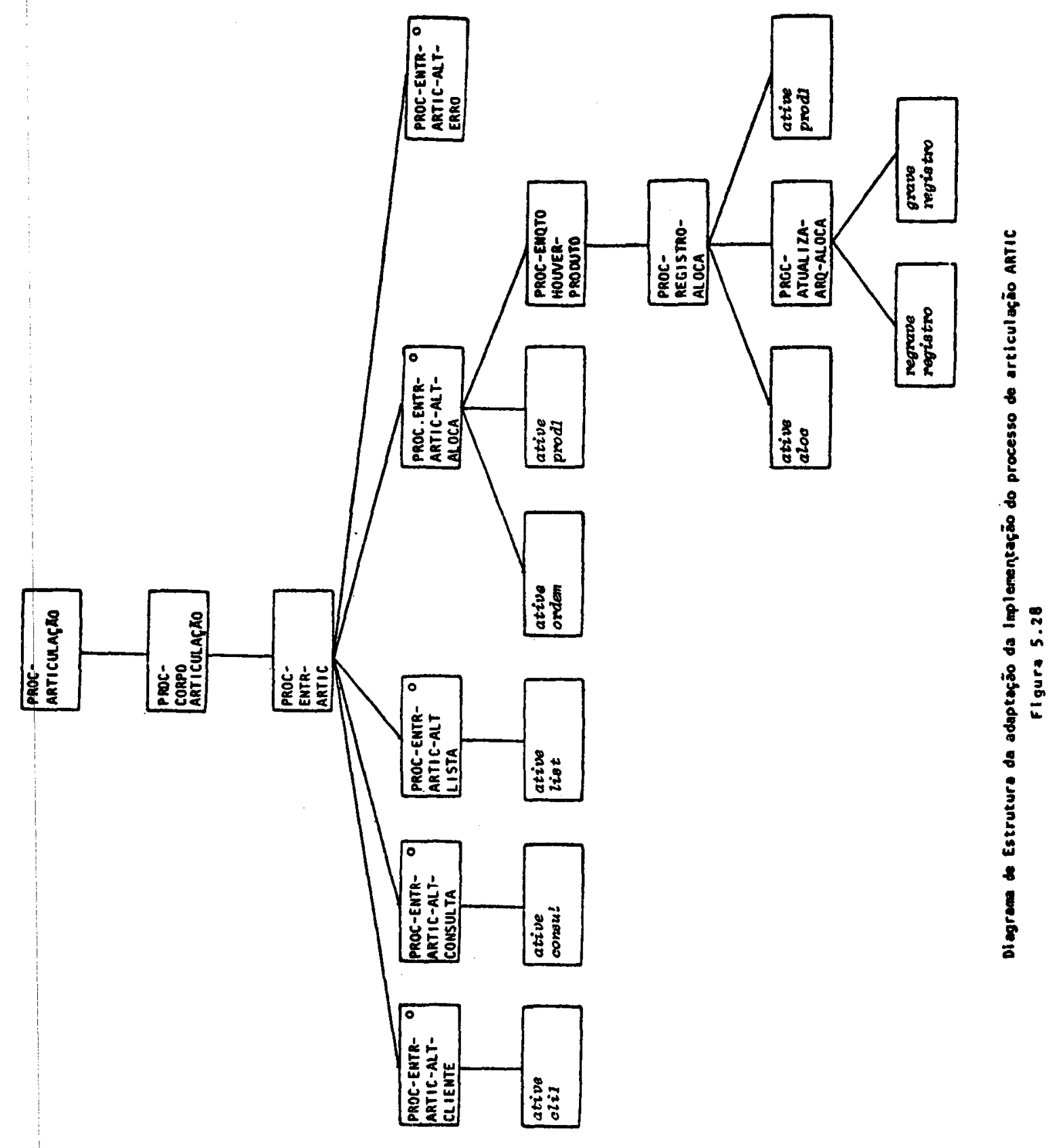




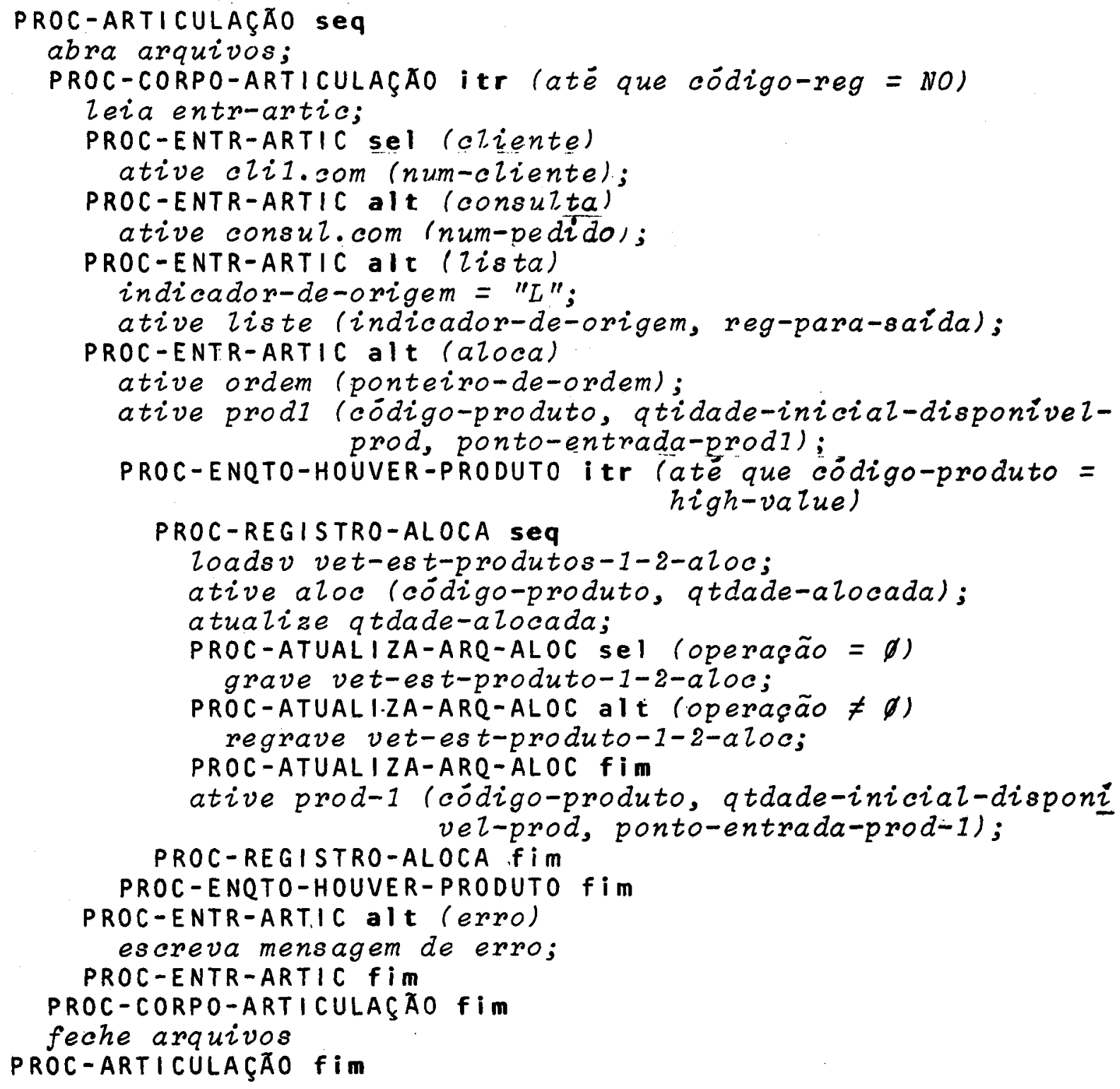

Texto Estruturado da adaptação da implementação do processo de articulação ARTIC

Figura 5.29 
IDENTIFICATION DIUISION.

FROGRAMIID. ARTIC.

RUTHOR. ROSANGELA FENTEADO.

* SUEROTINÁ QUE IMFLEMENTA O FROCESSO DE GRTICULRCAO ARTIC. EXEMFLO DA FRIMEIRA IMFLEMENTACAO APRESENTAPOR JACKSON EM [JA83].

ENUIRONMENT DIUISION.

INFUT-OUTFUT SECTION.

FILE-CONTFOL.

SELECT ARQ-VET-EST-CLIENTE-1 ASSIGN TO DISK

ACCESS MDOE IS RANDOH

ORGANIZATION IS INDEXED

RECORD KEY IS NRO-CLIENTE.

SELECT ARQ-UET-EST-FRODUTOS-1-Z-ALOC ASSIGN TO DISK

ACCESS MODE IS RANOOM

ORGANIZATION IS INDEXED

RECORO KEY IS CODIGO-FRODUTO-ALOC.

SELECT ARQ-NRO-CLIENTE ASSILN TO DISK

ACCESS MODE IS SEQUENTTAL

DRGANIZFTION IS LINE SEQUENTIAL.

SELECT ARQ-NRO-FEDIDO ASSIGN TO DISK

ACLESS MODE IS SEQUENTIAL

ORGANIZATION IS LINE SEQUENTIAL.

DATA DIUISION.

FILE SECTTON.

FD AKQ-UET-EST-CL IENTE-1

LAEEL RECORD IS STANDARD

VALUE OF FILE-ID IS "EI:CLI.DAT"

01 REG-CLIENTE.

Q2 NRO-CLIENTE FIC $X(4)$.

Q2 NOME-CLIENTE PIC $A(30)$

QE ENOERECO-CLIENTE PIC X(40).

FD ARQ-VET -EST-FRDDUTOS-1-2-ALOC

LAEEL RECORD IS STANDARD

UALUE OF FILE-ID IS "B:ALLP.DAT"

01 VET-EST-PRODUTOS-1-2-ALOC.
G2 CODIGOMRODUTO-ALOC
PIC $X(5)$

Q2 QTOADE-JA-ALOCADA PIC $9(4)$.

FD ARQ-NRO-CLJENTE

LAEEL RECORD IS STANDARD

VALUE OF FILE-IU IS "E:NUMCLI.DAT".

01 REQ-NRO-CLIENTE.

G2 NUM-CLIENTE

FD ARQ -NRO-FEDIDO

PIC $9(4)$.

LAEEL RECORD IS STANDARD

URLUE OF FILE-ID IS "E:NUMPED.DAT".

01 REG-NRO FEDIDO.

Q2 NUM-F.EOIDO

WORKING-STORAGE SECTION.

O1 NUMERO-CLIENTE

FIC $x(4)$.

G1 NUMERO-FEDIDO

01 CODIGO-REG

Q1 INDICADOR-DE-ORIGEM

91 REG-PARA-SAIDA

Q1 CADASTRO-ENCONTRADO

01 CODIGO-FROOUTO

Q1 QTDADE-INICIAL-DISPONIVEL-F'ROD

Q1 QTDADE-ALOCADA

Q1 DFERACAO

Q1 FONTO-ENTRFOR-PRODI

Q1 PONTEIRO-ORDEN

Q1 CODIGO-DE-TRANSACAO

SCREEN SECTION

O1 TELA-LIMF'A FLANK SCREEN.

PIC $9(4)$.

PIC $X(4)$.

PIC $X X$.

PIC $X X X$ UALUE "L "

PIC $X(29)$ VAlUE SFACES.

FIC $A$.

PIC $X(5)$

PIC $9(4)$.

FIC $9(4)$

FIC 9.

FIC 9 .

PIC 9 .

FIC 9 .

Implementação do processo de articulação ARTIC Figura 5.30 
I'RUGEOUR: DLUTLIUN .

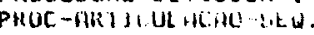

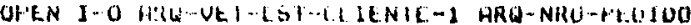

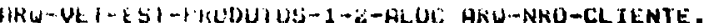

PROC-CORFU-HNTICULHLOHU-J IN

MOVE "S" IO CHUHSIRO-LNLONTRHDO

UISTLLY TELA-LIMFN.

Dlsplar $(2,1)$ "DIGIIt hS INFORMACOES SOLICITHDAs".

DISFlar ( 3 , 1) "COOdIO OA TRHASACAO".

ACLEH $(3, \mathrm{aE})$ COUICO-NEG.

If lOOU IBO RE " "NU"

(30) 10 FHUL-CORPU-HKTILULACAO-FIM.

MOVE, I TO CODIGO ODE-TRANSACRO.

IF CUOLOO-RLG $\approx ": "$

MOUE 1 TO CODIOO-DE-TRANSACAO.

IF COOIGO-REG a "LO"

MOVE 2 TO EULIGO-OE-TKANSACAO.

IF COOIOU-REG "L.

MOUE 3 TO CUDIGO-DE-TRANSACAO.

IF CODIGO-REG - "A "

HOVE 4 TO CODIGO-DL-TRANSACAO.

PROC-ENTR-RKTIC-SEL.

GO 10 FROC-ENTR-ARTIC-ALT-CL. LENTE

PKOC-ENTR-FIRTIC-ALT-CONSULTR

FROC-ENTR-ARTIC-HLT-LISTA

PROC-ENTR-GRTIC-ALT-ALOLA

PROC-ENTR-ARTIC-ALT-ERRO

PROC-ENTR-AR TIC-ALT-ERRO
DEPENDINB ON CODIGO-DE-TRANSACAO

PROC-ENTR-ARTIC-ALT-CLIENTEE.

OISFLAY (S, 1) "NLIMERO DO CLIENTE".

ACCEPT $(5,20)$ NUMERO-CLIENTE.

MOVE NUMERO-CLIENTE TO NRD-CLIENTE.

READ ARQ-VET-EST-CLIENTE-1 INUALIO KEY

DISPLAY (6, 16) "CLIENTE NAO CADASTRADO"

STOP " "

GO TO PROC-ENTR-ARTIC-FIM.

READ ARQ-NRO-CLIENTE AT END

GO TO FROC-ENTR-ARTIC-FIM

MOVE NUMERO-CLIENTE TO NUM-CLIENTE.

REWRITE REG-NRO-CLIENTE.

CHAIN "BICLI1.COM".

PROC-ENTR-ARTIC-ALT-CONSULTA.

DISPLAY (5. 1) "NUMERO DO PEDIDO".

ACCEPT (5. 2Q) NUMERO-PEDIOO.

REPD ARQ-NRO-FEDIOO RT END

GO 10 PROC-ENTR-ARTIC-FIM.

MOVE NUMERU-PEDIDO TO NUM-PEDIDO.

REWRITE REG-NRO-FEDIDD.

CHAIN "B : CONSUL , COM".

PROC-ENTR-ARTIC-RLT-LISTR

CALL "LIST" USING INOICRDOR-DE-ORIGEM REG-PARA-SAIDA.

GO TO PROC-ENTR-ARTIC FIK.

PROC-ENTR-PRTIC-ALT-ALOCR.

CALL "ORDEM" USING PONTEIRO-ORDEM.

MOVE 1 TO PONTO-ENTRAOA-PROD1.

CRLL "PRODI" USING COUIGO-FRODUTO

QTDRDE-INICIAL-DISPONIVEL-PROD

MOVE 2 TO PONTO-ENTAGOA-FRODI

PROC-ENGTO-HOUUER-PRODUTO-ITR.

IF CODIGO-FRODUTO = HIGH-VALUE OR

PONTO-ENTRROA-FROOI $=3$

BO TO FROC-ENQTO-HOUUER-PRODUTO-FIM.

MOVE 1 TO OPERACAO.

KOVE COOIGO-PRODUTO TO CODIGO-PRODUTO-ALOC.

READ ARQ-UET-EST-PRODUTOS-1-2-ALOC INUALID KEY

MDVE ZEROS TO QTOADE-JA-ALDCADA

MOUE ZERO TO OFERACAO.

MOVE QTDADE-JA-ALOCADA TO OTDADE-ALOCADA.

PRDC-REGISTRD-ALOCA-SEQ.

CALL "RLOC" USING COOIOO-FRODUTO QTDADE-ALOCAOA.

ADD QTORUE-FLOCADA TO OTDADE-JA-ALOCADA.

PROC-ATUALIZA-ARQ-ALOC-SEL

IF OPERACAO 0

WRITE VET-EST-PRODUTOS-1-Z-QLOC

GO TO PROL-ATUAL IZA-ARQ-ALOC-FIM.

PROC-ATURLIZH-QRO-ALOC-ALT.

AEWRITE VET-EGT FRODUTOS-1-2-ALDC.

PROC-RTURLIIZA-ARQ-ALOC-FIM.

IF CODIGO-FRODUTO O HICH-VALUE

MOVE 3 TO PONTO-ENTKAOH-FROD 1.

CALL "PRODI" USING COOIGO-PHODUTO

QTDFDE-SNICIAL-UISFONIVEL-PROO

FONTO-ENTRADA-FRQOLI.

PROC-REG187KO-ALDCA-F゙IH.

QO TO FROC-ENGTO-HOUVER-FRODUTO-ITR.

PROC-ENGTO-HOUVER-PROOUTO-FIH. GO TU FROC-ENTR-AKTIC-FIH.

PRDC-ENIR-ARTIC-ALT-EKRO.

DI:SLLAY (15. 30) "COOIGO U10ITADO ERRHOO - VERIFIQUE". stor " ".

PHOC - LHTHAGRTIC-FIK.

GO TU PROC-CORFO-RATICULACAO-ITR

PROC-COHFU-AITICULACAU-FIM.

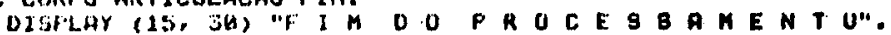

CI.UEE AKQ-VEI-ESY-CI. IENTE-1 ARQ-NHU-PLOIDO HKG-VEI -EET-FRUUU ROS-1-Z-RLOC ARQ-NRO-CLIENTE.
STUFF KUN.

PROL: - GAIS I IGIII.HLHO-I IM.

Figura 5.30 (cont.) 
5.6. - Sobre Alguns Resultados do Processamento

A implementação desse sistema é feita por processamento imediato das transações. Assim, os arquivos são indexados com acesso aleatörio. Algumas informaçōes sāo solicitadas do usuārio que mantēm um diālogo com o sistema. Essas informaçöes são digitadas e aparecem, nesse exemplo, em negrito. 0 que - sistema solicita é colocado somente em letra maiúscula'.

As possibilidades que podem ocorrer, na execução desse sistema, são as seguintes:

CODIGO DA TRANSAÇÃO:

C: PARA CLIENTE

CO: PARA CONSULTA

A : PARA ALOCAÇÃO

$L$ : PARA LISTA

Para CODIGO DA TRANSAÇAOO = C pode-se ter para CODIGO DA TRANSAÇĂO PEDIDO-CLIENTE uma das seguintes alternativas:

MO: MODIFICAR A QUANTIDADE PEDIDA OU MODIFICAR A DATA DE ENTREGA

CO: COLOCAÇÃO DE PEDIDO

CA: CANCELAMENTO DE PEDIDO

RE: RECEBIMENTO DE PEDIDO

Algumas ocorrências do diálogo usuārio/sistema são mostradas a seguir e o relatörio é mostrado na figura 5.31 . 


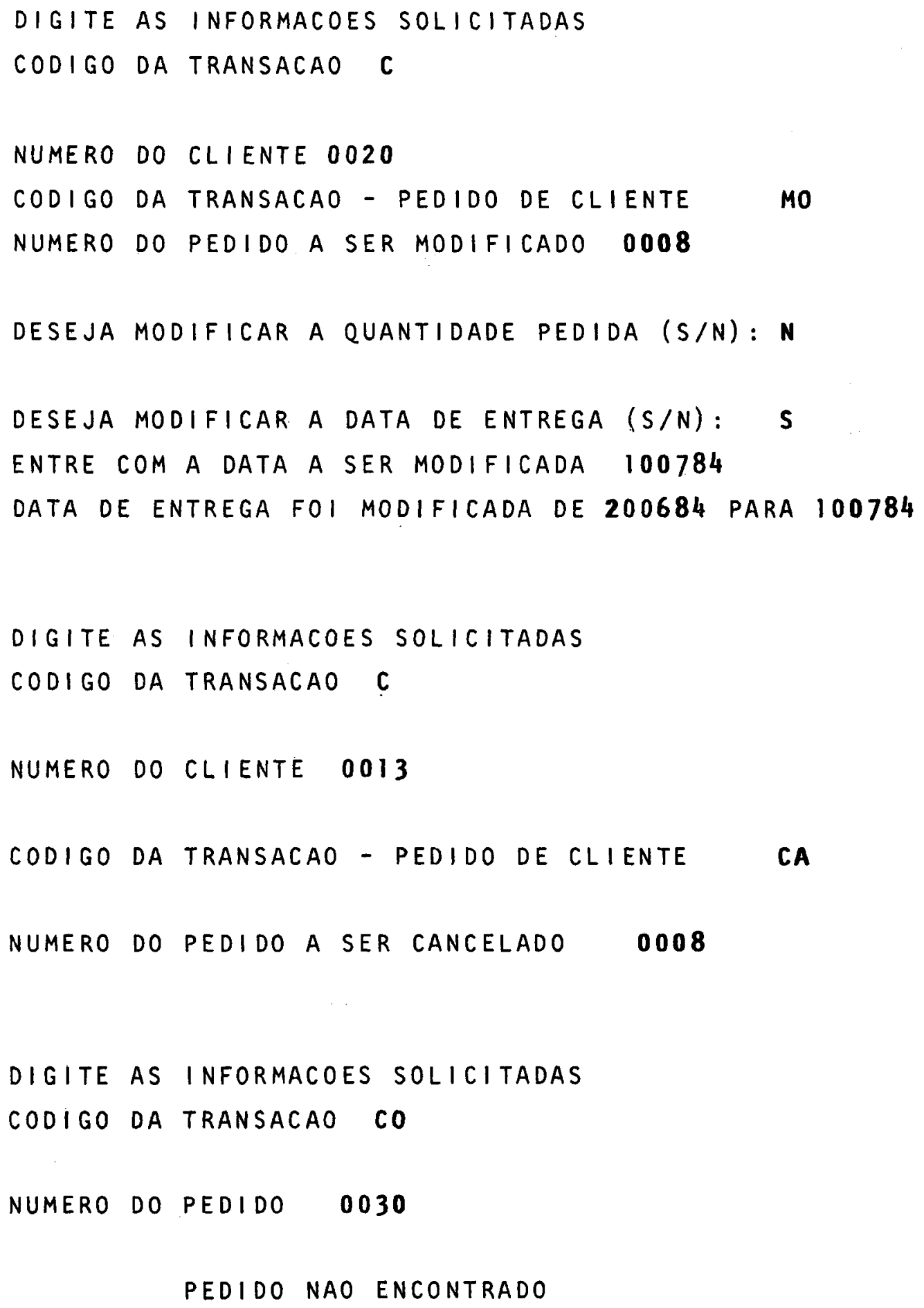


DIGITE AS INFORMACOES SOLICITADAS

CODIGO DA TRANSACAO C

NUMERO DO CLIENTE 0060

CODIGO DA TRANSACAO - PEDIDO DE CLIENTE CO

CODIGO DO PRODUTO CDOO5

QUANTIDADE PEDIDA 0250

DATA DE ENTREGA $\mathbf{2 5 0 6 8 4}$

DIGITE AS INFORMACOES SOLICITADAS

CODIGO DA TRANSACAO C

NUMERO DO CLIENTE 0060

CODIGO DA TRANSACAO - PEDIDO DE CLIENTE MO

NUMERO DO PEDIDO A SER MODIFICADO 0007

DESEJA MODIFICAR A QUANTIDADE PEDIDA (S/N): S

ENTRE COM A QUANTIDADE A SER MODIFICADA 0500

QUANTIDADE MODIFICADA DE 0250 PARA 0500

DIGITE AS INFORMACOES SOLICITADAS

CODIGO DA TRANSACAO CO

NUMERO DO PEDIDO 0008

PEDIDO 0008 ESTA CANCELADO 


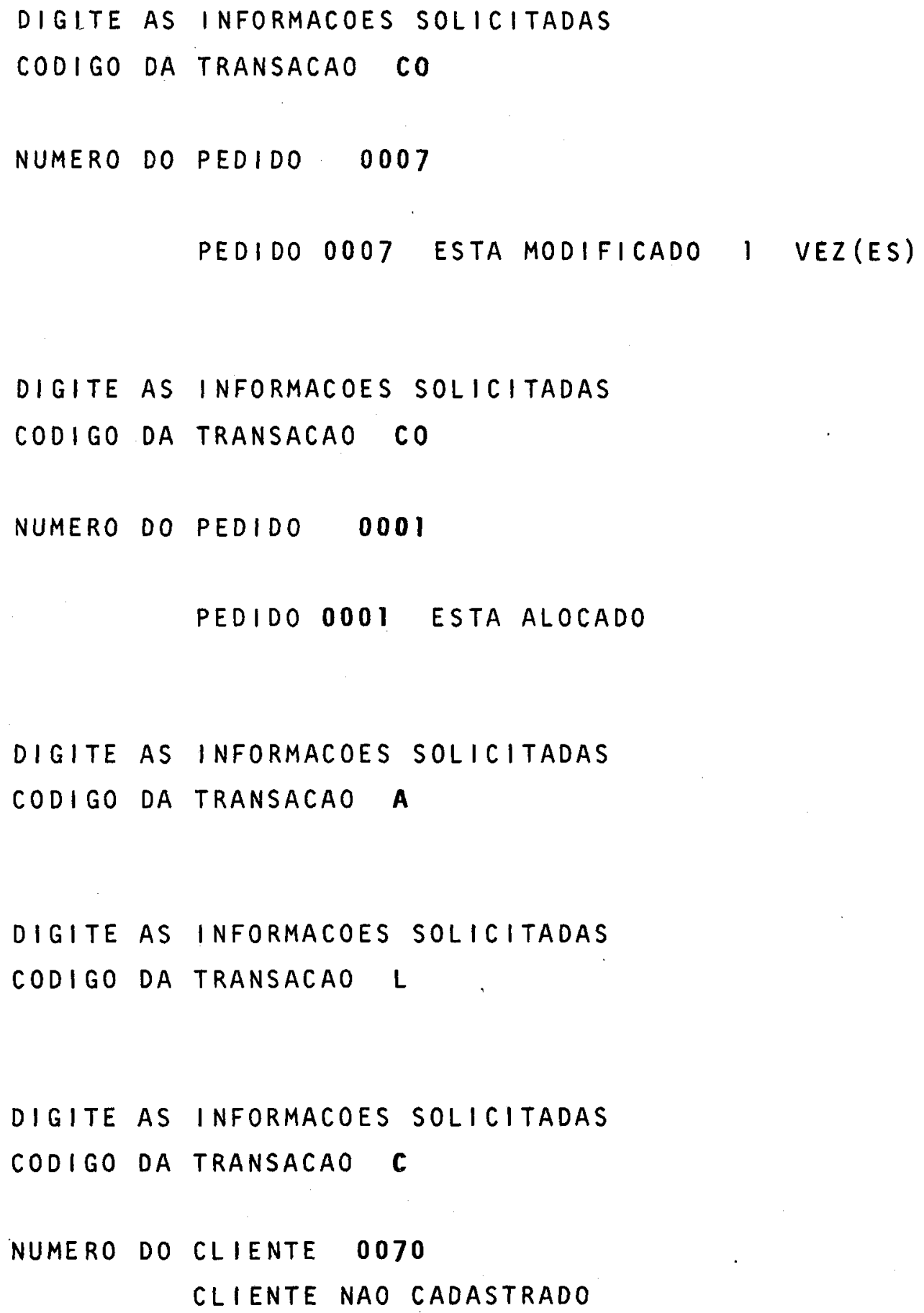




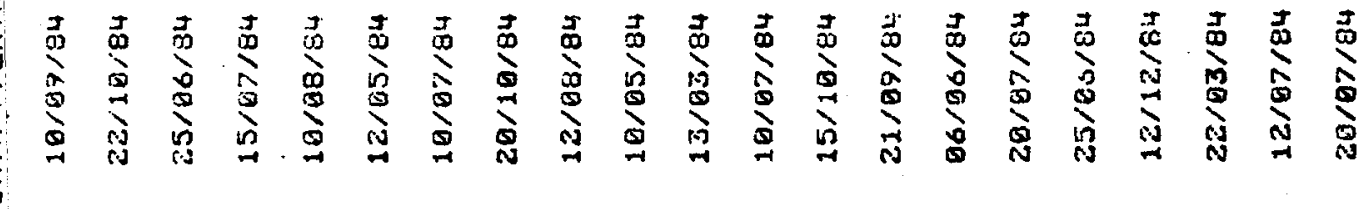

总

总

*

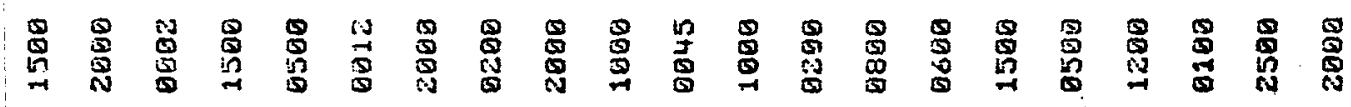

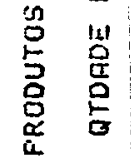

岁

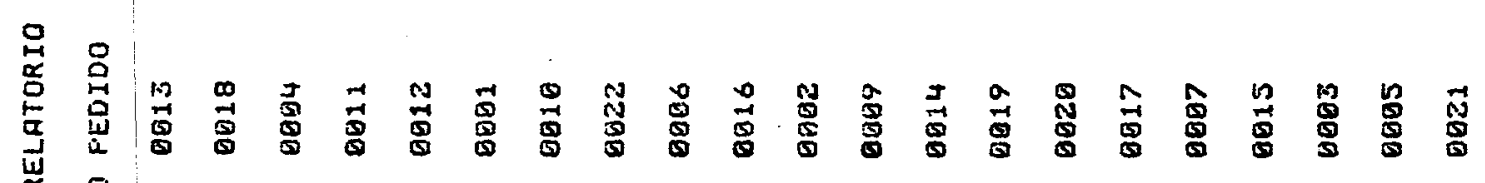
$\frac{\sigma}{z}$

经

是

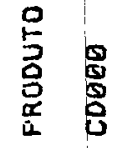

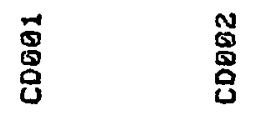

曷

号

: 
5.7. - Conclusões

Com a implementação desse problema-exemplo, foi possivel entender melhor os conceitos do método JSD.

Como foi visto, se o sistema fosse manual, a função de ALOC seria desenvolvida por um funcionário que faria a alocação de um produto por vez. Com o sitema automatizado, quando um fluxo A "alimenta" o articulador, ARTIC, a alocação é feita para todos os produtos. No texto de [Ja83] não é feito ne nhum comentärio sobre o modo utilizado para alocação. Optou-se pelo segundo modo por ser uma solução mais comumente adotada na pràtica.

O articulador ARTIC, para um sistema não automatizado, poderia ser realizado por uma "recepcionista" que dividi ria as diversas tarefas entre as pessoas aptas e executä-las.

Durante a fase de implementação, pode-se notar que os diagramas de estrutura e textos estruturados correspondentes, elaborados na fase de especificação, foram modificados, como se pōde ver nesse capitulo. Jackson, em [Ja83], não apresenta nenhum diagrama de estrutura nem texto estruturado da fase de implementação, como tambēm não tece nenhum comentärio sobre essas modificações. A inclusão de tais diagramas de estrutura e textos estruturados neste trabalho destina-se a vencer o hiato de documentação decorrente dessa omissão.

Observe-se que os nomes de parägrafos COBOL dos programas são os rótulos que constam do texto estruturado do respectivo processo. A tabulação dos textos estruturados não pô de ser seguida devido às restrições da linguagem.

Nas seções 5.3 .1 e 5.4. faz-se menção a criação de arquivos que não figuram no D/S devido a restrições de memōria do equipamento utilizado na implementação. Isso foi ocasionado pela impossibilidade de implementar todos os processos que compõem o DIS, figura 5.01, como subrotinas de ARTIC chamadas por CALL, tendo em vista que a capacidade de memória seria excedida. o recurso utilizado foi realizar as chamadas das rotinas CLIl e CONSUL atravēs de CHAIN. Isso obrigou a criação dos arquivos ARQ-NRO-CLIENTE E ARQ-NRO-PEDIDO. 


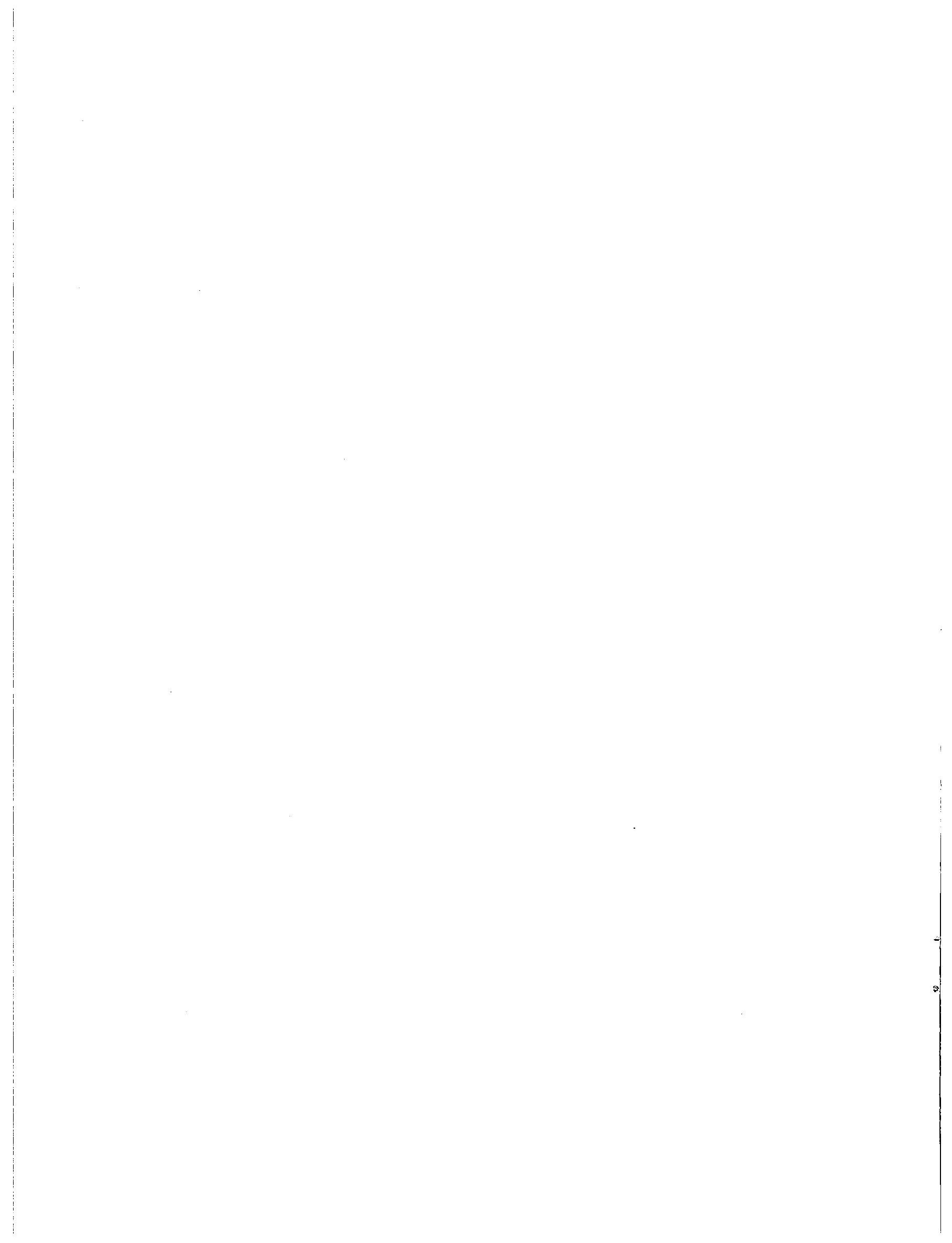




\section{CONCLUSÕES}

61 . - Conclusöes Finais

Como foi mostrado no capítulo 2 , nenhum dos exemplos de JSP apresentados na literatura técnica especializada contém uma solução completa que incluía listagem de programa em certa linguagem. Isso ë feito neste trabalho, no Capitulo 3, para todos os exemplos esboçados em [Ja76a], acrescentandose mais um exemplo em que se combinam os conceitos ilustrados pelos demais. Acredita-se que, com isso, este trabalho está dan do uma contribuição efetiva aos profissionais da área, para que possam melhor absorver os princípios e técnicas recomendadas por Jackson.observou-se também, no capítulo 2 , que a documentação do método JSD é feita apenas em linguagem natural. A fim de melhorar essa documentação, utilizou-se, neste trabalho, os diagramas de estrutura e textos estruturados de JSP e os recursos do Sistema PSL/PSA. Todos os passos do método JSD foram descritos na forma de diagramas de estrutura. Os textos estruturados correspondentes foram elaborados com auxilio do Sistema PSL/PSA, que possui mais recursos de documentação que outros métodos, co mo foi mostrado em [Pe83d]. Cada um desses passos foi descrito como sendo um PROCESS, no Sistema PSL/PSA. O texto estruturado correspondente foi descrito na PROCEDURE relativa ao processo. Alguns relatörios obtidos através do PSA são mostrados no Apêndice. Através desses relatórios, o acesso à documentação fica facilitado. Por exemplo, desejando-se informaçōes sobre um processo de modelagem, pode-se fazer uma consulta ao relatörio KWIC (KEYWORO IN CONTEXT), obtendo-se o nome pelo qual esse pro cesso aparece em outros relatórios. Com o relatório FPS (FORMATTED PROBLEM STATMENT), é possível tomar conhecimento dé todas as relações existentes entre esse processo e os outros e- 
lementos do sistema. Outras informações relevantes a um determi nado objeto podem ser obtidas através de outros relatórios PSA. Os relatórios FUNCTION FLOW DATA DIAGRAM e EXTENDED PICTURE for necem uma visão gräfica global do mëtodo JSD. Nesses relatórios aparecem os passos que compõem JSD, o que eles utilizam e que produzem.

Como foi mencionado no capitulo 2 , não havia nenhum exemplo completo, suficientemente, para facilitar a solução de problemas reais com o uso do método JSD. Nesta dissertação, ao apresentar o sistema de atendimento a pedidos de clientes, extraído de [Ja83], desde a especificação até a implementa çäo, incluindo as listagens dos programas, pretende-se cobrir essa lacuna. A documentação da especificação desse sistema pode ser vista no capitulo 4 e a da implementação correspondente encontra-se no capitulo 5 .

Analisando a contribuição que JSD acrescenta a JSP, pode se dizer que há uma ampliação das fronteiras do mundo real dentre as que tem que ser consideradas para a elaboração do pro jeto do sistema. Para JSP, são as características das informaçöes que cruzam a fronteira, isto é, as entradas e sáidas do sistema, que influenciam sua estruturação. Essas característi cas não são estāveis ao longo do tempo. Conseqüentemente, suas alterações provocam modificaçōes no sistema, o que requer esfor ços de manutenção. Ao transpor as fronteiras e analisar as características das entidades do mundo real relacionadas ao siste ma, bem mais estáveis ao longo do tempo, e nelas basear a modularização e estruturação a serem consideradas no projeto do sís tema, JSD visa a diminuição dos esforços de manutenção e trata os sistemas de maneira mais integrada.

Analisando as vantagens que JSP/JSD oferecem quando considerados em termos da abordagem operacional, pode-se dizer que a especificação do sistema, feita atravēs de diagramas de estrutura e textos estruturados, é teoricamente executável, poils, como mencionado nos capítulos 1 e 2 , desde que submetida a transformações automatizadas, pode gerar cōdigo em uma lingua gem de alto nível. 


\section{2. - Sugestões para Novas Pesquisas}

o desenvolvimento das outras implementações do problema-exemplo que foi objeto de enfoque no capitulo 4 , sugeridas por Jackson em [Ja83], poderia ser realizado. Os outros exemplos também apresentados por Jackson, em seu livro [Ja83], po deriam ser implementados de modo a fornecer mais subsidios para os possíveis usuärios desse método na prática profissiorial.

Um outro assunto a ser explorado poderia ser a implementação de problemas-exemplo do método JSP em outras lingua gens de programação, alēm da linguagem COBOL, visto que esse mé todo independe da linguagem utilizada.

Uma contribuição interessante à área de Anālise e Projeto de Sistemas de Informação seria, por exemplo, aplicar - método JSD ao desenvolvimento de um projeto real, usando o sistema PSL/PSA como instrumento de documentação. Dessa forma, poder-se-ia verificar quais os pontos omissos desse mêtodo quan to à sua aplicação a problemas existentes na prätica profissional.

Da mesma forma que foi possível um melhor entendimento do método JSD com a utilização do Sistema PSL/PSA, podese obter melhor entendimento dos exemplos apresentados em [Ja83] com o uso do referido instrumento para documentá-los.

Jackson, em [Ja83], diz que um dos aspectos não cobertos pelo seu livro é o de documentação, frisando que isso não é feito não porque não considera esse aspecto importante, mas sim porque foge aos objetivos do livro. Um assunto de pesquisa relevante seria, assim, dar cobertura a esse aspecto, por exemplo, com o uso do sistema PSL/PSA.

Outra contribuição pode ser a comparação do método JSD com outros métodos de Análise e Projeto de Sistemas de Informação, a fim de que se observe quais os pontos que são melhor abrangidos pela abordagem operacional e pela abordagem con vencional. 

Ba 81

$$
\text { Ba.81a }
$$

- BASILI,V.R.;YEH,R.T. - Proceedings COMPCON 81-IEEE Computer Society International Conference. Washington D.C., 1981.

Be 81

- BERGLAND,G.D. - A Guided Tour of Program Design Methodologies. Computer, $14(10)$, oct. 1981 .

Be81 a

- BERGLAND,G.D.;GORDON,R.D. - Software Design

Strategies (Tutorial), IEEE Computer Society, Catalog No 389, 1981 .

$B \cap 78$

- BERNSTEIN,C.M. - Experience With Exxon's Implementation of the Jackson Program Design Method. In: AFIPS Conference Proceedings Vol.47, National Computer Conference, 1978.

Bo79

- BOEHM,B.W. - Software Engineering: RED Trends and Defense Needs. In: Wegner,P. (ED), Research Directions in Software Technology. The MIT Press, Cambridge, 1979.

Br82 - BROOKES, C.H.P.; JEFFERY,D.R.; LAWRENCE,M.J. Information Systems Design. Prentice-Hall Austria, 1982 . 
Cal81 - CAMERON,J.R. - Two Pairs of Examples in the Jackson Approach to System Development. In: Bergland.G.0. e Gordon,R.S. (EDS) Software Design Strategies (Tutorial), IEEE Computer Society, Catalog n? 389,1981 .

Ci83 - CHIOSSI,T.;PENTEADO,R.;COSTA,G. - Alguns Métodos para Anälise e Projeto de Sistemas de Informação vistos sob o Angulo do Método Systematics. In: Anais do Encontro de Metodologias de Sistemas, Belo Horizonte, 1983.

ChBI - CHAPIN,N. - Graphic Tools In The Design of Information Systems. In: Cotterman,W.W. et all (EDS) Systems Analysis and Design: A Foundation for the 1980's. North-Holland, 1981.

Co81 - COTTERMAN,W.W.; et all-Systems, Analysis and Design: A Foundation for the 1980's. New York, North-Holland, 1981 .

De77 - DeWOLF,J.B. - Requirements Specification and Preliminary Design for Real-Time Systems. In: Proceedings COMPSAC77 - IEEE Computer Software $\&$ Applications Conference, Chicago, nov. 1977.

EI77 - ELSHOFF,J.L. - On Optimal Module Size With Respect to Compilation Cost. In: Proceedings COMPSAC77 IEEE Computer Software \& Applications Conference. Chicago, nov. 1977.

Em81 - EMERSON,T.J. - The Logical Structure of Design. In: Proceedings COMPSAC 81 - The IEEE Computer Software E Applications Conference. Chicago, nov. 1981 . 
- GATEWORd Jr.,F.E. - A Structured Requirements

Process Using the Improved Programming

Technologies. IBM Washington Systems Center, GC22-9011-00, 1977 .

Ge 83

- Germano,F.;MASIERo,P.C.;PENTEAdo,R. - Anälise Comparativa dos Métodos SA/SD, HIPO, PSL/PSA, SOP, Systematics e PDL. In: Anais do Encontro de Metodologias de Sistemas, Belo Horizonte, 1983.

G168 - GLANS,T.B.; ET ALL - Management Systems. New York, Holt Renehart $\&$ Winson Inc. 1968.

Gn77 - GANE, C.;SARSON,T. - Structured Systems Analysis: Tools and Techniques. Improved System Technologies Inc., 1977 .

Go 80 - GOODENOUGH,J.B.;MCGOWAN,C.L. - Software Quality Assurance: Testing and Validation. Proceedings of the IEEE $68(9)$, sep. 1980.

Gr75 - GRINOLEY,C.8.B. - Systematics: A New Approach to Systems Analysis. New York, McGraw Hill, 1975.

Ha79 - HAMILTON,M.;ZELDIN,S. - The Relationship Between Design and Verification. The Journal of System and Software $1(1)$, North-Holland, 1979.

Ib6I - IBM Study Organization Plan - Documentation Techniques. C20-8075-0. IBM Corporation, 1961 .

Ib63a - IBM Study Organization Plan - The Approach. F20.8135-0. IBM Corporation, 1963.

Ib63b - IBM Study Organization Plan - The Method Phase 1. F20-8136-0. IBM Corporation, 1963. 
Ib63c - IBM Study Organization Plan - The Method Phase 11 , F20-8137-0, IBM Corporation, 1963.

1b63d - IBM Study Organization Plan - The Method Phase 111 , F20-8138-0. IBM Corporation, 1963.

Ib74 - IBM Corporation, Data Processing Division - HIPO: A Design Aid and Documentation Technique. White Plains, New York, 1974.

Ii82 - I ivari,J. - Taxonomy of The Experimental and Evolutionary Approaches To Systemeering. In: Hawgood,J. (ED) Evolutionary Information Systems. North-Holland, IFIP, 1982 .

In78 - Infotech State of the Art Report on Structured Analysis and Design: Vol. I Analysis and Bibliography, Vol. II Invited Papers Softech Inc., 1978 .

Ja75 - JACKSON,M. - Principles of Program Design. Academic Press, 1975.

Ja76 - JACKSON,M. - Data Structure as a Basis for Program
Design. In: Bates,D. (ED). Structured Programming
- Infotech International Limited. England 1976.

Ja76a - JACKSON,M.A. - Constructive Methods of Program Design. In: Goods, G, and Hartmanis, J. (EDS), Proceeding of the. $1^{\text {st }}$ Conference of the European Corporation in Informatics (ECI-76). In: Lecture Notes in Computer Science, Vol.44, Springer Verlag, 1976. Reprinted in: Bergland,G.D. e Gordon,R.D. (EDS) Software Design Strategies (Tutorial), IEEE Computer Society, Catalog n:389, 1981 . 
- JACKSON,M.A. - Information Systems: Modelling, Sequencing and Transformations. In: Proceedings of the Third International Conference on Software Engineering. IEEE, 1978. Reprinted in: Bergland,G.D. e Gordon,R.D. (EDS) Software Design Strategies (Tutorial), IEEE Computer Society, Catalog $389,1981$.

Ja 81 - JACKSON,M. - Some Principles Underlying a System Development Method. In: Systems Analysis and Design: a Foundation for 1980's. W.W. Cotterman et all (EDS). North-Holland, 1981 .

Ja83 - JACKSON,M. - System Development. Prentice-Hall International, Inc., 1983.

Ja84 - JACKSON,M. - O Futuro para Métodos Estruturados. Informātica \& Administração $1(6)$, 1984. Tradução de trabalho publicado no Infotech State of Art Report.

Jo81 - JONES,C. - A Survey of Programming Design and Specification Techniques. In: Tutorial on Programming Productivity: Issues for the Eighties. IEEE, 1981

Kr78 - KRAKOWIAK,S. - Methods and Tools for Information Systems Design. In: Bracchi,G. and Lockemann,P.C. (EDS) Information Systems Methodology Conference Proceedings. Lecture Notes in Computer Science Vo .65 , Springer Verlag, 1978 .

Le80 - LEHAMN,M.M. - Programs Life Cycles, and Laws of Software Evolution. Proceedings of the IEEE, $68(9)$, sep. 1980 . 
- LUNDEBERG,M.;GOLDKUHL,G.;NILSON,A. - A Systematic Approach to Information Systems Development-II. Problem and Data Oriented Methodology. Information Systems, $4(2), 1979$.

- LUNDEBERG,M.;GOLDKUHK,G.;NILSON,A. - Information Systems Development: a Systematic Approach, Prentice-Hall, 1981 .

Mel 76

- McGOWAN,C.L.;KELLY,J.R. - A Review of Some Design Methodologies. Softech Draft Report. Invited Presentation for Infotech State of the Art Conference on Structured Design. Amsterdam, 1976.

Mel80 - MENARD,J.B. - Exxon's Experience With the Michael Jackson Design Method. Database, 12(3), mar. 1980.

Ne81 - NELSON,E. - Functional Programming Analysis. The Journal of Systems and Software, 2(3), NorthHolland, sep. 1981 .

Pe8 2 - PENTEADO,R.;MASIERO,P. - Formulação de um Problema de Processamento da Informação em HIPO. In: Anais do IV Congresso Regional de Informātica, Curitiba, 1982 .

Pe82a - PENTEADO,R,;SANTOS,C.;NAKAMURA,e. - Documentação em PSL/PSA do Problema Exemplo do SOP. In: Anais do $X V$ Congresso Nacional de Informätica, Ric de Janeiro, 1982 .

Pe83 - PENTEAdo,R.;COSTA,g.;germano,f. - Formulação de Um Problema de Processamento de Informação em SoP. In: Anais do Encontro de Metodologias de Sistemas, Belo Horizonte, 1983 . 


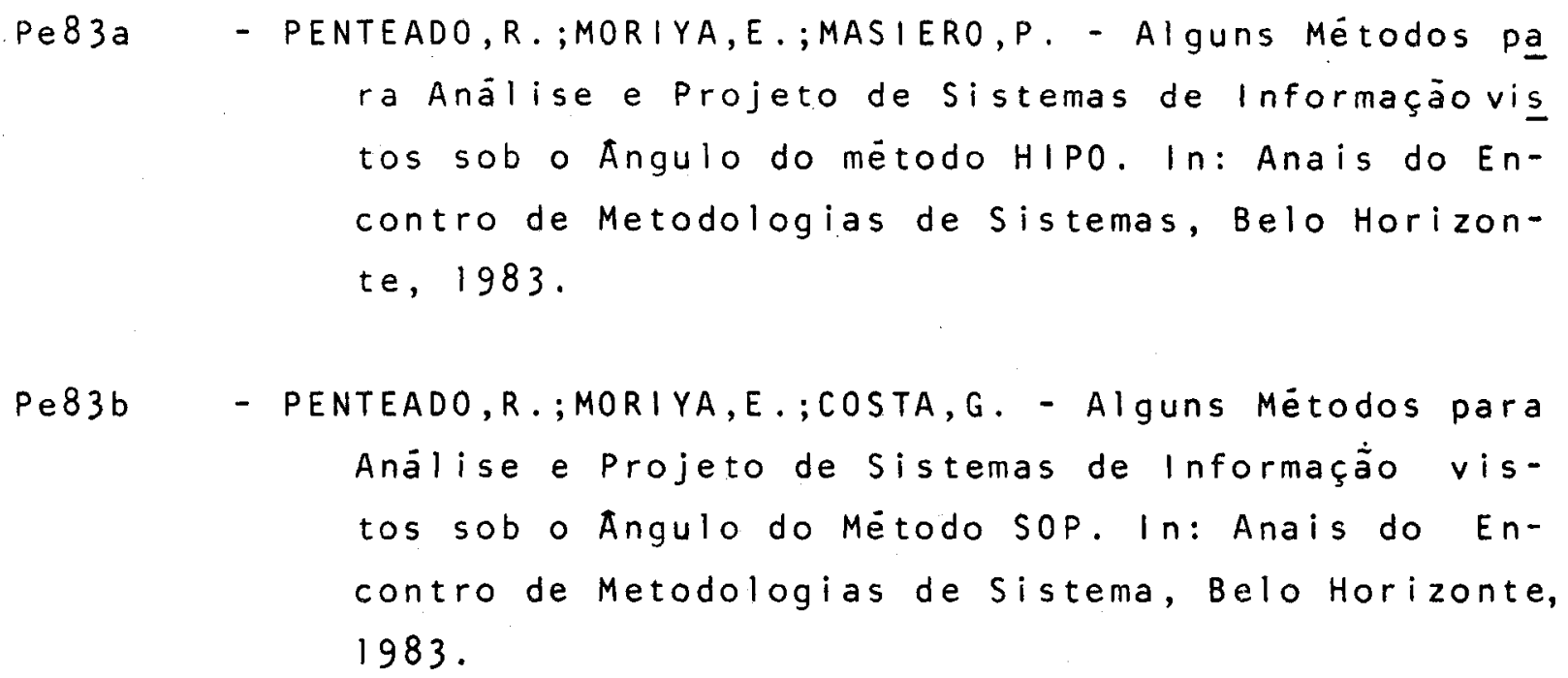

P383c - PENTEADO,R.;MORIYA,E.;MASIERO,P. - AIguns Métodos Pa ra Anālise e Projeto de Sistemas de Informaçãovís tos sob o Angulo da Anālise Estruturada. In: Anais do Encontro de Metodologias de Sistemas, Belo Horizonte, 1983.

Pe83d - PENTEADO,R.;FABBRI,S.;CHIOSSI,T. - Alguns Métodos pa ra Anälise e Projeto de Sistemas de Informação $v$ istos sob o Angulo do Sistema PSL/PSA. In: Anais do Encontro de Metodologias de Sistemas, Belo Horizonte, 1983.

Pt77 - PETERS.L.J.; TRIPP,L.L. - Comparing Software Design Methodologies. Datamation $23(11)$ nov. 1977.

Pt80 - PETERS.L.J. - Software Representations and Composition Techniques - Proceedings of the IEEE $68(9)$, sep. 1980 .

Rb79 - ROBINSON,K.A. - An Entity/Event Data Modeling Method. The Computer Journal, 22(3), 1979. 
- ROSENQUIST,C.J. - Entity Life Cycle Models and Their Applicability to Information Systems Development Life Cycles - A Framework for Information Systems Design and Implementation. The Computer Journal, 25(3), aug. 1982 .

- SCHNEIDER,H.J. - Techniques and Formal Tools for Design, Realization and Evaluation of Evolutionary Information Systems. In: Hawgood,J. (ED)

Evolutionary Information Systems. North-Holland IFIP, 1982 .

Sh82 - SHAW, C. - Structured Charts for Jackson Structured Programming. Software Engineering Notes, $7(1)$, Jan. 1982 .

So83 - SHOODMAN,M.L. - Software Engineering, Design Reability and Management. McGraw-Hill, 1983.

Te75 - TEICHROEW,D.;GERMANO,F.S.;MORAES,P.S. - ComputerAided, Structures Documentation of Information Processing System Requirements. In: Anais do VIII Congresso Nacional de Processamento de Dados, São Paulo, 1975 .

Te77 - TEICHROEW,D.;HERSHEY,E.A.,III - PSL/PSA: A ComputerAided Technique for Structures Documentation and Analysis of Information Processing Systems. IEEE Transactions Software Engineering, SE-3(1), 1977.

Te81 - TEICHROEW,D.;GERMANO,F.;SILVA,L. - Applications of the Entity - Relationship Approach. In: Chen,P.P. (ED) Entity - Relationship Approach to Information, Modeling and Analysis. ER Institute, 1981. 
- TRIANCE,J.M. - Structured Programming in COBOL - the current options. The Computer Journal, 23(3), aug. 1980 .

Tr83 - TRIANCE,J.M. - The Proposed COBOL Standard - Its Significance. The Computer Journal $26(1)$, feb. 1983 .

Wa74 - WARNIER,J.D. - Logical Construction of Programs. Van Nostrand Reinhold Co., 1974.

We79 - WEGNER,P. (ED) - Research Directions in Sof tware Technology. The MIT Press, Cambridge, 1979.

Ya81 - YAMANO,K.; MATSUMOTO, Y. - Unified Function Design Technique Based on Data Flow Concept. In: Proceedings COMPSAC 81 - IEEE Computer Software $\varepsilon$ Applications Conference. Chicago, nov. 1981.

Yo75 - YOURDON,E.;CONSTANTINE,L.L. - Techniques of Program Structure and Design. Prentice-Hall, 1975.

YO79 - YOURDON,E.;GANE, C, ; SARSON,T.;LISTER,T.R. - Learning to Program in Structured COBOL. Prentice-Hall, 1979 .

Za84 - ZAVE,P. - The Operational Versus The Conventional Approach to Software Development.

Communications of the ACM, 27(2), fev. 1984. 
A P $\hat{E} N D \mid C E$ 


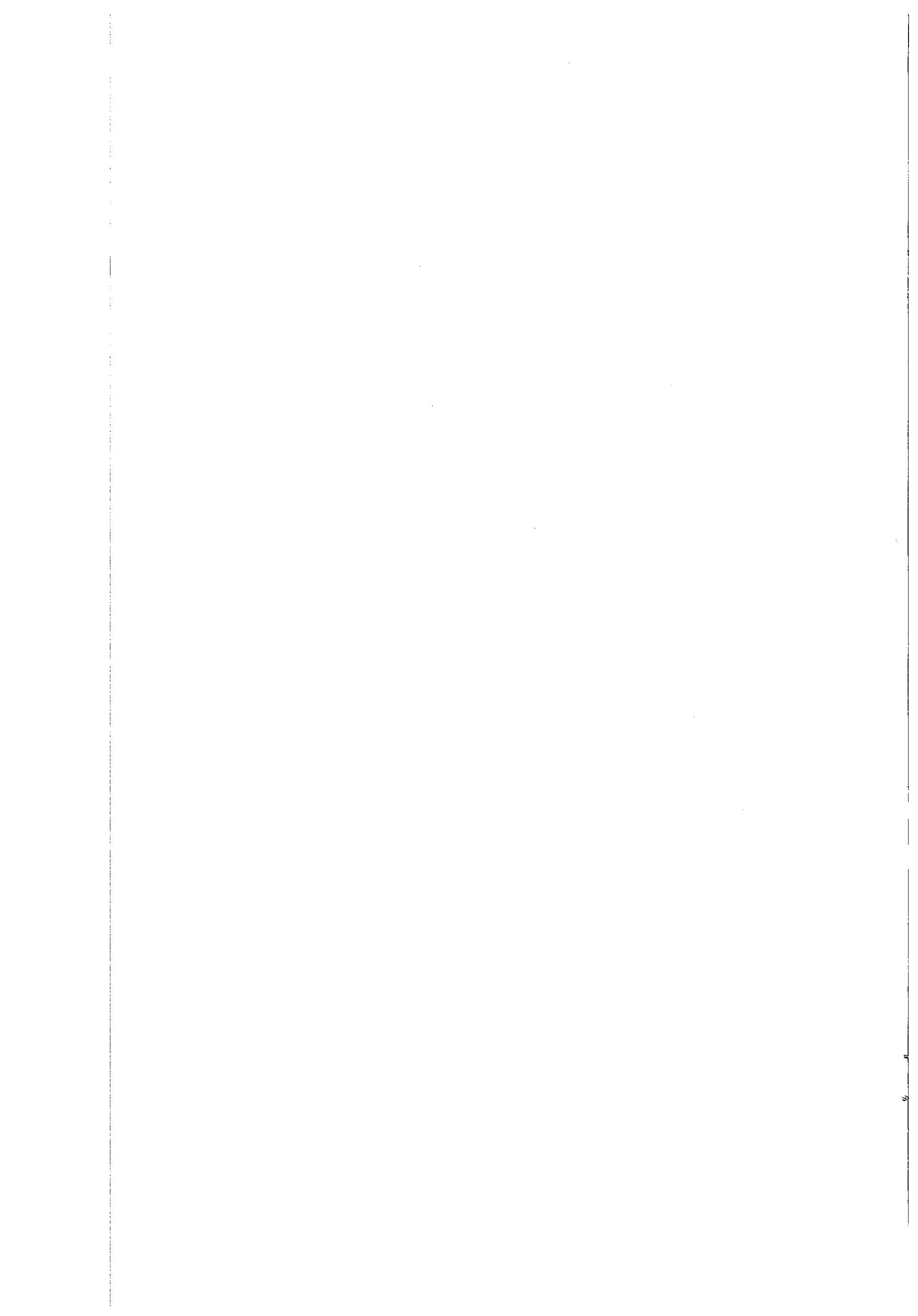


Para utilizar este apêndice deve-se proceder da seguinte maneira:

Todo conceito distinguido pelo símbolo (\$) nos capí tulos deve ser procurado no relatório.KWIC, com o nome que se encontra no referido capítulo. Por exemplo: seleção (\$), ao pesquisar o KWIC encontra-se SELEÇÃO CONCEITO-DE-. A formação do no me ocorre da seguinte maneira: a primeira parte de um nome composto è aquela que não è precedida por hífen; as partes intermediārias são aquelas seguidas e precedidas por hifen e a parte fi nal é aquela precedida por hífen. No caso-exemplo tem-se CONCEITO-DE-SELECAO. Como o relatörio FPS é ordenado por tipo de objeto e dentro de tipo por ordem alfabética de nome, deve-se consul tar o relatório NAME LIST para se saber qual o tipo desse objeto. Esse relatório está ordenado alfabeticamente por nome. Assim, en contra-se CONCEITO-DE-SELECAO como sendo MEMO. O próximo passo é a pesquisa dos MEMO's no relatório FPS até que se encontre CONCEITO-DE-SELECAO.

Os relatörios EXTENDED PICTURE E FUNCTION FLOW DATA DIAGRAM mostram, de maneira gráfica;os passos, entradas e saídas do mëtodo JSD.

o relatório DATA ACTIVITY INTERACTION REPORT mostra. atravēs de matrizes o que è usado, derivado, atualizado etc.,pelos processos, que são os passos de JSD.

A dinâmica do sistema é mostrada através do relatórIO DYNAMIC INTERACTION REPORT.

Name List

Keyword Indexed (KWIC)

Formatted Problem Statement (FPS)

Extended Picture

Function Flow Data Diagram

Data Activity Interaction Report

Dynamic Interaction Report 


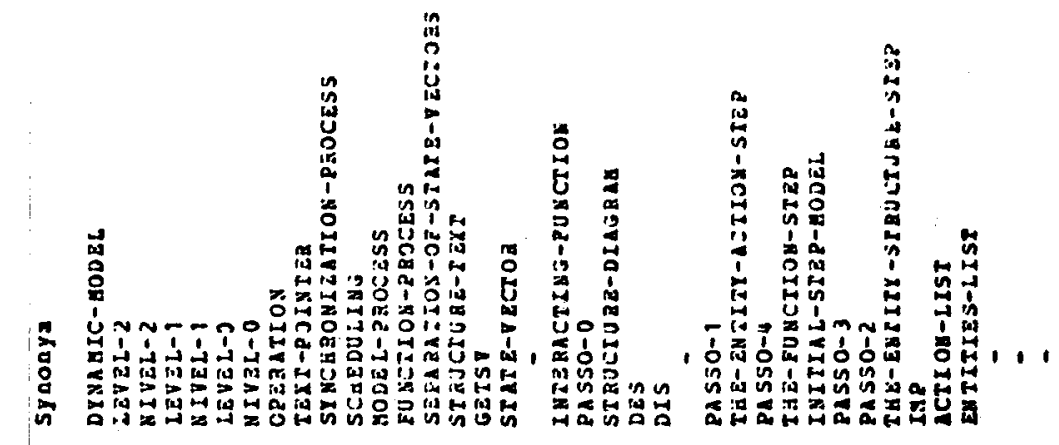

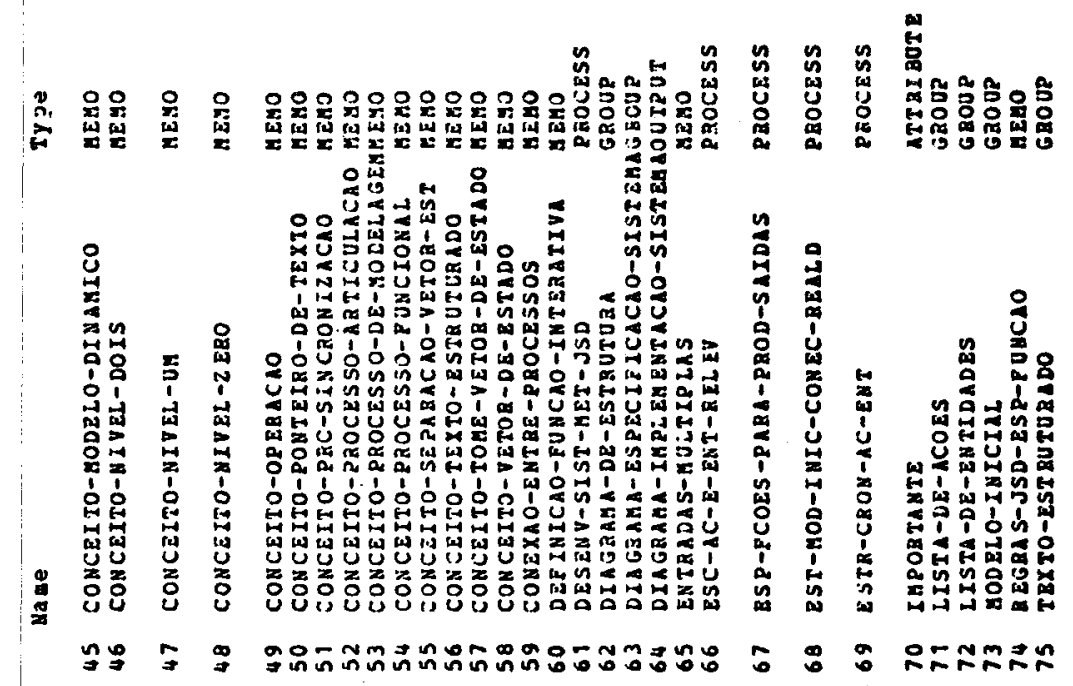

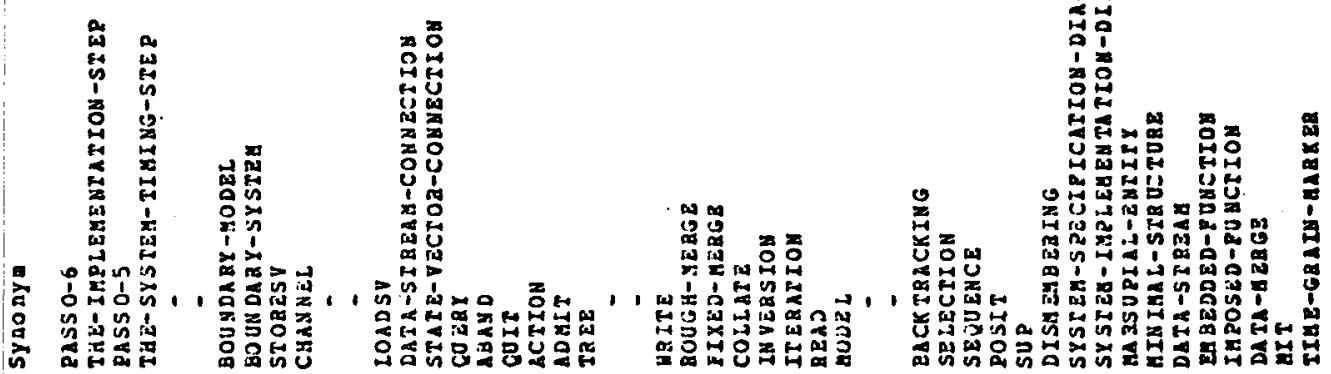



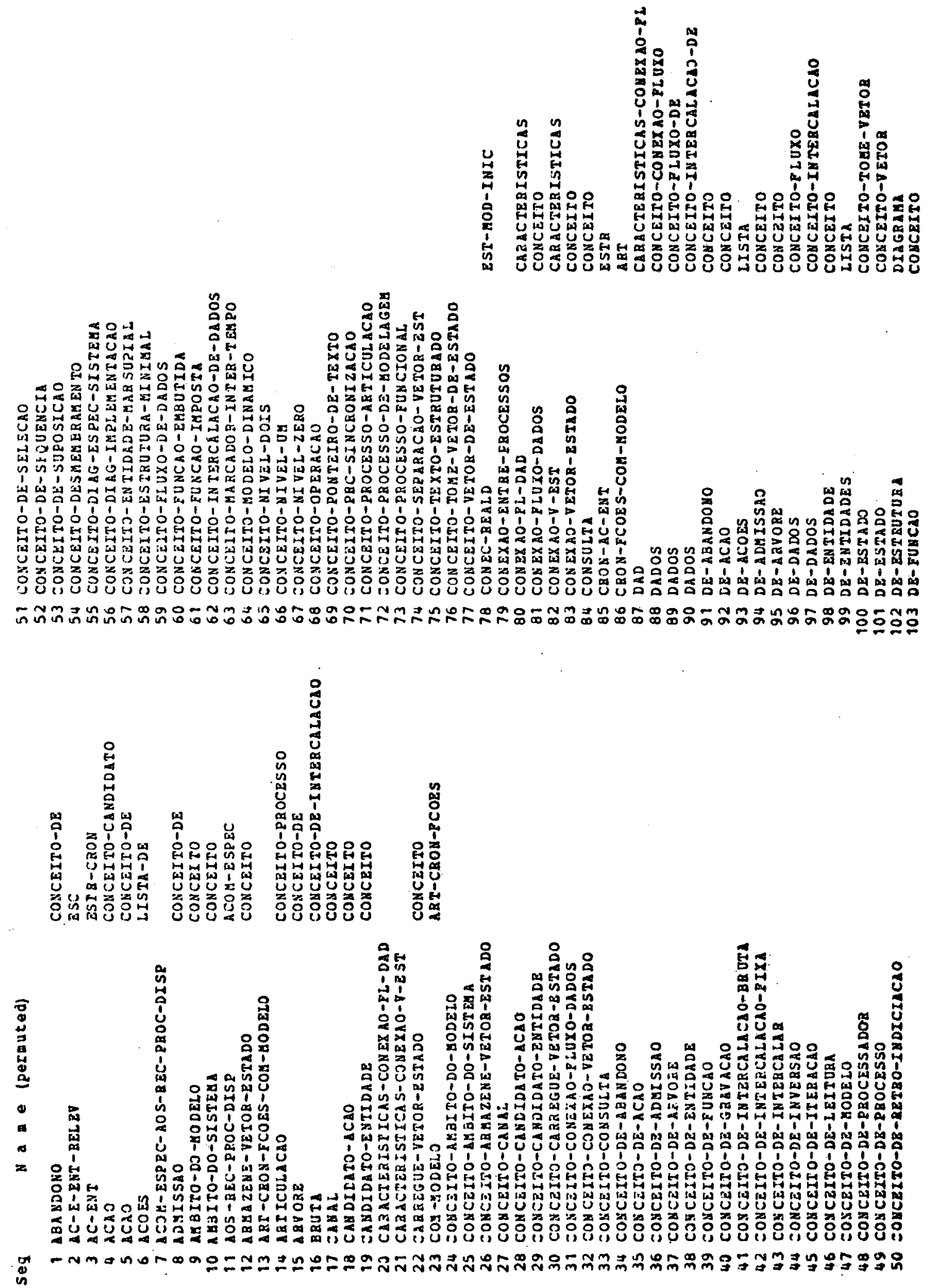


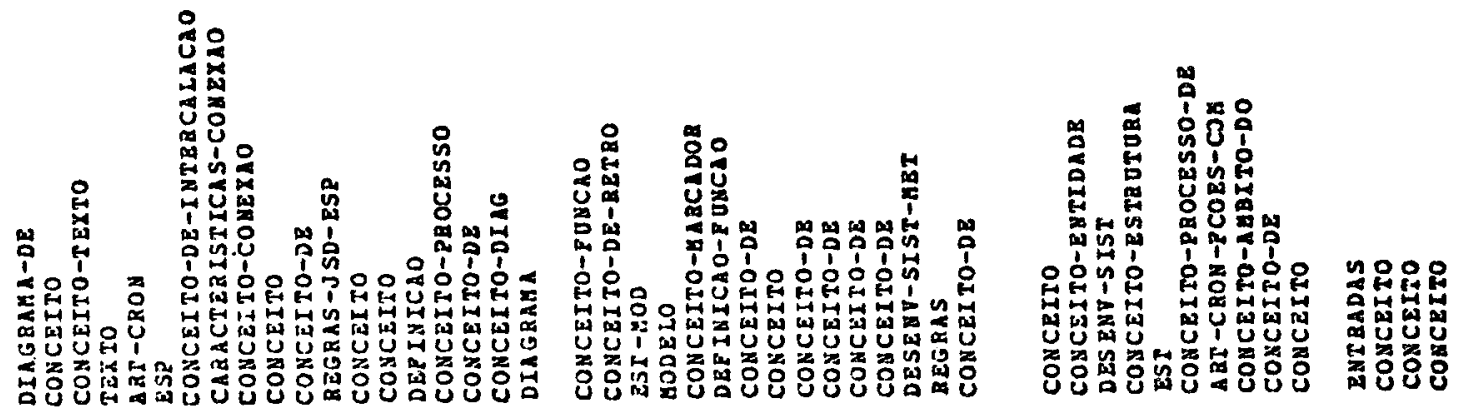

욜
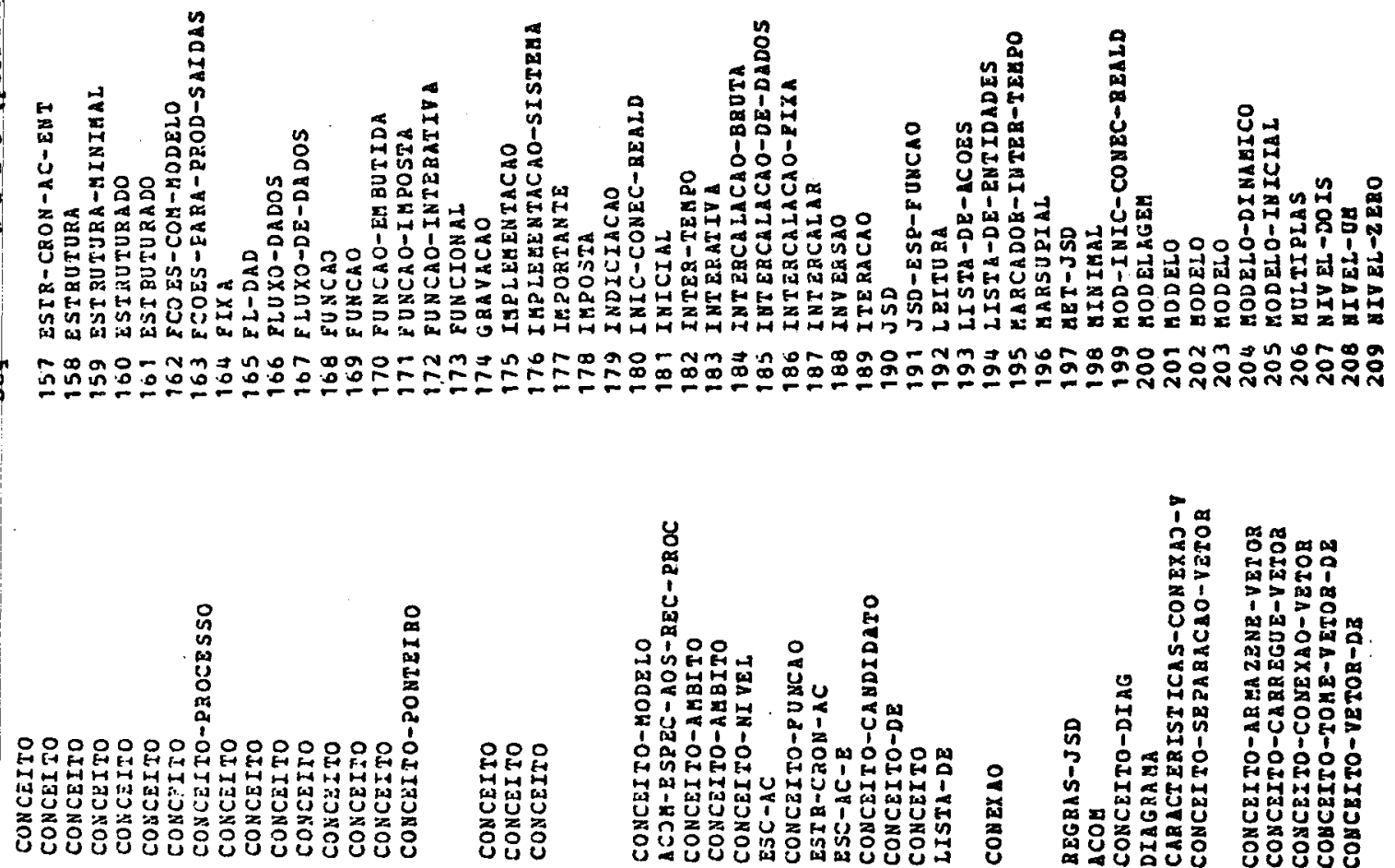

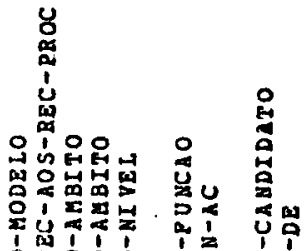

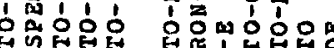

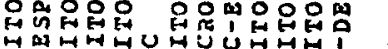

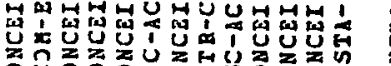

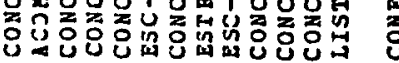
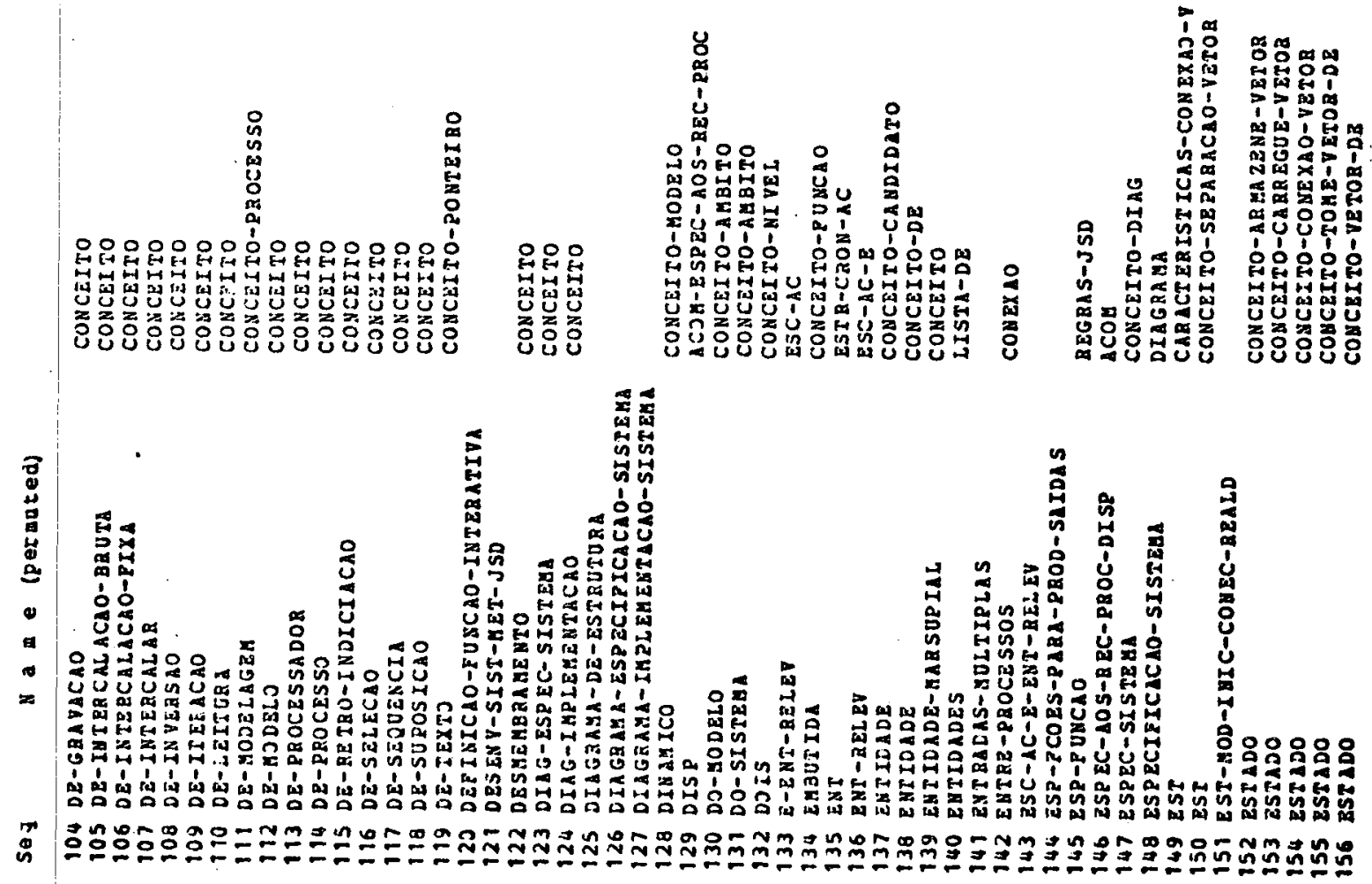


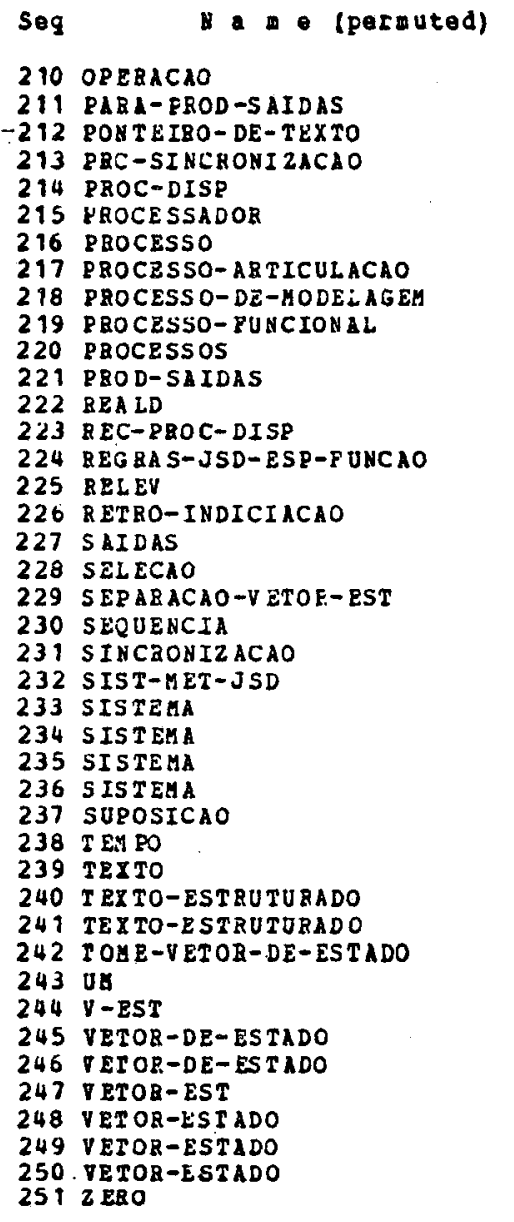

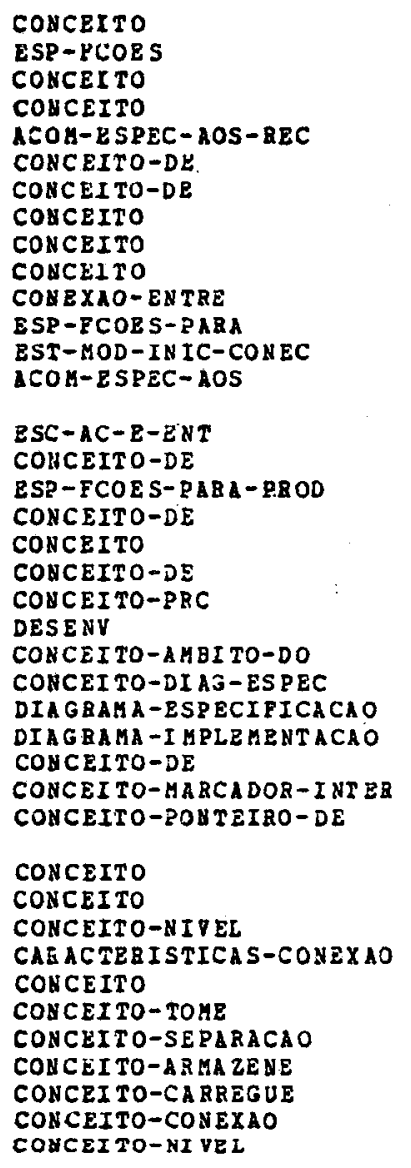



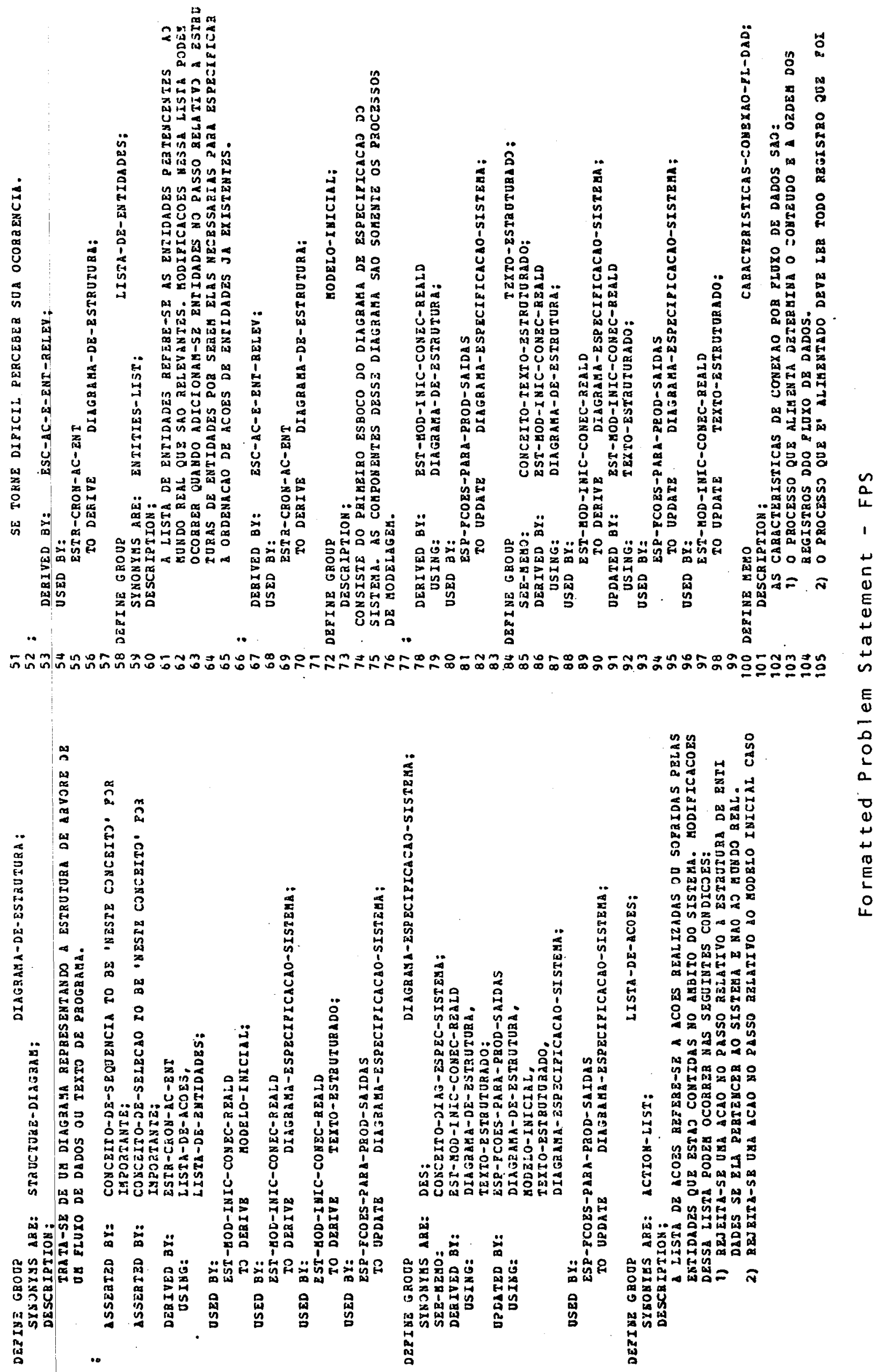

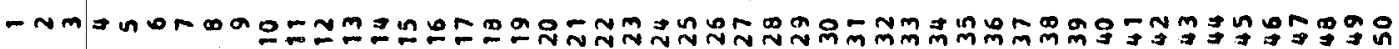




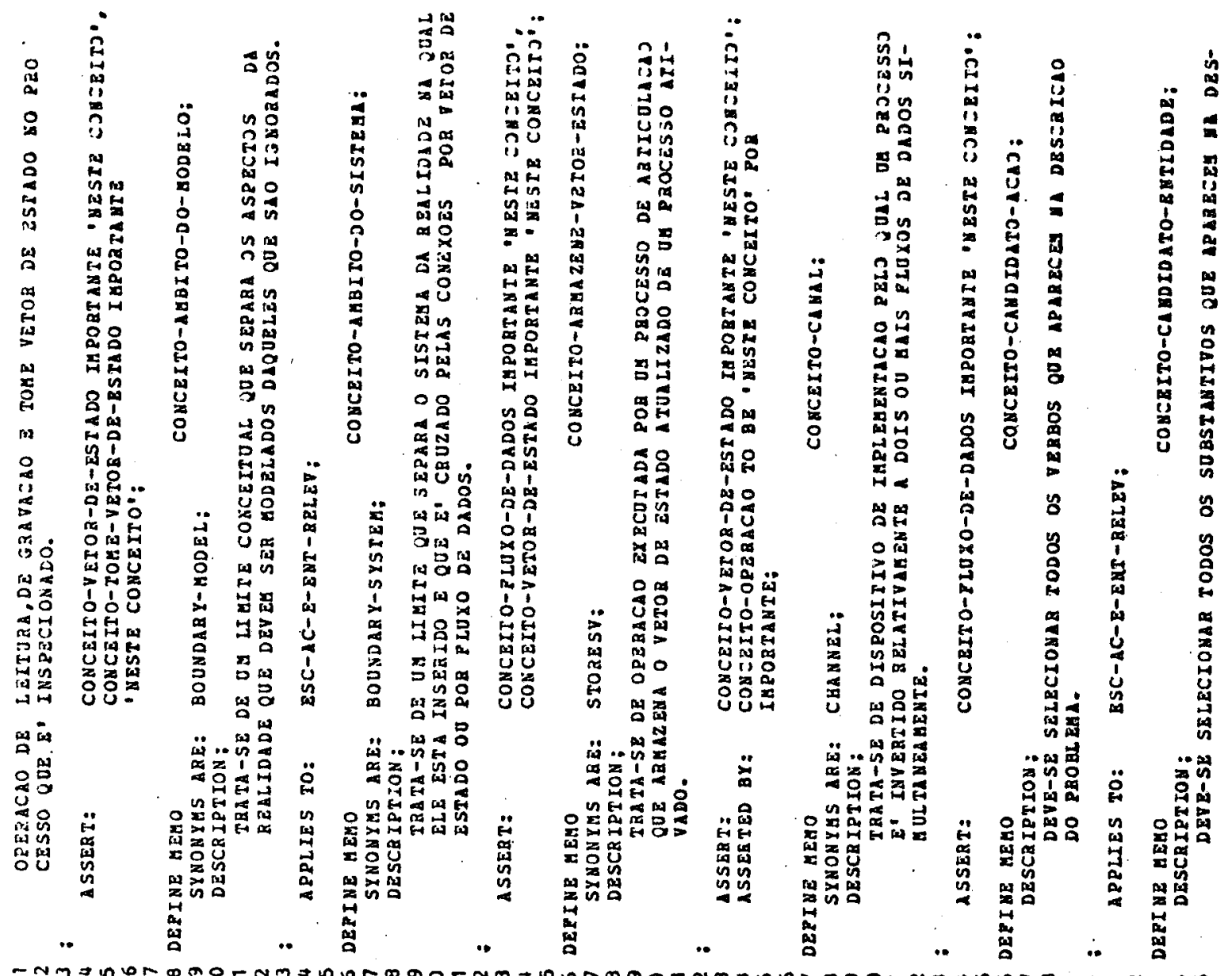

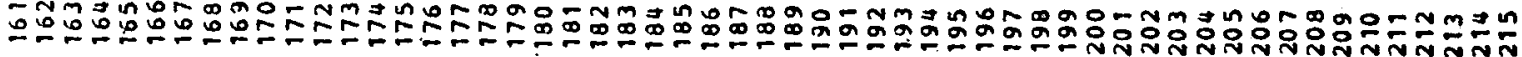

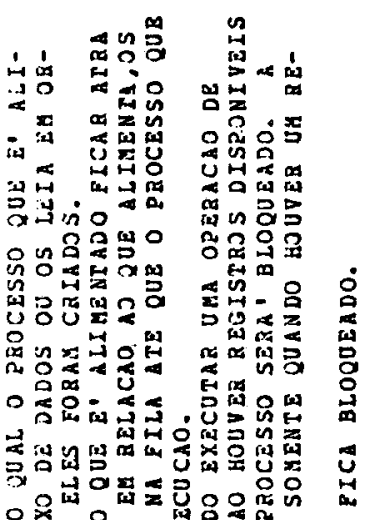

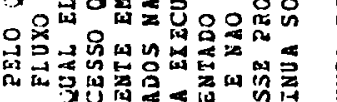

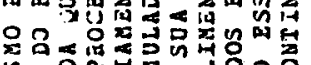

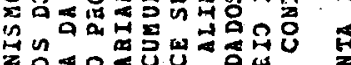

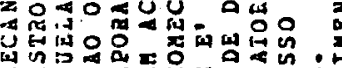

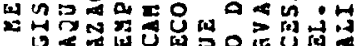

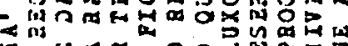

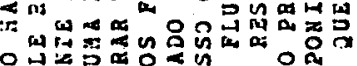

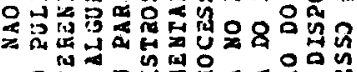

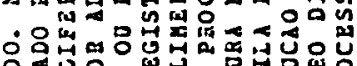

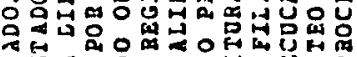

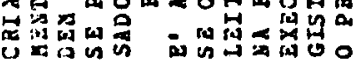

$$
\text { m } a \text { ज }
$$

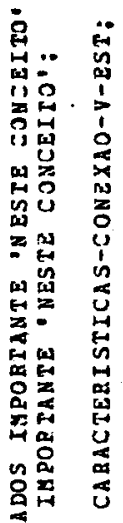

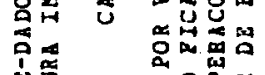

$\circ$ 영 哭

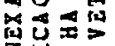

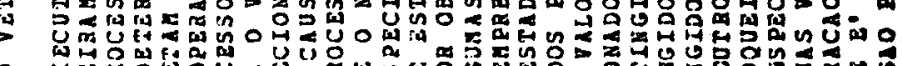

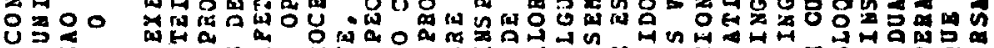

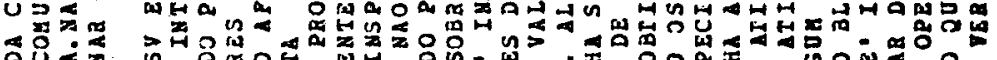

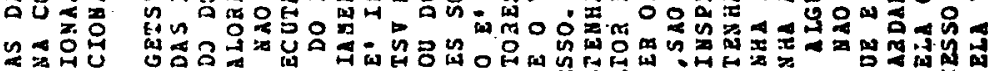
式出

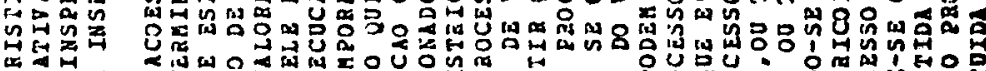
...

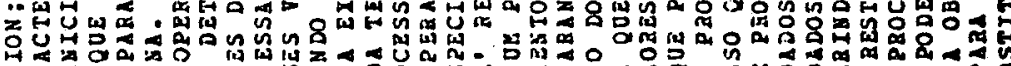

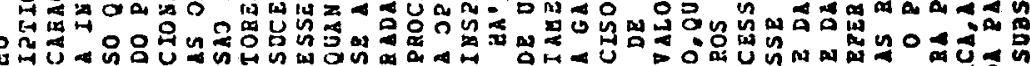

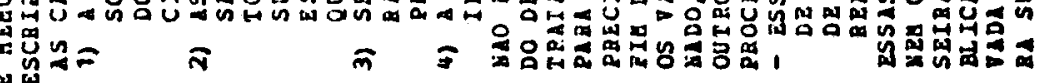
禺

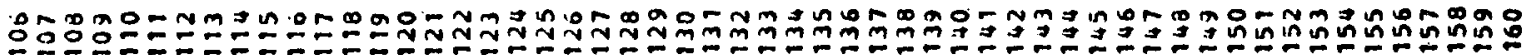




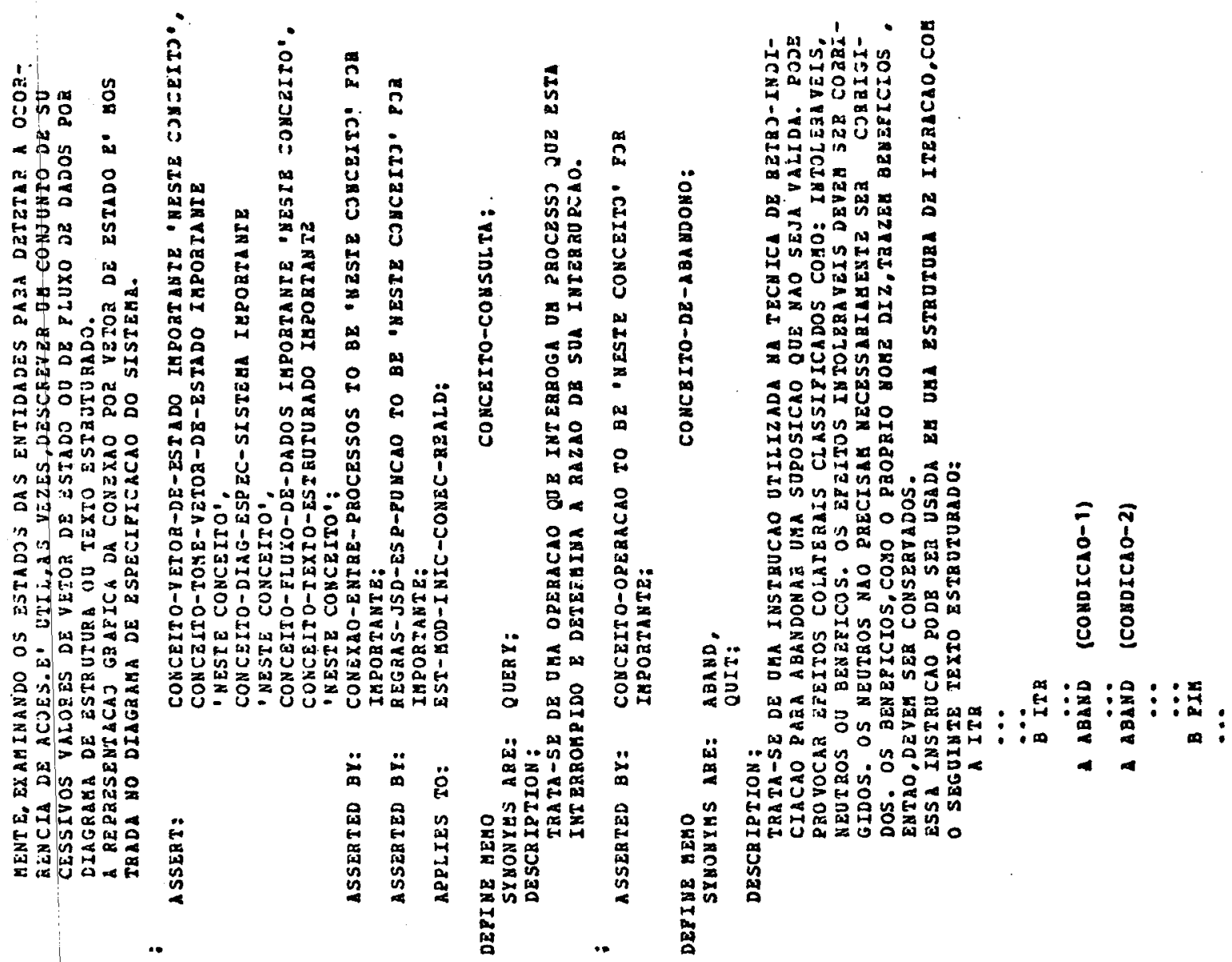

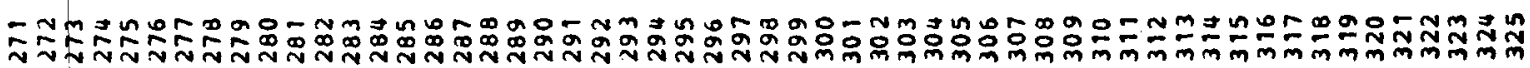

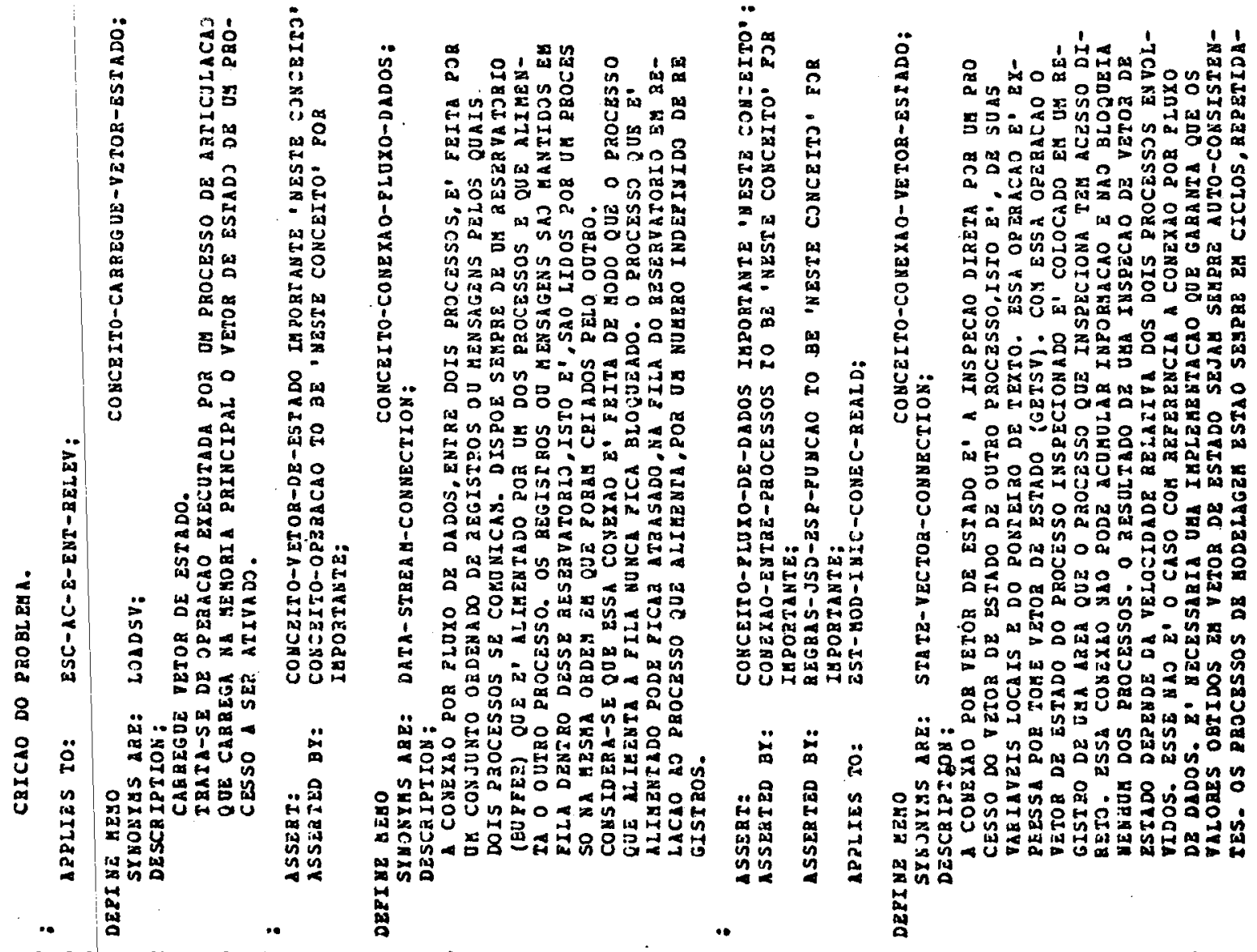

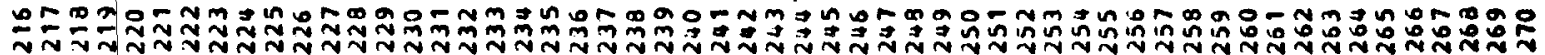




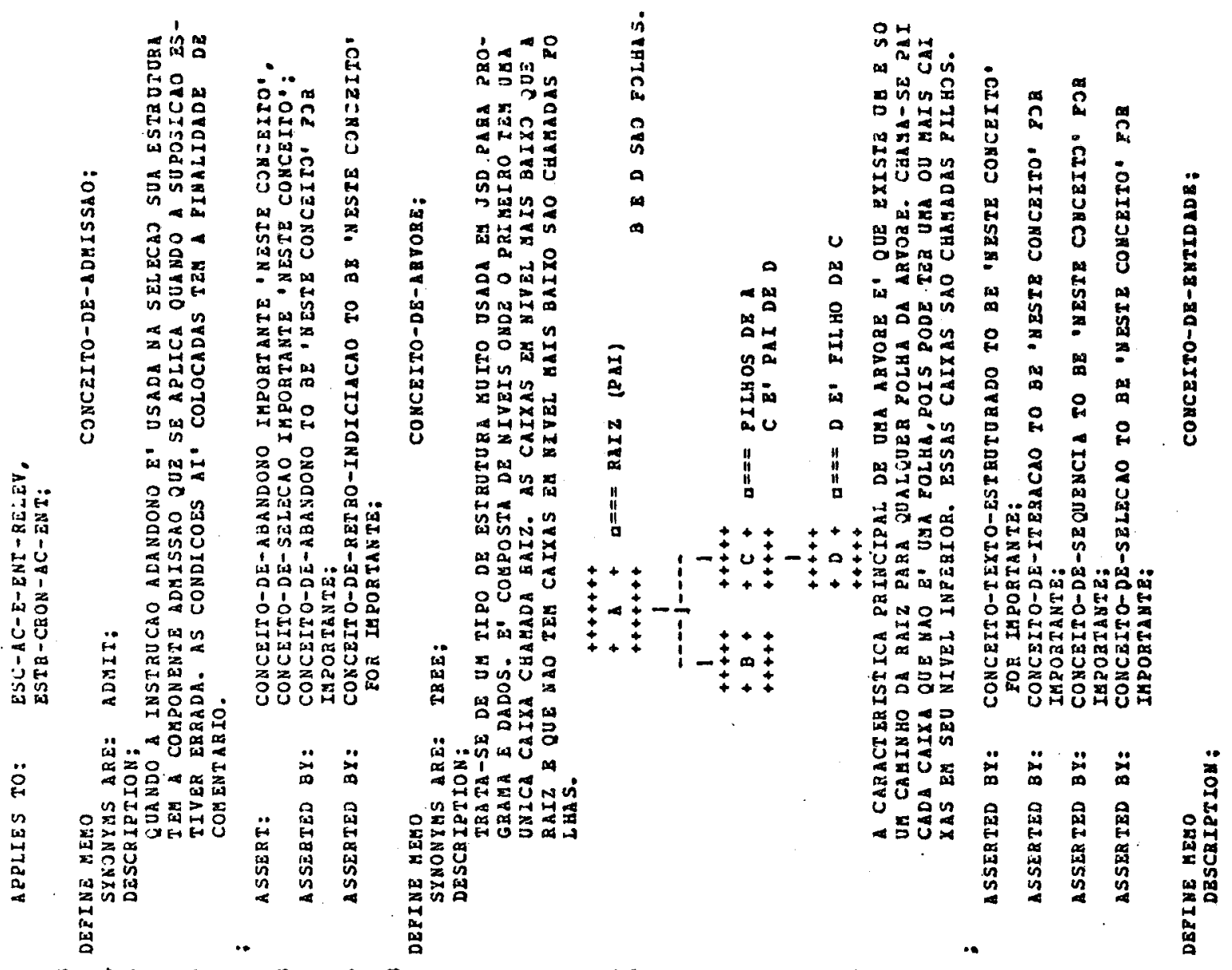

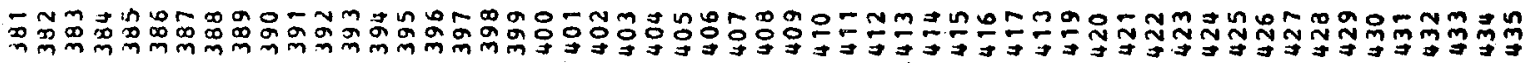

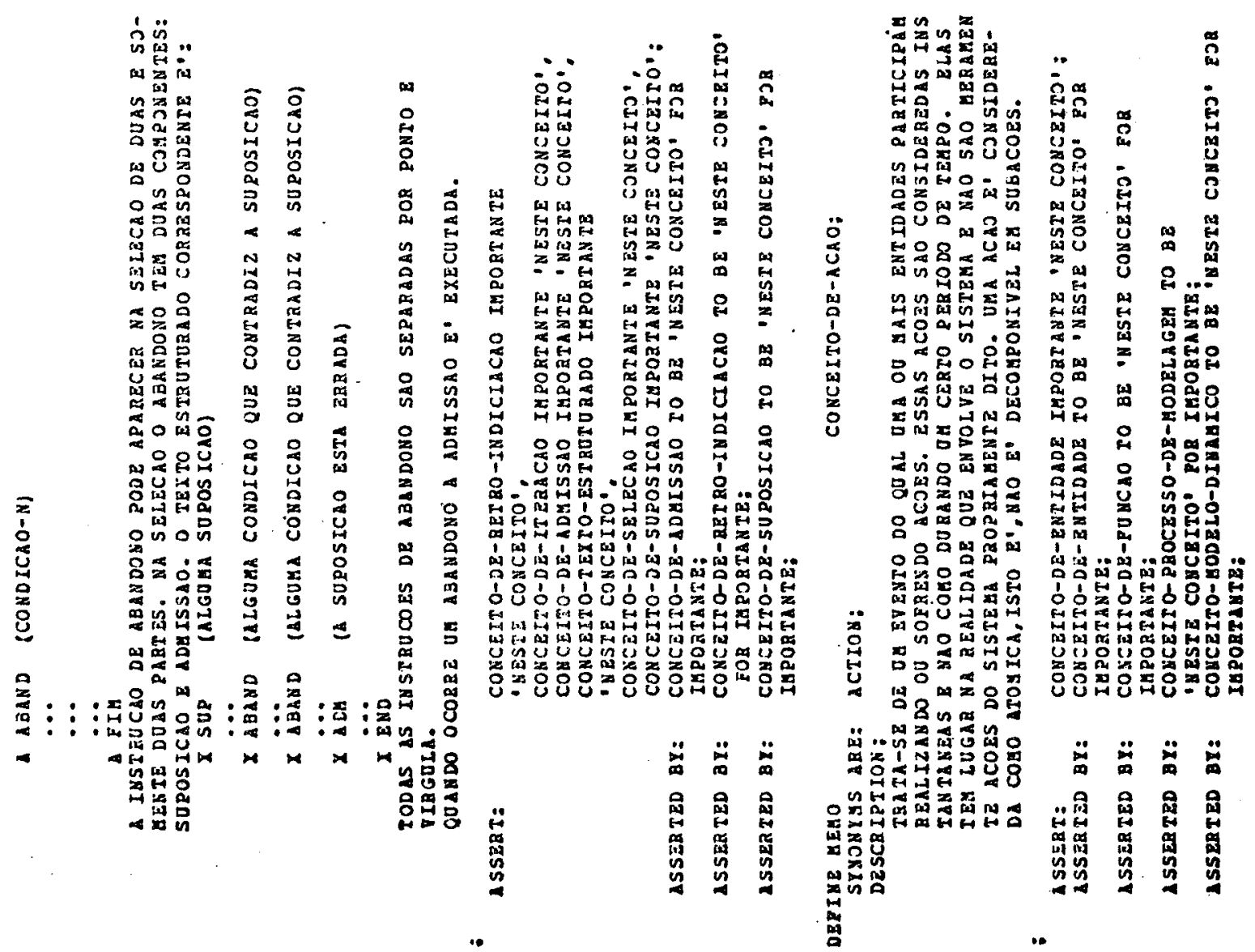

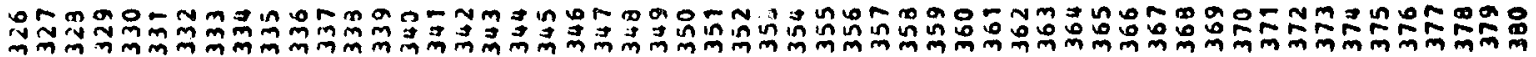




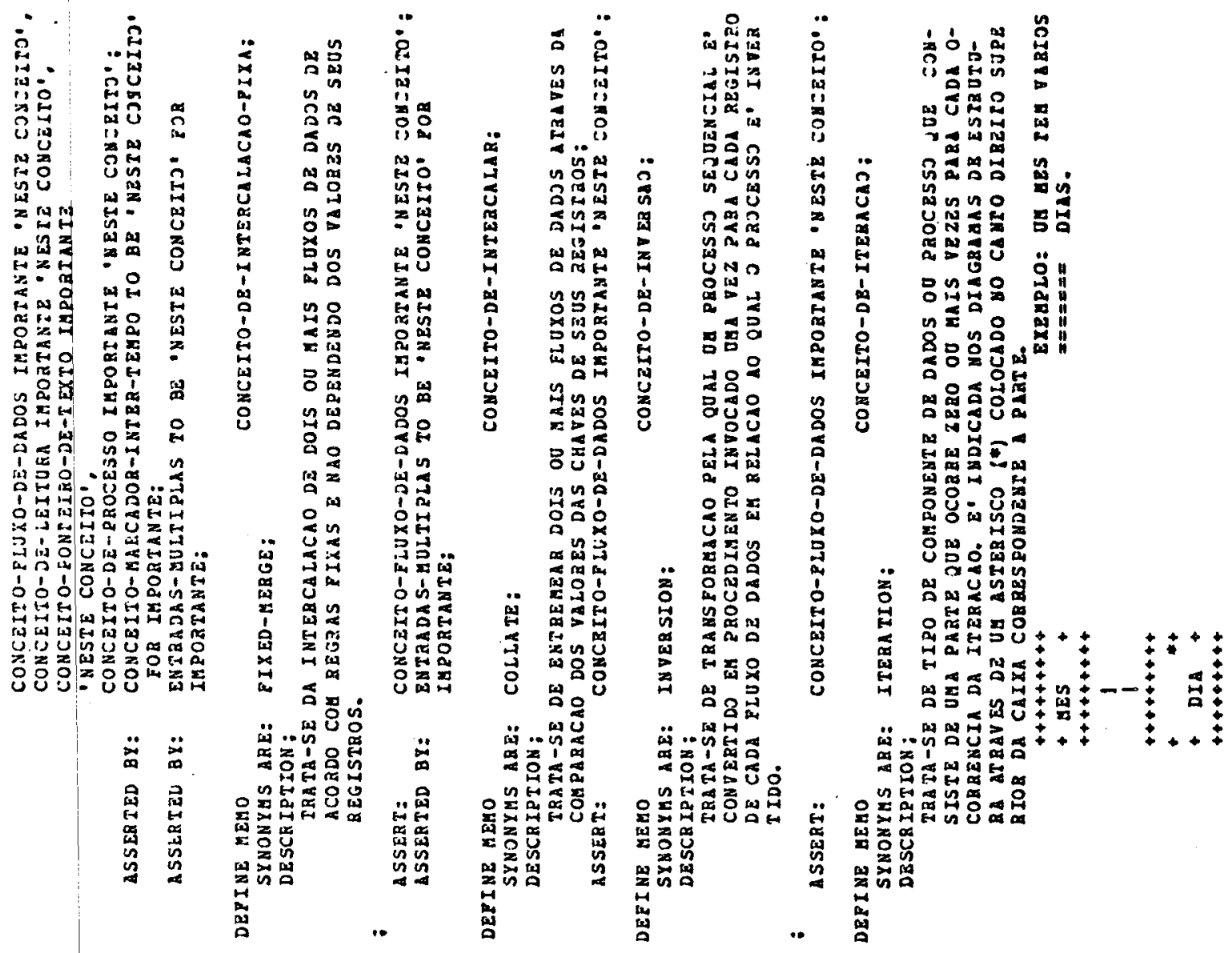

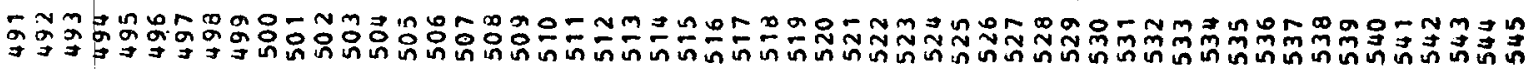

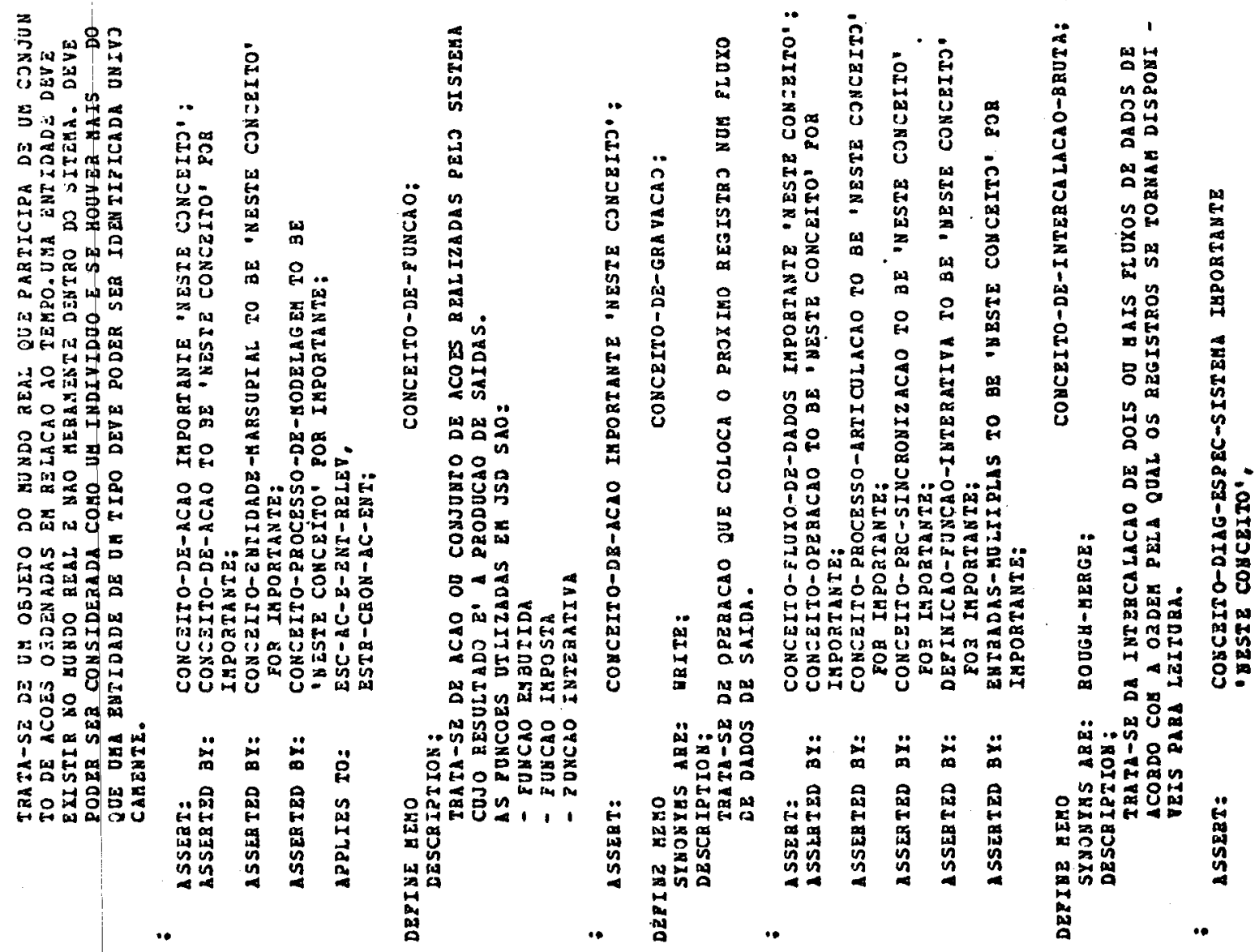

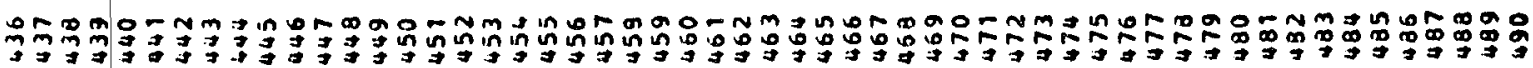




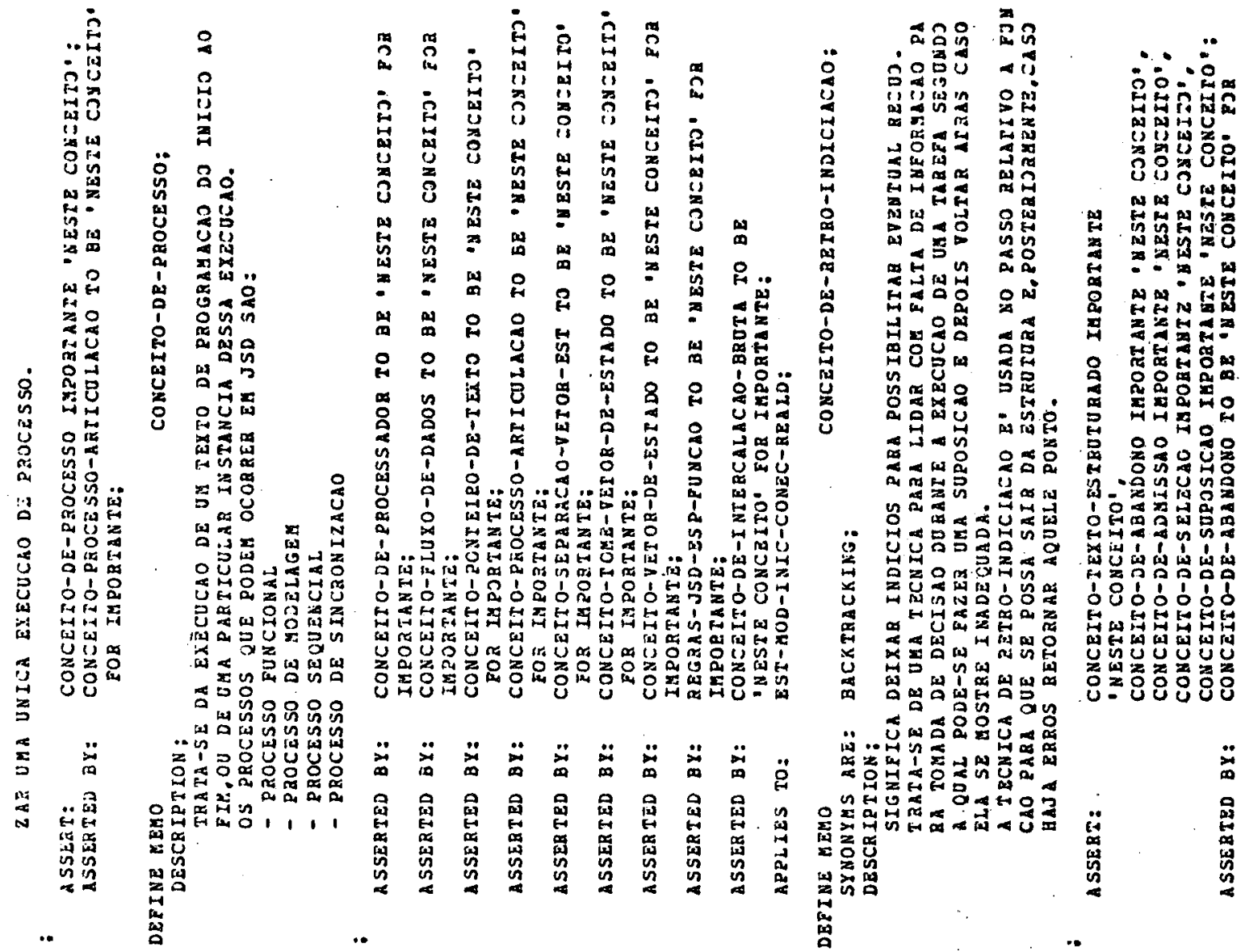

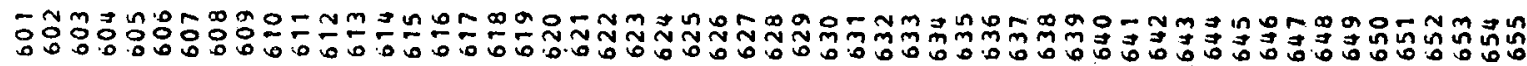

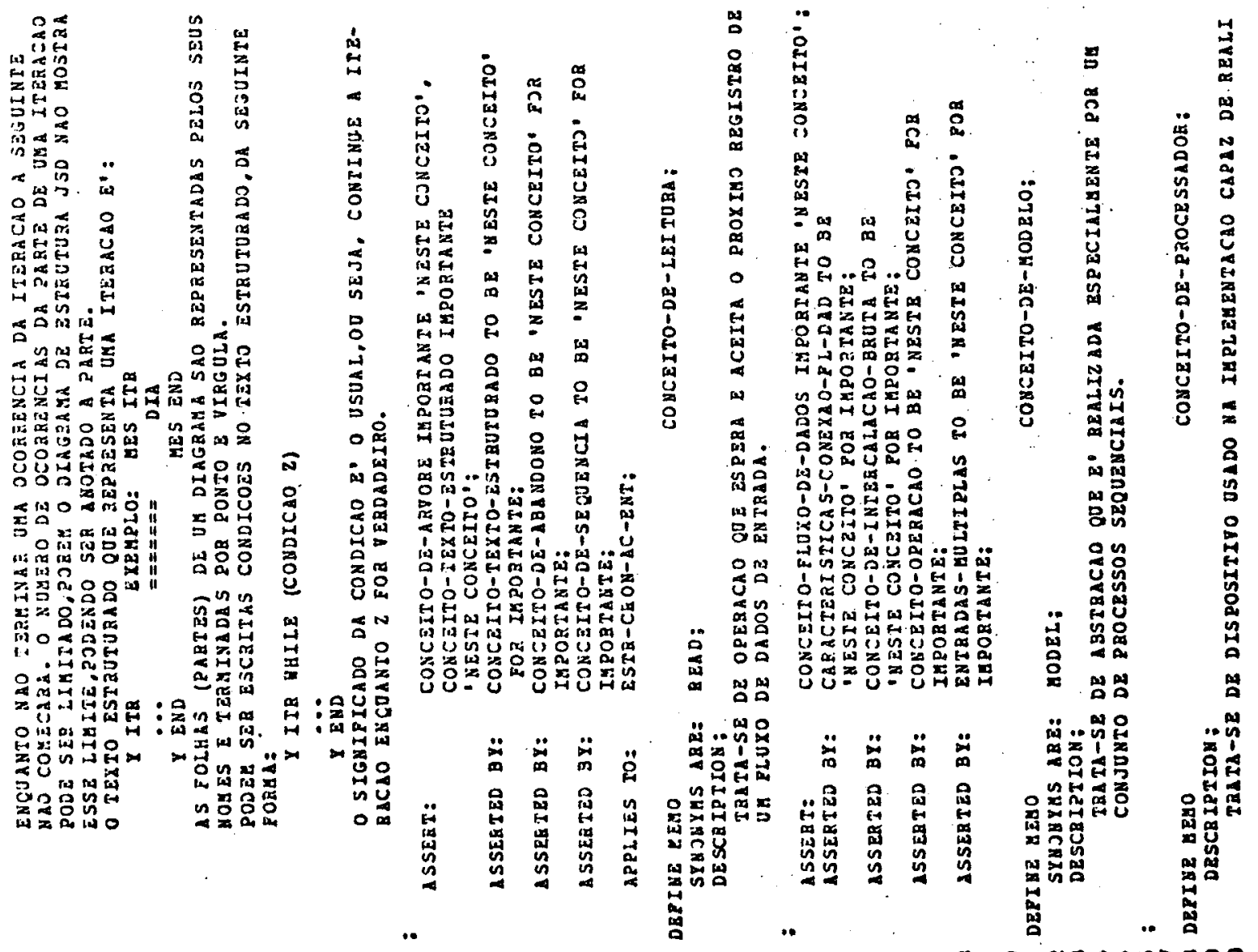

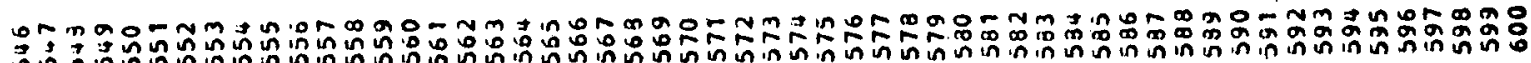




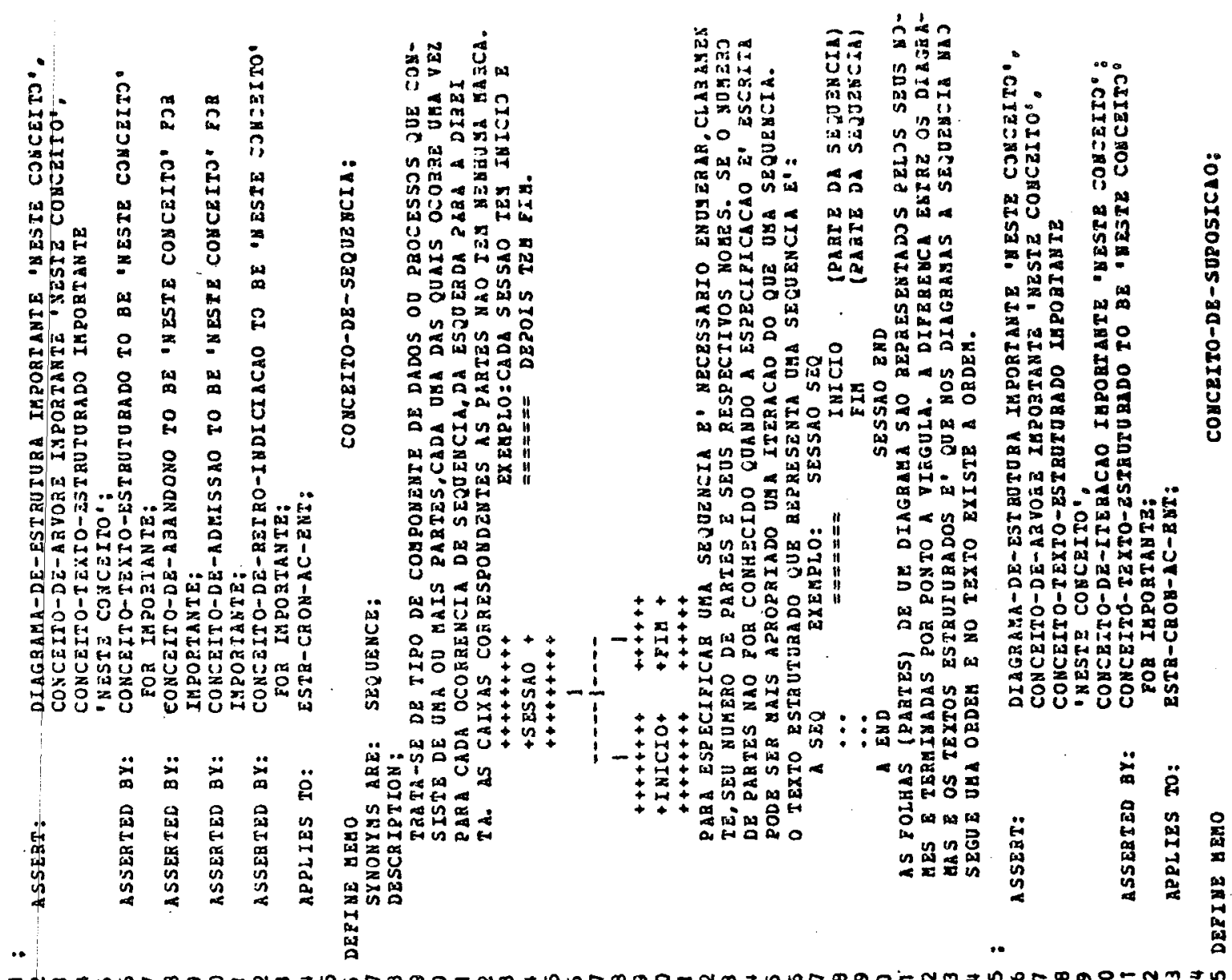

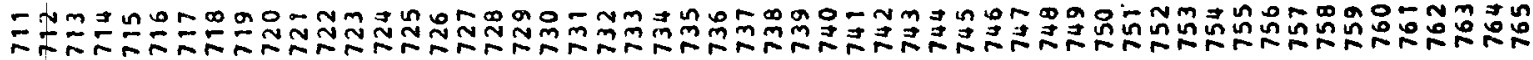

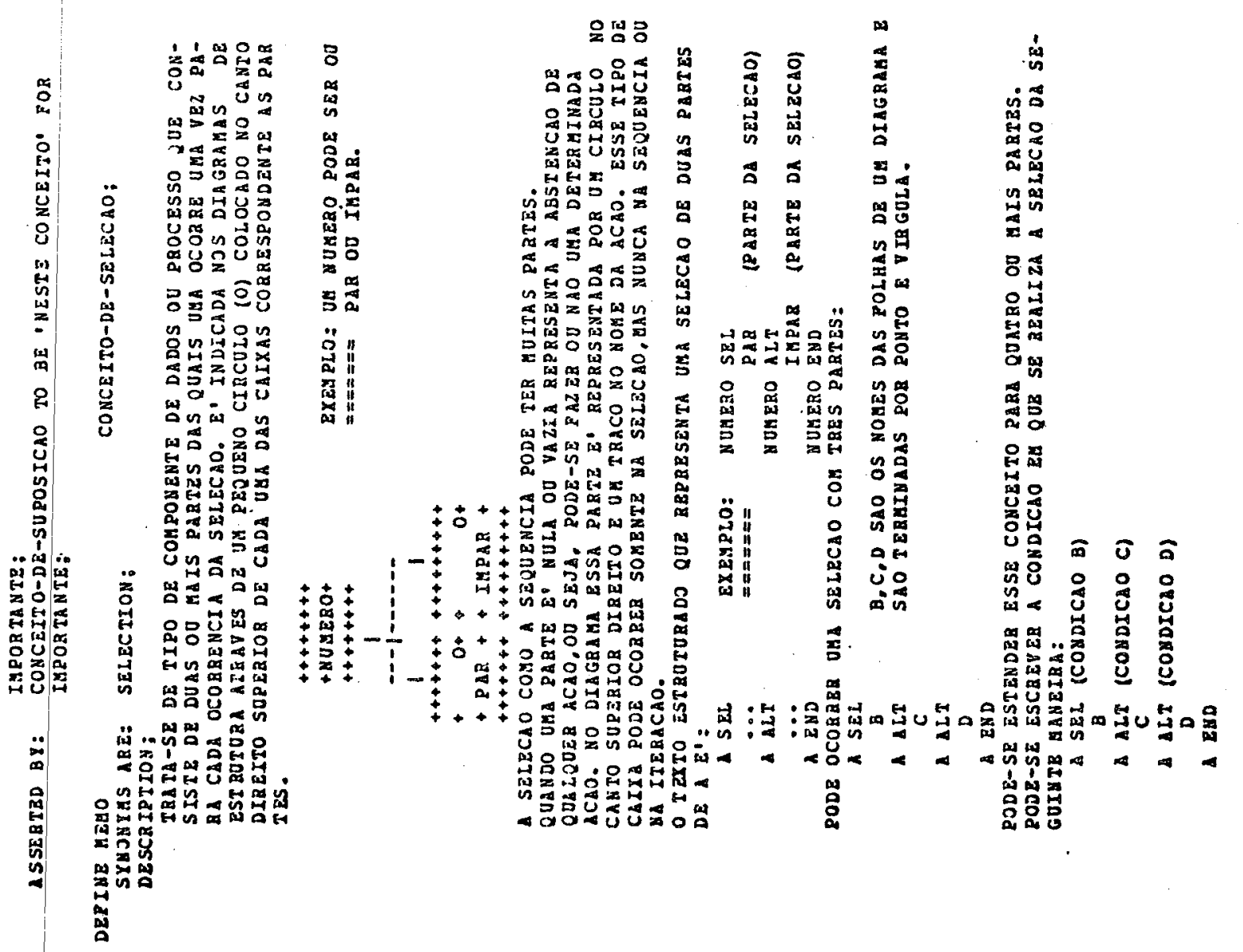

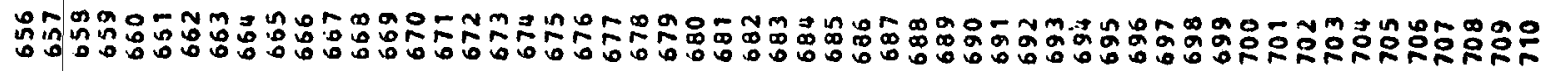




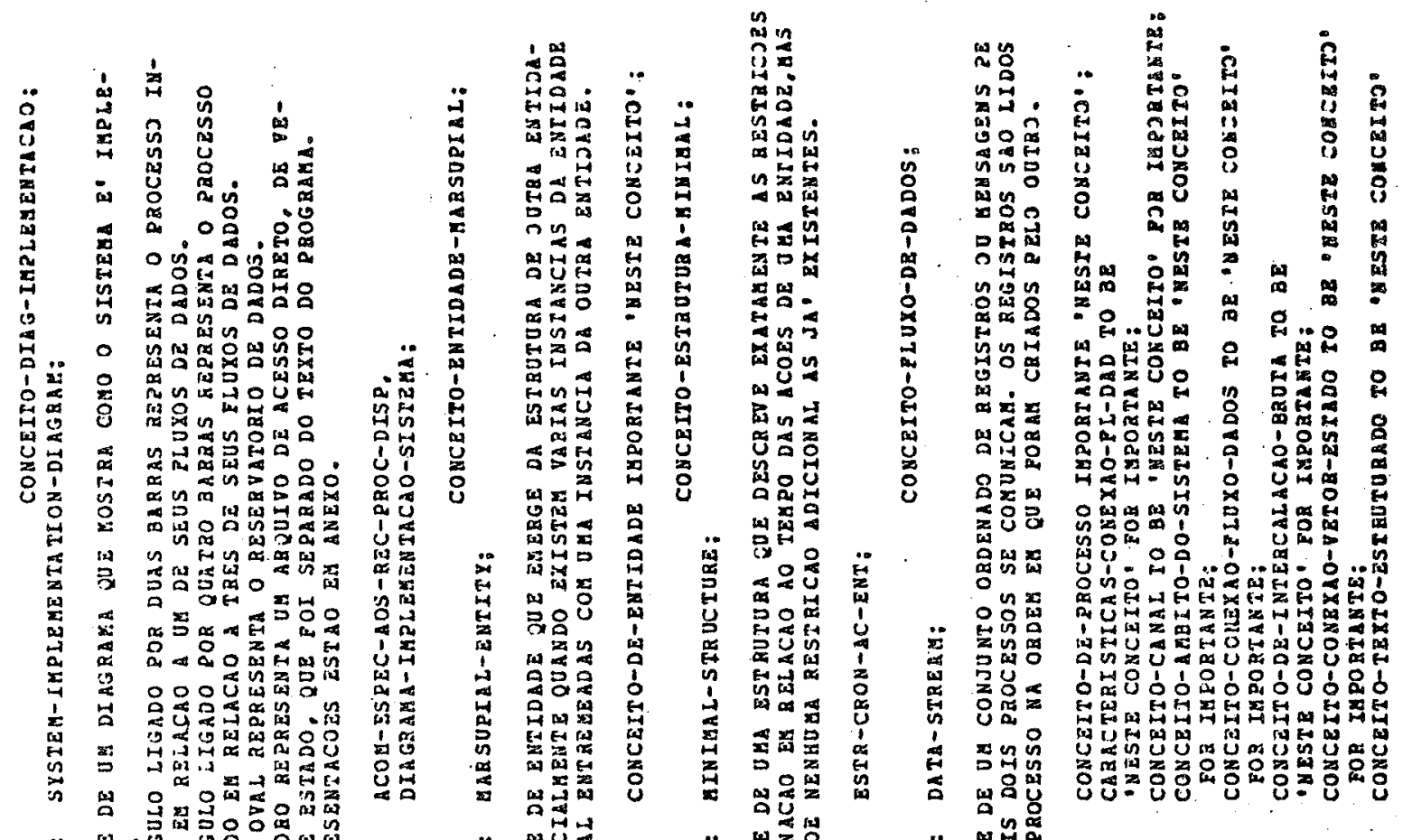

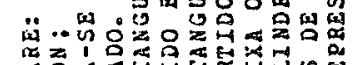

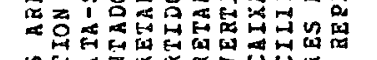

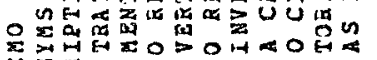
政 贸究昆 売

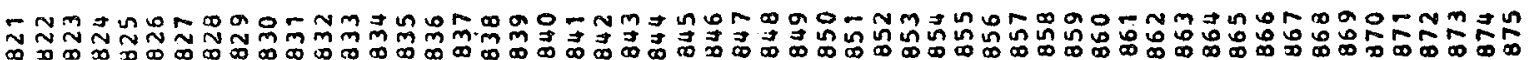

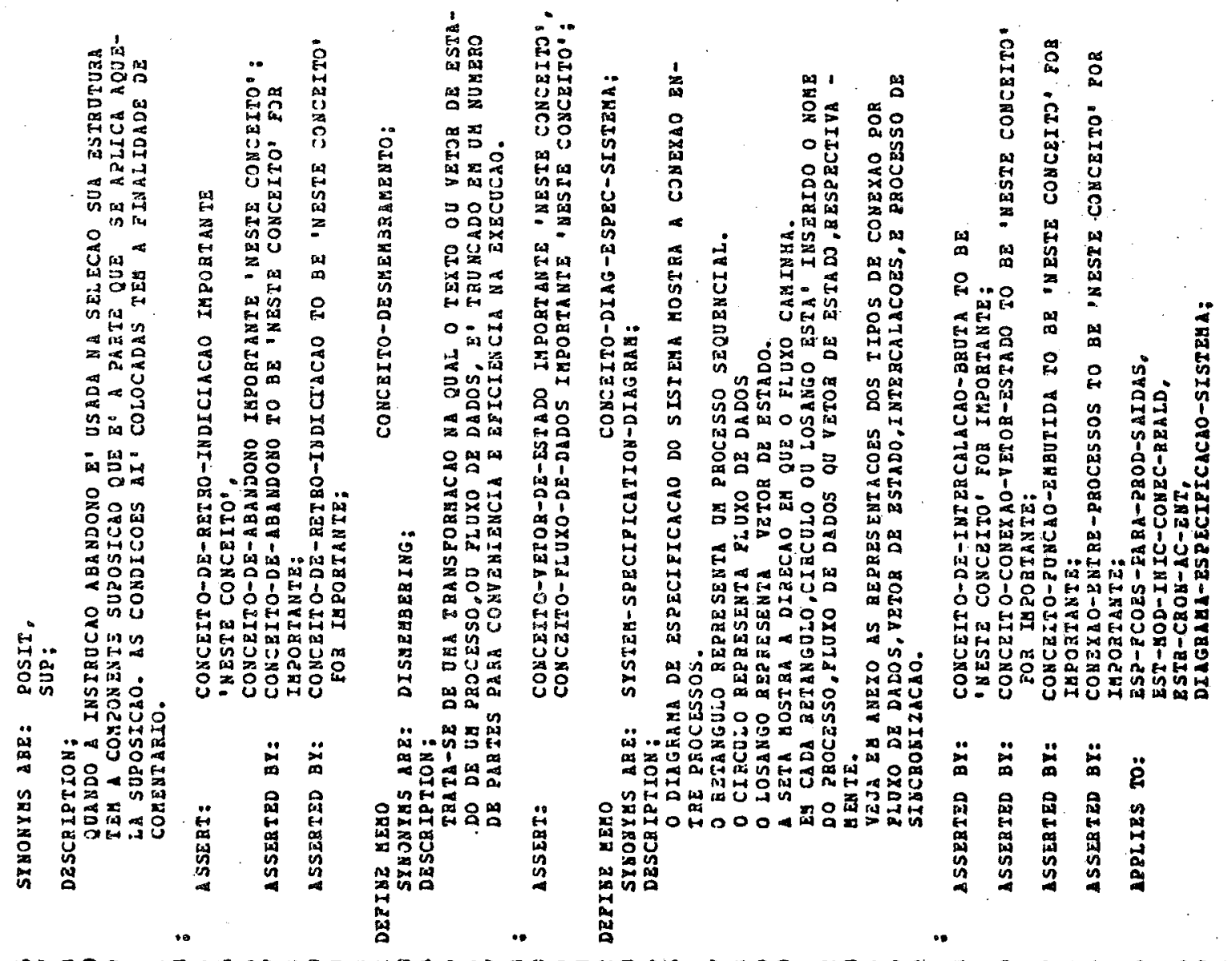

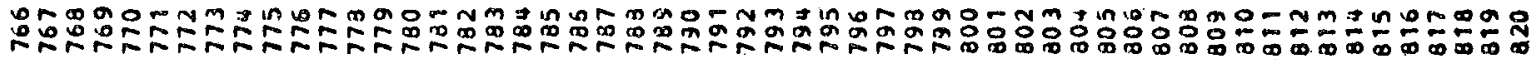


Anexo Conceito-Diag-Espec-Sistema

$p$
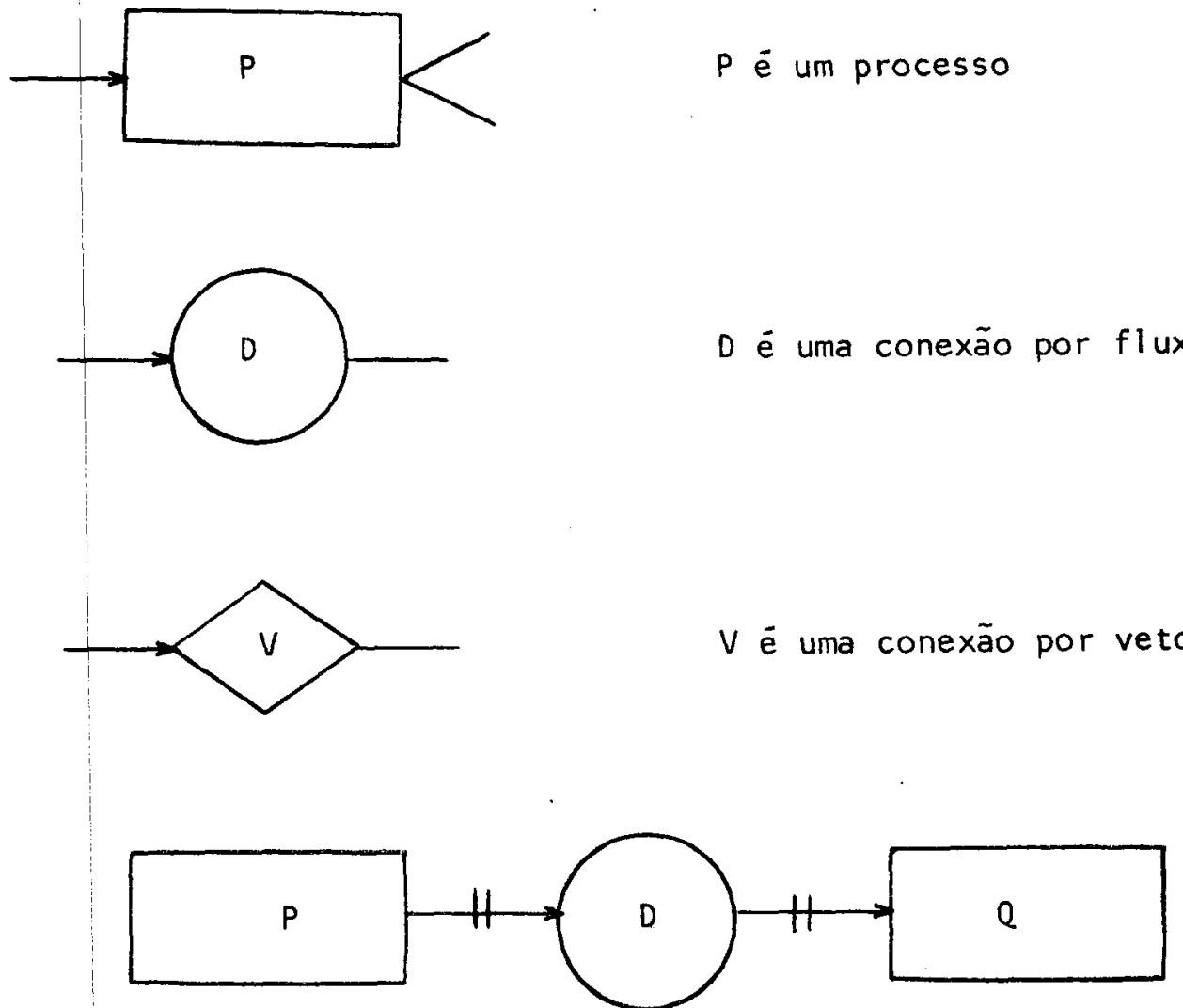

D é uma conexão por fluxo de dados

$V$ é uma conexão por vetor de estado para muitos.

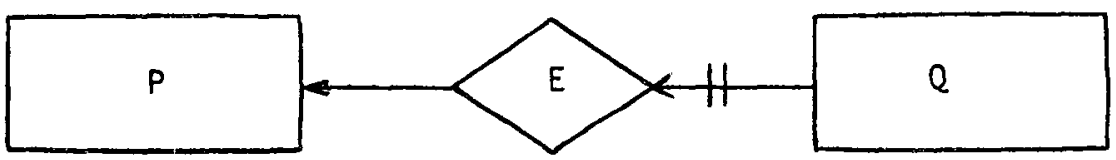

Conexão muitos

Conexão muitos para um.

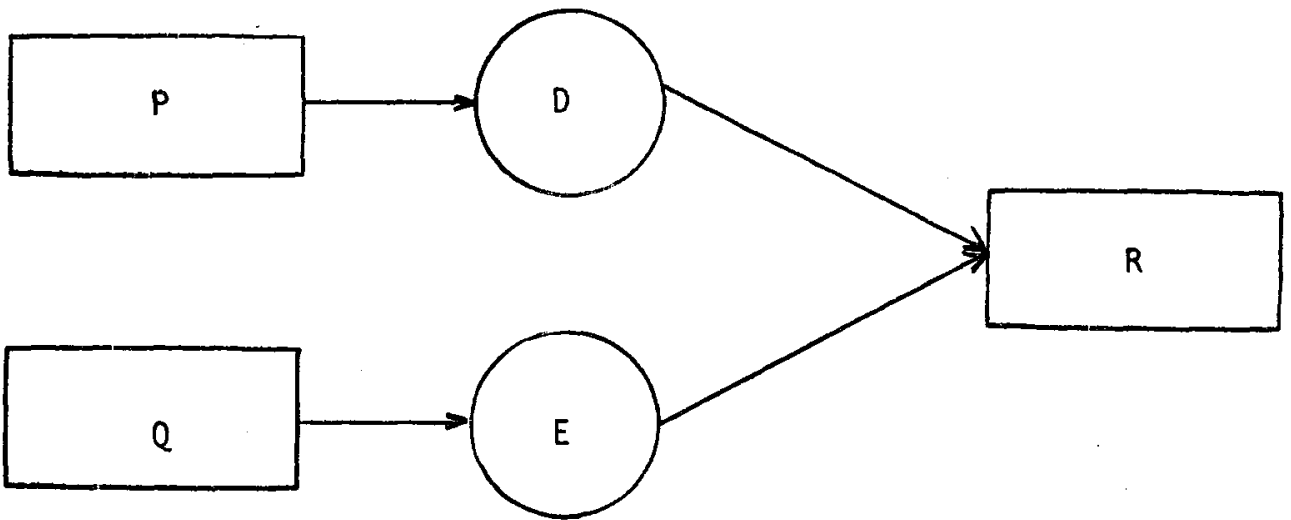

$R$ intercala os fluxos de dados $D$ e $E$ por intercalção fixa ou intercalação de dados. 

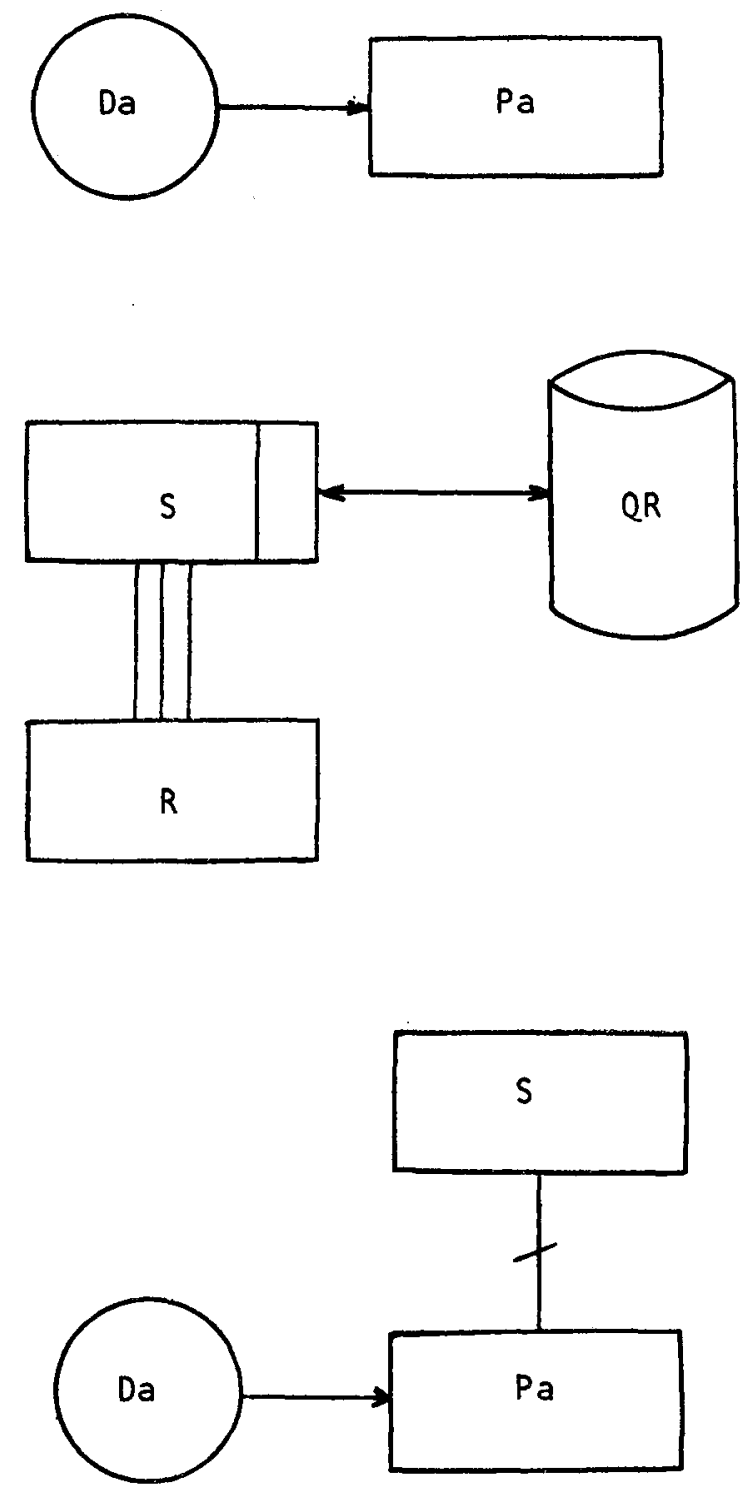

Pa è uma parte desmembrada de um processo $P$.

$R$ é invertido com relação a dois fluxos de dados e seus vetores de estado estão separados. 0 pro cesso de articulação $S$ recupera e armazena os vetores de estado de $Q(Q R)$.

A parte desmembrada $\mathrm{Pa}$ de um pro cesso $P$ é executada al gum número de vezes pelo processo de articu lação S.

llustrações referentes ao Diagrama de Implementação do Sistema 


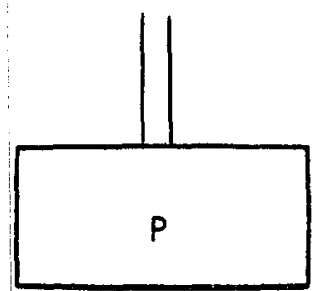

S

P

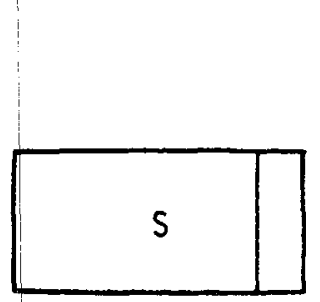

B
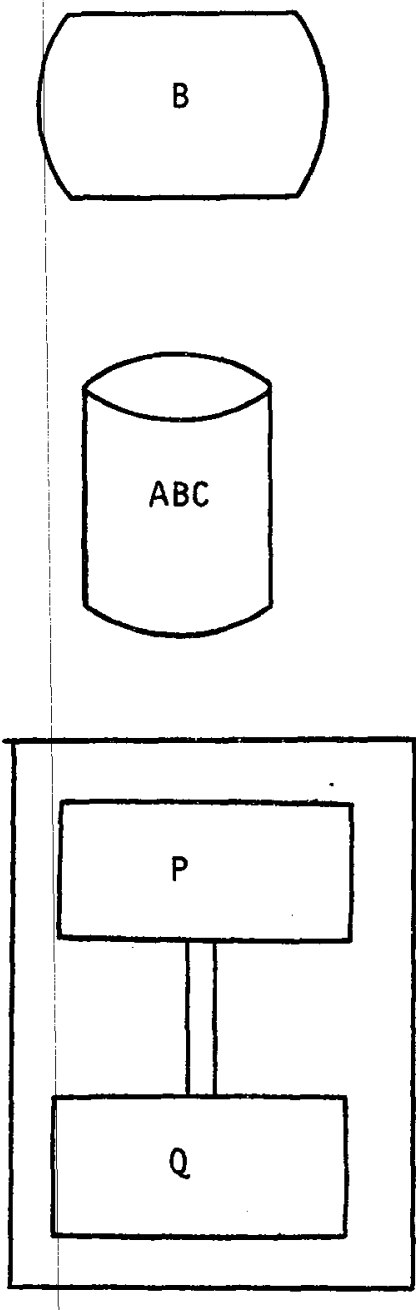

lustrações referentes ao Diagrama de Implementação do Siste ma (cont.)
$P$ é um processo invertido com relação a um de seus fluxos de dados.

$P$ é um processo invertido com relação a mais de um de seus fluxos de dados.

S é processo de articulação.

B é um reservatório (buffer).
$P$ e $Q$ invertidos. $Q$ invertido é subrotina de $P$. 


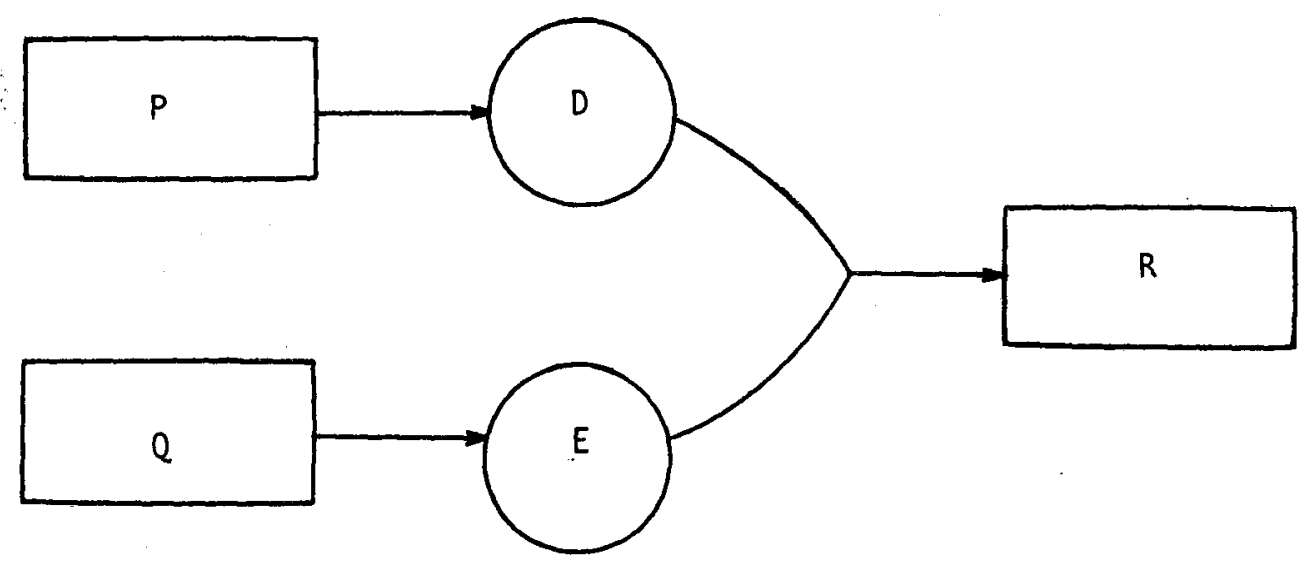

$R$ intercala os fluxos $D$ e $E$ por intercalção bruta.

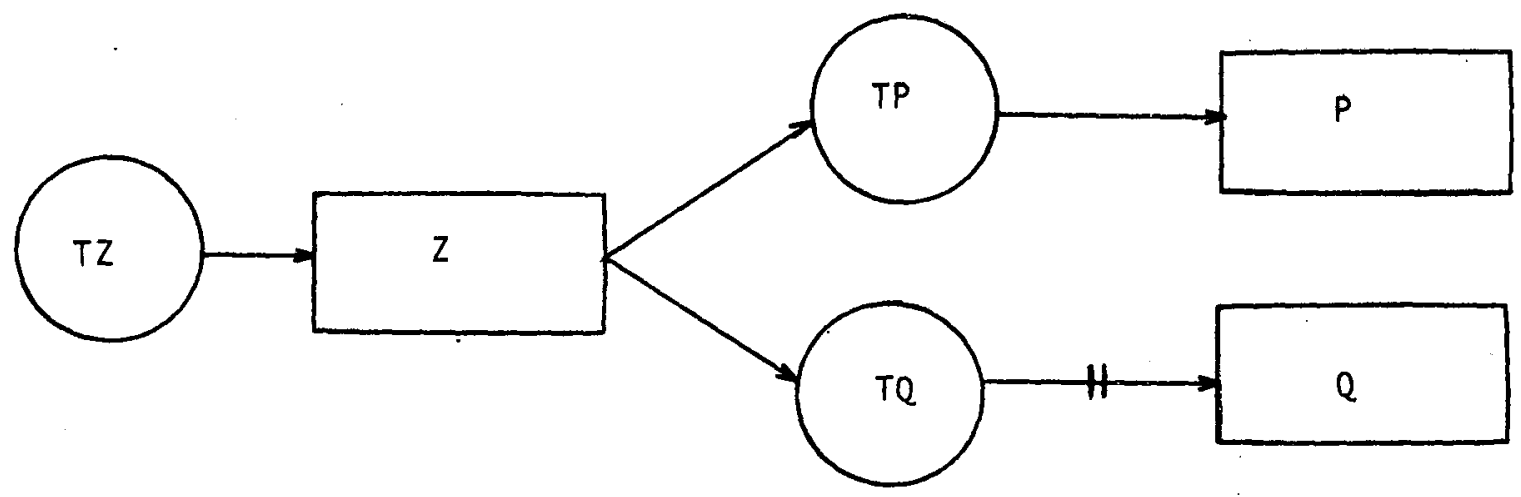

$Z$ é o processo de sincronização que grava os fluxos de marcadores de intervalo de tempo, TP e TQ, para os processos $P$ e $Q$ para sincroni zar essa execução.

llustrações referentes ao Diagrama de Implementação do sís tema (cont.) 


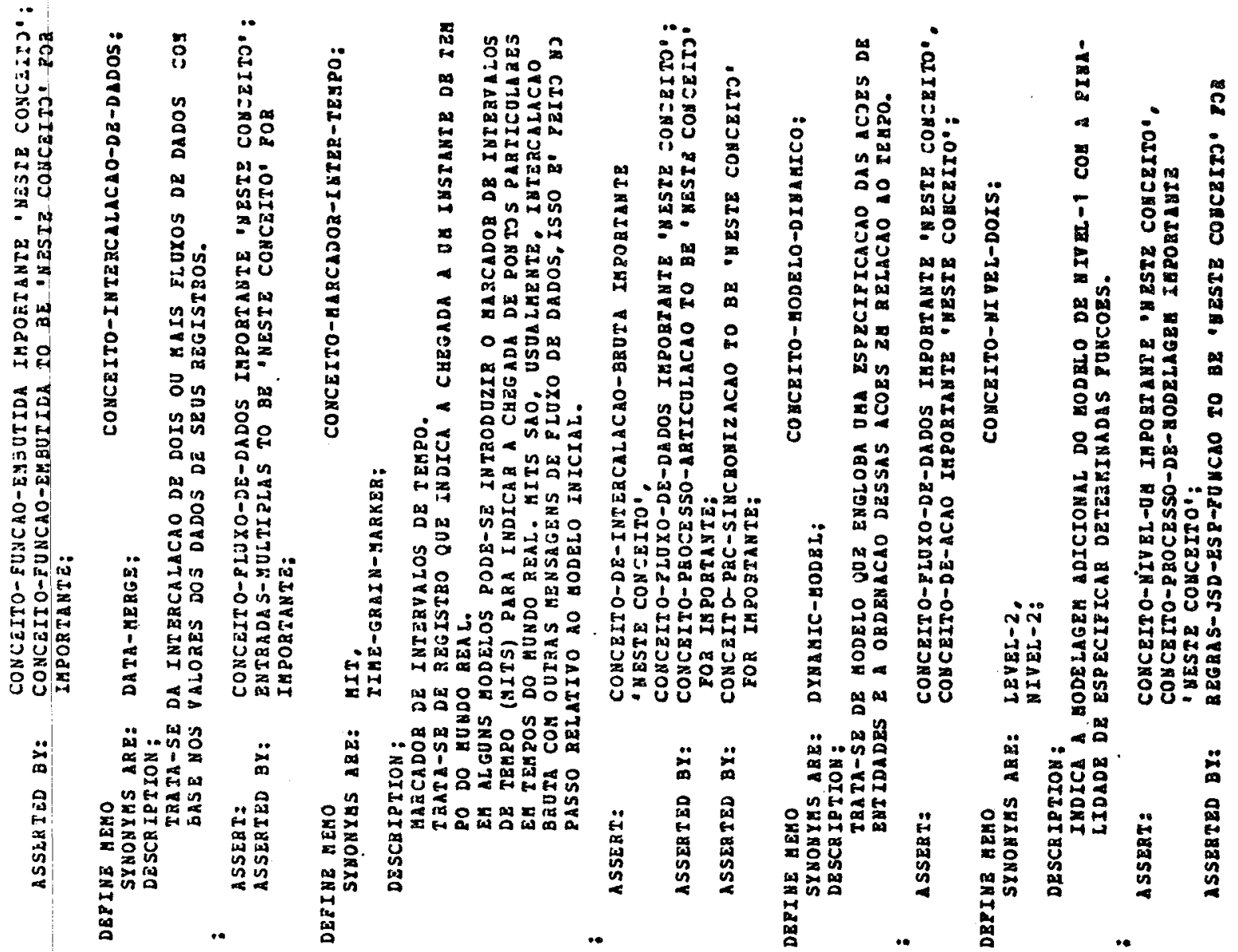

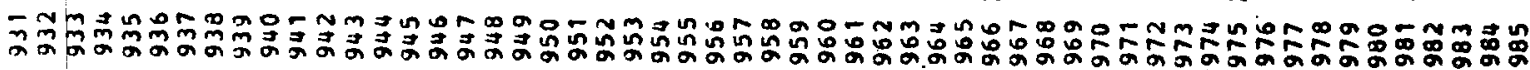

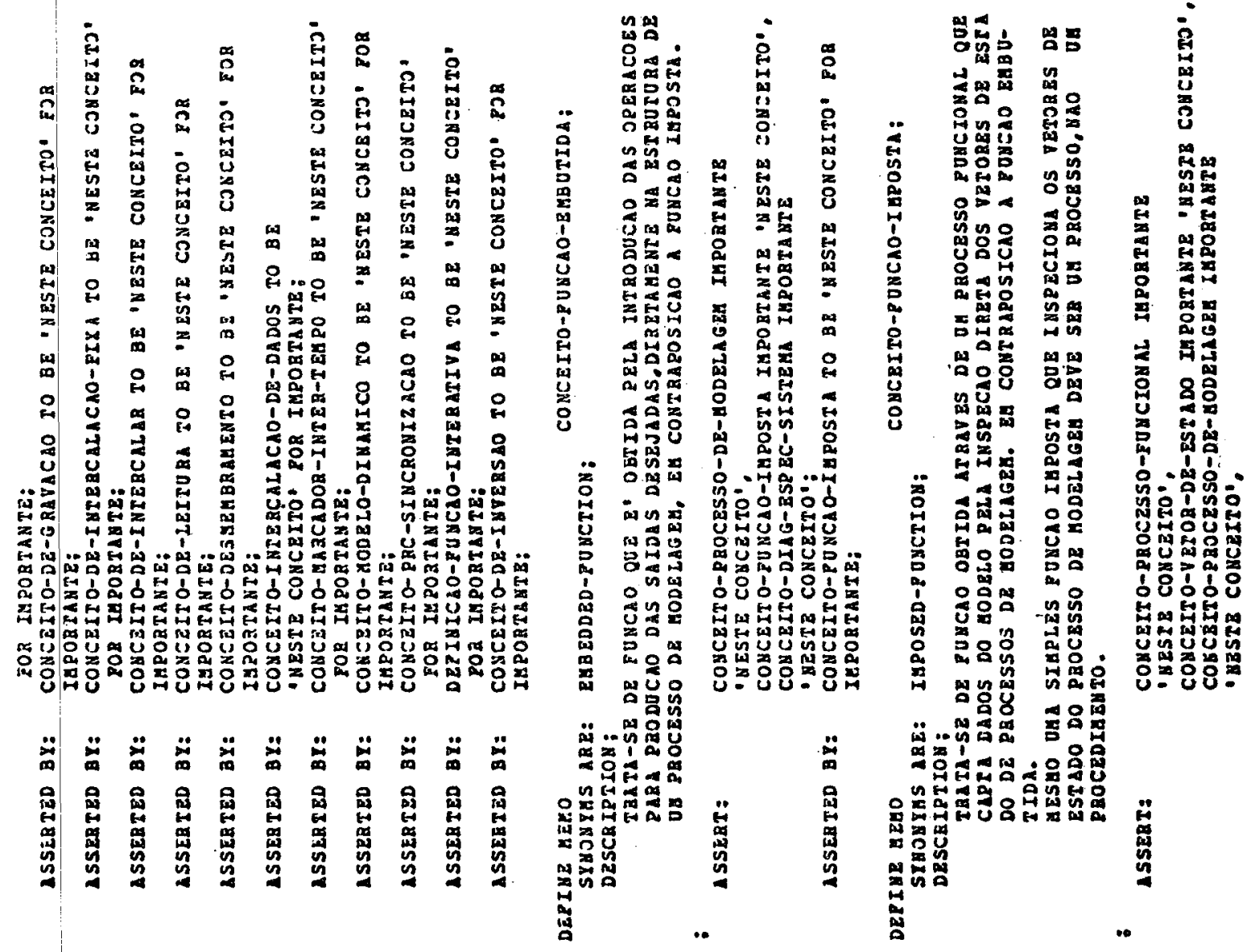

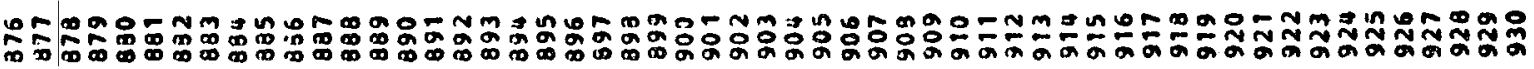




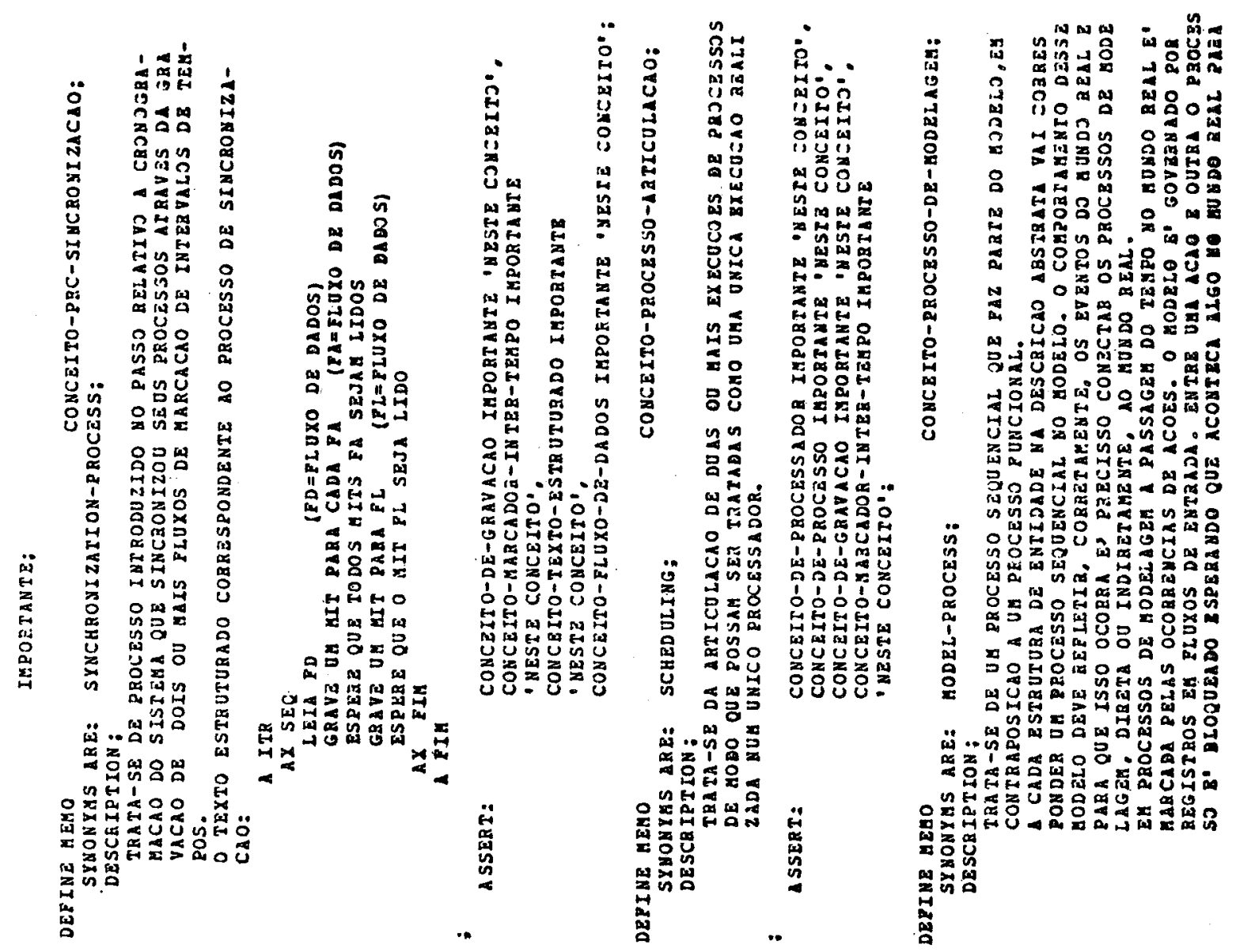

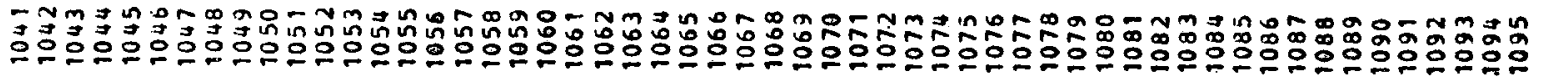

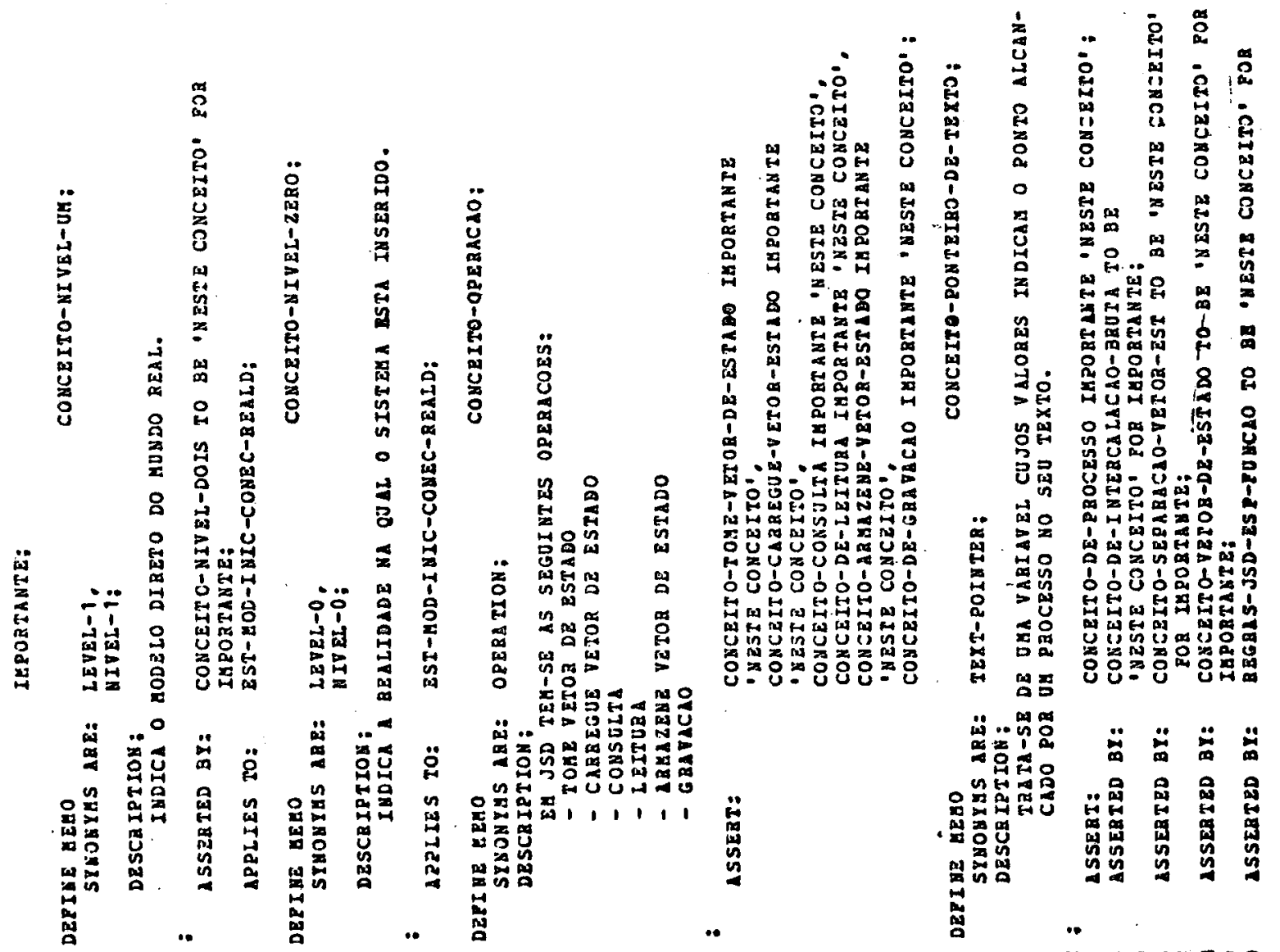

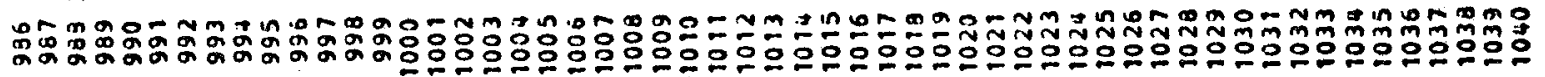




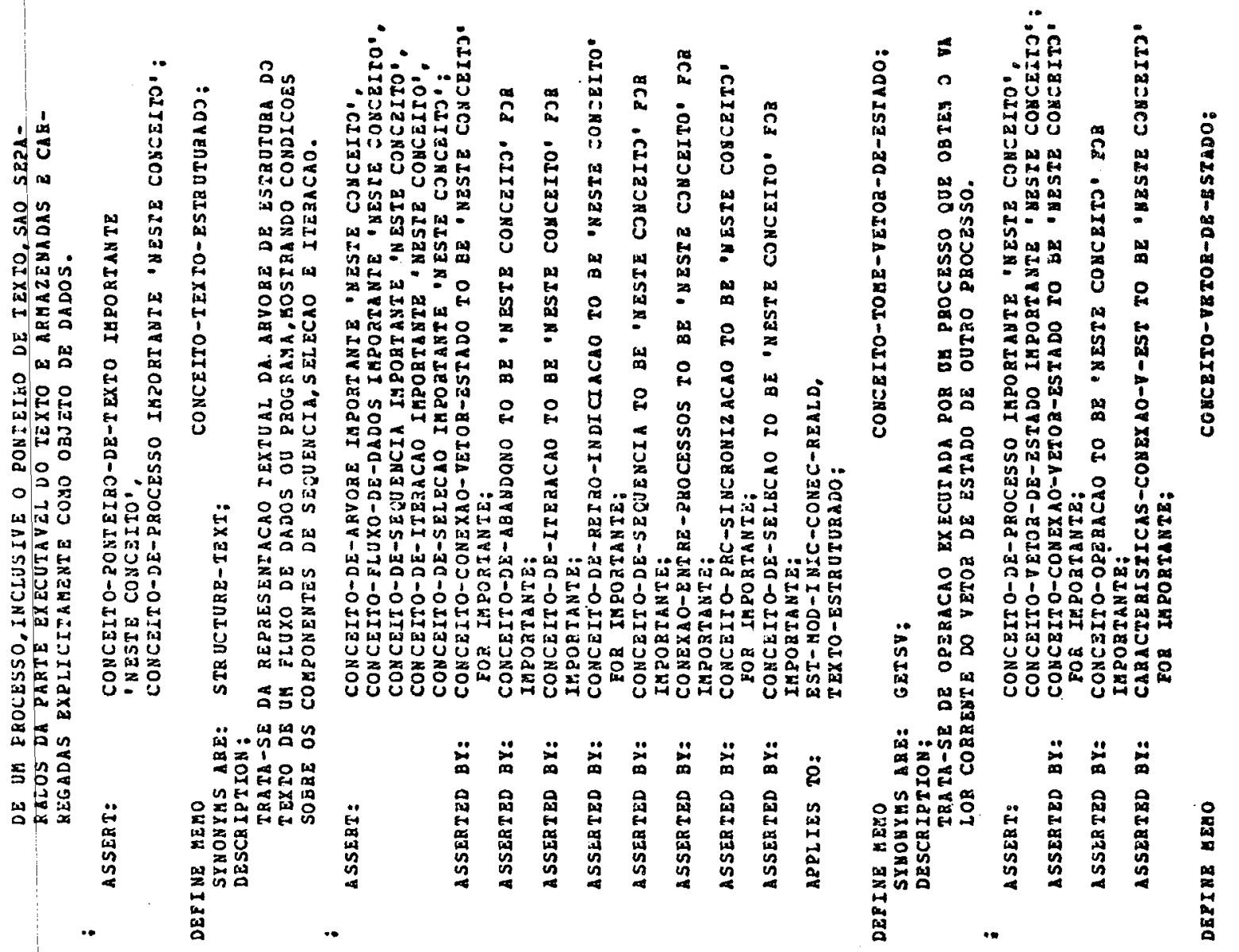

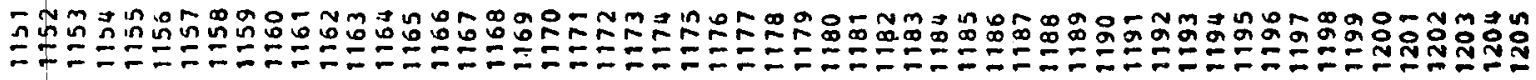

委㶽

0 in

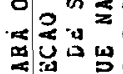

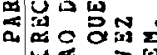

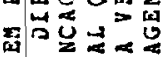

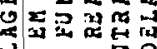

뱀씩웅응응

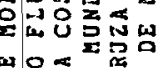

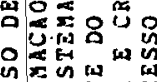

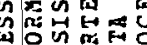

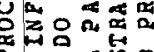

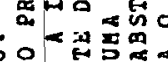

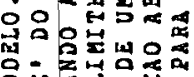

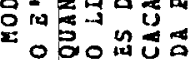

일.

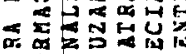

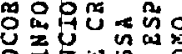

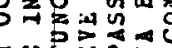

펼

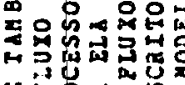

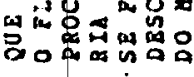

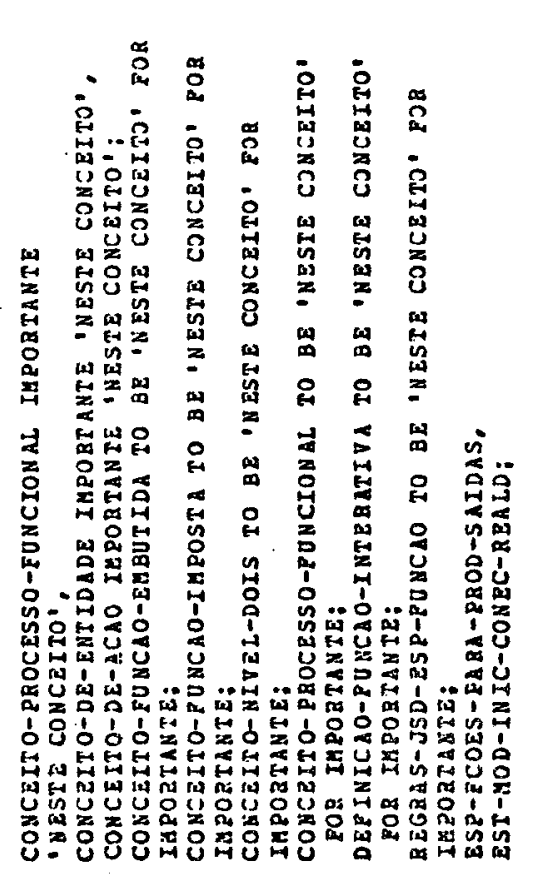

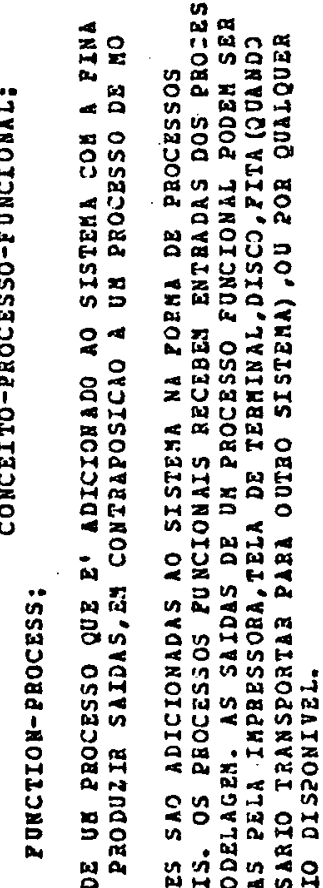

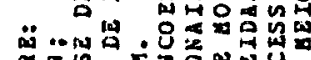

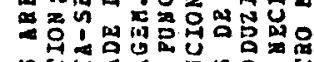

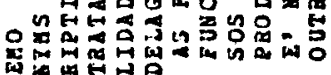

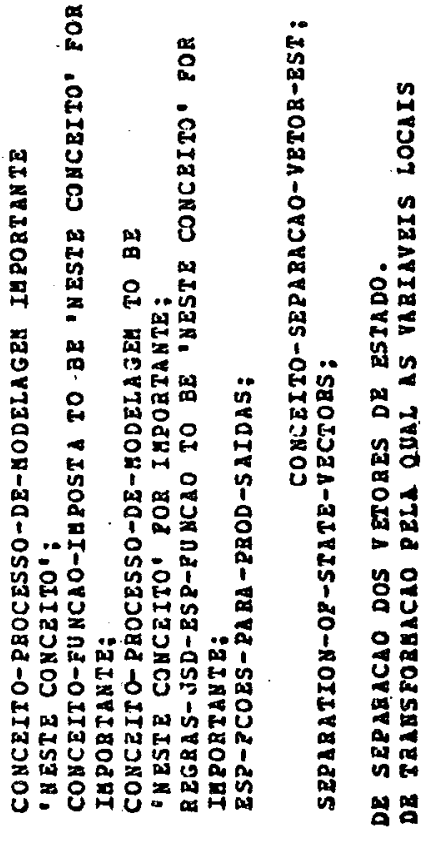

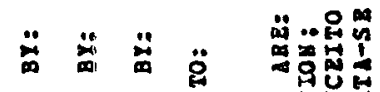

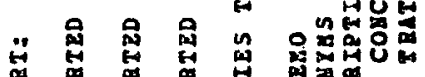

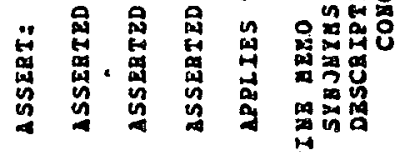

ลำ 


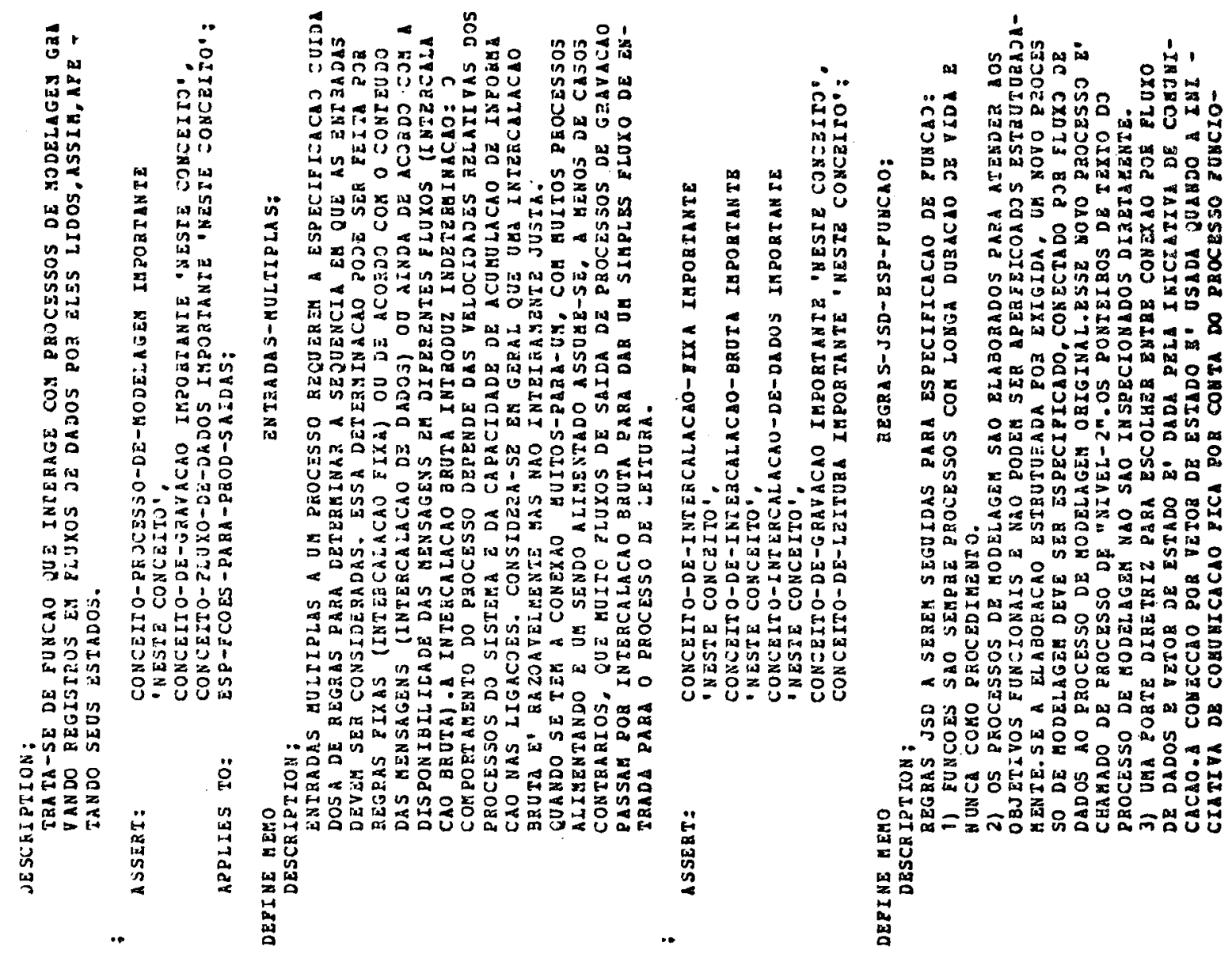

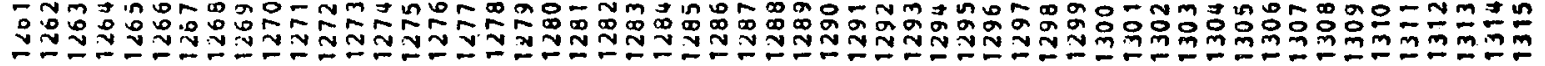
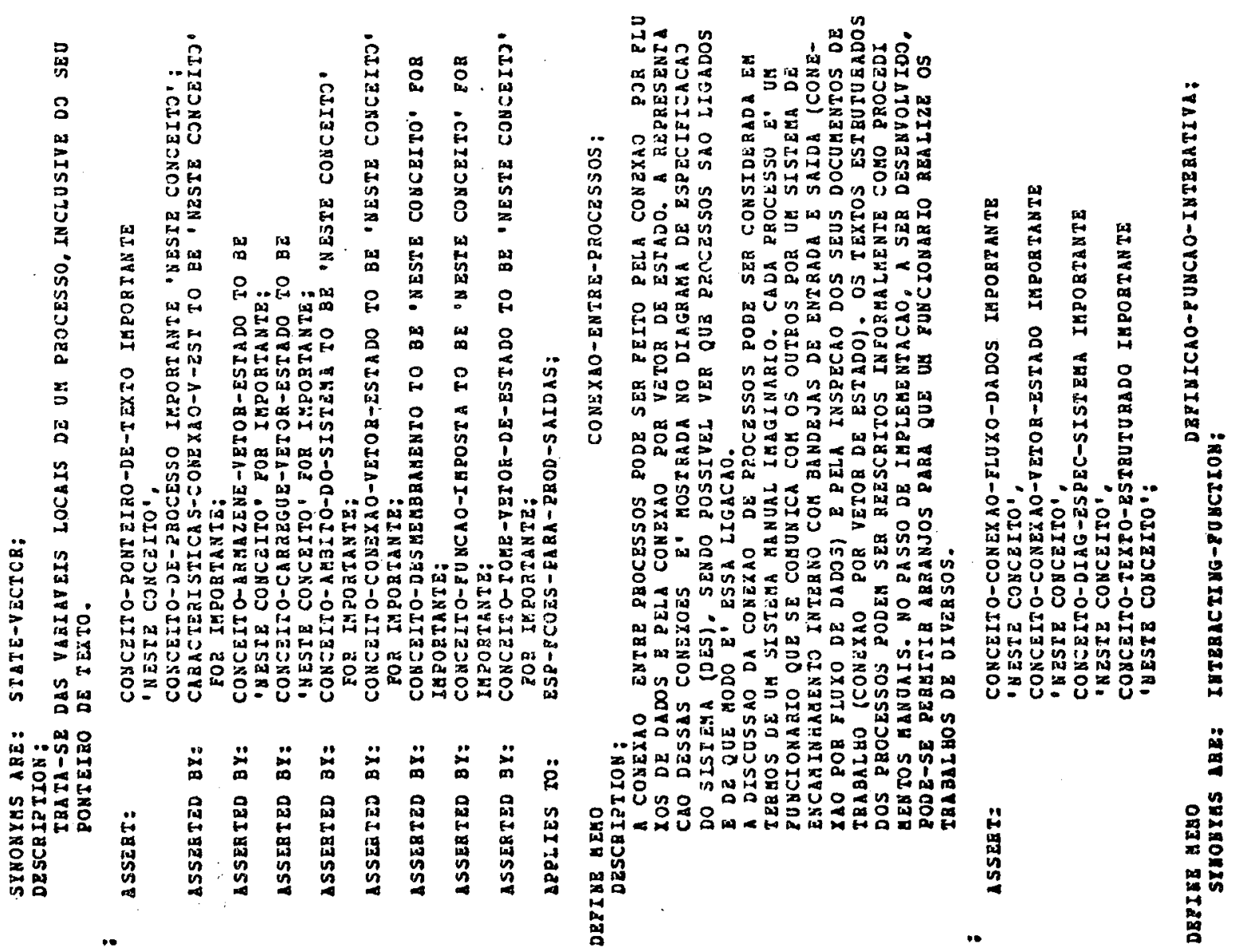

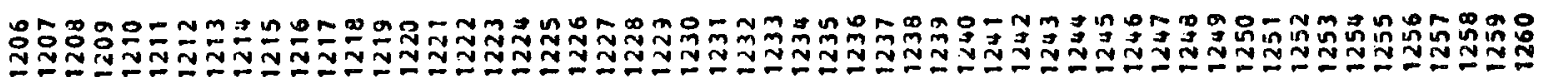




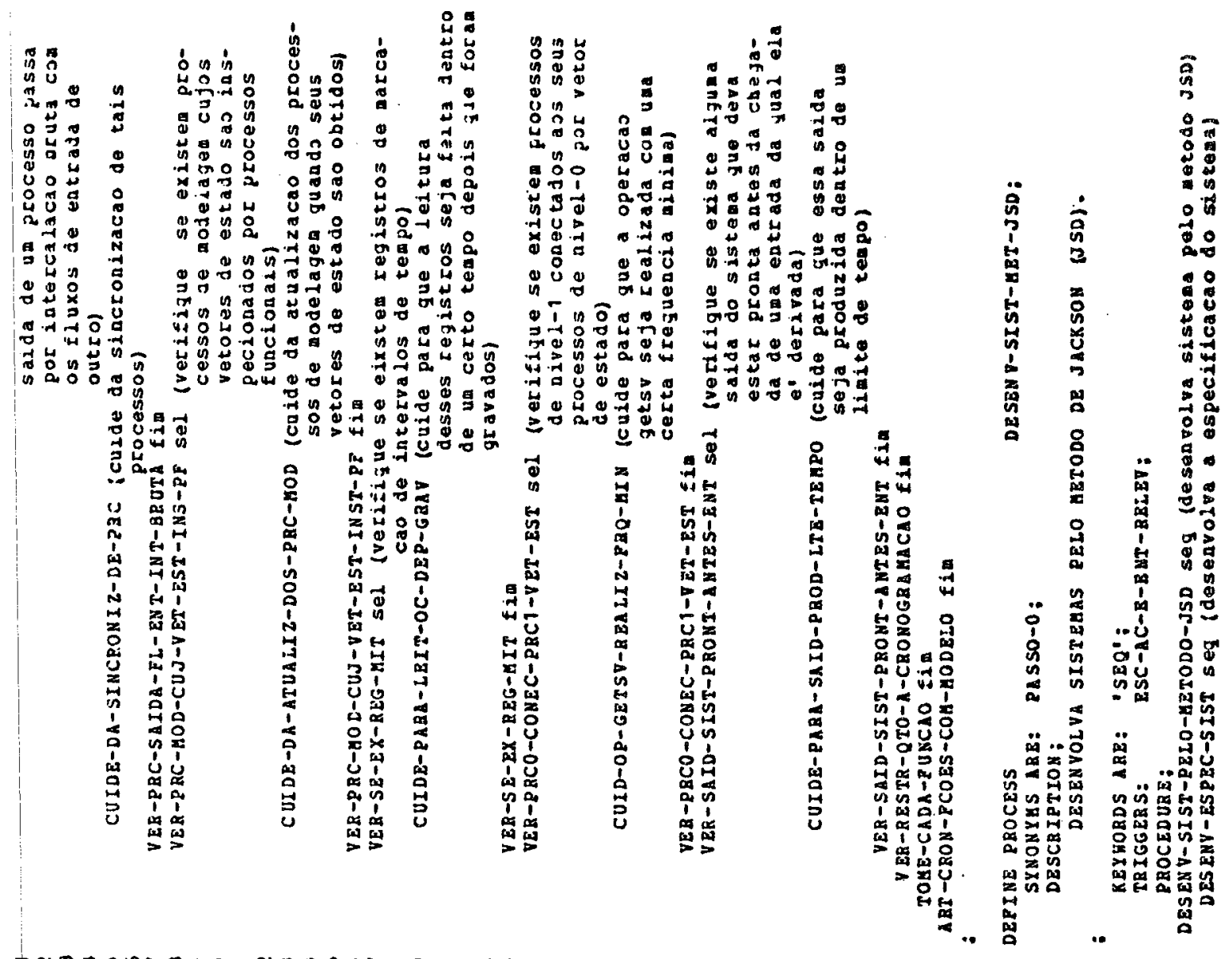

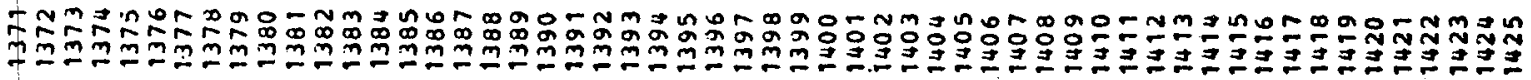

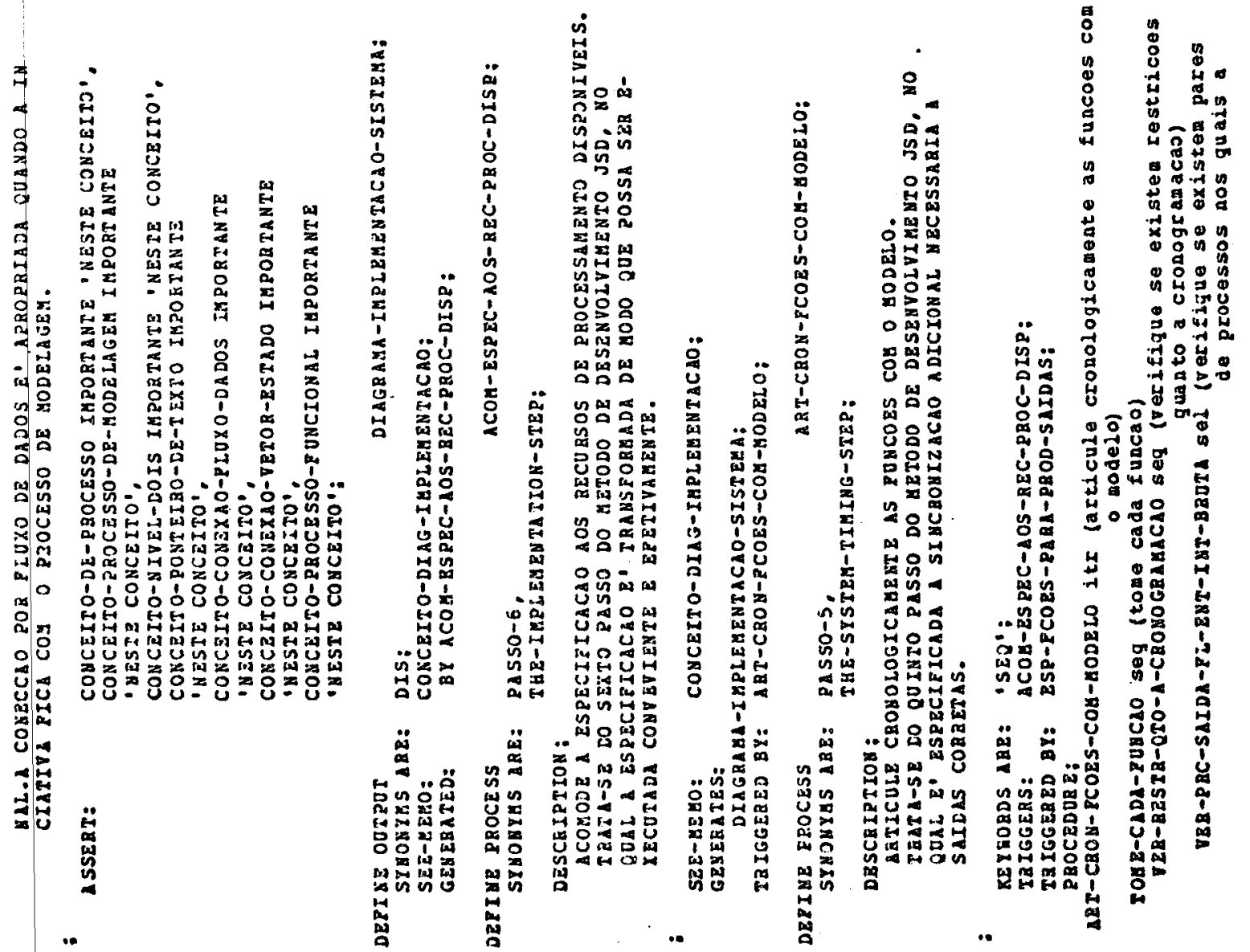

ำ

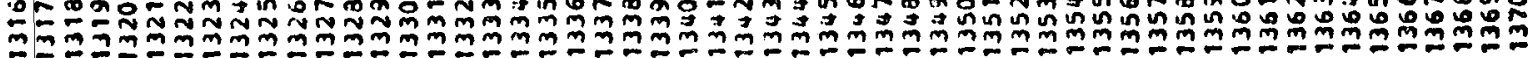




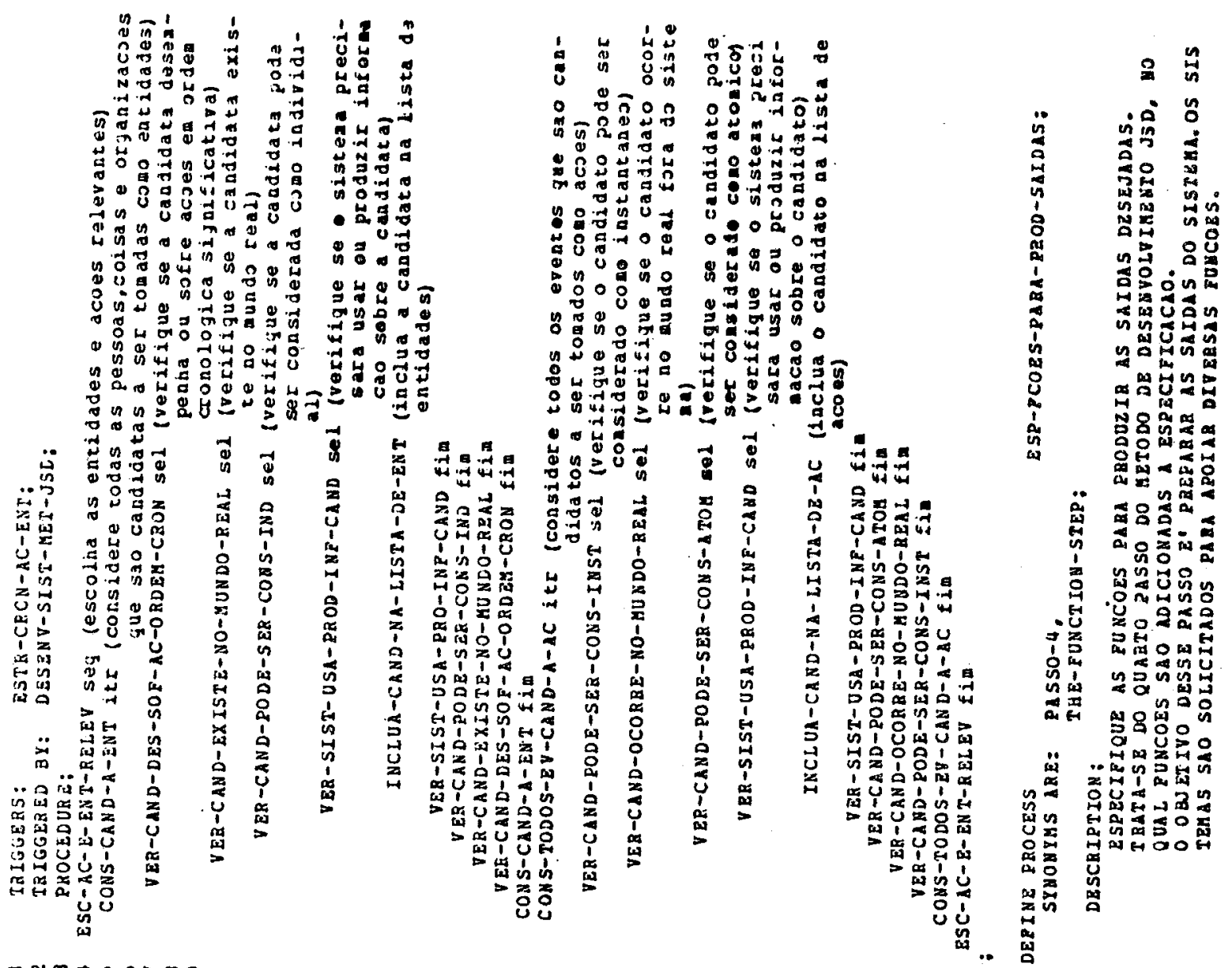

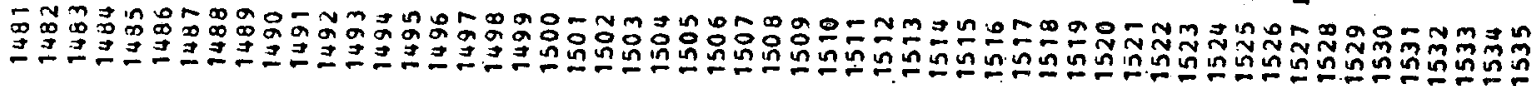

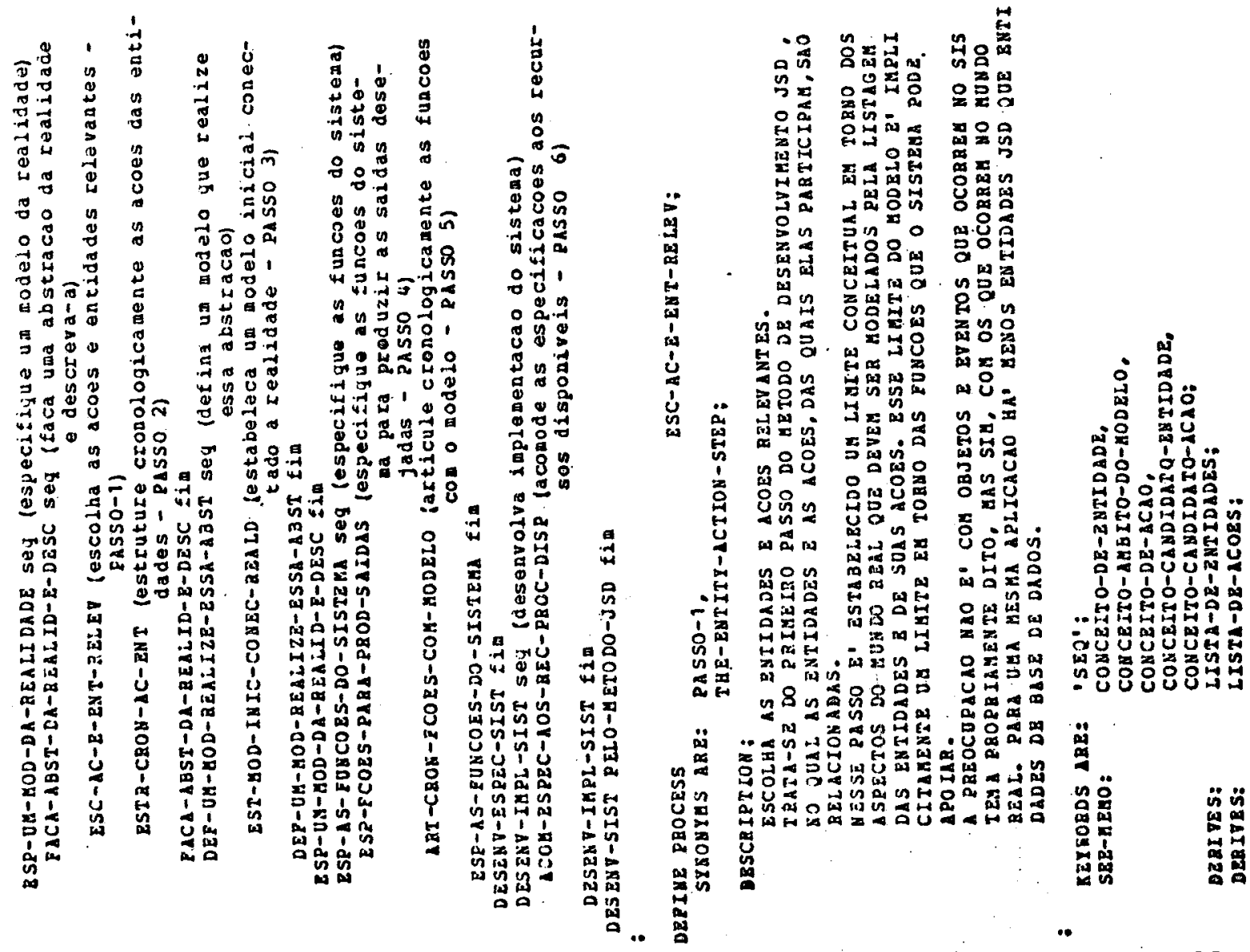

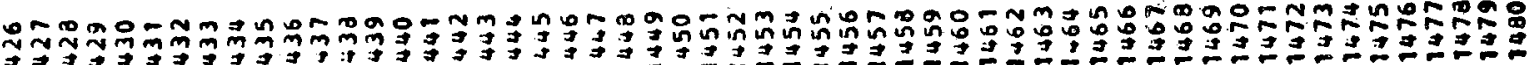




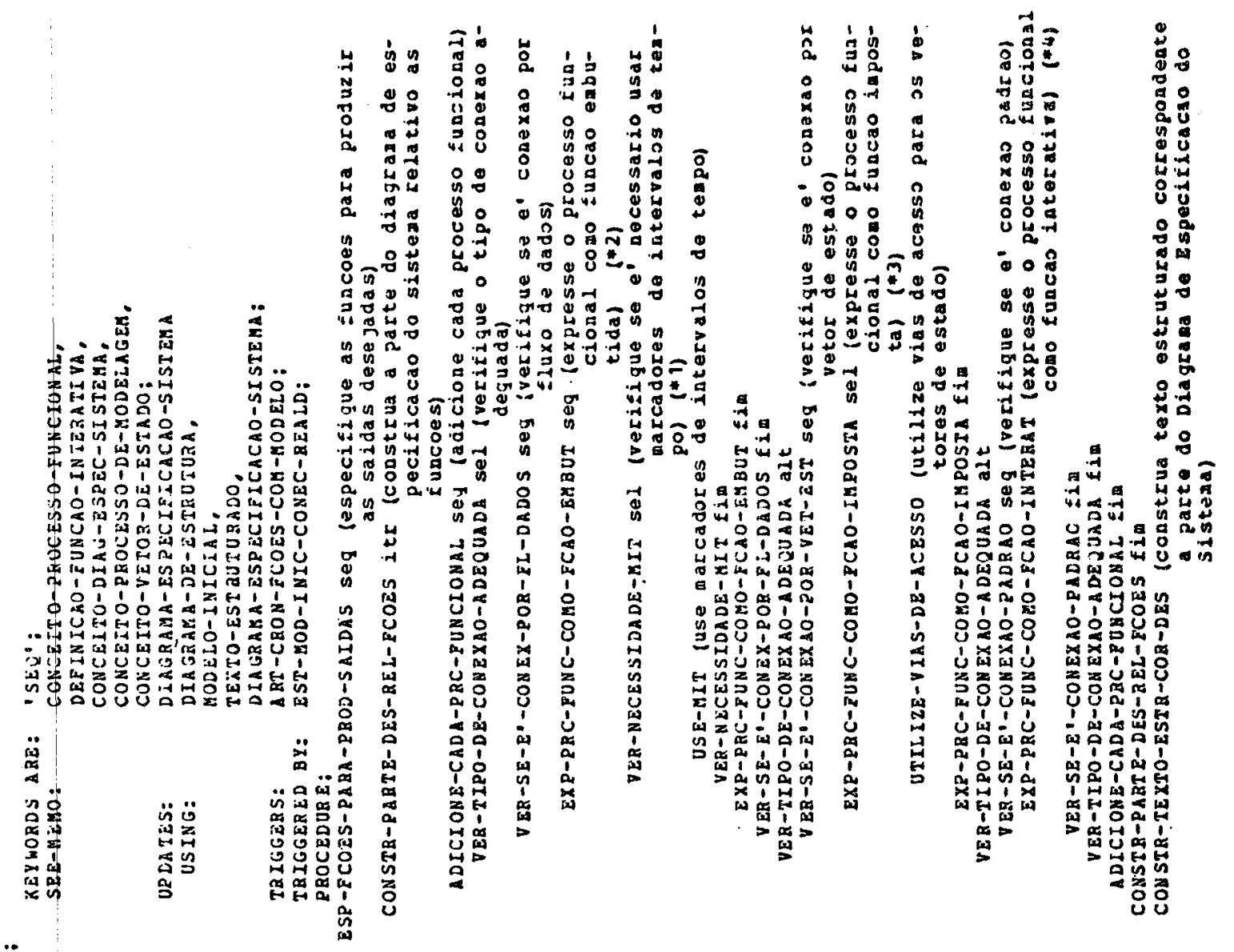

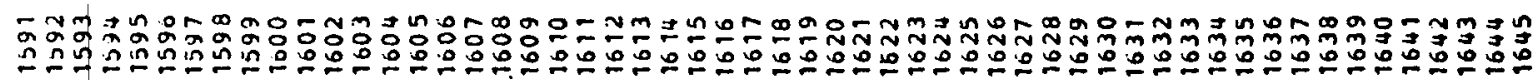

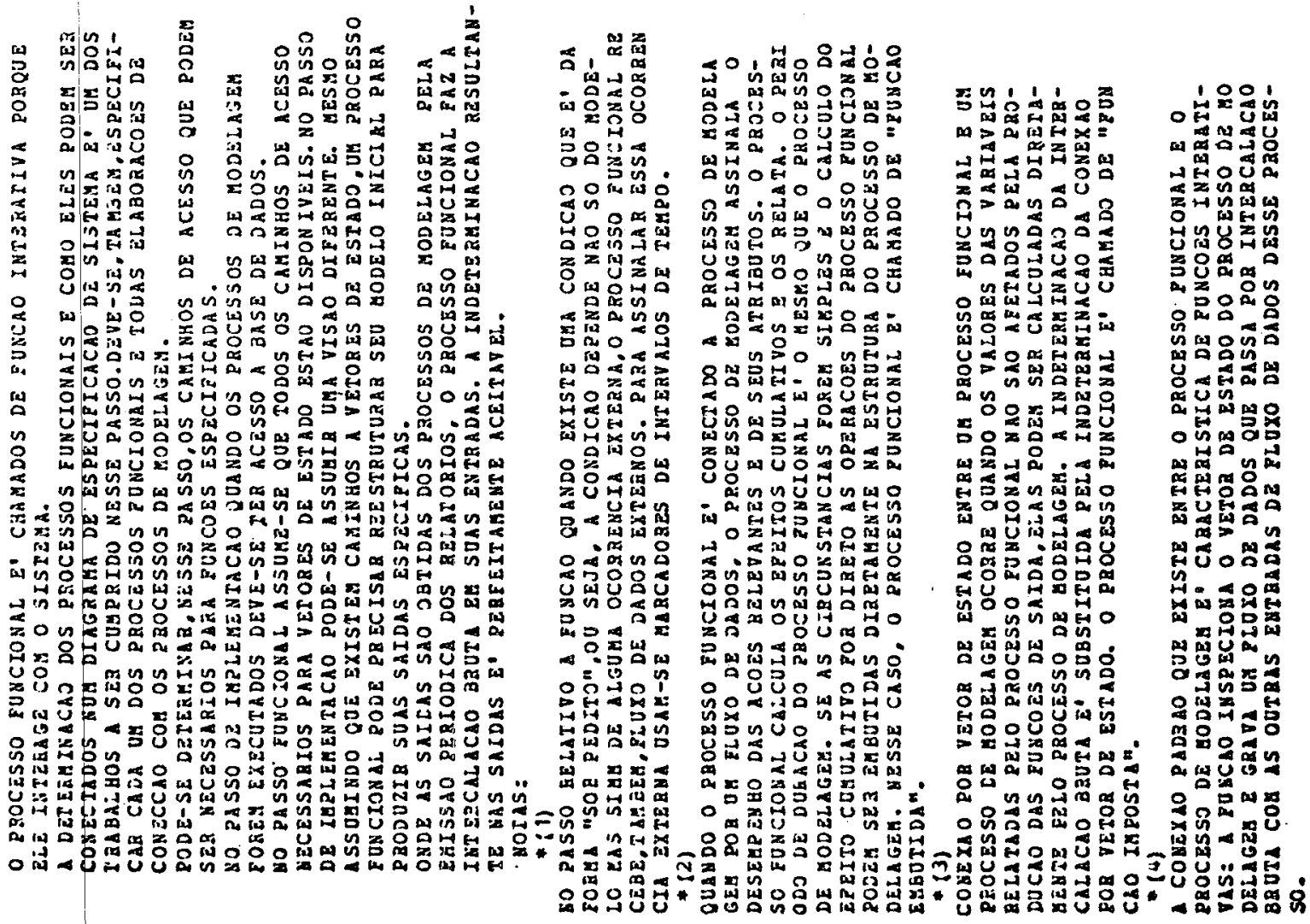




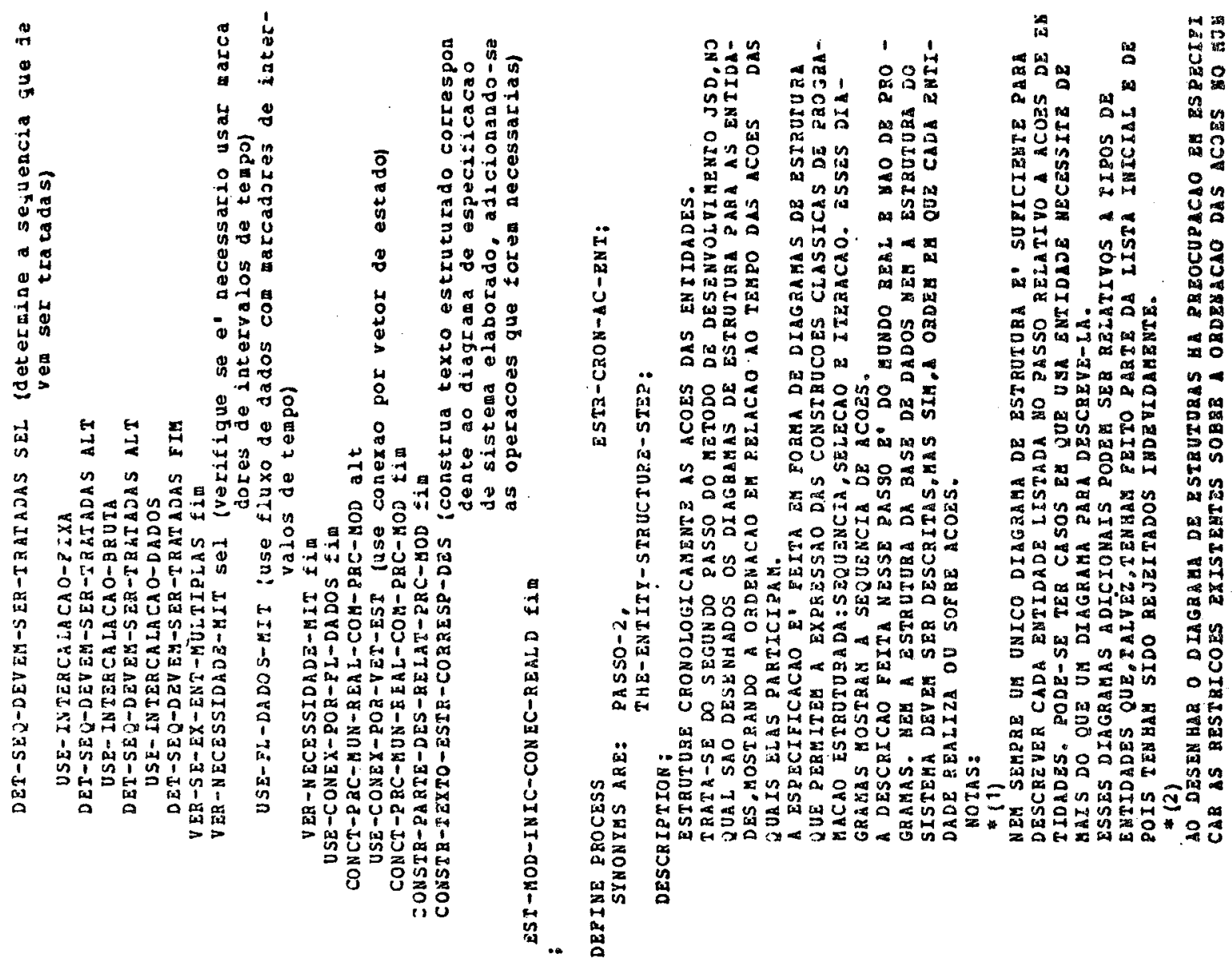

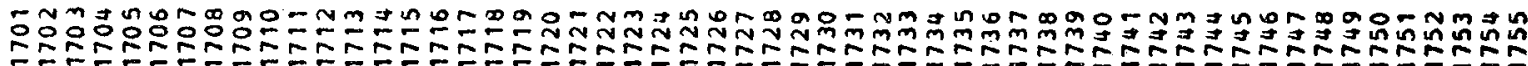
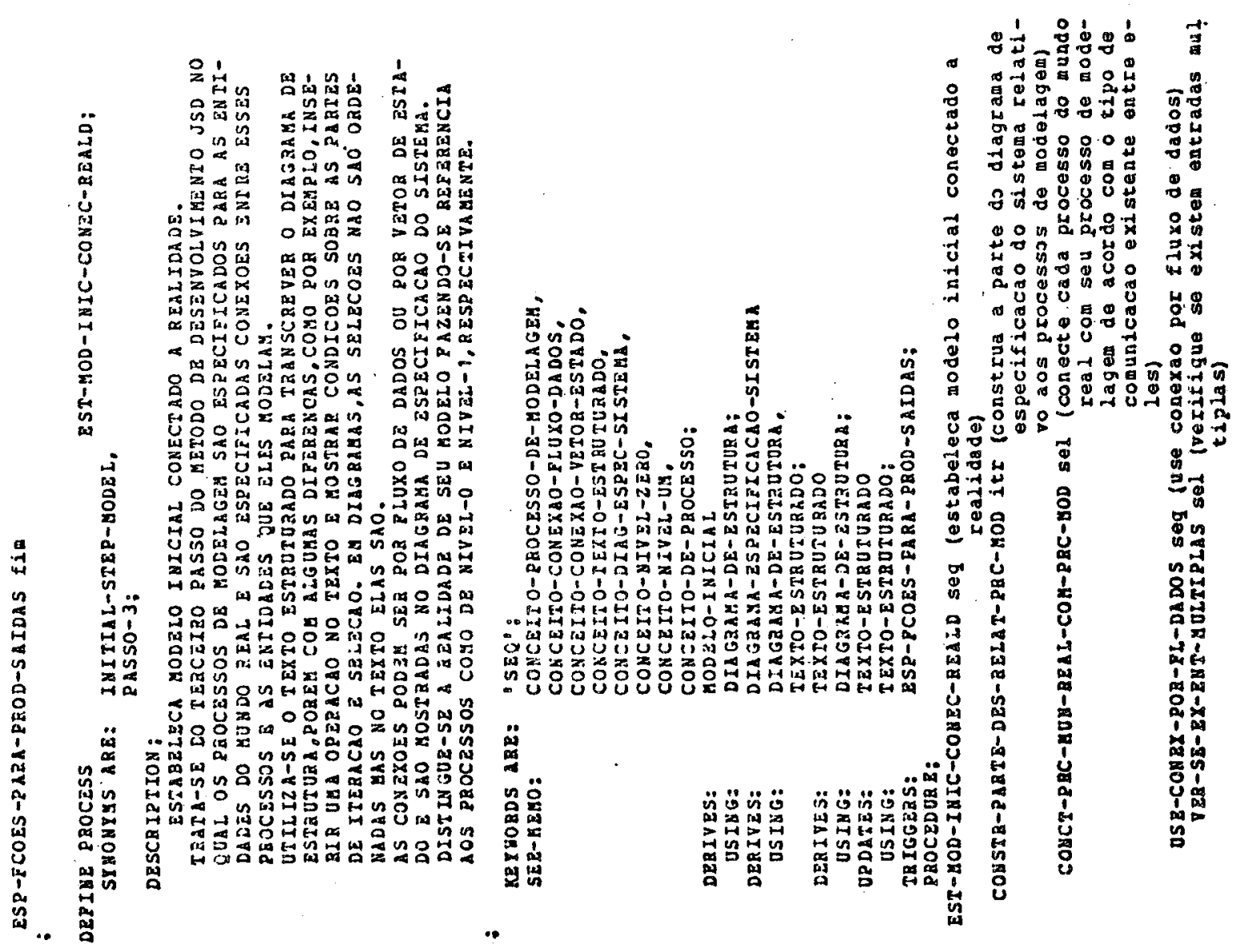

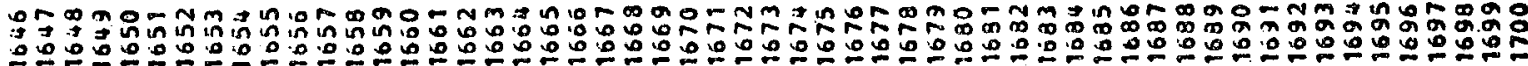




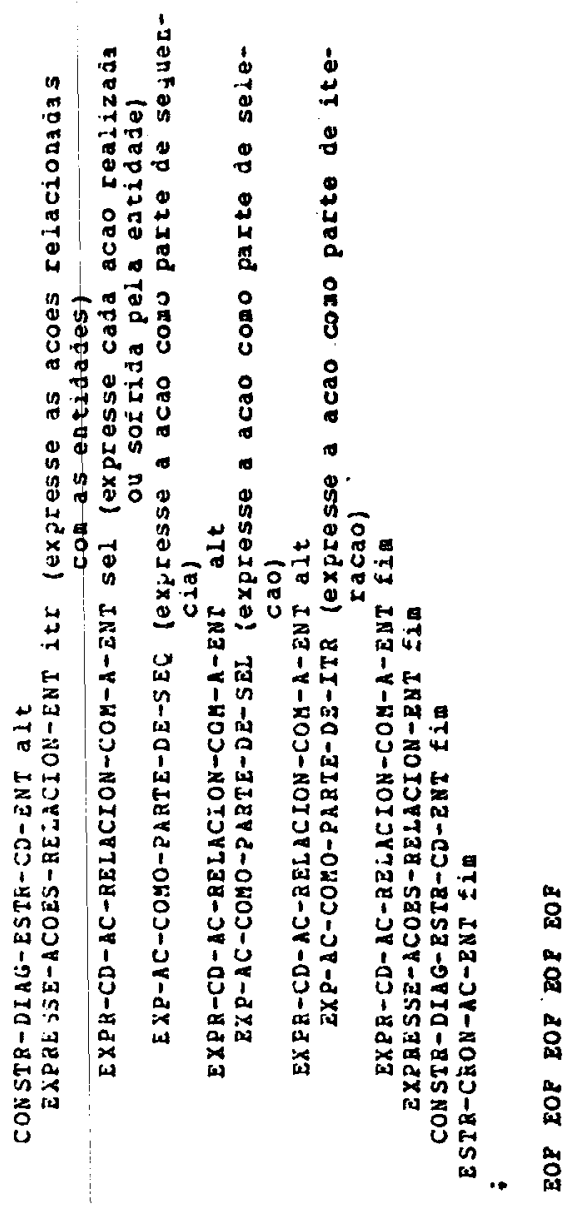

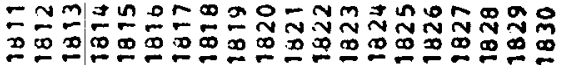

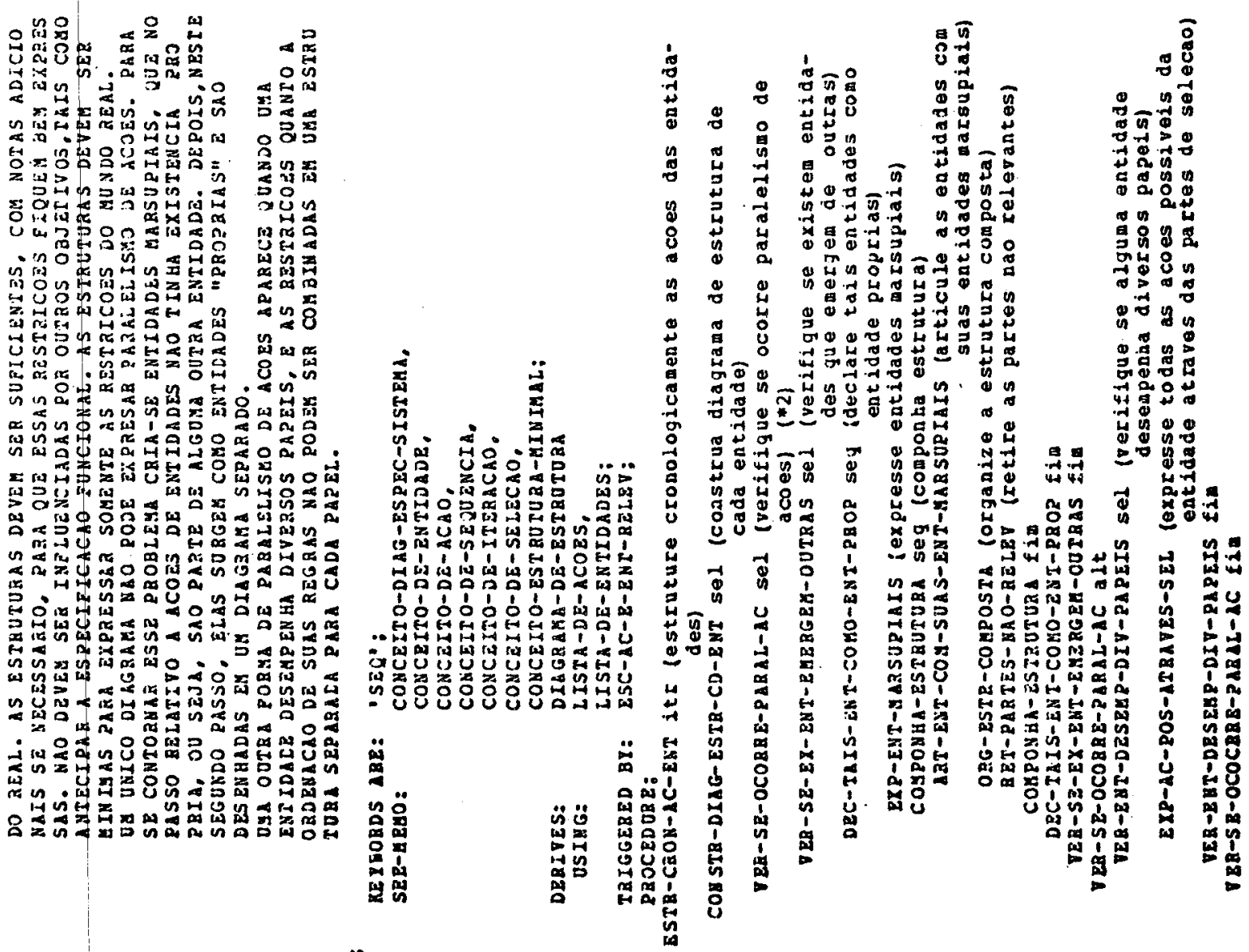

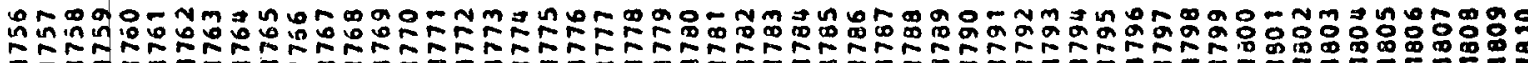




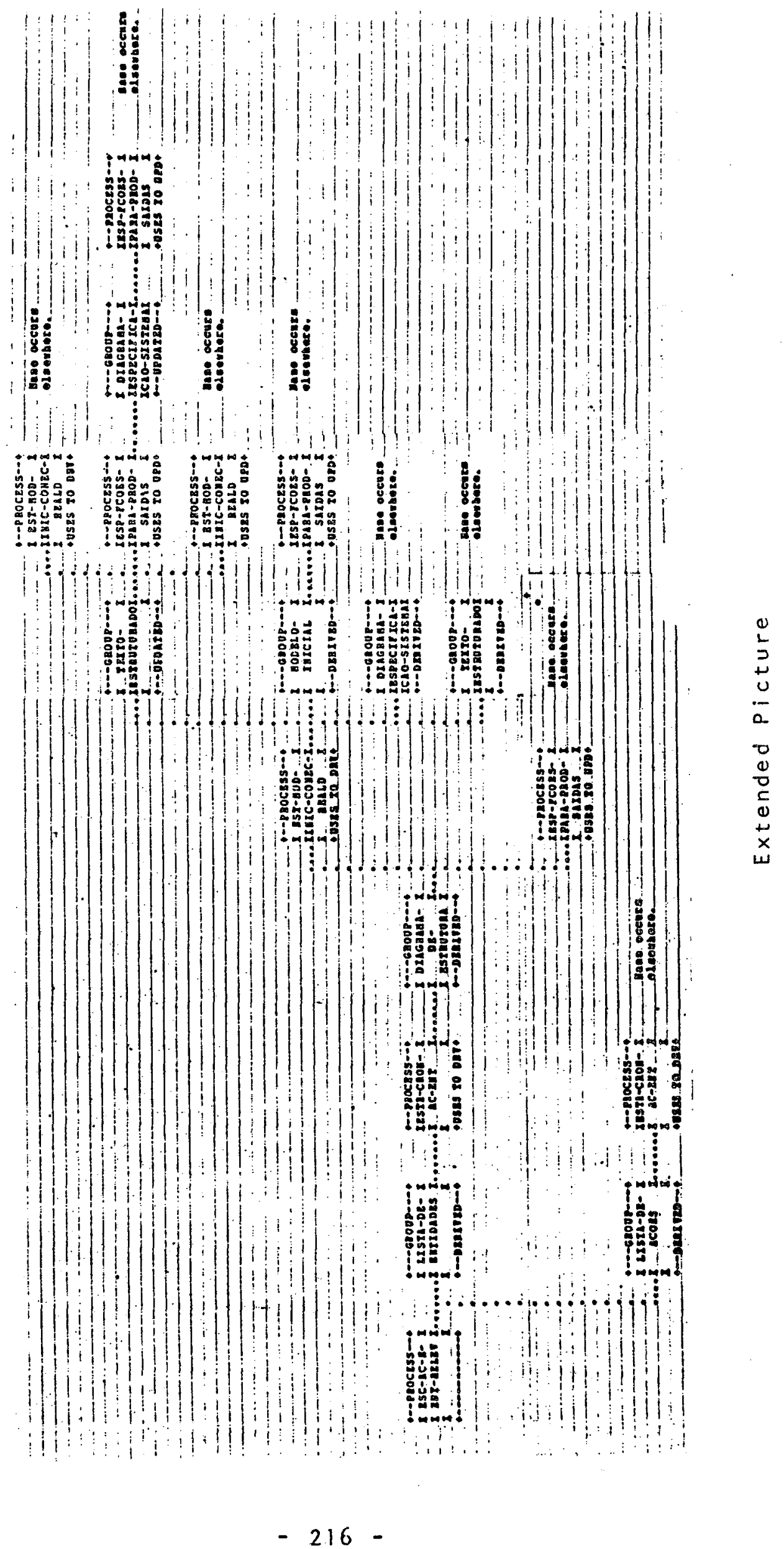




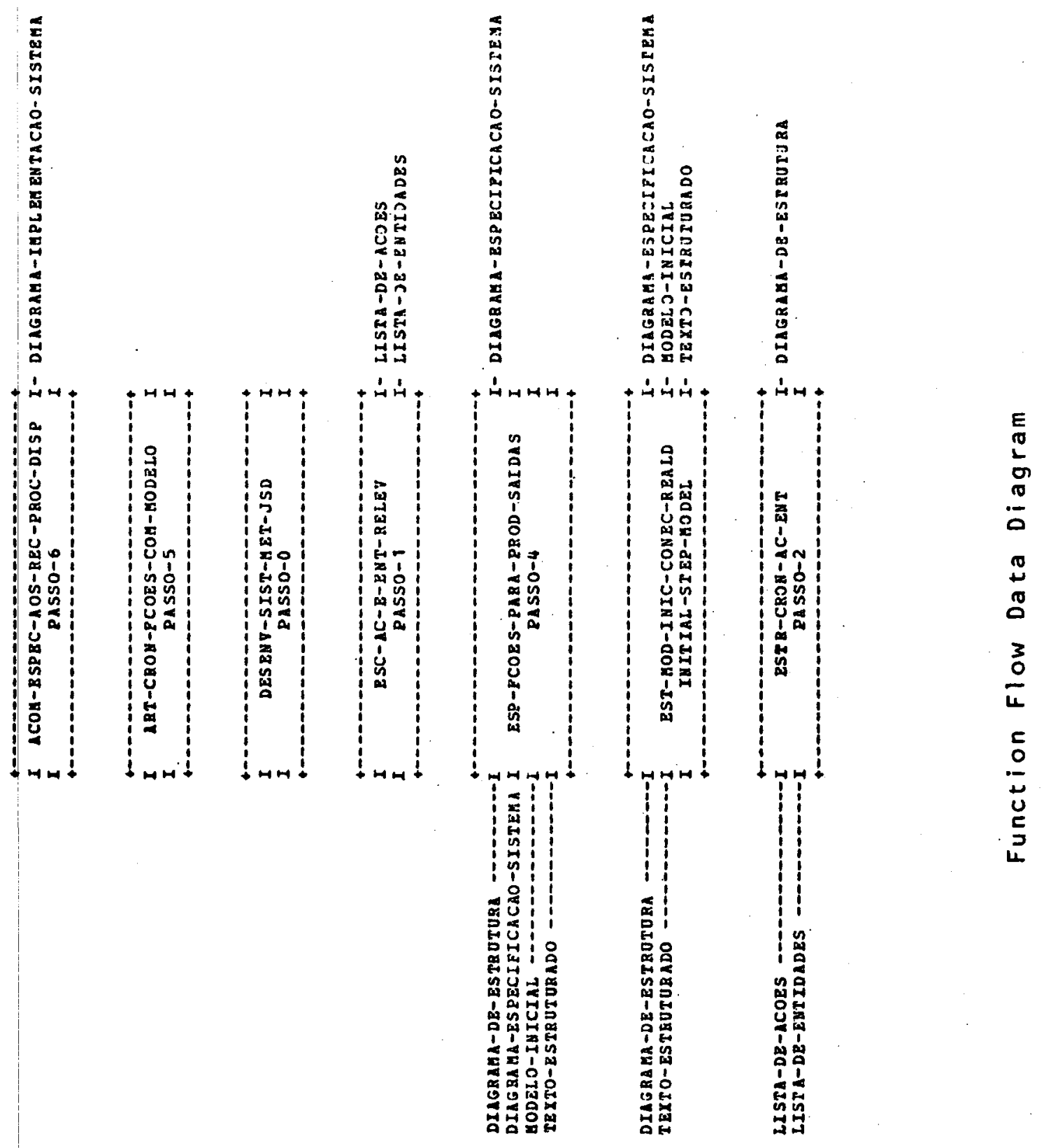




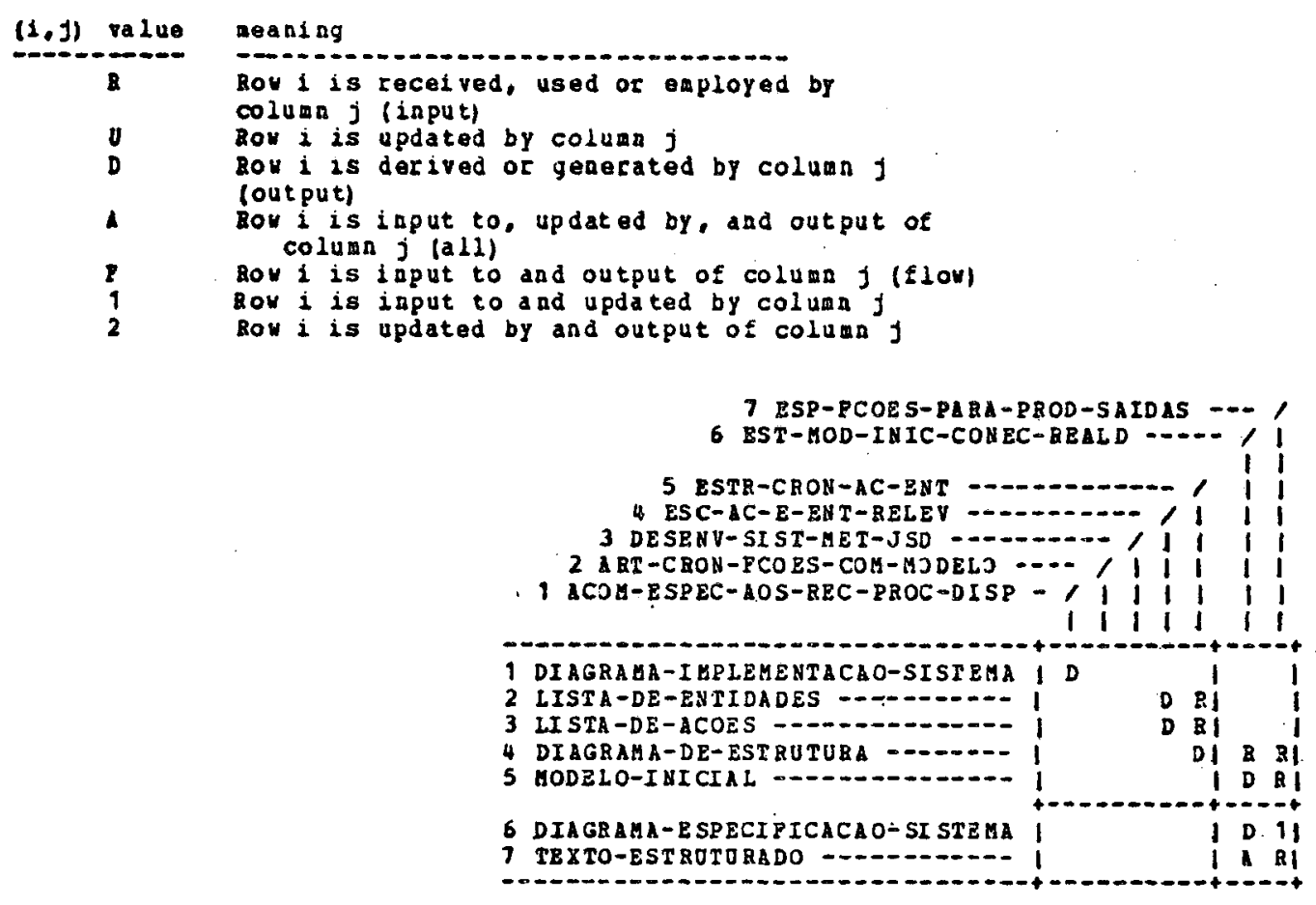

Data

DIAGRAMA-IBPLEMENTACAO-SISTEMA (OUTPUT) (RON i) nOt DeEIVEd bY ang PROzESS

Activities

ART-CRON-BCOES-COM- MODELO

DESENV-SIST-MET-JSD

(PROCESS) (Column 2) Does Not Iateract lith ang Data

ESC-AC-E-EHT-Z ZLEV

(PBOCESS) (Column

(PBOCESS) (COlumn
(PROCESS) (Column

2) Does Not Interact ith ang Data

Process Interaction Matrix (Incidence)

4) Derives Something. Bat Does Not use/Employ anytining

The rovs and columas are proczss names from above.

n asterisk in (i,j) means that something derived

or updated by RROCESS $i$ is used or employed by process $j$.

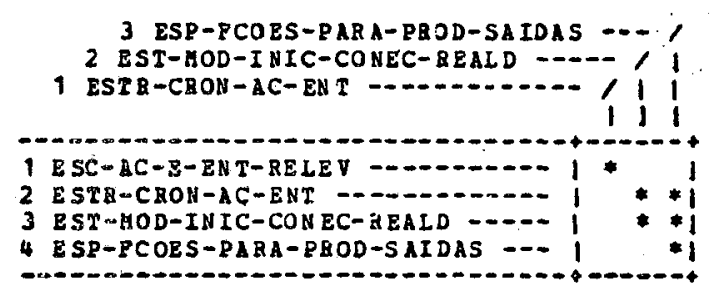

Process Iateraction Matrix analysis

ICOR-ESPEC-1OS-REC-PROC-DISP (PROCESS

LRT-CRON-BCOES-COH-MODELO (PROCESS)

DES EHT-SIST- MET-JSD

ESC $-\mathbf{A C}-\mathrm{E}-\mathrm{E} U T-R E L E V$
(PROCESS)

(PBOCESS)
No Interaction With othar processes
No Interaction ith Other processes
No Interact2u With Other Processes

No Predecessors Por this PaOcas

Data Activity Interaction Report 
Dypadc Iateraction hatrix

1 neans nou 1 TEIGGers colung J

$x$ means Boy $i$ is the same as Coluar $J$

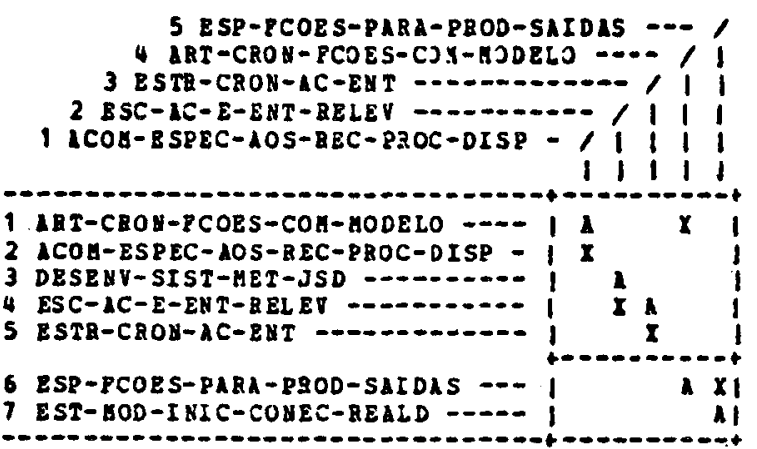

Observation pessages are printed only when certain conditions are discovered. They do not necessarily indicate that sonething is riong, but they highlight situations that could be potential probless.

The meaning of these messages is presented belov.

- Observation NO. 1: NOT THIJZERED BY A RROCESS, EVENT, OR INRUT

- Observation No. 2: NOT UTILIZRD 9Y AHOTHER PROCESS

When the DYManICS parameter is in efaect, Observation No. 1 is printed if no pacess, EVENT, OF IHPUT name TRIGGERS the given RaOCESS. When the COBTROL parameter is in effect, observation No. 2 is printed if the given PROCESS is not UTILIZED BY another PBOCESS.

- Observation No. 3: DOES NOT IALTI TE ANI ACTION OA OCCURAEHCE

Inis message is printed uhen the given EVEUT does not TRIJGER any PROCESS.

- Observation Ho. 4: DOES NOT IHITIATE aHY guRTHER PROCESSING

If the given process does not initiate any further processing or sezuence of events, then this observation is printed. If the giTer PAOCESS INCEPTIOH-CAOSES OI TEAYIHATION-CAUSBS an EVEHT then the wessage is not printed.

- Observation HO. 5: IS MOT IM RESPOASE TO AWI OOTPUT

This aessage is printed when the given IRPuT is not

IH RESPOYSE TO a AY OUTPUT nase.

- Obserration No. 6: WAY BE DYMAICALLY INCONSISTEMr

The tro nanes given participate in tuo separate dyanic

relationships vith each other. Ihis ma be an inconsistency. For

exaApI e. EV ZUT E1 TBIGGERS PROCESS P2 and PROCESS P2 IUCBPTIOA-CAUSES EVEAT EI

Column Observation tessages

$1 C O A-E S P E C-10 S-B B C-P B O C-0 T S P$ BSC-AC-E-EHT-RELEV

ESTR-CBOA-AC-ENT

LET-CBON-FCOES - CON- MODELO

RS P-FCOBS-PABA-PROD-SAIDLS

Rov Observation bessages

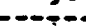

$1 C O K-E S R$ EC- $\triangle O S-8$ EC- HHOC-DISE

ESTR $-C$ BON- $\triangle C-E N I$
(PROCESS) (COLuma 1) DOt OTILIZED by another PROEESS

(Paocess) (Columa 2) not OTILIzED by anotner PzOCESS

(PAOCBSS) (Columa 3) not OTILIZED by anjther PROCESS

(PROCESS) (Columa 4) not UTILIZED by ansthac pROCESS

(PQOCESS) (COLUAB 5) not URILILED by anotber PBOCESS

(PROCESS) (Roy 2) does ast laitlate any fucther processing (PRocess) (Roy 5) does not initiata any, furtber processiay

Dynamic Interaction Report 